Energy status and ovarian follicular development

Li Meng 


\section{Thesis committee}

\section{Promotor}

Prof. Dr J. Keijer

Professor of Human and Animal Physiology

Wageningen University \& Research

\section{Co-promotor}

Dr K.J. Teerds

Associate Professor of Human and Animal Physiology

Wageningen University \& Research

\section{Other members}

Prof. Dr B. Kemp, Wageningen University \& Research

Dr J. Visser, Erasmus University, Rotterdam

Dr B.A.J. Roelen, Utrecht University

Dr A. Hoek, University of Groningen

This research was conducted under the auspices of the Graduate School of Wageningen Institute of Animal Sciences (WIAS) 


\title{
Energy status and ovarian follicular development
}

\author{
Li Meng
}

Thesis

submitted in fulfilment of the requirements for the degree of doctor at Wageningen University \& Research

by the authority of the Rector Magnificus

Prof. Dr A.P.J. Mol,

in the presence of the

Thesis committee appointed by the Academic Board

to be defended in public

on Wednesday 7 December 2016

at 1:30 p.m. in the Aula. 
Li Meng

Energy status and ovarian follicular development

144 pages

PhD thesis, Wageningen University \& Research, Wageningen, NL (2016)

With references, with summary in English

ISBN 978-94-6257-917-0; DOI 10.18174/389440 


\section{Table of Contents}

$\begin{array}{lr}\text { Abbreviations } & 6\end{array}$

$\begin{array}{lll}\text { Chapter } 1 \text { General Introduction } & 9\end{array}$

Chapter 2 Preantral follicular atresia occurs mainly by autophagy, while antral follicles 33 degenerate mainly by apoptosis

Chapter 3 Prolonged hypothyroidism severely reduces ovarian follicle reserve in adult rats

Chapter 4 Dietary-induced chronic hypothyroidism negatively affects rat follicular development and ovulation rate and is associated with oxidative stress

Chapter 5 Skeletal muscle pseudo-starvation driven energy expenditure negatively affects ovarian follicular development in mice

Chapter 6 General discussion

Acknowledgement

Curriculum Vitae

List of Publications

Training and Education 
List of Abbreviations

\begin{tabular}{|c|c|}
\hline Abbreviation & Full Name \\
\hline $4-\mathrm{HNE}$ & 4-hydroxynonenal \\
\hline$A B C$ & avidin-biotin complex \\
\hline ACTB & b-actin \\
\hline AKT & protein kinase B \\
\hline $\mathrm{AL}$ & ad libitum \\
\hline AMH & anti-Müllerian hormone \\
\hline AMPK & amp activated protein kinase \\
\hline ATP & adenosine-tri-phosphate \\
\hline BAT & brown adipose tissue \\
\hline bFGF & basic fibroblast growth factor \\
\hline BMP4 & bone morphogenic protein 4 \\
\hline BMP7 & bone morphogenic protein 7 \\
\hline BMR & basal metabolic rate \\
\hline CAT & catalase \\
\hline cCASP3 & cleaved caspase 3 \\
\hline $\mathrm{CL}$ & corpora lutea \\
\hline COXIV & cytochrome c oxidase subunit IV \\
\hline $\mathrm{CR}$ & caloric restriction \\
\hline CXCR4 & chemokine receptor 4 \\
\hline DAB & 3-3' diaminobenzidine \\
\hline FADH2 & reduced Flavin Adenine Dinucleotide \\
\hline FGF21 & fibroblast growth factor 21 \\
\hline FOXL2 & forkhead box L2 \\
\hline FOXO & forkhead box O \\
\hline FOXO3a & forkhead box O3a \\
\hline $\mathrm{FSH}$ & follicle stimulating hormone \\
\hline G6PD & glucose-6-phosphate dehydrogenase \\
\hline GAPDH & glyceraldehyde 3-phosphate dehydrogenase \\
\hline GDF15 & growth differentiation factor 15 \\
\hline GDF9 & growth differentiation factor 9 \\
\hline GDNF & glial-derived neurotrophic factor \\
\hline GHBP & growth hormone binding protein \\
\hline GHR & growth hormone receptor \\
\hline GLRXs & glutaredoxins \\
\hline $\mathrm{GnRH}$ & gonadotropin releasing hormone \\
\hline GSH & glutathione \\
\hline GSTMs & glutathione S-transferases Mu \\
\hline IGF1 & insulin-like growth factor 1 \\
\hline IGF1R & insulin-like growth factor 1 receptor 1 \\
\hline $\mathrm{IHC}$ & immunohistochemistry \\
\hline IRS2 & insulin receptor substrate 2 \\
\hline KGF & keratinocyte growth factor \\
\hline KL & kit ligand \\
\hline
\end{tabular}




\begin{tabular}{|c|c|}
\hline LC3 & microtubule associated light-chain protein 3 \\
\hline LCM & laser capture microdissection \\
\hline LH & luteinizing hormone \\
\hline LIF & leukemia inhibitory factor \\
\hline mTORC1 & mammalian target of rapamycin complex 1 \\
\hline $\mathrm{NADH}$ & reduced Nicotinamide Adenine Dinucleotide \\
\hline NOBOX & newborn ovary homeobox-encoding gene \\
\hline OGTT & oral glucose tolerance test \\
\hline OXPHOS & oxidative phosphorylation \\
\hline P27 & p27kip1 \\
\hline PAS & periodic acid Schiff's reagent \\
\hline PBS & phosphate buffered saline \\
\hline PDGF & platelet-derived growth factor \\
\hline Phospho AKT & phosphorylated protein kinase B \\
\hline Phospho IRS2 & phosphorylated insulin receptor substrate 2 \\
\hline $\mathrm{PI3K}$ & phosphatidylinositol 3-kinase \\
\hline PP & postpartum \\
\hline PPARGC1 $\alpha$ & proliferator-activated receptor gamma coactivator 1 alpha \\
\hline PRAS40 & proline-rich AKT substrate $40 \mathrm{kDa}$ \\
\hline PRDXs & peroxiredoxins \\
\hline PTEN & phosphatase and tensin homolog deleted on chromosome 10 \\
\hline PTU & propyl-2-thiouracyl \\
\hline qRT-PCR & quantitative real time reverse transcription polymerase chain reaction \\
\hline RAPTOR & regulatory-associated protein of mTOR \\
\hline RER & respiratory exchange ratio \\
\hline ROS & reactive oxygen species \\
\hline RPS18 & ribosomal protein S18 \\
\hline SMAD3 & smad family member 3 \\
\hline SODs & superoxide dismutases \\
\hline SOHLH1 & spermatogenesis and oogenesis-specific basic helix-loop-helix 1 \\
\hline SOHLH2 & spermatogenesis and oogenesis-specific basic helix-loop-helix 2 \\
\hline SQSTM1/p62 & sequestosome 1 \\
\hline $\mathrm{T}_{3}$ & tri-iodothyronine \\
\hline $\mathrm{T}_{4}$ & thyroxin \\
\hline TH & thyroid hormone \\
\hline TRH & thyrotropin-releasing hormone \\
\hline TRIB3 & Tribbles homolog 3 \\
\hline TSC1 & tuberous sclerosis 1 \\
\hline $\mathrm{TSC} 2$ & tuberous sclerosis 2 \\
\hline TSH & thyroid-stimulating hormone \\
\hline TXNs & thioredoxins \\
\hline UCP1 & uncoupling protein 1 \\
\hline UCP1-TG & mice ectopically expressing UCP1 in skeletal muscle \\
\hline UCP2 & uncoupling protein 2 \\
\hline WT & wild-type \\
\hline
\end{tabular}



Chapter 1

General Introduction 



\subsection{Ovarian follicular development}

\section{Morphology}

The differentiation of primordial germ cells into oogonia and subsequently oocytes is important for the survival of a species. In rodents, primordial germ cells migrate from the epiblast (embryonic ectoderm) at the base of the allantois to the genital ridge, the site of origin of the somatic cells of the developing gonad [1-3]. When incorporated in the future ovary, the indifferent primordial germ cells develop into oogonia which undergo multiple mitotic divisions with incomplete cytokinesis resulting in numerous interconnected germ cells $[1,2]$. When mitotic divisions cease, the oogonia enter the prophase of the first meiotic division and are now named primary oocytes [1]. These oocytes arrest in the diplotene stage of the meiotic prophase I and in rodents remain localized in clusters, so called germ-line cysts (Figure 1) [2]. Around the time of birth, these cysts begin to break down, during which time most oocytes are lost through apoptosis $[2,4]$, while the remaining oocytes, which now become surrounded by a single layer of flat somatic pre-granulosa cells, constitute the primordial follicle pool. This pool of follicles forms the ovarian reserve [1]. Throughout reproductive life, dormant primordial follicles are continuously recruited from this resting pool to the growing pool of follicles.

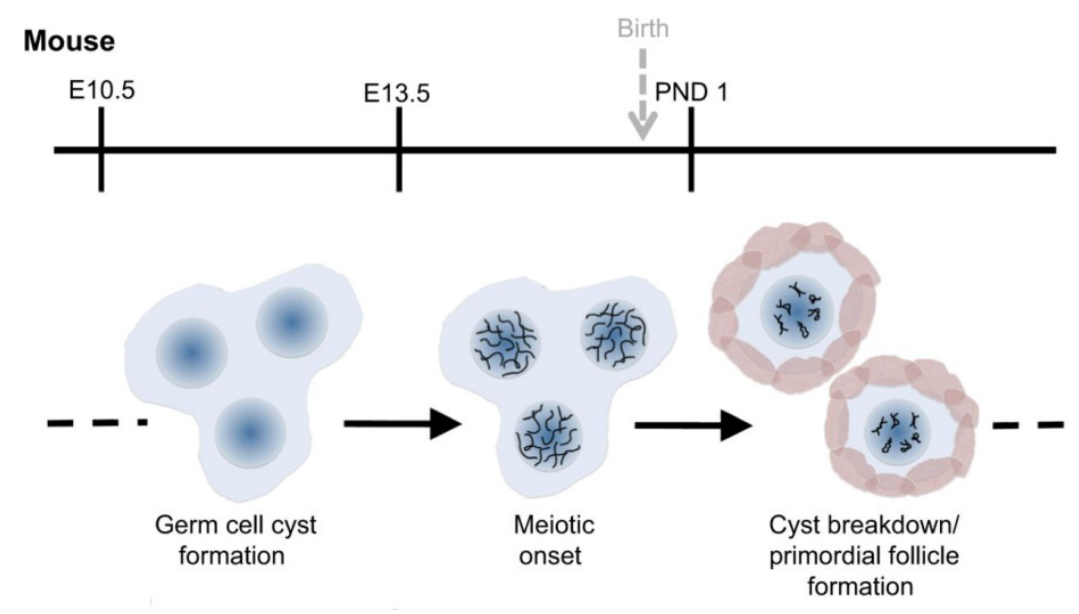

Figure 1 Timeline of primordial follicle formation in the mouse. Primordial germ cells colonize the somatic gonad at about E10.5. These cells undergo mitotic divisions, form cysts, and then cease mitosis and enter meiosis around E13.5. Finally, around the time of birth these cysts break down to form the primordial follicle pool. Abbreviations: E, embryonic day; PND, post-natal day (Adapted from [1]).

Following recruitment of primordial follicles, changes occur in the primary oocyte and surrounding pre-granulosa cells leading to the formation of a primary follicle (Figure 2). The primary follicle contains an enlarged primary oocyte and a layer of cuboidal cells, called granulosa cell layer. Gap junctions connect the oocyte and the immediately surrounding granulosa cells, facilitating the transport of, for instance, nutrients, amino acids, nucleotides, and lipid precursors from the granulosa cells to the oocyte [5].

Ongoing proliferation of the granulosa cells leads to the formation of multiple granulosa cell layers surrounding the oocyte. The follicles at this stage are now named preantral follicles. During this developmental process the granulosa cell layer becomes surrounded by somatic cells recruited from 
the ovarian stroma, forming the theca layer. The theca cells have the morphological features of steroid-producing cells and in contrast to the granulosa layer, this layer is highly vascularised. The granulosa cells are separated from the theca cells and the ovarian blood supply by a distinct basement membrane. In order to reach the granulosa cells and oocyte, nutrients from the circulation have to pass this barrier [5].

At a certain stage of preantral follicle growth granulosa cells start to release fluid in the intercellular space resulting in fluid-filled cavities between the granulosa cells. These cavities merge to form a single fluid-filled chamber, the antrum. From this stage onward the oocyte stops growing, the follicle increases further in size due to the enlargement of the antrum and proliferation of granulosa and theca cells [6]. The oocyte becomes located on a stalk surrounded by specialized granulosa cells, the cumulus granulosa cells. The cumulus cells nourish the oocyte and participate in oocyte maturation.

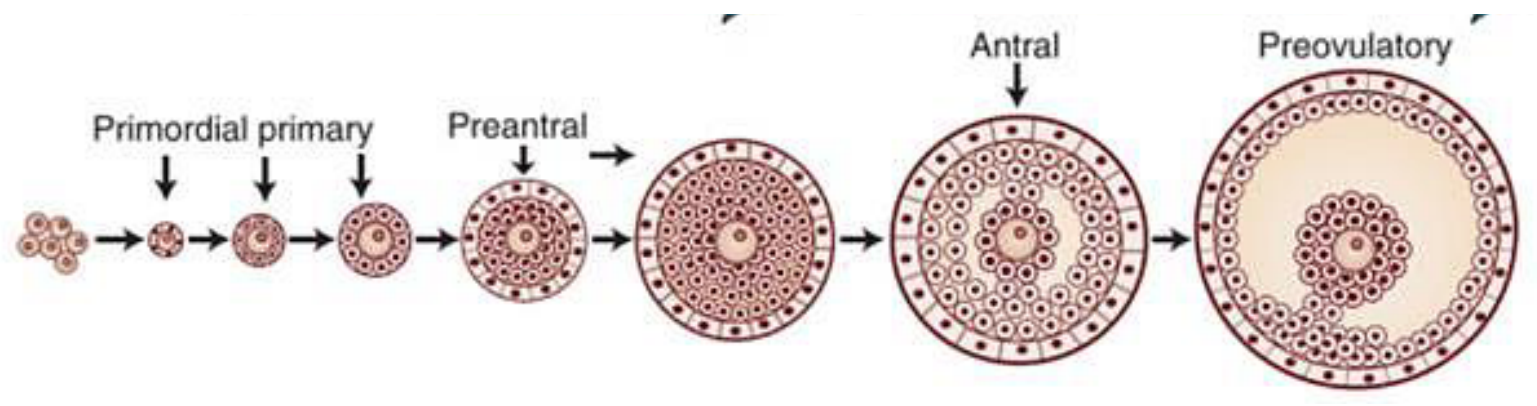

Figure 2 Schematic overview of ovarian follicular development. Adapted from Physiology of Reproduction [7].

\section{Initial recruitment and preantral follicle growth}

The pool of primordial follicles serves as the ovarian reserve. From this pool, follicles are continuously recruited, leading to a gradual depletion of this follicle pool. The rate at which this recruitment of primordial follicles occurs, also named initial recruitment, determines female fertile life span (Figure 3) [8]. Initial recruitment is believed to be a continuous process that starts just after the establishment of the primordial follicle pool. Up to puberty these growing follicles degenerate long before reaching the large antral stage [6].

The process of initial recruitment is thought to be tightly regulated by different growth factors, hormones and cytokines (summarized in table 1). Resting primordial follicles are known to be under constant pressure by several inhibitory factors to remain dormant. One of the factors that has been shown to be involved in the regulation of recruitment of primordial follicles is anti-Müllerian hormone (AMH). $\mathrm{AMH}$, a protein hormone with a molecular weight of $140 \mathrm{kDa}$, is a member of the transforming growth factor $\beta$ super family of growth and differentiation factors [9]. AMH becomes firstly apparent in the granulosa cells of recruited primordial follicles [10] and continues to be secreted by the granulosa cells of preantral and early antral follicles [11]. As soon as small antral follicles are selected for ovulation, AMH production ceases [12]. Studies in AMH null mice have revealed that $\mathrm{AMH}$ plays an inhibitory role in the recruitment of primordial follicles, as at the age of 4 months the number growing follicles was nearly threefold higher in the knockout mice than in wild type mice while the number of primordial follicles had significantly decreased [10, 13]. In line with 
these observations in vitro studies employing mouse and rat ovaries showed that addition of $\mathrm{AMH}$ significantly inhibited the recruitment of primordial follicles $[10,14,15]$. Therefore, it has been hypothesized that $\mathrm{AMH}$ may play a role in preventing premature exhaustion of the ovarian follicular reserve [16].

Besides $\mathrm{AMH}$, several other factors have been demonstrated to be involved in the transition of primordial follicles to primary follicles. I will focus here on three well-defined factors, growth differentiation factor 9 (GDF9), basic fibroblast growth factor (bFGF, also known as FGF2) and insulinlike growth factor 1 (IGF1), since these factors have been known to play an important role in ovarian follicle development and their functions are relatively clearly defined. GDF9 is a protein hormone with a molecular weight of $51 \mathrm{kDa}$ and a member of the transforming growth factor $\beta$ super family, like $\mathrm{AMH}$. Depending on the species it is first expressed in oocytes of either primordial or of primary follicles $[17,18]$. The observations on the role of GDF9 in primordial follicle recruitment are somewhat contradictory. Although in vitro studies of neonatal rat ovaries suggest that GDF9 does not affect the recruitment of primordial follicles [19], intraperitoneal injection of GDF9 in neonatal rats led to enhanced primordial follicle recruitment, supporting an activating role of GDF9 in the initial recruitment process [17]. In line with this, GDF9 has been shown to facilitate the recruitment of primordial follicles in cultured human ovarian tissue slices [20]. In addition, GDF9 has been shown to promote primordial follicular activation in in vitro cultures of goat and hamster ovaries $[21,22]$.

bFGF, a protein with a molecular weight of $31 \mathrm{kDa}$, is expressed in oocytes of primordial follicles. In cultured neonatal rat ovaries, bFGF can promote primordial follicle activation [23]. In line with these observations, blocking endogenous bFGF with bFGF neutralizing antibodies results in the accumulation of primordial follicles [23]. Additionally, the expression of kit ligand (KL) appears to be elevated in ovaries cultured in the presence of bFGF [24], suggesting that bFGF may mediate primordial follicle recruitment through enhanced expression of KL. KL has been reported to promote the primordial to primary follicle transition possibly by binding to its receptor present on oocytes [24]. Moreover, bFGF-stimulated follicular activation in cultured rat ovaries is inhibited by an anti-Kit antibody that blocks KL signalling [24]. These results suggest that oocyte-derived bFGF may be required for the optimal promotion of primordial to primary follicle transition, presumably by increased expression of KL by the granulosa cells.

IGF1, a peptide hormone with a molecular weight of $7.5 \mathrm{kDa}$, is produced peripherally by the liver as well as locally in the ovary by the granulosa cells. Although contradictory observations have been reported, this growth factor is thought to play an important role in primordial follicle recruitment as well as in later stages of ovarian follicle development. Slot et al. [25] have shown in mice that had severely reduced IGF1 levels due to a complete inactivation of the growth hormone receptor, that accumulation of primordial follicles occurred, suggestive of reduced primordial follicle recruitment. Subsequent administration of IGF1 led to a rapid reduction in the size of the primordial follicle pool, implicating a role for IGF1 in primordial follicle recruitment. In contrast, under in vitro conditions using a rat ovarian culture system, it appeared that IGF-1 was unable to influence the recruitment of primordial follicles [26]. This discrepancy may be due to the difference in experimental conditions.

Follicle stimulating hormone (FSH) plays a very important role in late preantral and antral follicle development, but is presumably not involved in primordial follicle recruitment. This assumption is 
based on two studies. Gosden et al. have shown that primordial follicles do not express FSH receptors [27]. Second, Dierich et al. have shown that disruption of the functioning of the FSH receptor does not block the process of initial recruitment of primordial follicles, but that the development of these recruited follicles is blocked at the late preantral stage [27].

In light of the above, it may be clear that initial recruitment is a complex process in which numerous factors interact in concert. If one of these factors becomes dysfunctional, other factor(s) may compensate for this loss, thereby ensuring ongoing recruitment of primordial follicles, preserving fertility.

Table 1. Overview of the relatively well-characterized factors involved in primordial follicle recruitment. Key references are listed.

\begin{tabular}{llll}
\hline Factors & Localization of Primordial & Functions & Reference \\
& follicles & & \\
\hline PTEN & Oocyte & Inhibiting & Reddy et al. [28] \\
FOXO3a & Oocyte & Inhibiting & John et al. [29], Castrillon et al. [30] \\
P27 & Oocyte and pregranulosa cells & Inhibiting & Rajareddy et al. [31] \\
FOXL2 & Pregranulosa cells & Inhibiting & Schmidt et al. [32], Uda et al. [33] \\
SDF1 and its & Oocyte and pregranulosa cells & Inhibiting & Holt et al. [34] \\
receptor CXCR4 & & & \\
GDNF & Oocyte & Activating & Dole et al. [35] \\
Insulin & Receptor in the oocyte & Activating & Yu et al. [36], Kezele et al [26]., Samoto et al.[37] \\
bFGF & Oocyte & Activating & Nilsson et al. [23, 24] \\
KGF & Precursor theca and stromal cells & Activating & Kezele et al. [38] \\
PDGF & Oocyte & Activating & Nilsson et al. [39], Hutt et al. [40] \\
BMP7 & Precursor theca and stromal cells & Activating & Lee et al. [41, 42] \\
BMP4 & Precursor theca and stromal cells & Activating & Nilsson et al. [43] \\
SMAD3 & Oocytes & Activating & Xu et al. [44], Tomic et al. [45] \\
LIF & Pregranulosa cells & Activating & Nilsson et al. [46] \\
NOBOX & Oocyte & Activating & Rajkovic et al. [47], Suzumori et al. [48], Choi et \\
& & & al. [49] \\
SOHLH1 & Oocyte & Activating & Pangas et al. [50], Choi et al. [51] \\
SOHLH2 & Oocyte & Activating & Choi et al. [52], Toyoda et al. [53] \\
\hline
\end{tabular}

PTEN, phosphatase and tensin homolog deleted on chromosome 10; FOXO3a, forkhead box O3a; P27, p27kip1; FOXL2, forkhead box protein L2; SDF1, stromal-derived factor 1; CXCR4, chemokine receptor 4; GDNF, glial-derived neurotrophic factor; KGF, keratinocyte growth facto; PDGF, platelet-derived growth factor; BMP7, bone morphogenic protein 7; BMP4, bone morphogenic protein 4; SMAD3, SMAD family member 3; LIF, leukemia inhibitory factor; NOBOX, newborn ovary homeobox-encoding gene; SOHLH1, spermatogenesis and oogenesis-specific basic helix-loop-helix 1; SOHLH2, spermatogenesis and oogenesis-specific basic helix-loop-helix 2.

Once recruited, the primordial follicles start to grow. Compared with the regulation of initial recruitment of primordial follicles, substantially more is known about the regulation of the growth of preantral and antral follicles. At the preantral stage of development communication between granulosa cells and the oocyte becomes more and more important. For instance, follicular growth in mice is inhibited when the expression of connexin 37, a gap junction protein expressed at the oocytegranulosa cells junction is knocked out [54]. Moreover, maturation of oocytes isolated from preantral follicles is possible in vitro as long as the oocytes are surrounded by granulosa cells, presumably 
because factors secreted by these granulosa cells play an important role in oocyte growth and maturation [55].

Some factors not only play a role in the process of initial recruitment but are also important for further follicle growth and development. Although many factors have been identified, I shall focus here on GDF9, AMH and FSH. Studies using GDF9 null mice have demonstrated that follicle growth is arrested at the primary stage, suggestive of a role for GDF9 in the growth of follicles beyond the primary stage [18]. In vitro studies further indicate that GDF9 treatment enhances growth and differentiation of preantral follicles in culture [56] and promotes theca cell steroid production [57] and proliferation [58]. The role of AMH in preantral follicular growth is species dependent. In mice $\mathrm{AMH}$ is shown to inhibit FSH-driven growth of late preantral follicles in vitro [59], while in primates $\mathrm{AMH}$ has been shown to promote preantral follicle growth in vitro [60]. In accordance with these observations, the highest level of AMH expression in mice and primates is observed in granulosa cells of preantral and small antral follicles [61]. These findings suggest a role for AMH in preantral follicle development beyond the primordial-primary transition.

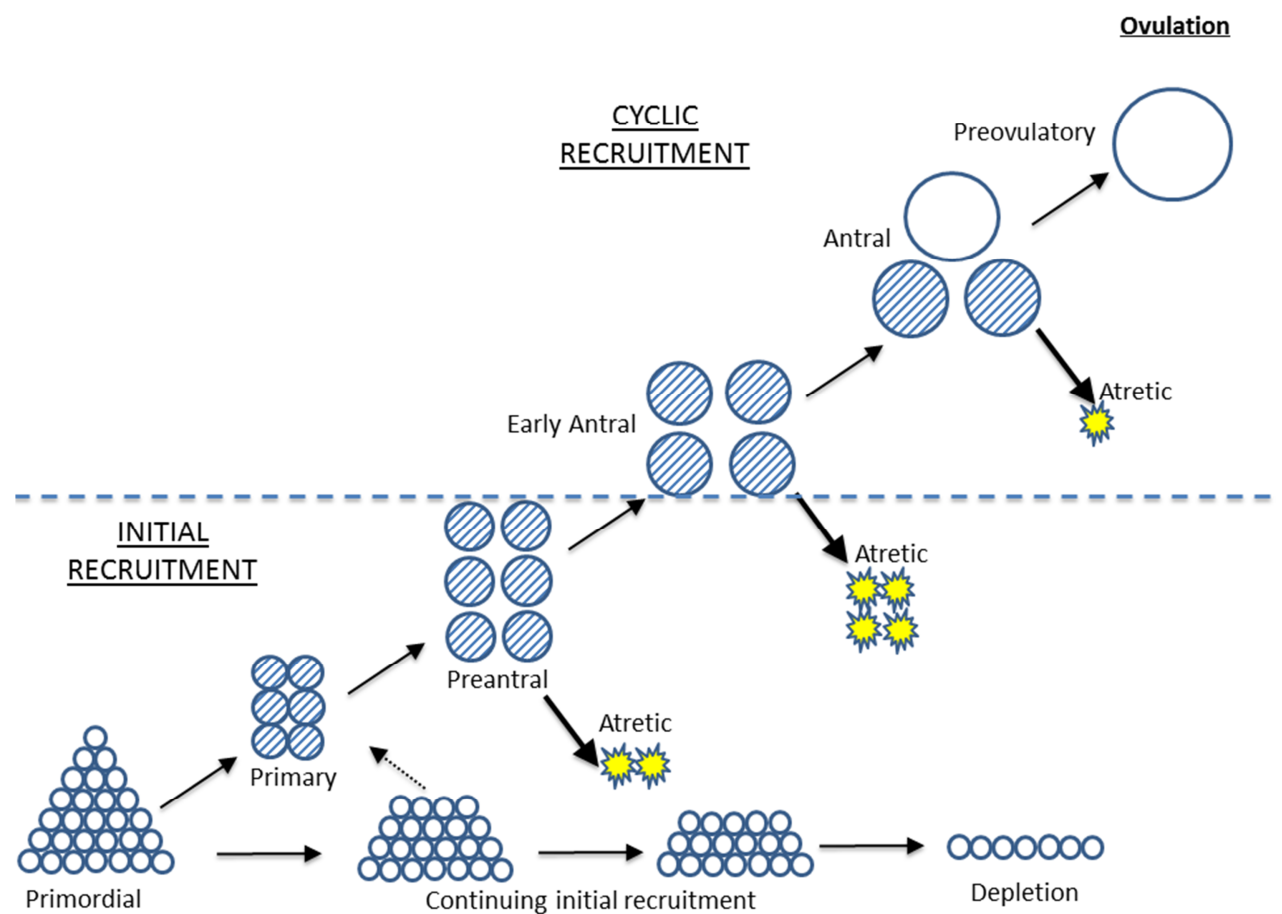

Figure 3 Life history of follicles in rodents. Selective primordial follicles are continuously recruited to grow (initial recruitment) throughout life whereas most of primordial follicles remain dormant. Once started to grow, primordial follicles develop through primary and preantral stages before obtaining an antral cavity. Cyclic recruitment of small antral follicles starts at the onset of the follicular phase of the oestrous cycle. These follicles will grow further and ovulate or degenerate by a process named atresia. During reproductive life, continuous recruitment of primordial into the pool of growing follicles results in depletion of the follicle pool (adapted from $[6,62])$.

Many studies have reported on the growth-promoting and anti-atretic effects of FSH in relation to antral follicle development, however, the possible effects of FSH in preantral follicle development has received less attention. FSH receptors expression becomes first apparent in granulosa cells of small preantral follicles [63]. These receptors are also functional, as treatment with FSH can stimulate 
the growth of these follicles [64]. Studies in which FSH is depleted by either hypophysectomy or GnRH antagonist treatment, show a decreased ovarian weight that is associated with a reduced number of developing preantral follicles [64]. Not surprisingly, treatment of hypophysectomized, or $\mathrm{GnRH}$ antagonist-treated mice with FSH results in increased ovarian weight and preantral follicle numbers [65]. Several in vitro studies using preantral follicles from different species have confirmed the role of FSH in the promotion of preantral follicle growth [66-69]. Despite these observations, FSH receptor null mice do show growth of follicles up to the late preantral stage, though no formation of antral follicles is observed [65]. Taken together, it can be concluded that preantral follicles are responsive to $\mathrm{FSH}$, but not FSH dependent, in order to grow up to the late preantral stage. Other factors as discussed above can apparently compensate for the absence of FSH up to the late preantral stage.

\section{Cyclic recruitment}

Following initial recruitment, most follicles develop up to the early antral stage after which they stop growing. During every estrous cycle a cohort of these small antral follicles is recruited to resume growth, a process named cyclic recruitment. FSH plays an important role in the decision which follicles will be recruited [6]. The number of antral follicles in this recruited cohort is, however, larger than the number of follicles that will eventually ovulate, implicating that further selection is taking place. The selection of these dominant follicles has been well investigated in mono-ovulatory species, like primates and cattle [6]. The underlying mechanisms behind the selection of small antral follicles in the rodents are broadly similar to the process in mono-ovulatory species with the major exception that multiple antral follicles become dominant during each estrous cycle [6].

From the group of cyclic recruited small antral follicles selection of the dominant follicles takes place. Although the exact factors determining the selection of dominant follicles is still unclear, the selected follicles are assumed to indirectly inhibit growth and development of subordinate follicles by increasing local levels of estrogens and inhibin, which in turn exert a negative feedback upon the release of FSH by the anterior pituitary. Dominant follicles are thought to be more sensitive to FSH. Less-developed, subordinate follicles do not survive such a decline in FSH concentrations and undergo atresia [6]. In addition, it has been suggested that dominant follicles may also produce atretogenic factors, which directly affect neighboring subordinate follicles, resulting in their degeneration. The continued growth of dominant follicles is partly a consequence of increased exposure to locally produced factors. Increased production of bFGF, for instance, leads to an enhanced vascularization of the theca layer allowing a higher uptake of luteinizing hormone (LH) and FSH from the circulation [70]. Moreover, an enhanced bioactivity of IGF1 further augments responsiveness of dominant follicles to $\mathrm{FSH}[71,72]$. Such increased responsiveness of dominant follicles to FSH in turn stimulates the expression of both FSH and at a later stage LH receptors on granulosa cells [73]. In cohort with FSH, IGF1 enhances estrogen secretion by granulosa cells, presumably further contributing to the growth of the dominant follicles [74]. Additional information on the function of IGF1 on ovarian follicle development will be presented in Chapter 5 .

$\mathrm{AMH}$ is another factor that may play a role in the process of cyclic recruitment, since more growing follicles are observed in AMH knockout mice despite lower FSH levels [13]. As indicated above, in rodents, AMH expression levels are highest in preantral and small antral follicles. AMH expression decreases in the FSH-dependent larger antral follicles, and therefore it has been suggested that AMH 
may be involved in the FSH-dependent cyclic selection in addition to primordial follicle recruitment [75]. Indeed, an in vivo study in which FSH levels were modulated has shown that, in the presence of both high and low serum FSH concentrations, more growing follicles are found in AMH knockout mice than in wild-type mice [59]. Therefore, the decrease in AMH expression as observed in antral follicles, may contribute to the process of selection for dominance.

It may be clear from the above that ovarian follicle development is an extremely complex process which is regulated by multiple endocrine, paracrine and autocrine factors that act in accordance to select the proper follicles for ovulation. One has to keep in mind, however, that the majority of ovarian follicles never reach this stage as they undergo preliminary degeneration by a process named atresia.

\section{Ovarian follicular atresia}

Throughout reproductive life in mammals, primordial follicles are continuously recruited, entering the pool of growing follicles. Depending on the species, only 0.1 to $10 \%$ of all the recruited follicles will reach the preovulatory stage and ovulate. All the other follicles will degenerate before reaching the preovulatory stage [76-78]. This degeneration process, named atresia, can occur at all stages of follicular development and ensures that only the healthiest follicles, containing oocytes of optimal quality will have the opportunity to become fertilized during reproductive life [62]. In the following part of this chapter, I will provide a global overview of the process of ovarian follicular atresia, with specific emphasis of the role of apoptosis and autophagy as well as oxidative stress/disturbed redox balance in this process.

Although follicular atresia can occur at all stages of follicular development, the highest incidence of atresia is found during the transition from the preantral to the antral stage [6]. Apoptotic cell death has been recognized as a hallmark of follicular atresia, especially in antral follicular degeneration [77]. Apoptosis is a cell-intrinsic programmed cell death pathway used by multicellular organisms to eliminate unneeded or potentially dangerous cells [79]. The morphological characteristics of apoptosis are cell shrinkage, distorted contact with neighboring cells, chromatin condensation and bleb formation of the plasma membrane [80]. At the final stage, the cell becomes fragmented into compact membrane-enveloped structures, called apoptotic bodies, which contain cytosol, condensed chromatin and cell organelles. The apoptotic bodies are subsequently phagocytosed by macrophages and removed from the tissue without causing an inflammatory response [80]. These morphological changes in apoptotic cells are the consequence of intracellular events, which are controlled by two major pathways: the intrinsic and the extrinsic apoptotic signaling pathway [79]. Activation of either of these two pathways can lead to activation of different initiator caspases which converge at the level of the effector caspase (Figure 4), i.e., the activation of caspase-3 and subsequent internucleosomal DNA fragmentation [81]. Initiation of apoptosis can thus be triggered by extrinsic factors, such as cytokines, and intrinsic factors, such as oxidative stress, a pathological state when pro-oxidants are not neutralized adequately by antioxidant defense mechanisms [82]. 


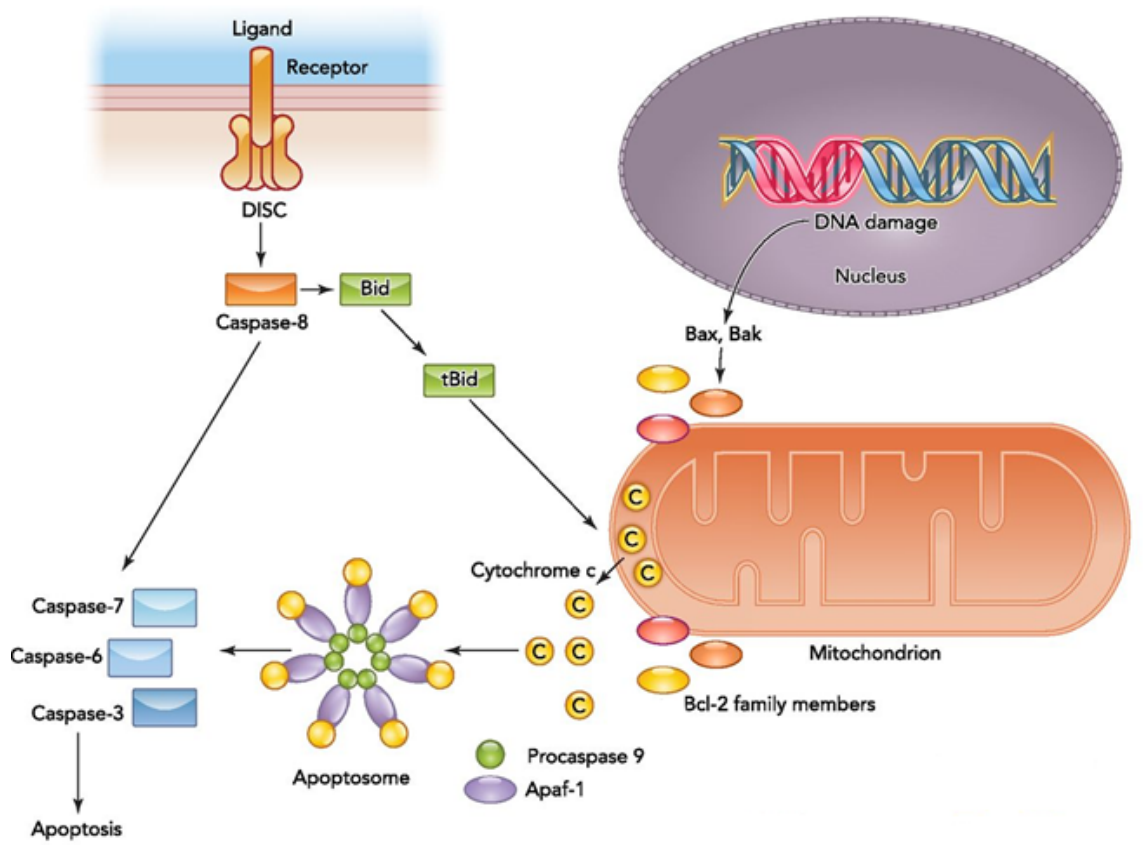

Figure 4. Overview of the intrinsic and extrinsic apoptotic signalling pathways. The extrinsic pathway is activated upon binding of a death ligand to the death receptor, resulting in activation of the death-inducing signalling complex. Caspase- 8 then either directly activates the downstream caspase 7 and 6 or cleaves Bid as an amplification step. The intrinsic pathway is activated in response to physiological signals or cellular stresses such as DNA damage. Upon activation, the balance between antiapoptotic and proapoptotic $\mathrm{Bcl}-2$ members on the mitochondrial membrane becomes disrupted, resulting in outer mitochondrial membrane permeabilization and cytochrome $\mathrm{c}$ release. The released cytosolic cytochrome $\mathrm{c}$ binds to the apoptotic caspase activating factor (Apaf1), recruiting procaspase-9 to form the apoptosome. Activated caspase- 9 within the apotosome can then promote efficient activation of downstream caspases 3 and 7 that are responsible for the execution phase of apoptosis (adapted from [79]).

Nowadays, it is generally accepted that atresia is the default fate of follicles, a process that is initiated when cells fail to receive sufficient signals to suppress the apoptotic pathway and/or when atretogenic factors are released promoting follicular cell death [77]. Examples of anti-apoptotic factors include FSH, estrogens, IGF1 and GH, while androgens can act as atretogenic factors [83]. Suppression of FSH levels due to, for instance, hypophysectomy results in massive apoptosis of granulosa cells in growing follicles [64]. In line with this, small antral and preovulatory rat follicles immediately undergo apoptosis when cultured in the absence of FSH, while FSH supplementation to the medium of these cultures prevents the spontaneous onset of granulosa cell death and thus atresia [84, 85]. It has been hypothesized that FSH may exert its anti-atretogenic effect by modulation of oxidative stress. Support for this assumption comes from several studies. The absence of FSH in the culture medium increases the production of reactive oxygen species (ROS) prior to any morphological or physiological indications of apoptosis, while FSH supplementation suppresses ROS production in the cultured large antral follicles $[82,86]$. Furthermore, FSH treatment of female rats has been shown to enhance the expression of antioxidant genes, such as superoxide dismutase 2 [87]. In vitro exposure of goat granulosa cells to FSH has been shown to lead to increased activity of the antioxidant enzyme catalase [88], while FSH treatment in rats results in enhanced ovarian synthesis of the antioxidant glutathione (GSH) [89]. In another series of experiments, it has been shown that FSH protects pre-ovulatory follicles from undergoing apoptosis via increased GSH and 
decreased ROS production, while depletion of GSH significantly inhibits the antiapoptotic effect of FSH on granulosa cells $[82,86]$. Glutamate cysteine ligase, an enzyme essential for the de novo synthesis of GSH, is specifically expressed in granulosa cells of healthy follicles [90]. Overexpression of glutamate cysteine ligase in human granulosa tumor cells enhances GSH production and protects these cells from oxidative stress-induced cell death [91]. Taken together, these studies suggest that the effects of FSH on granulosa cells apoptosis, and thus follicular atresia, is associated with inhibition of oxidative stress.

Recently, it has become increasingly clear that apoptosis may not be the only process involved in follicular atresia, but that autophagy may participate in this process as well. Hulas-Stasiak and Gawron [92] have shown that in the neonatal period when primordial and primary follicles undergo massive degeneration, autophagy is the dominant form of follicular atresia. Furthermore, human granulosa cells exposed in vitro to oxidized low-density lipoprotein, show morphological signs of autophagy [93]. Choi et al. [94] have demonstrated the presence of microtubule-associated lightchain protein 3 (LC3), a marker for autophagy in the rat ovary. Further evidence supporting a role for autophagy in ovarian follicle attrition stems from smoke exposure studies in mice [95-97]. Smoke exposure has been shown to cause ovarian follicle loss by activation of autophagy. Together these studies suggest that autophagy may be play a role in ovarian follicular attrition under both normal physiological conditions and /or toxicant-induced ovarian follicular degeneration.

Autophagy is an evolutionary conserved intracellular mechanism whereby damaged organelles and proteins are degraded and recycled to be reused by the cell. Three types of autophagy have been described in mammalian cells: micro-autophagy, chaperone-mediated autophagy and macroautophagy [98]. Macro-autophagy (further referred to as autophagy) is the most extensively studied type of autophagy. It functions mainly as a cell protective mechanism by ensuring cell survival via the removal of damaged subcellular components under stressful conditions such as cytotoxicity, nutrient depletion, accumulation of reactive oxygen species or infection [95, 99-101]. Dysregulated autophagy can lead to a number of pathologies, including neurodegeneration, cancer and metabolic diseases [102]. Recently, autophagy has been increasingly recognized as an alternative pathway for the induction of cell death [99, 103, 104]. A number of studies has shown that autophagy can act independently of apoptosis to induce cells death under physiological conditions $[105,106]$.

LC3, as indicated above, is widely used as a marker for autophagy. LC3 determines the size of the autophagosome and participates in cargo recognition [107]. LC3 is synthesized in an inactive form, pro-LC3, that immediately after synthesis is processed to generate soluble LC3-I which can be converted into an active autophagosome membrane-bound form, LC3-II (Figure 5) [107]. Ubiquitinbinding protein QSQTM1/p62 plays an important role in the clearance of ubiquitinated protein aggregates by functioning as an adapter protein that interacts with LC3-II to target aggregates for autophagy-specific degradation [107]. Inhibition of autophagy is correlated with increased intracellular levels of p62 in mammals, suggesting that steady-state levels of this protein reflect the autophagic status of a cell. Similarly, decreased p62 levels are associated with autophagy activation [108]. Beside these observations it has been reported that the expression levels of p62 can also change independent of autophagy and thus analysis of the presence of $p 62$ alone may not be sufficient to obtain insight in the relation between autophagy and cell death [109]. By analysing both 
LC3 and p62 protein levels a better indication can be obtained about the role of autophagy in cellular function.

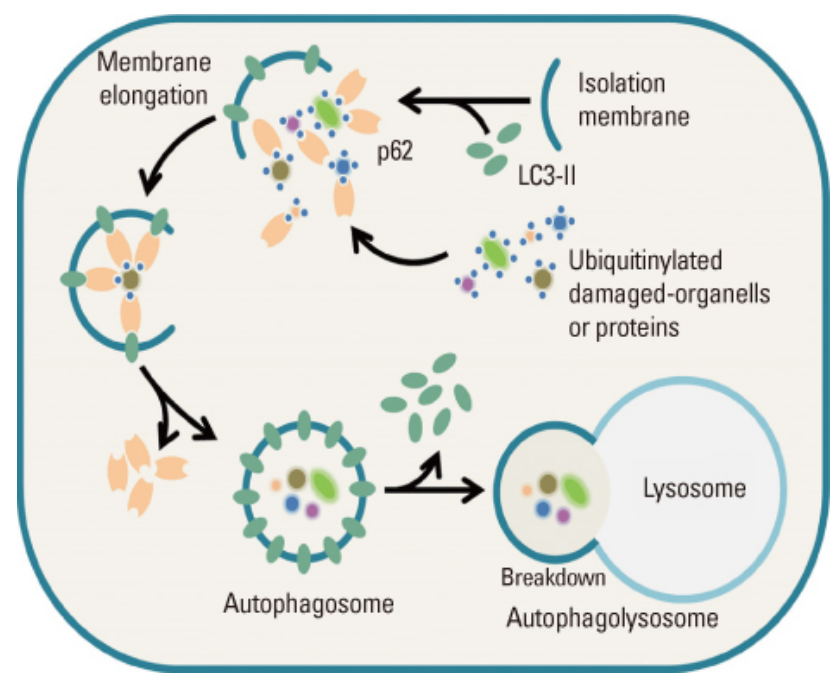

Fig. 5. Simplified schematic overview of the process of autophagy. Autophagy is initiated by the formation of an isolation membrane. The concerted action of the autophagy core machinery proteins at the phagophore assembly site is thought to lead to the expansion of the isolation membrane into an autophagosome (vesicle elongation). Ubiquitinylated damaged organelles or proteins may be directly targeted for degradation via the autophagic pathway. The p62 protein interacts with ubiquitinylated damaged organelles or proteins in cells. This complex is then selectively tied to the autophagosome through the interaction between p62 and light chain 3-II (LC3-II). When the outer membrane of the autophagosome fuses with a lysosome, it forms an autophagolysosome. Finally, the sequestered material is degraded inside the autophagolyosome and recycled (adapted from [110]).

\subsection{Energy status and female reproduction}

Successful reproduction is related to the energy status of the organism. Obesity and/or overweight as well as underweight are negatively associated with female fertility [111, 112]. A decreased success in spontaneous conception, an increased rate of anovulation, and increased risks of miscarriage have been reported in obese women at reproductive age [113]. Furthermore, there are indications that maternal obesity may affect the reproductive capacity in their children [114]. It is therefore not surprising that the effects of overweight and obesity on female fertility are widely studied.

Underweight due to limited energy intake, such as caloric restriction (CR) or anorexia nervosa, has also a negative effect on female fertility, including ovarian folliculogenesis. For example, CR in adult mice leads to a reduced recruitment of primordial follicles and a lower number of atretic follicles, suggestive of a halt in ovarian follicular development. After return to ad libitum food intake the CR mice appeared to have an expanded reproductive lifespan [115]. Anorexia can lead to a decrease in plasma gonadotropin levels and in severe cases even lead to complete absence of menstruation [116-119]. Furthermore, an increase in miscarriage incidence has been reported in women suffering from anorexia [120]. Despite this knowledge it is not clear whether these reproductive problems are due to alterations in body fat mass as such or are the result of altered availability of metabolic fuels i.e., glucose, amino acids, short-chain and long-chain fatty acids, for reproduction. From an evolutionary perspective, a driving role for metabolic fuel availability would make sense, since even a 
temporary shortage in fuel availability could indicate that the body is not optimally equipped to successfully complete a pregnancy [121].

In this thesis, the effect of metabolic status on female reproduction is examined using two animal models in which an altered metabolic flux, resulting in altered metabolic fuel availability, was imposed; a diet-induced thyroid hormone deficiency model and a genetic model of skeletal muscle semi-starvation. Thyroid hormone plays an important role in regulating energy expenditure, mainly via regulation of the activity, or expression, of uncoupling proteins in peripheral tissues [122]. Thyroid hormone deficiency limits energy dissipation and thus alters metabolic fuel availability. Metabolic fuel availability is also altered by ectopic expression of uncoupling protein 1 (UCP1) in skeletal muscle, which causes an energy drain towards this tissue [123] by inducing semi-energy starvation in this tissue, potentially impacting other tissues such as the ovary [124]. To better understand the role of metabolic fuel availability on female reproduction, I therefore examined the effects of these two contrasting metabolic models, on female reproduction, focusing on ovarian follicular development.

\subsection{Thyroid hormone deficiency and ovarian follicular development}

\section{Thyroid hormone synthesis}

An adequate functioning of the thyroid critically depends on sufficient availability of the essential trace element iodine. The production of thyroid hormone (TH) is controlled by a well-defined negative feedback system, including thyrotropin-releasing hormone (TRH) synthesis and release by the hypothalamus to stimulate thyroid-stimulating hormone (TSH) synthesis and release by the pituitary, which then stimulates the synthesis and release of the THs thyroxin $\left(T_{4}\right)$ and triiodothyronine $\left(T_{3}\right)$ by the thyroid gland (Figure 6). Due to the negative feedback system, plasma $\mathrm{TH}$ concentrations are normally kept at a relatively stable level in both humans and animals. Alterations in peripheral TH concentrations due to, for instance, a severe reduction in plasma iodine content, will lead to a compensatory increase in TRH synthesis by the hypothalamus in order to maintain a strict control over $\mathrm{T}_{4}$ and $\mathrm{T}_{3}$ concentrations [125].

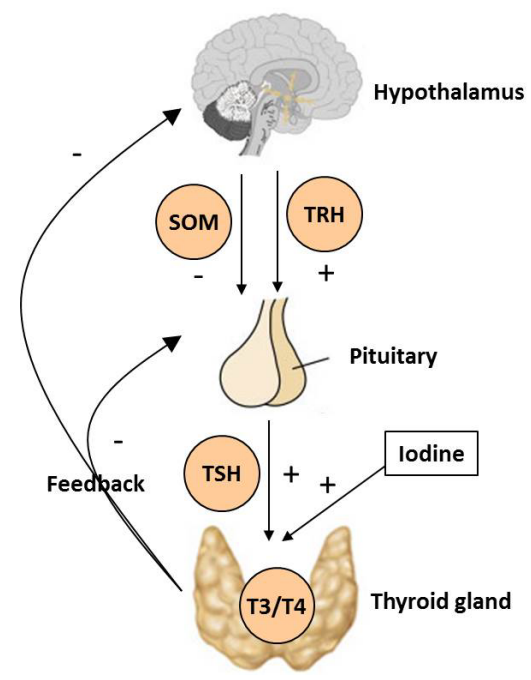

Figure 6 Schematic overview of thyroid hormone (TH) synthesis. $\mathrm{TH}$ production is controlled by the thyrotropin-releasing hormone (TRH) produced by neurons in the paraventricular nucleus of hypothalamus. The TRH is released to the blood in the eminentia mediana and reaches the anterior pituitary gland via a portal system, where TRH induces synthesis and secretion of thyroid stimulating hormone (TSH). TSH is released in the blood stream and stimulates the production of the THs tr-iodothyronine $\left(T_{3}\right)$ and thyroxin $\left(\mathrm{T}_{4}\right)$ by the thyroid gland. Increased $\mathrm{TH}$ concentrations can stimulate somatostatin (SOM) release by hypothalamic neurons. SOM inhibits the release of TSH from the pituitary and thus inhibits TH synthesis. Figure adapted from Teerds et al. (unpublished). 


\section{Thyroid hormone and metabolism}

$\mathrm{TH}$ is involved in the regulation of metabolic processes and is essential for normal growth and development. For example, TH regulates the expression of peroxisome proliferator-activated receptor and liver $\mathrm{X}$ receptor, genes involved in the regulation of metabolic processes. TH plays an important role in energy expenditure via both central and peripheral actions. TH maintains basal metabolic rate (BMR), facilitates non-shivering thermogenesis, and modulates appetite and food intake [126]. TH stimulates BMR by increasing adenosine-tri-phosphate [127] production for metabolic processes. In addition, TH maintains BMR via uncoupling oxidative phosphorylation (OXPHOS) in mitochondria by regulating the expression of uncoupling proteins $[126,128]$. Besides these functions, TH also plays a distinct role in carbohydrate and lipid metabolism. For example, TH modulates hepatic insulin sensitivity, which is especially important for the suppression of hepatic gluconeogenesis [126, 129].

\section{Hypothyroidism and ovarian follicular development}

The effect of TH deficiency on ovarian follicular development is not fully understood. The prevalence of severe hypothyroidism in women of reproductive age ranges from 2 to $4 \%$. The main causes of hypothyroidism in women are autoimmune thyroid disease and iodine insufficiency [130]. Although it is not possible in women to precisely analyse the size of the ovarian follicle pool, as well as monitor the development of follicles from the primordial to the preovulatory stage, it has been shown that ovarian folliculogenesis as well as ovulation is disturbed under chronic hypothyroid conditions. In general, however, these clinical studies are retrospective and lack proper controls [131]. In animal models like the rat, it is possible to determine the effects of chronic hypothyroidism on follicular development in more detail. In one of these studies it has been shown that neonatal induced hypothyroidism leads to a delayed vaginal opening, smaller ovaries, a reduced number of antral follicles and more atretic follicles [132]. Nevertheless, the number of animal studies investigating the effect of hypothyroidism on ovarian follicular development in adulthood is limited and the observations contradictory. Some studies in rats report that hypothyroidism induced in adulthood causes irregular estrous cycles and ovarian atrophy $[133,134]$, while Hapon et al. have shown that virgin adult hypothyroid rats show prolonged periods of vaginal dioestrus. In adult female mice, hypothyroidism results in infertility, probably due to impaired ovarian follicular development [135]. None of these studies provides a detailed analysis of ovarian follicle reserve. Furthermore, no direct comparison has been made on the effects of neonatally induced hypothyroidism and hypothyroidism induced in adulthood on follicular development and ovarian reserve. Furthermore, there is no clear evidence concerning the pathways involved in how decreased TH levels can influence follicular development. It is, for instance, unclear whether TH directly affects follicular development or whether these effects are indirect via effects of TH on metabolism and thus energy flux in the body.

\subsection{Muscle starvation-like model and ovarian follicular development}

In order for an organism to function properly, it needs to have access to sufficient energy supply. Energy substrates such as carbohydrates, lipids and proteins are transported into cells after which they are metabolized in the cytosolic and mitochondrial compartments to be transformed into the metabolic intermediates reduced Nicotinamide Adenine Dinucleotide (NADH) and reduced Flavin Adenine Dinucleotide (FADH2), which feed OXPHOS to produce ATP [136]. Briefly, NADH and FADH2 
supply electrons to the electron transport chain which leads to the reduction of molecular oxygen to water. Electron transfer through the electron transport chain controls pumping of protons $\left(\mathrm{H}^{+}\right)$from the mitochondrial matrix to the intermitochondrial membrane space, thus creating a proton motive force, whose energy is used by ATP synthase (FoF1ATPase) for the phosphorylation of adenosine diphosphate (Figure 7). The end product, ATP, is an energy-rich intermediate that can be directly used by cells for biochemical reactions. Despite the high efficiency of OXPHOS, not all of the generated energy is converted into ATP. Part of the energy produced is lost as heat due to the reentry of $\mathrm{H}^{+}$into the mitochondrial matrix independent of ATP synthase, by a process named protonleak. In brown adipose tissue (BAT), proton leak is mediated by uncoupling protein 1 (UCP1), which is one of members of the mitochondrial anion carrier family.

UCP1 is located in the inner mitochondrial membrane and predominantly expressed in BAT. Recent evidence indicates that UCP1 is also present in beige/brite adipocytes in subcutaneous white adipose tissue [137]. When active, UCP1 uncouples the mitochondrial respiratory chain from ATP production to dissipate energy as heat, a process known as non-shivering thermogenesis. UCP1 can be activated under several conditions, such as cold stress, activation of the sympathetic nervous system, as well as by humeral input via thyroid hormone [138]. When chronically activated by cold exposure, UCP1 mediated BAT-dependent thermogenesis enhances the oxidation of metabolic substrates necessary for enhancing thermogenesis. Under these conditions, not only lipids stored in BAT but also glucose and free fatty acids from the circulation are used as energy sources [136]. The importance of energy dissipation by UCP1 is well established; overexpression of UCP1 prevents the development of obesity [139], while UCP1 ablation can induce obesity [140].

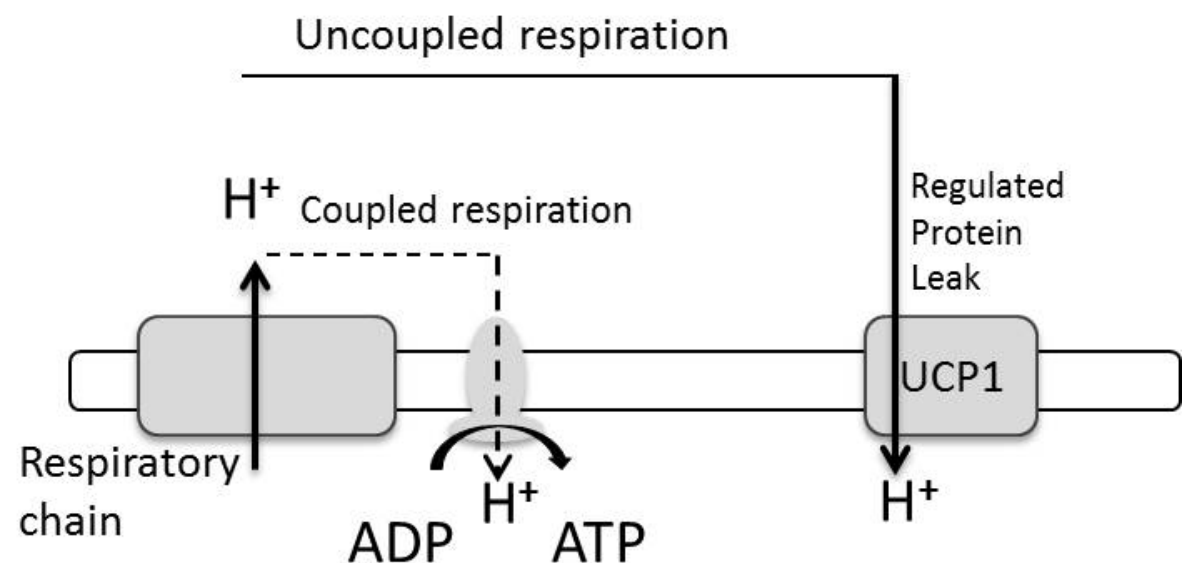

Figure 7, Schematic representation of inducible-UCP1 mediated proton leak (adapted from [136])

The uncoupling, energy dissipatory function of UCP1 has been used to create a mouse model with increased energy expenditure specifically in skeletal muscle (UCP1-TG), the UCP1-TG mouse model [141]. In this mouse model, UCP1 is expressed under control of the human skeletal actin (HSA) promotor that is specifically expressed in skeletal muscle [141]. While the homogeneous ectopic expression of UCP1 results in embryonic lethality, the hemizygous UCP1-TG mice show increased whole body energy expenditure [141]. The UCP1-TG mice are smaller and have smaller muscles, but 
the muscles are structurally and functionally intact: morphology is maintained and no effect is seen on voluntary activity and running wheel activity [142]. The muscles of the UCP1-TG mice show a more oxidative phenotype [124], probably as a compensatory reaction. Indeed, it has been shown that the skeletal muscle mitochondria of UCP1-TG mice are markedly less efficient; a higher oxygen consumption rate is needed to generate the same membrane potential (Figure 8) [143]. The phenotype resulting from the uncoupling of muscle mitochondria can be considered as skeletalmuscle semi-starvation. Indeed, in the UCP1-TG mice there is an energy drain towards skeletal muscle tissue to provide this tissue with sufficient energy [124, 144]. The increased energy expenditure, the increased food intake and the maintenance of adiposity, support the assumption that nutrient flux is altered in these mice. The UCP1-TG mouse model, where increased energy drain towards the muscle is genetically imposed, thus provides us with a unique model to study ovarian follicle development under the condition of increased nutrient flux. It eliminates several of the confounding factors, such as excessive exercise, long term dietary energy restriction or altered fat mass, of other models. Ovaries and in particular ovarian follicular reserve have not been analyzed in UCP1-TG mice model until now.

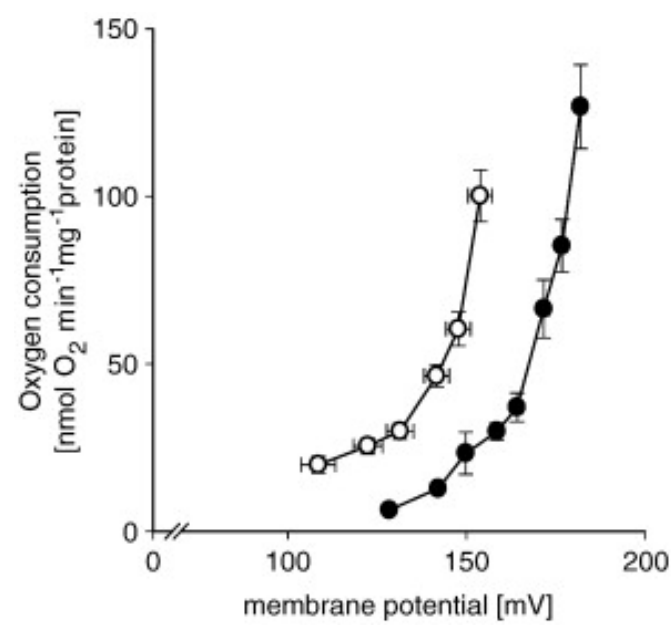

Figure 8. The figure shows that UCP1-TG mice (open symbols) consume more oxygen to generate the same membrane potential as wild type littermate controls (black symbols), indicative of an decreased mitochondrial energy efficiency (taken from [138]).

\subsection{Aims and outline of this thesis}

\section{Aims}

The overall goal of this thesis was to investigate the effects of an altered metabolism, and particularly an altered energy status, on ovarian follicular development. This was assessed by histological/immunohistological techniques. Histology/immunohistology is one of the few techniques available that facilitate separate analysis of the different cell types in the ovary simultaneously. While histology and immunohistochemistry were the primary techniques that were used, analysis was supported by general (molecular) biological techniques, such as western blotting and real time reverse transcription polymerase chain reaction (qRT-PCR). In addition, laser capture microdissection of specific cell types, followed by qRT-PCR, was employed, a novel technique to address the study of follicular development in the ovary. This facilitated the analysis of changes in mRNA 
expression in specific cell types complementary to immunohistochemistry. The research described in this thesis can be divided in 3 specific aims:

The first aim was to establish the role of autophagy in follicular degeneration under normal physiological conditions, with focus on preantral and antral follicles;

The second aim was to elucidate the effects of a diet-induced reduction in thyroid hormone concentrations, affecting whole body metabolism, on ovarian follicular development;

The third aim was to investigate the effect of increased nutrient flux on ovarian follicular development and the possible underlying mechanism.

\section{Outline of this thesis}

In chapter 2, the role of autophagy in ovarian follicle development and degeneration under normal physiological conditions is investigated. Autophagy was assessed by immunohistochemical analysis of two classic autophagy markers, LC3 and P62. In addition, laser capture microdissection followed by qPCR was employed. The focus is on preantral and antral follicular atresia.

To investigate the effects of dietary induced chronic hypothyroidism initiated in adulthood on the rat ovarian follicular development, ovarian follicular reserve was determined by counting follicle numbers. A biomarker for growing follicle numbers, plasma AMH concentrations, was measured to confirm the follicle counting. The results obtained are described in chapter 3.

Next, the effects of foetal/postnatal dietary induced chronic hypothyroidism on follicular development was investigated. The onset of puberty was evaluated and ovarian follicle numbers were scored at pre-puberty, young adult and adult time points. The role of oxidative stress was specifically investigated. The results are described in chapter 4.

In chapter 5, the effects of muscle semi-starvation on ovarian follicular development and the underlying mechanisms were investigated, using a hypothesis driven approach. A unique mouse model with ectopic expression of UCP-1 in skeletal muscle was employed as the primary study model. As this transgene has extremely high levels of FGF21, the possible role of this growth factor was addressed by combining the UCP1 transgene with a FGF21 knockout model.

Finally, in chapter 6, the general discussion, the outcomes of this thesis are discussed and recommendations for future research are presented. 


\subsection{References}

1. Grive KJ, Freiman RN. The developmental origins of the mammalian ovarian reserve. Development 2015; 142:2554-2563.

2. Pepling ME. Follicular assembly: mechanisms of action. Reproduction 2012; 143:139-149.

3. McLaren A. Primordial germ cells in the mouse. Dev Biol 2003; 262:1-15.

4. Lei L, Spradling AC. Mouse primordial germ cells produce cysts that partially fragment prior to meiosis. Development 2013; 140:2075-2081.

5. Hennet ML, Combelles CM. The antral follicle: a microenvironment for oocyte differentiation. Int J Dev Biol 2012; 56:819-831.

6. McGee EA, Hsueh AJW. Initial and cyclic recruitment of ovarian follicles. Endocr Rev 2000; 21:200-214.

7. Knobil E, Neill JD. Knobil and Neill's physiology of reproduction. Amsterdam ; Boston: Elsevier; 2006.

8. Adhikari D, Liu K. Molecular mechanisms underlying the activation of mammalian primordial follicles. Endocr Rev 2009; 30:438-464.

9. Massague J, Chen YG. Controlling TGF-beta signaling. Genes Dev 2000; 14:627-644.

10. Durlinger AL, Visser JA, Themmen AP. Regulation of ovarian function: the role of anti-Mullerian hormone. Reproduction 2002; 124:601-609.

11. Weenen C, Laven JS, Von Bergh AR, Cranfield M, Groome NP, Visser JA, Kramer P, Fauser BC, Themmen AP. AntiMullerian hormone expression pattern in the human ovary: potential implications for initial and cyclic follicle recruitment. Mol Hum Reprod 2004; 10:77-83.

12. Themmen AP. Anti-Mullerian hormone: its role in follicular growth initiation and survival and as an ovarian reserve marker. J Natl Cancer Inst Monogr 2005:18-21.

13. Durlinger AL, Kramer P, Karels B, de Jong FH, Uilenbroek JT, Grootegoed JA, Themmen AP. Control of primordial follicle recruitment by anti-Mullerian hormone in the mouse ovary. Endocrinology 1999; 140:5789-5796.

14. Carlsson IB, Scott JE, Visser JA, Ritvos O, Themmen AP, Hovatta O. Anti-Mullerian hormone inhibits initiation of growth of human primordial ovarian follicles in vitro. Hum Reprod 2006; 21:2223-2227.

15. Nilsson E, Rogers N, Skinner MK. Actions of anti-Mullerian hormone on the ovarian transcriptome to inhibit primordial to primary follicle transition. Reproduction 2007; 134:209-221.

16. Monniaux D, Drouilhet L, Rico C, Estienne A, Jarrier P, Touze JL, Sapa J, Phocas F, Dupont J, Dalbies-Tran R, Fabre S. Regulation of anti-Mullerian hormone production in domestic animals. Reprod Fertil Dev 2012; 25:1-16.

17. Vitt UA, McGee EA, Hayashi M, Hsueh AJW. In vivo treatment with GDF-9 stimulates primordial and primary follicle progression and theca cell marker CYP17 in ovaries of immature rats. Endocrinology 2000; 141:3814-3820.

18. Dong JW, Albertini DF, Nishimori K, Kumar TR, Lu NF, Matzuk MM. Growth differentiation factor-9 is required during early ovarian folliculogenesis. Nature 1996; 383:531-535.

19. Nilsson EE, Skinner MK. Growth and differentiation factor-9 stimulates progression of early primary but not primordial rat ovarian follicle development. Biol Reprod 2002; 67:1018-1024.

20. Hreinsson JG, Scott JE, Rasmussen C, Swahn ML, Hsueh AJW, Hovatta O. Growth differentiation factor-9 promotes the growth, development, and survival of human ovarian follicles in organ culture. J Clin Endocrinol Metab 2002; 87:316-321.

21. Martins FS, Celestino JJH, Saraiva MVA, Matos MHT, Bruno JB, Rocha CMC, Lima-Verde IB, Lucci CM, Bao SN, Figueiredo JR. Growth and differentiation factor-9 stimulates activation of goat primordial follicles in vitro and their progression to secondary follicles. Reprod Fert Develop 2008; 20:916-924.

22. Wang JR, Roy SK. Growth differentiation factor-9 and stem cell factor promote primordial follicle formation in the hamster: Modulation by follicle-stimulating hormone. Biol Reprod 2004; 70:577-585.

23. Nilsson E, Parrott JA, Skinner MK. Basic fibroblast growth factor induces primordial follicle development and initiates folliculogenesis. Mol Cell Endocrinol 2001; 175:123-130. 
24. Nilsson EE, Skinner MK. Kit ligand and basic fibroblast growth factor interactions in the induction of ovarian primordial to primary follicle transition. Mol Cell Endocrinol 2004; 214:19-25.

25. Slot KA, Kastelijn J, Bachelot A, Kelly PA, Binart N, Teerds KJ. Reduced recruitment and survival of primordial and growing follicles in GH receptor-deficient mice. Reproduction 2006; 131:525-532.

26. Kezele PR, Nilsson EE, Skinner MK. Insulin but not insulin-like growth factor-1 promotes the primordial to primary follicle transition. Mol Cell Endocrinol 2002; 192:37-43.

27. Dierich A, Sairam MR, Monaco L, Fimia GM, Gansmuller A, LeMeur M, Sassone-Corsi P. Impairing folliclestimulating hormone (FSH) signaling in vivo: targeted disruption of the FSH receptor leads to aberrant gametogenesis and hormonal imbalance. Proc Natl Acad Sci U S A 1998; 95:13612-13617.

28. Reddy P, Liu L, Adhikari D, Jagarlamudi K, Rajareddy S, Shen Y, Du C, Tang WL, Hamalainen T, Peng SL, Lan ZJ, Cooney AJ, et al. Oocyte-specific deletion of Pten causes premature activation of the primordial follicle pool. Science 2008; 319:611-613.

29. John GB, Gallardo TD, Shirley LJ, Castrillon DH. Foxo3 is a PI3K-dependent molecular switch controlling the initiation of oocyte growth. Dev Biol 2008; 321:197-204.

30. Castrillon DH, Miao LL, Kollipara R, Horner JW, DePinho RA. Suppression of ovarian follicle activation in mice by the transcription factor Foxo3a. Science 2003; 301:215-218.

31. Rajareddy S, Reddy P, Du C, Liu L, Jagarlamudi K, Tang W, Shen Y, Berthet C, Peng SL, Kaldis P, Liu K. p27kip1 (cyclin-dependent kinase inhibitor $1 \mathrm{~B}$ ) controls ovarian development by suppressing follicle endowment and activation and promoting follicle atresia in mice. Mol Endocrinol 2007; 21:2189-2202.

32. Schmidt D, Ovitt CE, Anlag K, Fehsenfeld S, Gredsted L, Treier AC, Treier M. The murine winged-helix transcription factor Fox 12 is required for granulosa cell differentiation and ovary maintenance. Development 2004; 131:933-942.

33. Uda M, Ottolenghi C, Deiana M, Kimber W, Forabosco A, Cao A, Schlessinger D, Pilia G. Foxl2 disruption causes mouse ovarian failure by pervasive blockage of follicle development. Hum Mol Genet 2004; 13:1171-1181.

34. Holt JE, Jackson A, Roman SD, Aitken RJ, Koopman P, McLaughlin EA. CXCR4/SDF1 interaction inhibits the primordial to primary follicle transition in the neonatal mouse ovary. Dev Biol 2006; 293:449-460.

35. Dole G, Nilsson EE, Skinner MK. Glial-derived neurotrophic factor promotes ovarian primordial follicle development and cell-cell interactions during folliculogenesis. Reproduction 2008; 135:671-682.

36. Yu N, Roy SK. Development of primordial and prenatal follicles from undifferentiated somatic cells and oocytes in the hamster prenatal ovary in vitro: effect of insulin. Biol Reprod 1999; 61:1558-1567.

37. Samoto T, Maruo T, Ladinesllave CA, Matsuo H, Deguchi J, Barnea ER, Mochizuki M. Insulin-receptor expression in follicular and stromal compartments of the human ovary over the course of follicular-growth, regression and atresia. Endocr J 1993; 40:715-726.

38. Kezele P, Nilsson EE, Skinner MK. Keratinocyte growth factor acts as a mesenchymal factor that promotes ovarian primordial to primary follicle transition. Biol Reprod 2005; 73:967-973.

39. Nilsson EE, Detzel C, Skinner MK. Platelet-derived growth factor modulates the primordial to primary follicle transition. Reproduction 2006; 131:1007-1015.

40. Hutt KJ, McLaughlin EA, Holland MK. KIT/KIT ligand in mammalian oogenesis and folliculogenesis: Roles in rabbit and murine ovarian follicle activation and oocyte growth. Biol Reprod 2006; 75:421-433.

41. Lee WS, Otsuka F, Moore RK, Shimasaki S. Effect of bone morphogenetic protein-7 on folliculogenesis and ovulation in the rat. Biol Reprod 2001; 65:994-999.

42. Lee WS, Yoon SJ, Yoon TK, Cha KY, Lee SH, Shimasaki S, Lee S, Lee KA. Effects of bone morphogenetic protein-7 (BMP-7) on primordial follicular growth in the mouse ovary. Mol Reprod Dev 2004; 69:159-163.

43. Nilsson EE, Skinner MK. Bone morphogenetic protein-4 acts as an ovarian follicle survival factor and promotes primordial follicle development. Biol Reprod 2003; 69:1265-1272.

44. Xu J, Oakley J, McGee EA. Stage-specific expression of Smad2 and Smad3 during folliculogenesis. Biol Reprod 2002; 66:1571-1578. 
45. Tomic D, Brodie SG, Deng C, Hickey RJ, Babus JK, Malkas LH, Flaws JA. Smad 3 may regulate follicular growth in the mouse ovary. Biol Reprod 2002; 66:917-923.

46. Nilsson EE, Kezele P, Skinner MK. Leukemia inhibitory factor (LIF) promotes the primordial to primary follicle transition in rat ovaries. Mol Cell Endocrinol 2002; 188:65-73.

47. Rajkovic A, Pangas SA, Ballow D, Suzumori N, Matzuk MM. NOBOX deficiency disrupts early folliculogenesis and oocyte-specific gene expression. Science 2004; 305:1157-1159.

48. Suzumori N, Yan CN, Matzuk MM, Rajkovic A. Nobox is a homeobox-encoding gene preferentially expressed in primordial and growing oocytes. Mech Dev 2002; 111:137-141.

49. Choi Y, Rajkovic A. Characterization of NOBOX DNA binding specificity and its regulation of Gdf9 and Pou5f1 promoters. J Biol Chem 2006; 281:35747-35756.

50. Pangas SA, Choi Y, Ballow DJ, Zhao YG, Westphal H, Matzuk MM, Rajkovic A. Oogenesis requires germ cell-specific transcriptional regulators Sohlh1 and Lhx8. Proc Natl Acad Sci U S A 2006; 103:8090-8095.

51. Choi Y, Ballow DJ, Xin Y, Rajkovic A. Lim homeobox gene, Lhx8, is essential for mouse oocyte differentiation and survival. Biol Reprod 2008; 79:442-449.

52. Choi Y, Yuan D, Rajkovic A. Germ Cell-Specific Transcriptional regulator Sohlh2 is essential for early mouse folliculogenesis and oocyte-specific gene expression. Biol Reprod 2008; 79:1176-1182.

53. Toyoda S, Miyazaki T, Miyazaki S, Yoshimura T, Yamamoto M, Tashiro F, Yamato E, Miyazaki J. Sohlh2 affects differentiation of KIT positive oocytes and spermatogonia. Dev Biol 2009; 325:238-248.

54. Simon AM, Goodenough DA, Li E, Paul DL. Female infertility in mice lacking connexin 37. Nature 1997; 385:525529.

55. Eppig JJ, Schroeder AC. Capacity of mouse oocytes from preantral follicles to undergo embryogenesis and development to live young after growth, maturation, and fertilization in vitro. Biol Reprod 1989; 41:268-276.

56. Vitt UA, Hayashi M, Klein C, Hsueh AJ. Growth differentiation factor-9 stimulates proliferation but suppresses the follicle-stimulating hormone-induced differentiation of cultured granulosa cells from small antral and preovulatory rat follicles. Biol Reprod 2000; 62:370-377.

57. Solovyeva EV, Hayashi M, Margi K, Barkats C, Klein C, Amsterdam A, Hsueh AJ, Tsafriri A. Growth differentiation factor-9 stimulates rat theca-interstitial cell androgen biosynthesis. Biol Reprod 2000; 63:1214-1218.

58. Spicer LJ, Aad PY, Allen DT, Mazerbourg S, Payne AH, Hsueh AJ. Growth differentiation factor 9 (GDF9) stimulates proliferation and inhibits steroidogenesis by bovine theca cells: influence of follicle size on responses to GDF9. Biol Reprod 2008; 78:243-253.

59. Durlinger AL, Gruijters MJ, Kramer P, Karels B, Kumar TR, Matzuk MM, Rose UM, de Jong FH, Uilenbroek JT, Grootegoed JA, Themmen AP. Anti-Mullerian hormone attenuates the effects of FSH on follicle development in the mouse ovary. Endocrinology 2001; 142:4891-4899.

60. Xu J, Bishop CV, Lawson MS, Park BS, Xu F. Anti-Mullerian hormone promotes pre-antral follicle growth, but inhibits antral follicle maturation and dominant follicle selection in primates. Hum Reprod 2016.

61. Durlinger AL, Gruijters MJ, Kramer P, Karels B, Ingraham HA, Nachtigal MW, Uilenbroek JTJ, Grootegoed JA, Themmen AP. Anti-Mullerian hormone inhibits initiation of primordial follicle growth in the mouse ovary. Endocrinology 2002; 143:1076-1084.

62. Hsueh AJ, Kawamura K, Cheng Y, Fauser BC. Intraovarian control of early folliculogenesis. Endocr Rev 2015; 36:124.

63. Oktay K, Briggs D, Gosden RG. Ontogeny of follicle-stimulating hormone receptor gene expression in isolated human ovarian follicles. J Clin Endocrinol Metab 1997; 82:3748-3751.

64. McGee EA, Perlas E, LaPolt PS, Tsafriri A, Hsueh AJ. Follicle-stimulating hormone enhances the development of preantral follicles in juvenile rats. Biol Reprod 1997; 57:990-998.

65. Abel MH, Wootton AN, Wilkins V, Huhtaniemi I, Knight PG, Charlton HM. The effect of a null mutation in the follicle-stimulating hormone receptor gene on mouse reproduction. Endocrinology 2000; 141:1795-1803. 
66. Kreeger PK, Fernandes NN, Woodruff TK, Shea LD. Regulation of mouse follicle development by folliclestimulating hormone in a three-dimensional in vitro culture system is dependent on follicle stage and dose. Biol Reprod 2005; 73:942-950.

67. Xu M, West-Farrell ER, Stouffer RL, Shea LD, Woodruff TK, Zelinski MB. Encapsulated three-dimensional culture supports development of nonhuman primate secondary follicles. Biol Reprod 2009; 81:587-594.

68. Cortvrindt R, Smitz J, VanSteirteghem AC. Assessment of the need for follicle stimulating hormone in early preantral mouse follicle culture in vitro. Hum Reprod 1997; 12:759-768.

69. Wright CS, Hovatta O, Margara R, Trew G, Winston RML, Franks S, Hardy K. Effects of follicle-stimulating hormone and serum substitution on the in-vitro growth of human ovarian follicles. Hum Reprod 1999; 14:1555-1562.

70. Magoffin DA. Ovarian theca cell. Int J Biochem Cell Biol 2005; 37:1344-1349.

71. Zhou J, Kumar TR, Matzuk MM, Bondy C. Insulin-like growth factor I regulates gonadotropin responsiveness in the murine ovary. Mol Endocrinol 1997; 11:1924-1933.

72. Adashi EY, Resnick CE, Hurwitz A, Ricciarellie E, Hernandez ER, Roberts CT, Leroith D, Rosenfeld R. The IntraOvarian Igf System. Growth Regul 1992; 2:10-15.

73. Armstrong DT, Xia P, de Gannes G, Tekpetey FR, Khamsi F. Differential effects of insulin-like growth factor-I and follicle-stimulating hormone on proliferation and differentiation of bovine cumulus cells and granulosa cells. Biol Reprod 1996; 54:331-338.

74. Glister C, Tannetta DS, Groome NP, Knight PG. Interactions between follicle-stimulating hormone and growth factors in modulating secretion of steroids and inhibin-related peptides by nonluteinized bovine granulosa cells. Biol Reprod 2001; 65:1020-1028.

75. Visser JA, de Jong FH, Laven JS, Themmen AP. Anti-Mullerian hormone: a new marker for ovarian function. Reproduction 2006; 131:1-9.

76. Faddy MJ, Gosden RG, Gougeon A, Richardson SJ, Nelson JF. Accelerated disappearance of ovarian follicles in midlife: implications for forecasting menopause. Hum Reprod 1992; 7:1342-1346.

77. Matsuda F, Inoue N, Manabe N, Ohkura S. Follicular growth and atresia in mammalian ovaries: regulation by survival and death of granulosa cells. J Reprod Dev 2012; 58:44-50.

78. Hirshfield AN. Development of follicles in the mammalian ovary. Int Rev Cytol 1991; 124:43-101.

79. Sendoel A, Hengartner MO. Apoptotic Cell Death Under Hypoxia. Physiology 2014; 29:168-176.

80. Hacker G. The morphology of apoptosis. Cell Tissue Res 2000; 301:5-17.

81. Sendoel A, Hengartner MO. Apoptotic cell death under hypoxia. Physiology (Bethesda) 2014; 29:168-176.

82. Devine PJ, Perreault SD, Luderer U. Roles of reactive oxygen species and antioxidants in ovarian toxicity. Biol Reprod 2012; 86:27.

83. Billig H, Furuta I, Hsueh AJ. Estrogens inhibit and androgens enhance ovarian granulosa cell apoptosis. Endocrinology 1993; 133:2204-2212.

84. Chun SY, Eisenhauer KM, Minami S, Billig H, Perlas E, Hsueh AJ. Hormonal regulation of apoptosis in early antral follicles: follicle-stimulating hormone as a major survival factor. Endocrinology 1996; 137:1447-1456.

85. Chun SY, Billig H, Tilly JL, Furuta I, Tsafriri A, Hsueh AJW. Gonadotropin suppression of apoptosis in cultured preovulatory follicles - mediatory role of endogenous Insulin-like growth-factor-I. Endocrinology 1994; 135:18451853.

86. Tsai-Turton $\mathrm{M}$, Luderer $\mathrm{U}$. Opposing effects of glutathione depletion and follicle-stimulating hormone on reactive oxygen species and apoptosis in cultured preovulatory rat follicles. Endocrinology 2006; 147:1224-1236.

87. Tilly JL, Tilly KI. Inhibitors of oxidative stress mimic the ability of follicle-stimulating-hormone to suppress apoptosis in cultured rat ovarian follicles. Endocrinology 1995; 136:242-252. 
88. Behl R, Pandey RS. FSH induced stimulation of catalase activity in goat granulosa cells in vitro. Anim Reprod Sci 2002; 70:215-221.

89. Luderer U, Kavanagh TJ, White CC, Faustman EM. Gonadotropin regulation of glutathione synthesis in the rat ovary. Reprod Toxicol 2001; 15:495-504.

90. Luderer U, Diaz D, Faustman EM, Kavanagh TJ. Localization of glutamate cysteine ligase subunit mRNA within the rat ovary and relationship to follicular apoptosis. Mol Reprod Dev 2003; 65:254-261.

91. Cortes-Wanstreet MM, Giedzinski E, Limoli CL, Luderer U. Overexpression of glutamate-cysteine ligase protects human COV434 granulosa tumour cells against oxidative and gamma-radiation-induced cell death. Mutagenesis 2009; 24:211-224.

92. Hulas-Stasiak M, Gawron A. Follicular atresia in the prepubertal spiny mouse (Acomys cahirinus) ovary. Apoptosis 2011; 16:967-975.

93. Duerrschmidt N, Zabirnyk O, Nowicki M, Ricken A, Hmeidan FA, Blumenauer V, Borlak J, Spanel-Borowski K. Lectin-like oxidized low-density lipoprotein receptor-1-mediated autophagy in human granulosa cells as an alternative of programmed cell death. Endocrinology 2006; 147:3851-3860.

94. Choi JY, Jo MW, Lee EY, Yoon BK, Choi DS. The role of autophagy in follicular development and atresia in rat granulosa cells. Fertil Steril 2010; 93:2532-2537.

95. Gannon AM, Stampfli MR, Foster WG. Cigarette smoke exposure leads to follicle loss via an alternative ovarian cell death pathway in a mouse model. Toxicol Sci 2012; 125:274-284.

96. Gannon AM, Stampfli MR, Foster WG. Cigarette smoke exposure elicits increased autophagy and dysregulation of mitochondrial dynamics in murine granulosa cells. Biol Reprod 2013; 88:1-11.

97. Furlong HC, Stampfli MR, Gannon AM, Foster WG. Cigarette smoke exposure triggers the autophagic cascade via activation of the AMPK pathway in mice. Biol Reprod 2015; 93:1-10.

98. Lee J, Giordano S, Zhang J. Autophagy, mitochondria and oxidative stress: cross-talk and redox signalling. Biochem J 2012; 441:523-540.

99. Loos B, Engelbrecht AM, Lockshin RA, Klionsky DJ, Zakeri Z. The variability of autophagy and cell death susceptibility: Unanswered questions. Autophagy 2013; 9:1270-1285.

100. Moretti L, Attia A, Kim KW, Lu B. Crosstalk between Bak/Bax and mTOR signaling regulates radiation-induced autophagy. Autophagy 2007; 3:142-144.

101. Azad MB, Chen Y, Henson ES, Cizeau J, McMillan-Ward E, Israels SJ, Gibson SB. Hypoxia induces autophagic cell death in apoptosis-competent cells through a mechanism involving BNIP3. Autophagy 2008; 4:195-204.

102. Wirawan E, Vanden Berghe T, Lippens S, Agostinis P, Vandenabeele P. Autophagy: for better or for worse. Cell Res 2012; 22:43-61.

103. Oral O, Oz-Arslan D, Itah Z, Naghavi A, Deveci R, Karacali S, Gozuacik D. Cleavage of Atg3 protein by caspase-8 regulates autophagy during receptor-activated cell death. Apoptosis 2012; 17:810-820.

104. Fulda S. Autophagy and cell death. Autophagy 2012; 8:1250-1251.

105. Hashimoto D, Ohmuraya M, Hirota M, Yamamoto A, Suyama K, Ida S, Okumura Y, Takahashi E, Kido H, Araki K, Baba H, Mizushima N, et al. Involvement of autophagy in trypsinogen activation within the pancreatic acinar cells. J Cell Biol 2008; 181:1065-1072.

106. Kuma A, Hatano M, Matsui M, Yamamoto A, Nakaya H, Yoshimori T, Ohsumi Y, Tokuhisa T, Mizushima N. The role of autophagy during the early neonatal starvation period. Nature 2004; 432:1032-1036.

107. Klionsky DJ, Schulman BA. Dynamic regulation of macroautophagy by distinctive ubiquitin-like proteins. Nat Struct Mol Biol 2014; 21:336-345.

108. Klionsky DJ, Abdalla FC, Abeliovich H, Abraham RT, Acevedo-Arozena A, Adeli K, Agholme L, Agnello M, Agostinis P, Aguirre-Ghiso JA, Ahn HJ, Ait-Mohamed $O$, et al. Guidelines for the use and interpretation of assays for monitoring autophagy. Autophagy 2012; 8:445-544.

109. Mizushima N, Yoshimori T. How to interpret LC3 immunoblotting. Autophagy 2007; 3:542-545. 
111. Practice Committee of the American Society for Reproductive M. Obesity and reproduction: a committee opinion. Fertil Steril 2015; 104:1116-1126.

112. Evans JJ, Anderson GM. Balancing ovulation and anovulation: integration of the reproductive and energy balance axes by neuropeptides. Hum Reprod Update 2012; 18:313-332.

113. Seli E, Babayev E, Collins SC, Nemeth G, Horvath TL. Minireview: Metabolism of female reproduction: regulatory mechanisms and clinical implications. Mol Endocrinol 2014; 28:790-804.

114. Jungheim ES, Schoeller EL, Marquard KL, Louden ED, Schaffer JE, Moley KH. Diet-induced obesity model: abnormal oocytes and persistent growth abnormalities in the offspring. Endocrinology 2010; 151:4039-4046.

115. Selesniemi K, Lee HJ, Tilly JL. Moderate caloric restriction initiated in rodents during adulthood sustains function of the female reproductive axis into advanced chronological age. Aging Cell 2008; 7:622-629.

116. Braat DD, Schoemaker R, Schoemaker J. Life table analysis of fecundity in intravenously gonadotropin-releasing hormone-treated patients with normogonadotropic and hypogonadotropic amenorrhea. Fertil Steril 1991; 55:266-271.

117. Carpenter SE. Psychosocial menstrual disorders: stress, exercise and diet's effect on the menstrual cycle. Curr Opin Obstet Gynecol 1994; 6:536-539.

118. Reid RL, Van Vugt DA. Weight-related changes in reproduction function. Fertil Steril 1987; 48:905-913.

119. Schweiger U. Menstrual function and luteal-phase deficiency in relation to weight changes and dieting. Clin Obstet Gynecol 1991; 34:191-197.

120. Bulik CM, Sullivan PF, Fear JL, Pickering A, Dawn A, McCullin M. Fertility and reproduction in women with anorexia nervosa: a controlled study. J Clin Psychiatry 1999; 60:130-135; quiz 135-137.

121. Wade GN, Schneider JE, Li HY. Control of fertility by metabolic cues. Am J Physiol 1996; 270:E1-19.

122. Herwig A, Ross AW, Nilaweera KN, Morgan PJ, Barrett P. Hypothalamic thyroid hormone in energy balance regulation. Obesity facts 2008; 1:71-79.

123. Couplan E, Gelly C, Goubern M, Fleury C, Quesson B, Silberberg M, Thiaudiere E, Mateo P, Lonchampt M, Levens N, De Montrion $C$, Ortmann $S$, et al. High level of uncoupling protein 1 expression in muscle of transgenic mice selectively affects muscles at rest and decreases their Ilb fiber content. J Biol Chem 2002; 277:43079-43088.

124. Ost M, Keipert S, van Schothorst EM, Donner V, van der Stelt I, Kipp AP, Petzke KJ, Jove M, Pamplona R, PorteroOtin $\mathrm{M}$, Keijer J, Klaus S. Muscle mitohormesis promotes cellular survival via serine/glycine pathway flux. FASEB J 2015; 29:1314-1328.

125. Yen PM. Physiological and molecular basis of thyroid hormone action. Physiol Rev 2001; 81:1097-1142.

126. Mullur R, Liu YY, Brent GA. Thyroid hormone regulation of metabolism. Physiol Rev 2014; 94:355-382.

127. Aris JP, Alvers AL, Ferraiuolo RA, Fishwick LK, Hanvivatpong A, Hu D, Kirlew C, Leonard MT, Losin KJ, Marraffini M, Seo AY, Swanberg $V$, et al. Autophagy and leucine promote chronological longevity and respiration proficiency during calorie restriction in yeast. Exp Gerontol 2013; 48:1107-1119.

128. Harper ME, Brand MD. The quantitative contributions of mitochondrial proton leak and ATP turnover reactions to the changed respiration rates of hepatocytes from rats of different thyroid status. J Biol Chem 1993; 268:1485014860 .

129. Zhang YQ, Lee FY, Barrera G, Lee H, Vales C, Gonzalez FJ, Willson TM, Edwards PA. Activation of the nuclear receptor FXR improves hyperglycemia and hyperlipidemia in diabetic mice. Proc Natl Acad Sci U S A 2006; 103:1006-1011.

130. Dittrich R, Beckmann MW, Oppelt PG, Hoffmann I, Lotz L, Kuwert T, Mueller A. Thyroid hormone receptors and reproduction. J Reprod Immunol 2011; 90:58-66.

131. Krassas GE, Poppe K, Glinoer D. Thyroid function and human reproductive health. Endocr Rev 2010; 31:702-755. 
132. Dijkstra G, de Rooij DG, de Jong FH, van den Hurk R. Effect of hypothyroidism on ovarian follicular development, granulosa cell proliferation and peripheral hormone levels in the prepubertal rat. Eur J Endocrinol 1996; 134:649654.

133. Mattheij JA, Swarts JJ, Lokerse P, van Kampen JT, Van der Heide D. Effect of hypothyroidism on the pituitarygonadal axis in the adult female rat. J Endocrinol 1995; 146:87-94.

134. Tohei A, Imai A, Watanabe G, Taya K. Influence of thiouracil-induced hypothyroidism on adrenal and gonadal functions in adult female rats. J Vet Med Sci 1998; 60:439-446.

135. Jiang JY, Imai Y, Umezu M, Sato E. Characteristics of infertility in female hypothyroid (hyt) mice. Reproduction 2001; 122:695-700.

136. Busiello RA, Savarese S, Lombardi A. Mitochondrial uncoupling proteins and energy metabolism. Front Physiol 2015; 6.

137. Nedergaard J, Bengtsson T, Cannon B. Unexpected evidence for active brown adipose tissue in adult humans. Am J Physiol Endocrinol Metab 2007; 293:E444-452.

138. Nedergaard J, Cannon B. UCP1 mRNA does not produce heat. Biochim Biophys Acta 2013; 1831:943-949.

139. Krauss S, Zhang CY, Lowell BB. The mitochondrial uncoupling-protein homologues. Nat Rev Mol Cell Biol 2005; 6:248-261.

140. Feldmann HM, Golozoubova V, Cannon B, Nedergaard J. UCP1 ablation induces obesity and abolishes dietinduced thermogenesis in mice exempt from thermal stress by living at thermoneutrality. Cell Metab 2009; 9:203209.

141. Klaus S, Rudolph B, Dohrmann C, Wehr R. Expression of uncoupling protein 1 in skeletal muscle decreases muscle energy efficiency and affects thermoregulation and substrate oxidation. Physiol Genomics 2005; 21:193-200.

142. Keipert S, Ost M, Johann K, Imber F, Jastroch M, van Schothorst EM, Keijer J, Klaus S. Skeletal muscle mitochondrial uncoupling drives endocrine cross-talk through the induction of FGF21 as a myokine. Am J Physiol Endocrinol Metab 2014; 306:E469-482.

143. Keipert S, Klaus S, Heldmaier G, Jastroch M. UCP1 ectopically expressed in murine muscle displays native function and mitigates mitochondrial superoxide production. Biochim Biophys Acta 2010; 1797:324-330.

144. Ost M, Coleman V, Voigt A, van Schothorst EM, Keipert S, van der Stelt I, Ringel S, Graja A, Ambrosi T, Kipp AP, Jastroch M, Schulz TJ, et al. Muscle mitochondrial stress adaptation operates independently of endogenous FGF21 action. Mol Metab 2016; 5:79-90. 


\section{Chapter 2}

\section{Preantral follicular atresia occurs mainly through autophagy, while antral follicles degenerate mainly through apoptosis}

L Meng $^{\mathrm{a}}$, Sabrina Z. Jan ${ }^{\mathrm{b}}$, Geert Hamer ${ }^{\mathrm{b}}, \mathrm{J} \mathrm{Keijer}^{\mathrm{a}}, \mathrm{KJ}$ Teerds $^{\mathrm{a}}$

${ }^{a}$ Human and Animal Physiology, Wageningen University \& Research, P.O. Box 338, $6700 \mathrm{AH}$, Wageningen, The Netherlands

${ }^{\mathrm{b}}$ Reproductive Biology Laboratory, Academic Medical Center, University of Amsterdam, Q3.119, Meibergdreef 9, 1105 AZ, Amsterdam, the Netherlands

In advanced stage of preparation 


\begin{abstract}
There exists some controversy as to whether preantral and antral follicular atresia is caused by the induction of the same cell death pathway. There is general agreement that granulosa cell apoptosis is the cause of antral follicle attrition. Less clear is whether this cell death pathway is also activated in case of preatral follicle degeneration, as several reports mentioned that the incidence of granulosa cell apoptosis in preantral follicles was negligible. The objective of the present study is therefore to determine which cell death pathways are involved in (pre)antral follicular degeneration. Atretic preantal and antral follicles were investigated using immunohistochemistry as well as laser capture micro-dissection followed by qRT-PCR. Microtubule-associated light-chain protein 3 (LC3) and sequestosome 1 (SQSTM1/P62) were used as markers for autophagy; and cleaved caspase 3 (cCASP3) as marker for apoptosis. P62 immunostaining was less intense in granulosa cells of atretic preantral follicles compared to healthy preantral follicles, while no difference in LC3 immunostaining intensity was observed. This difference in p62 immunostaining was not observed in atretic antral follicles. mRNA levels of LC3 and p62 were not different between healthy and atretic (pre)antral follicles. The number of cCASP3 positive cells was negligible in preantral atretic follicles, while numerous in atretic antral follicles. Immunostaining and mRNA levels of the antioxidant enzyme superoxide dismutase 2 (SOD2) were reduced in both preantral and antral atretic follicles, suggesting that a disturbed antioxidant capacity may be involved in the initiation of follicular attrition. Taken together, preantral and antral follicular atresia are indeed due to activation of different cell death pathways as antral follicular degeneration is initiated by massive granulosa cell apoptosis, while preantral follicles atresia occurs mainly via enhanced granulosa cell autophagy.
\end{abstract}




\subsection{Introduction}

The most important functions of the female gonad are the formation and release of mature oocytes and the production of steroids necessary for the development of female secondary sexual characteristics. From the pool of dormant primordial follicles, follicles are continuously recruited into the pool of growing follicles, a process that takes place independent of gonadotropic hormones. These follicles grow until the early antral stage; estrous cyclic dependent increases in circulating follicle-stimulating hormone (FSH) concentrations are responsible for the cyclic recruitment of a cohort of small antral follicles, from which the dominant follicles are selected [1]. Follicular development is not a very efficient process as over $99 \%$ of ovarian follicles degenerate before ovulation by a process named atresia. In the adult female, atresia ensures that only healthy follicles, containing oocytes of optimal quality, will ovulate $[1,2]$. Although follicular atresia affects all stages of follicular development, the majority of follicles will undergo atresia in the penultimate stage of follicle growth during the transition from the preantral to antral stage [3].

It has long been assumed that granulosa cell death by apoptosis is the main cause of follicular atresia [4]. Recently, it has become increasingly apparent that apoptosis may not be the only process involved in follicular degeneration, but that other forms of cell death, such as autophagy, may also participate in this process. Hulas-Stasiak and Gawron [5] have shown that in the neonatal period when primordial and primary follicles undergo massive degeneration, autophagy is the dominant form of follicular atresia. Another study reported that human granulosa cells exposed in vitro to oxidized low-density lipoprotein show morphological signs of autophagy [6], while Choi et al. [7] demonstrated the presence of microtubule-associated light-chain protein 3 (LC3), a marker for autophagy, in the rat ovary.

Autophagy is an evolutionary conserved intracellular mechanism whereby damaged organelles and proteins are degraded and recycled to be reused by the cell. Three types of autophagy can be distinguished in mammalian cells: chaperone-mediated autophagy, micro-autophagy and macroautophagy. Macro-autophagy (herein referred to as autophagy), the mostly intensively studied type of autophagy, constitutively occurs at a low level in cells and can be further induced by stressful conditions such as nutrient or energy starvation, accumulation of reactive oxygen species (ROS) or infection [8]. Autophagy functions primarily as a cytoprotective mechanism. However, autophagic dysfunction due to excessive self-degradation can lead to a number of pathologies, including neurodegeneration, cancer and metabolic diseases [9]. Autophagy is a multistep process that involves the activation of a complex molecular machinery. LC3 is an important protein involved in autophagy as it determines the size of the autophagosome, participates in cargo recognition and is therefore widely used as marker to monitor autophagy [10]. LC3 is synthesized in an inactive form, pro-LC3 that immediately after synthesis is processed to generate soluble LC3-I which can be converted into an active autophagosome membrane-bound form, LC3-II [10] .

Ubiquitin-binding protein SQSTM1/p62 plays an important role in the clearance of ubiquitinated protein aggregates by functioning as an adaptor protein that interacts with LC3-II to target aggregates for autophagy-specific degradation [10]. Inhibition of autophagy correlates with increased levels of p62 in mammals, suggesting that steady-state levels of this protein reflect the autophagic status of a cell. Similarly, decreased p62 levels are associated with autophagy activation $[11,12]$. However, the 
expression levels of p62 can also change independent of autophagy and thus determining the presence of p62 alone may not be sufficient to obtain insight in the autophagic flux [13]. By analysing LC3 and p62 protein levels a better indication can be obtained about the role of autophagy in cell survival or cell death.

Although in general no difference is made between attrition of preantral and antral follicles. Nevertheless, histological observations suggest that there may be differences between the regulation of preantral and antral follicular degeneration. Spanel-Borowski [14] reported in the bitch two types of atretic patterns in ovarian follicles namely type $A$ in which the oocyte degenerates while granulosa cells remain intact, and type $B$ in which the granulosa cells show signs of extensive degeneration while the oocyte is initially unaffected. Spanel-Borowski suggests based on histological analysis that type $A$ is the predominant form of atresia in preantral follicles, while in antral follicles only type $B$ is observed. In line with these observations, Teerds and Dorrington [15] reported histological differences in atresia of preantral and antral follicles, with oocyte fragmentation, disordered granulosa layer and hypertrophied theca layer being the characteristics of atresia in preantral follicles and massive apoptosis of granulosa cells in the presence of a more or less intact oocyte being characteristic of atresia in antral follicles.

In line with the reports on roles for both autophagy and apoptosis in follicular atresia, the present study addresses the question whether the observed histological differences in preantral and antral follicular atresia are representative of different cell death pathways. For this purpose, LC3 and p62 are used as markers of autophagy and active, cleaved caspase 3 (cCASP3) is used as a marker of apoptosis in combination with immunohistochemistry and laser capture microdissection (LCM) followed by quantitative real-time reverse transcription polymerase chain reaction (qRT-PCR).

\subsection{Material and Methods}

\section{Animals}

The animal experiment described in this study was approved by the Animal Welfare Committee of Wageningen University \& Research. Wistar WU (HsdCpbWU) female rats were bred in the animal facility of Wageningen University \& Research. The female rats were weaned at the age of 28 days and group housed ( 3 animals per cage). Animals had free access to water and Teklad rat chow (Harlan). The room temperature $\left(20.5-21.5^{\circ} \mathrm{C}\right)$, humidity (55-65\%) and light regime (60-80 lux, lights on from 03:00 to 17:00 local daylight saving time) were controlled. Cage enrichment was provided in the form of $10 \mathrm{~cm}$ sisal rope. Six female rats were sacrificed at the pro-estrous stage of the estrous cycle at the age of 11 to 14 weeks. Rats were anesthetized using carbon dioxide and oxygen (flow: 1:2) and killed by decapitation after which ovaries were collected, fixed in either $4 \%$ phosphate buffered paraformaldehyde (for immunohistochemical purposes) or in methacarn (for LCM) and stored at $4{ }^{0} \mathrm{C}$ for 24 hours. After fixation, the paraformaldehyde fixed ovaries were washed in phosphate buffer and embedded in paraffin. The methacarn fixed ovaries were immediate transferred to ethanol $100 \%$ and embedded in paraffin. Five $\mu \mathrm{m}$ thick paraffin sections were cut and mounted on super frost plus slides (Menzel, Braunschweig, Germany). 


\section{Immunohistochemistry}

To determine the presence of proteins (LC3, p62, CCASP3, superoxide dismutase 2 (SOD2)) in rat ovaries, immunohistochemistry was performed according to Hoevenaars et al. $[16,17]$ with modifications. For each antibody, staining of the ovarian sections of the different animals was performed simultaneously in a single session. Briefly, sections were deparaffinized and rehydrated, after which epitope antigen retrieval in a microwave oven was performed at $96^{\circ} \mathrm{C}$ (Table 1). Slides were cooled down to room temperature, rinsed with phosphate buffered saline (PBS) $0.01 \mathrm{M}, \mathrm{pH} 7.4$ and subsequently endogenous peroxidase activity was blocked with $3 \%(\mathrm{v} / \mathrm{v})$ hydrogen peroxide in methanol. After rinsing in PBS, sections were incubated with $10 \%(\mathrm{wt} / \mathrm{v})$ normal goat serum in PBS. After removal of the goat serum, sections were incubated overnight at $4^{0} \mathrm{C}$ in a humid chamber with the primary antibodies (for details see Table 1 ) diluted in PBS $+0.05 \%$ BSAC (Aurion, Wageningen, The Netherlands). Sections were rinsed again and treated with the corresponding secondary biotinlabelled antibody diluted in PBS-BSAc at room temperature (for details see Table 1). The avidin-biotin complex (ABC, Vector Laboratories, Burlingame, CA) was diluted 1:1500 (v/v) in PBS-BSAc. Bound antibodies were visualized using 3-3' diaminobenzidine (Immpact DAB, Vector Laboratories) diluted 1:400 (v/v). Sections were counterstained with Mayer's haematoxylin. Control sections were incubated with isotype IgG (Vector Laboratories), instead of the respective primary antibodies, according to the manufactures instructions. The background staining in the controls was negligible.

\section{Follicular nomenclature}

Follicles were classified according to Flaws et al. [18] and Slot et al. [19] with minor modifications. Briefly, preantral and antral follicles were identified as healthy when they contained an intact oocyte and an organized granulosa layer with proliferating (mitotic) cells, while the surrounding theca layer had a healthy appearance and did not show any signs of hypertrophy. Atretic preantral follicles were recognized by the presence of a degenerating oocyte, disorganized granulosa cell layer, while the surrounding theca cells showed signs of hypertrophy. Antral follicles were considered to be atretic when more than $5 \%$ of the granulosa cells showed morphological signs of apoptosis; the oocyte was either intact and completely surrounded by cumulus granulosa cells, or was no longer or only partially surrounded by cumulus granulosa cells and showed signs of resumption of meiosis such as breakdown of the nuclear membrane with or without formation of a pseudo-maturation spindle [20].

\section{Western blotting}

Western blotting was performed as described by Kus et al. [21] and Meng et al. [17] with minor modifications. Briefly, ovaries were homogenized in RIPA lysis buffer (50 mM Tris Cl, pH 7.4 / 150 mM $\mathrm{NaCl} / 1 \%$ Nonidet P-40 / 1\% sodium deoxycholate / 0.1\% SDS) with protease inhibitors (complete Mini-EDTA free, cat no 04693159001, Roche, Mannheim, Germany). The sample was sonicated using the Sonifier Cell Disruptor (Model SLPe, Branson, Eemnes, The Netherlands) and centrifuged for 10 $\mathrm{min}$ at $14000 \mathrm{rpm}$ at $4^{\circ} \mathrm{C}$. Protein concentrations were determined using the RC DC Protein Assay Kit II (Bio-Rad, Veenendaal, The Netherlands). SDS-PAGE gels were run using the Mini-Protean Tetra cell system (Bio-Rad). Proteins from the SDS-PAGE gels were transferred onto a $0.20 \mu \mathrm{m}$ PVDF membrane (Millipore, Amsterdam, The Netherlands). The blot was incubated overnight at $4^{\circ} \mathrm{C}$ with the primary antibodies (LC3, diluted 1:200; p62, diluted 1:1000; SOD2, diluted 1:5000; for antibody product information see Table 1), rinsed with PBS-Tween20.(0.1\%) followed by incubation for $1 \mathrm{~h}$ with IRDye680-conjugated donkey anti-mouse for LC3 and p62 (LI-COR Biosciences, Leusden, The Netherlands) or IRDye800-conjugated donkey anti-rabbit for SOD2 (LI-COR Biosciences) diluted 
1:5000 in odyssey blocking buffer (LI-COR Biosciences) at room temperature. Images of the membranes were obtained using the Odyssey infrared imaging system (LI-COR Biosciences).

\section{LCM}

To prevent RNA degradation, all the following procedures were conducted under RNase-free conditions. A quick haematoxylin staining protocol followed by LCM was done according to Janz et al [22]. Next, sections were dehydrated and air-dried for $5 \mathrm{~min}$. A drop of mineral oil was added onto the sections prior to LCM. The granulosa cells of healthy and atretic antral follicles were captured under 40x magnification (PALM Laser MicroBeam System, P.A.L.M. GmbH, Bernried, Germany in combination with a Zeiss Axioscope microscope, Carl Zeiss, Jena, Germany). Around $1 \times 10^{4}$ granulosa cells per follicle were collected into silicon coated adhesive cap500 caps (Zeiss, Gottingen, Germany). After microdissection, the caps were treated with $20 \mu \mathrm{l}$ of extraction buffer (Picopure RNA Isolation kit, Arcturus, San Diego, CA) and incubated for $30 \mathrm{~min}$ at $42^{\circ} \mathrm{C}$. The resulting cell lysates were stored at $-80^{\circ} \mathrm{C}$ until further use.

\section{RNA isolation and amplification}

Total RNA from the cell lysates was extracted using the Picopure RNA Isolation kit (Arcturus) according to the manufacturer's instructions, including on-column DNase treatment (Qiagen, Venlo, The Netherlands). To generate sufficient cDNA samples for qPCR, LCM-derived RNA samples were subjected to RNA amplification using the Ovation ${ }^{\circledR}$ PicoSL WTA System V2 (Nugen, Leek, the Netherlands) in accordance with the manufacturer's instructions. The cDNA yield was measured by Qubit (ThermoFisher Scientific, Breda, The Netherlands).

\section{qRT-PCR}

qRT-PCR was used to investigate the mRNA expression of the genes $L C 3, p 62$ and Sod 2 in granulosa cells of both healthy and atretic follicles. QRT-PCR reactions were performed with iQ SYBR Green Supermix (Bio-Rad) using the MyIQ single-colour real-time PCR detection system (Bio-Rad). Individual samples were measured in duplicate. A standard curve using serial dilutions of pooled CDNA samples was prepared. A negative control without CDNA template, and a negative control without reverse transcriptase (RT) were included in every assay. Only standard curves with efficiency between 90 and $110 \%$ and a correlation coefficient above 0.99 were accepted. Data were normalized against the reference gene ribosomal protein S18 (Rps18). Primers were designed using the NCBI Primer-Blast (NCBI Web site). Sequences of the used primers were as follows:

LC3; 5'-CGGGTTGAGGAGACACACAA-3' and 5'-TCTTTGTTCGAAGCTCCGGC-3',

p62; 5'-GCTCATCTTTCCCAACCCCT-3' and 5'-CTGATGGAGCAGAAGCCGAC-3', Sod2; 5'-GGTGGAGAACCCAAAGGAGAG-3' and 5'-TGATTAGAGCAGGCGGCAAT-3', Rps18; 5' - TTCAGCACATCCTGCGAGTA-3' and 5' - TTGGTGAGGTCAATGTCTGC-3'. PCR annealing temperatures of these primers was $60^{\circ} \mathrm{C}$.

\section{Statistical analysis}

GraphPad Prism version 5.03 (Graphpad Software, San Diego, USA) was used for statistical analysis of the qRT-PCR data, with the Student's t test being used to compare mRNA expression in healthy and atretic follicles. P-values $<0.05$ were considered statistically significant. 
Table 1 - Antibodies used for immunohistochemistry.

\begin{tabular}{|c|c|c|c|c|c|}
\hline $\begin{array}{l}\text { Primary } \\
\text { antibody }\end{array}$ & $\begin{array}{l}\text { Antigen retrieval } \\
\text { buffer (10 mM) }\end{array}$ & $\begin{array}{l}\text { Primary } \\
\text { antibody } \\
\text { dilution }\end{array}$ & $\begin{array}{l}\text { Secondary } \\
\text { antibody } \\
\text { dilution }\end{array}$ & Source & Lot Number \\
\hline LC3 & $\begin{array}{c}\text { Tris/EDTA } \\
\mathrm{pH} 9 \text { (15 min) }\end{array}$ & $1: 100$ & $\begin{array}{l}\text { Goat anti-mouse, } \\
1: 200\end{array}$ & $\begin{array}{l}\text { Nano Tools (0231- } \\
\text { 100/LC3-5F10), } \\
\text { Teningen, Germany }\end{array}$ & 0231s0302 \\
\hline $\begin{array}{l}\text { SQSTM1/ } \\
\text { p62 }\end{array}$ & $\begin{array}{l}\text { Sodium citrate } \\
\mathrm{pH} 6 \text { (10 min) }\end{array}$ & $1: 500$ & $\begin{array}{l}\text { Goat anti-mouse, } \\
1: 400\end{array}$ & $\begin{array}{c}\text { Abcam plc } \\
\text { (ab56416), } \\
\text { Cambridge, UK }\end{array}$ & GR108093-1 \\
\hline $\begin{array}{c}\text { cCASP3 } \\
\text { (Cleaved } \\
\text { Caspase 3) }\end{array}$ & $\begin{array}{c}\text { Tris/EDTA } \\
\mathrm{pH} 9 \text { (10 min) }\end{array}$ & 1:3000 & $\begin{array}{l}\text { Goat anti-rabbit, } \\
1: 400\end{array}$ & $\begin{array}{l}\text { Cell signalling } \\
\text { (CST9661S), Bioke, } \\
\text { The Netherlands }\end{array}$ & 42 \\
\hline SOD2 & $\begin{array}{l}\text { Sodium Citrate } \\
\text { pH } 6 \text { (10 min) }\end{array}$ & 1:1000 & $\begin{array}{l}\text { Goat anti-rabbit, } \\
1: 400\end{array}$ & $\begin{array}{c}\text { Abcam plc } \\
\text { (ab13533) } \\
\text { Cambridge, UK }\end{array}$ & GR67500-4 \\
\hline
\end{tabular}

All secondary antibodies were obtained from Vector Laboratories (Vector, Burlingame, CA, USA).

\subsection{Results}

\section{Autophagy and apoptosis in follicular atresia}

\section{Preantral follicles}

Strong LC3 staining was observed in the granulosa cells of healthy (Figure 1A) and atretic (Figure 1B) preantral follicles in approximately the same stage of development, while staining was faint to absent in theca cells. Clear p62 staining was found in granulosa cells of healthy preantral follicles (Figure 2A), while in granulosa cells of atretic preantal follicles p62 staining was faint to absent (Figure 2B). Also p62 immunostaining was absent in theca cells. Immunostaining for active, cleaved form of Caspase 3 (cCASP3) was negligible in granulosa and theca cells of healthy (Figure $3 \mathrm{~A}$ ) and atretic preantral follicles (Figure 3B).

These data implicate that not apoptosis but autophagy plays a role in attrition of preantral follicles.

\section{Antral follicles}

In antral follicles, strong LC3 staining was observed in granulosa cells of healthy (Figure 1C) and atretic antral follicles (Figure 1D). LC3 staining was faint to absent in the oocytes and theca cells, like in preantral follicles. Strong p62 staining was observed in the granulosa cells of healthy antral follicles (Figure 2C), while in granulosa cells of atretic antral follicles p62 immunostaining was moderate to strong (Figure 2D). In theca cells p62 Immunostaining was faint to absent. cCASP3 staining was absent in the granulosa and theca cells of healthy antral follicles (Figure $3 \mathrm{C}$ ), however, many apoptotic cells with CCASP3 positive staining were present in the granulosa layer of atretic antral follicles (Figure 3D). These results suggest that in contrast to preantral follicular atresia, apoptosis is the major regulator of antral follicular atresia. 

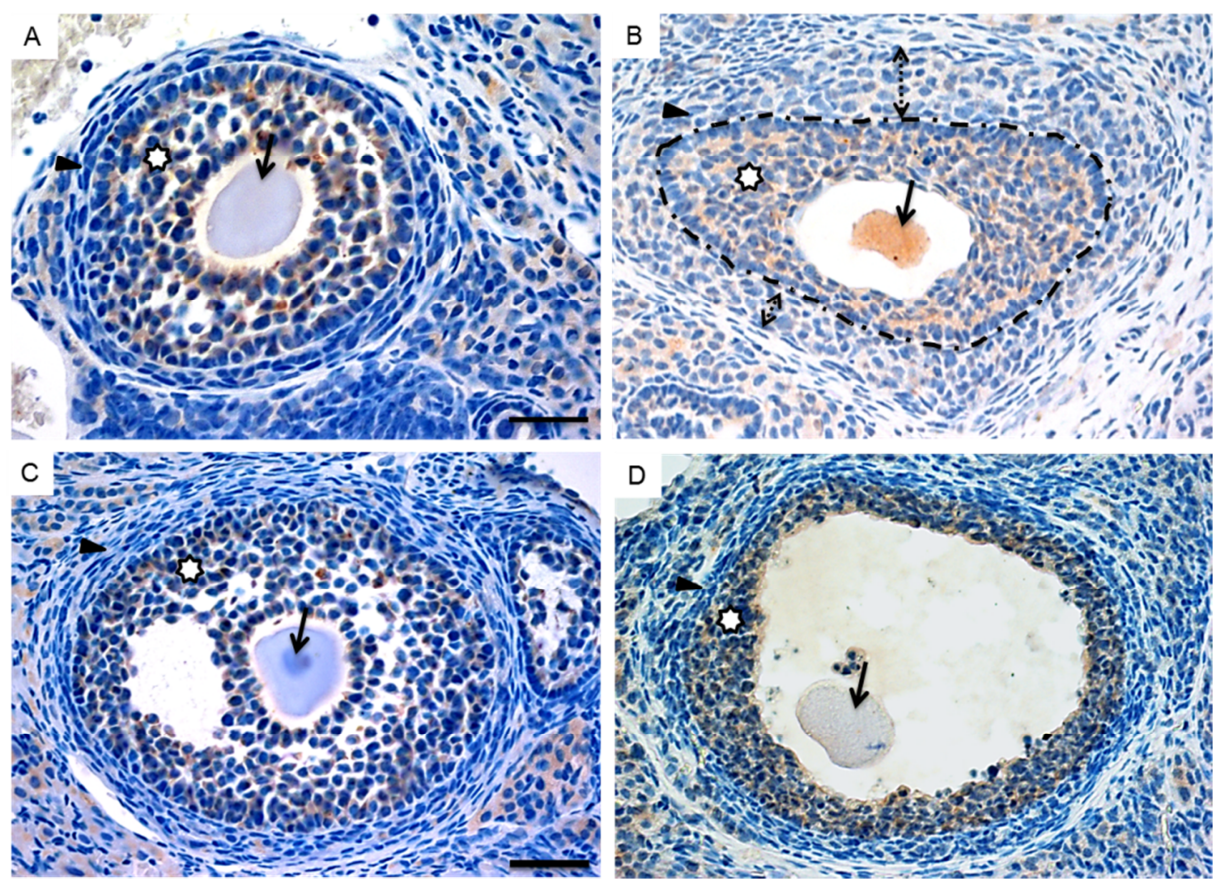

Figure 1 - Representative LC3 staining (brown) of the adult rat ovary. (A) Healthy preantral follicle with strong LC3 staining in granulosa cells; (B) Atretic preantral follicle with strong LC3 staining in granulosa cell, the disorganized granulosa layer is indicated by a surrounding dashed line and hypertrophied theca cells are indicated by a dotted two sided arrow; (C) Healthy early antral follicle with strong LC3 staining in granulosa cells; (D) Atretic early antral follicle with strong LC3 staining in granulosa cells. Granulosa cells are indicated by asterisks, theca cells by arrowheads and oocytes by arrows. Scale bars represent $50 \mu \mathrm{m}$.
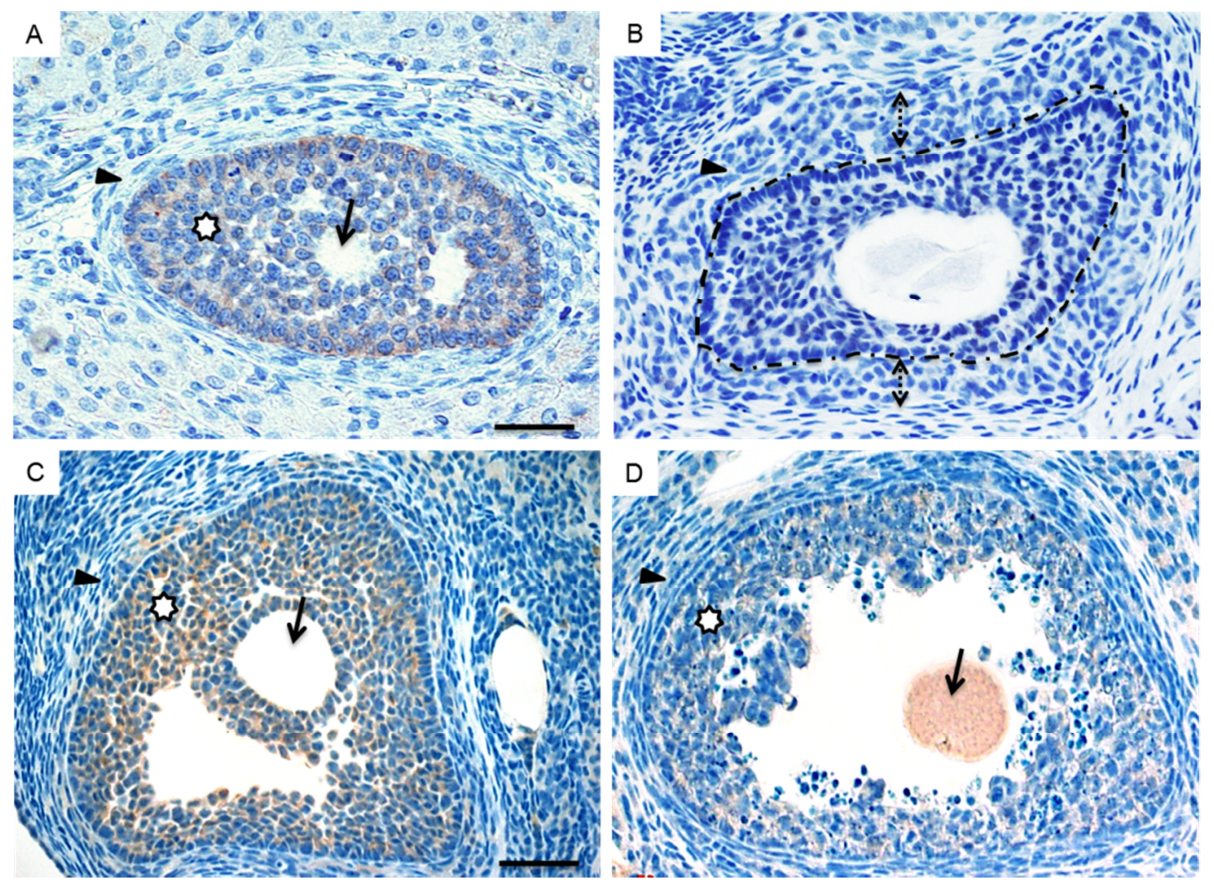

Figure 2 - Representative SQSTM1/P62 immunostaining (brown) of an adult rat ovary. (A) Healthy preantral follicle with strong p62 staining in granulosa cells; (B) Atretic preantral follicle with faint to absent p62 staining in granulosa cells, the disorganized granulosa layer is indicated by a surrounding dashed line and hypertrophied theca cells are indicated by a dotted two sided arrow; (C) Healthy early antral follicle with strong p62 staining in granulosa cells; (D) Atretic early antral follicle with moderate to strong p62 staining in granulosa cells. Granulosa cells are indicated by asterisks, theca cells barrowheads and oocytes by arrows. Scale bars represent $50 \mu \mathrm{m}$. 

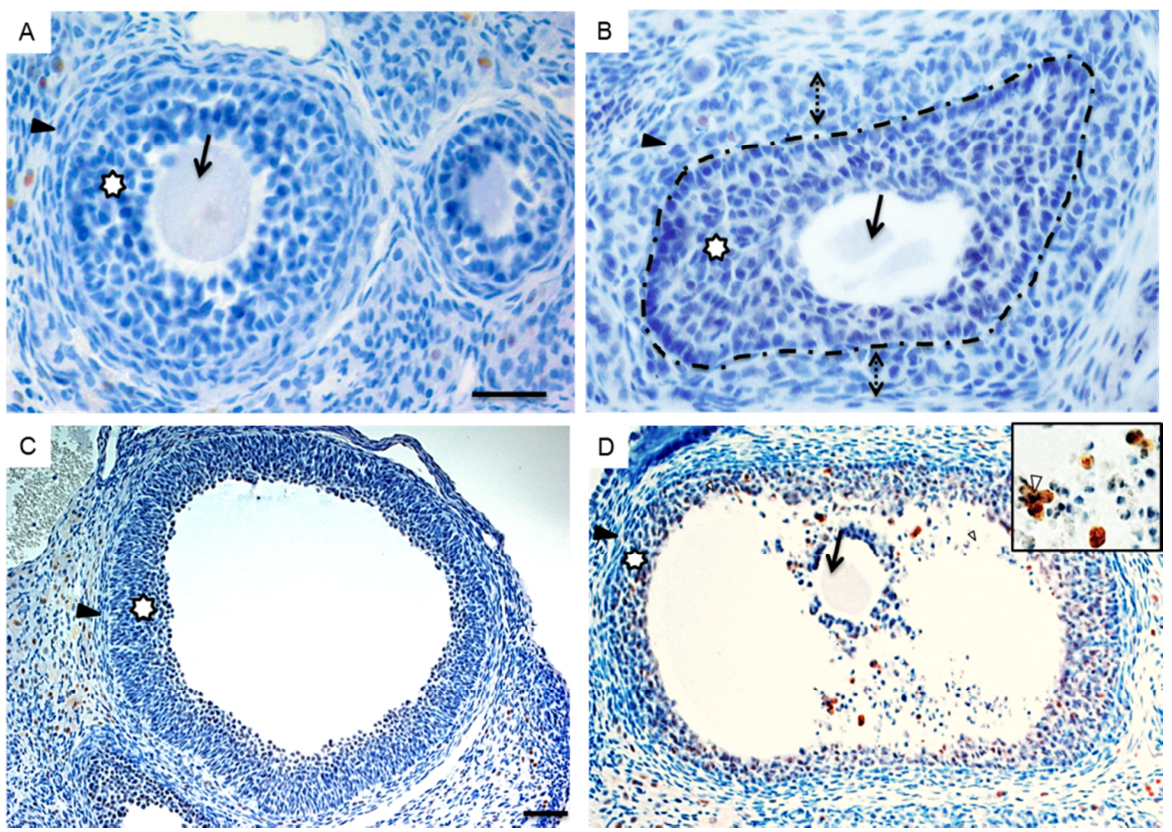

Figure 3 - Representative cCASP3 immunostaining. (A) Healthy preantral follicle with no positive cCASP3 staining in granulosa cells; (B) Atretic preantral follicles with no positive CCASP3 staining in granulosa cells, the disorganized granulosa cells is indicated by a surrounding dashed line and hypertrophied theca cells are indicated by a dotted two sided arrow; (C) Healthy large antral follicle, the absence of CCASP3 staining in granulosa cells; (D) Atretic large antral follicles with numerous granulosa cell derived apoptotic bodies adjacent to and within the antrum that stain positively for the presence of cCASP3. Granulosa cells are indicated by asterisks, theca cells by arrowheads and oocytes by arrows. Scale bars represent $50 \mu \mathrm{m}$.
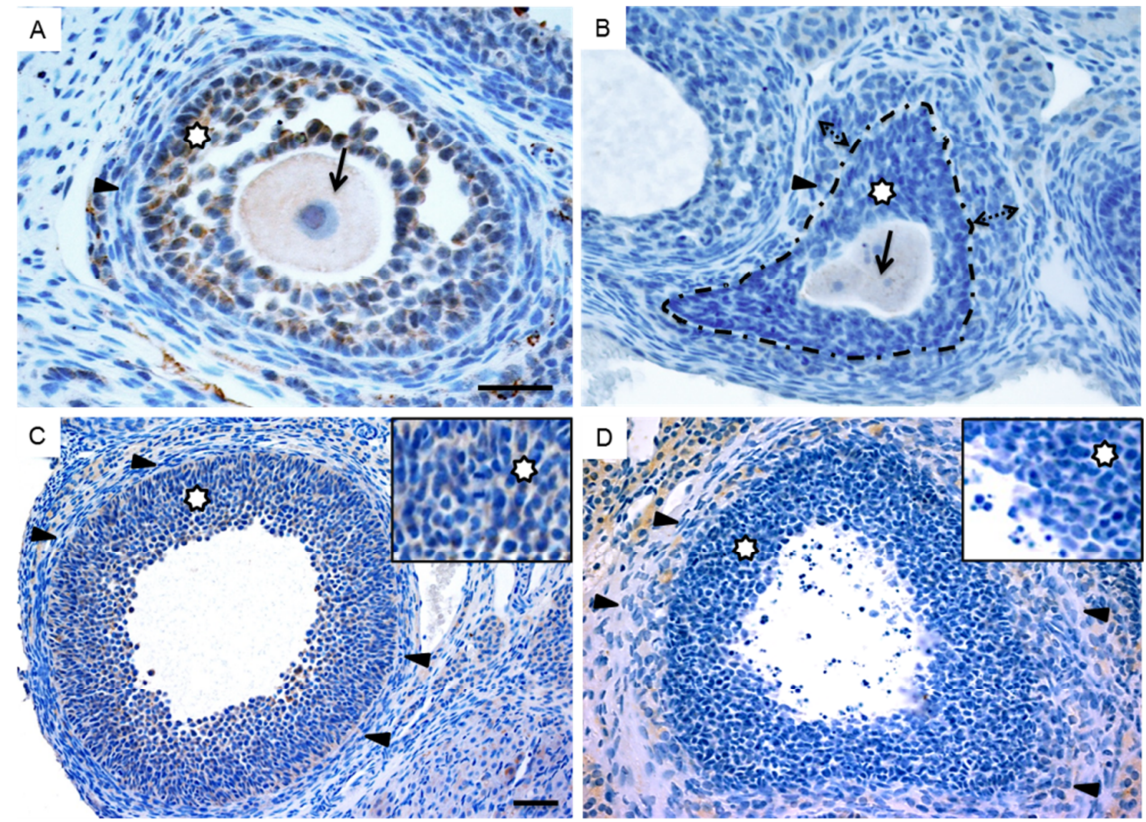

Figure 4 - Representative SOD2 immunostaining (brown) in an adult rat ovary. (A) Healthy preantral follicle with moderate to strong SOD2 staining in granulosa cells; (B) Atretic preantral follicle with faint to absent staining SOD2 in granulosa cells, the disorganized granulosa cells are indicated by a surrounding dashed line and hypertrophied theca cells are indicated by a dotted two sided arrow; (C) Healthy antral follicle with strong SOD2 staining in the granulosa cells; (D) Atretic antral follicle with faint to absent SOD2 staining in the granulosa cells. Granulosa cells are indicated by asterisks, theca cells by arrowheads and oocytes by arrows. Scale bars represent $50 \mu \mathrm{m}$ 


\section{SOD2 and ovarian follicular atresia}

By determining the presence of antioxidant enzyme SOD2, it was investigated whether mitochondrial accumulation of ROS could play a role in follicular attrition. Moderate to strong SOD2 immunostaining was observed in granulosa cells of healthy preantral (Figure 4A) and antral follicles (Figure 4C). SOD2 staining was faint to absent in granulosa cells of both atretic preantral (Figure 4B) and antral follicles (Figure 4D). The staining in theca cells of prenatral and antral follicles was faint to moderate and did not undergo changes when follicles underwent atresia (Figure 4). These results suggest that the presence of SOD2 in granulosa cells differed between healthy and atretic follicles.

\section{Western blotting}

To confirm that the antibodies (LC3, p62, SOD2) used in the present study indeed identified the correct proteins in the rat ovary, western blotting was performed (supplemental Figure 1). The blot for LC3 showed two clear bands representing LC3 I and LC3 II. The blots for p62 and SOD2 showed a single band at the expected size of $62 \mathrm{kDa}$ and $25 \mathrm{kDa}$, respectively. The validity of the antibody against cCASP3 was tested previously $[23,24]$.

\section{qRT-PCR}

In order to investigate the gene expression of $L c 3, p 62$ and Sod 2 in granulosa cells of healthy and atretic preantral and antral follicles LCM in combination with qRT-PCR was performed. Independent of the stage of follicular development, no difference in $L c 3$ and $p 62$ gene expression was observed between healthy and atretic follicles (Figure 5A,B). In contrast, Sod2 mRNA expression was significantly reduced in granulosa cells of atretic preantral and antral follicles compared to healthy follicles at the same stage of development.
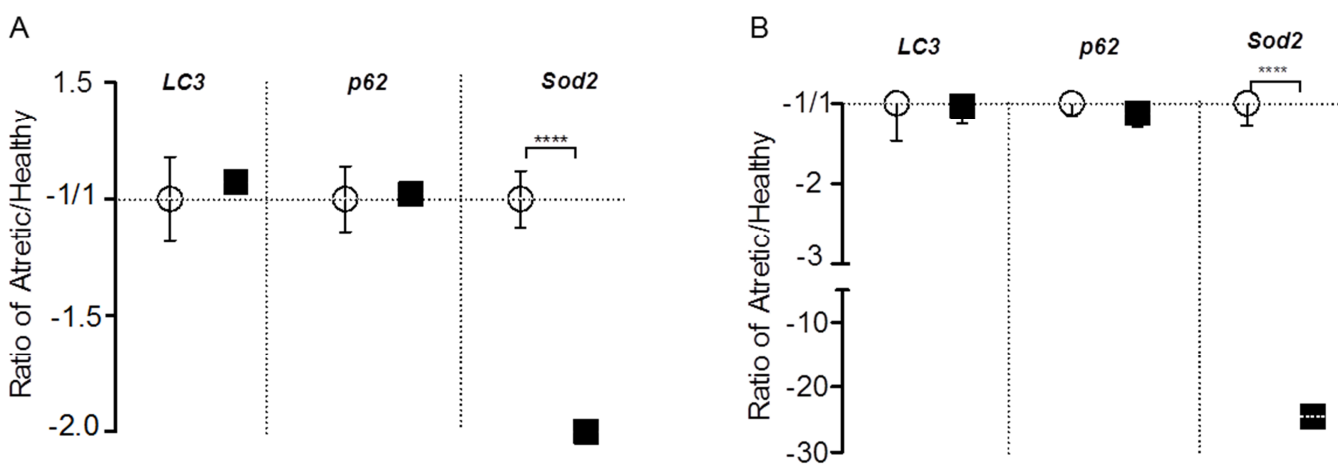

Figure 5 - Gene expression in granulosa cells of healthy (open circles, $n=6$ ) and atretic follicles (filled squares, $n=6$ ) as measured by qRT-PCR. Differences in gene expression are expressed as ratio of mRNA levels in atretic follicles over healthy follicles, with no change indicated as $1 /-1$ or -1 . (A) Healthy and atretic preantral follicles; (B) Healthy and atretic antral follicles; Lc3, microtubule-associated protein 1 light chain 3; p62, Sqstm1, sequestosome 1; Sod2, superoxide dismutase 2; $* * * *, \mathrm{p}<0.0001$

\subsection{Discussion}

The present study is to our knowledge the first study that provides evidence that granulosa cell death in preantral and antral follicular atresia are executed by different cell death pathways. Immunohistochemical analysis shows the absence of p62 and cCASP3 staining in preantral atretic 
follicles in combination with the presence LC3 staining, indicative of autophagy. In contrast, in atretic antral follicles LC3, p62 and CCASP3 immunostaining is observed, suggesting that granulosa cell death in these follicles is due to apoptosis and that autophagy is not likely to play an important role here. SOD2 immunostaining and mRNA levels are reduced in preantral and antral atretic follicles, suggesting that reduced ROS clearance may play a role in follicular atresia.

In the canine ovary, Spanel-Borowski $[14,25]$ was one of the first to describe the presence of a morphological difference between preantral and antral follicular atresia. More recently, it was shown in the prepubertal rat ovary, using in situ 3'- end labelling of DNA with digoxigenin-deoxy-UTP to detect apoptotic cells, that apoptosis is minimal in preantral follicles [26]. These observations are fully in line with the negligible cCASP3 immunolabelling in preantral follicles in the present study. At the same time, this does not mean that granulosa cells of preantral follicles do not have the capacity to undergo apoptosis. Withdrawal of diethylstilbestrol stimulation in immature rats resulted in a significant increase in in situ oligoxigenin-dideoxy-UTP labelling of DNA in large preantral follicles [27]. This pathway of preantral granulosa cell death, however, does not seem to be favoured as cell death pathway under normal in vivo conditions.

Choi and colleagues [7] were the first to report on a possible role of autophagy in follicular development and atresia. These authors showed moderate to strong LC3 immunostaining in granulosa cells of healthy primordial up to late antral follicles in immature rats treated with equine chorionic gonadotropin. In line with our results, significant LC3 staining was observed in atretic antral follicles, while co-localization of LC3 and CCASP3 immunostaining was observed in atretic antral follicles but not in preantral follicles [7]. It was suggested that granulosa cell autophagy might be directly involved in ovarian follicular atresia at all stages of follicular development. The present study is an extension of the work by Choi and colleagues, as we show that autophagy especially plays a role in preantral follicular atresia, while antral follicular attrition is triggered by granulosa cell apoptosis.

Additional evidence for the assumption that apoptosis is not the only death pathway active in the ovary comes from studies in which mice are exposed to cigarette smoke. Exposure for 8 weeks resulted in a decrease in follicle numbers without leading to a change in CCASP3 expression [28]. The levels of the autophagy related proteins BECLIN1 and LC3 were significantly increased under these conditions [29]. One of the processes that is suggested to play a role in smoke induced follicular autophagy is oxidative stress. Cigarette smoke exposure leads to an increase in the ovarian expression of HSP25, a small heath shock protein that is up-regulated under conditions of oxidative stress, while SOD2 expression is decreased, suggestive of loss of antioxidant activity [28]. In the present study we observe a strong reduction in both SOD2 immunostaining and granulosa cell Sod 2 mRNA levels in antral atretic follicles, implicating that autophagy and subsequent preantral follicular attrition may be initiated by a mitochondrial loss of antioxidant capacity. Whether a disturbance in antioxidant capacity is also the trigger of granulosa cell apoptosis in antral follicle or whether this is a consequence of activation of the apoptotic cascade warrants further investigation.

The next question that arises is, which pathway is involved in activation of granulosa cell autophagy. It has been shown that cigarette smoke exposure of rats leads to activation of AMPK- $\alpha 1$ and AMPK- $\alpha 2$ in the ovary, while at the same time inhibition of the anti-autophagic factors AKT and mTORC1 is observed [30]. AMPK is an important regulator of metabolism and inhibitor of the mTORC1 complex 
and is a direct activator of autophagy [31, 32]. Its activity is sensitive to ROS [33]. The data from Furlong et al. [30] suggest that cigarette smoke induced oxidative stress activates AMPK, leading to activation of autophagy and inhibition of mTORC1. Support for this hypothesis comes from a study by Choi et al, who demonstrated that AKT-mediated activation of mTORC1 suppresses granulosa cell autophagy during follicular development in vivo as well as in vitro [34]. The reduced SOD2 mRNA expression in granulosa cells of preantral follicles suggests that this pathway is also involved in preantral follicular atresia under physiological conditions, although this will need confirmation by additional experiments.

To our surprise, we did not observe a difference in p62 mRNA expression in granulosa cells from healthy and atretic preantral follicles, despite the obvious differences in immunostaining. Furlong et al were also unable to detect any differences in p62 mRNA expression between healthy and autophagic granulosa cells [30]. These authors hypothesised that the absence of a decrease in $p 62$ gene expression may be due to the large variability between control and treated groups. This is however not the case in our analysis. A change in p62 protein levels, without a difference $p 62 \mathrm{mRNA}$ was also seen in other studies (e.g. [35, 36]) and suggests a role for post transcriptional regulation.

In contrast to preantral follicular atresia, it is generally thought that antral follicular atresia and thus granulosa cell apoptosis is triggered by insufficient FSH levels [37]. FSH is thought to rescue granulosa cells of antral follicles from apoptosis via activation of the phosphatidylinositol 3-kinase (PI3K)-AKT signal transduction pathway. Activation of PI3K-AKT via binding of FSH to its receptor leads to phosphorylation of the forkhead box O (FOXO) subfamily of forkhead transcription factors which impacts among other processes survival of granulosa cells. In the presence of reduced FSH levels or insufficient FSH receptor numbers, FOXOs are dephosphorylated and translocate to the nucleus, resulting in enhanced transcription of pro-apoptotic factors (reviewed in [37]). These observations implicate a role for the AKT signalling pathway in both autophagy and apoptosis induced granulosa cell death. By influencing AKT though different pathways granulosa cells will either undergo autophagy (in FSH-independent preantral follicles) or apoptosis (in FSH-dependent antral follicles). The results of the present study open the way to further investigate the signal transduction pathways that lead to granulosa cell degradation.

In conclusion, the results suggest of the present study show that antral follicular attrition is initiated by massive granulosa cell apoptosis, while preantral follicles atresia occurs mainly via enhanced granulosa cell autophagy.

\section{Acknowledgements}

The authors would like to thank Eddy Rijntjes, Hans Swarts and Inge van der Stelt for their assistance. 


\subsection{References}

1. McGee EA, Hsueh AJ. Initial and cyclic recruitment of ovarian follicles. Endocr Rev 2000; 21:200-214.

2. Hsueh AJ, Kawamura K, Cheng Y, Fauser BC. Intraovarian control of early folliculogenesis. Endocr Rev 2015; 36:124.

3. Hirshfield AN. Development of follicles in the mammalian ovary. Int Rev Cytol 1991; 124:43-101.

4. Kaipia A, Hsueh AJ. Regulation of ovarian follicle atresia. Annu Rev Physiol 1997; 59:349-363.

5. Hulas-Stasiak M, Gawron A. Follicular atresia in the prepubertal spiny mouse (Acomys cahirinus) ovary. Apoptosis $2011 ; 16: 967-975$.

6. Duerrschmidt N, Zabirnyk O, Nowicki M, Ricken A, Hmeidan FA, Blumenauer V, Borlak J, Spanel-Borowski K. Lectinlike oxidized low-density lipoprotein receptor-1-mediated autophagy in human granulosa cells as an alternative of programmed cell death. Endocrinology 2006; 147:3851-3860.

7. Choi JY, Jo MW, Lee EY, Yoon BK, Choi DS. The role of autophagy in follicular development and atresia in rat granulosa cells. Fertil Steril 2010; 93:2532-2537.

8. Loos B, Engelbrecht AM, Lockshin RA, Klionsky DJ, Zakeri Z. The variability of autophagy and cell death susceptibility: Unanswered questions. Autophagy 2013; 9:1270-1285.

9. Wirawan E, Vanden Berghe T, Lippens S, Agostinis P, Vandenabeele P. Autophagy: for better or for worse. Cell Res $2012 ; 22: 43-61$.

10. Klionsky DJ, Schulman BA. Dynamic regulation of macroautophagy by distinctive ubiquitin-like proteins. Nat Struct Mol Biol 2014; 21:336-345.

11. Klionsky DJ, Abdalla FC, Abeliovich H, Abraham RT, Acevedo-Arozena A, Adeli K, Agholme L, Agnello M, Agostinis P, Aguirre-Ghiso JA, Ahn HJ, Ait-Mohamed O, et al. Guidelines for the use and interpretation of assays for monitoring autophagy. Autophagy 2012; 8:445-544.

12. Klionsky DJ, Abdelmohsen K, Abe A, Abedin MJ, Abeliovich H, Arozena AA, Adachi H, Adams CM, Adams PD, Adeli K, Adhihetty PJ, Adler SG, et al. Guidelines for the use and interpretation of assays for monitoring autophagy (3rd edition). Autophagy 2016; 12:1-222.

13. Mizushima N, Yoshimori T. How to interpret LC3 immunoblotting. Autophagy 2007; 3:542-545.

Spanel-Borowski K. Follicle Stages and Follicular Atresia. 2012:9-22.

15. Teerds KJ, Dorrington JH. Immunohistochemical localization of 3 beta-hydroxysteroid dehydrogenase in the rat ovary during follicular development and atresia. Biol Reprod 1993; 49:989-996.

16. Hoevenaars FPM, Keijer J, Herreman L, Palm I, Hegeman MA, Swarts HJM, van Schothorst EM. Adipose tissue metabolism and inflammation are differently affected by weight loss in obese mice due to either a high-fat diet restriction or change to a low-fat diet. Genes Nutr 2014; 9.

17. Meng L, Rijntjes E, Swarts H, Bunschoten A, van der Stelt I, Keijer J, Teerds K. Dietary-induced chronic hypothyroidism negatively affects rat follicular development and ovulation rate and is associated with oxidative stress. Biol Reprod 2016; 94:1-11.

18. Flaws JA, Abbud R, Mann RJ, Nilson JH, Hirshfield AN. Chronically elevated luteinizing hormone depletes primordial follicles in the mouse ovary. Biol Reprod 1997; 57:1233-1237.

19. Slot KA, Voorendt M, de Boer-Brouwer M, van Vugt HH, Teerds KJ. Estrous cycle dependent changes in expression and distribution of Fas, Fas ligand, $\mathrm{Bcl}-2$, Bax, and pro- and active caspase-3 in the rat ovary. The Journal of endocrinology 2006; 188:179-192.

20. Osman P. Rate and course of atresia during follicular development in the adult cyclic rat. J Reprod Fertil 1985; 73:261-270.

21. Kus V, Prazak T, Brauner P, Hensler M, Kuda O, Flachs P, Janovska P, Medrikova D, Rossmeisl M, Jilkova Z, Stefl B, Pastalkova $E$, et al. Induction of muscle thermogenesis by high-fat diet in mice: association with obesity-resistance. Am J Physiol Endocrinol Metab 2008; 295:E356-367.

22. Janz et al., The transcriptome dynamics of human spermatogenesis. 2016, under revision. 
23. Boada-Romero E, Serramito-Gomez I, Sacristan MP, Boone DL, Xavier RJ, Pimentel-Muinos FX. The T300A Crohn's disease risk polymorphism impairs function of the WD40 domain of ATG16L1. Nat Commun 2016; 7.

24. Fan L, Peng G, Sahgal N, Fazli L, Gleave M, Zhang Y, Hussain A, Qi J. Regulation of c-Myc expression by the histone demethylase JMJD1A is essential for prostate cancer cell growth and survival. Oncogene 2016; 35:2441-2452.

25. Spanelborowski K. Morphological investigations on follicular atresia in Canine ovaries. cell Tissue Res 1981; 214:155-168.

26. McGee E, Spears N, Minami S, Hsu SY, Chun SY, Billig H, Hsueh AJW. Preantral ovarian follicles in serum-free culture: Suppression of apoptosis after activation of the cyclic guanosine 3',5'-monophosphate pathway and stimulation of growth and differentiation by follicle-stimulating hormone. Endocrinology 1997; 138:2417-2424.

27. Billig H, Furuta I, Hsueh AJW. Estrogens Inhibit and androgens enhance ovarian granulosa-cell apoptosis. Endocrinology 1993; 133:2204-2212.

28. Gannon AM, Stampfli MR, Foster WG. Cigarette smoke exposure leads to follicle loss via an alternative ovarian cell death pathway in a mouse model. Toxicol Sci 2012; 125:274-284.

29. Gannon AM, Stampfli MR, Foster WG. Cigarette smoke exposure elicits increased autophagy and dysregulation of mitochondrial dynamics in murine granulosa cells. Biol Reprod 2013; 88:1-11.

30. Furlong HC, Stampfli MR, Gannon AM, Foster WG. Cigarette smoke exposure triggers the autophagic cascade via activation of the AMPK pathway in mice. Biol Reprod 2015; 93:1-10.

31. Kim J, Kundu M, Viollet B, Guan KL. AMPK and mTOR regulate autophagy through direct phosphorylation of Ulk1. Nat Cell Biol 2011; 13:132-U171.

32. Egan DF, Shackelford DB, Mihaylova MM, Gelino S, Kohnz RA, Mair W, Vasquez DS, Joshi A, Gwinn DM, Taylor R, Asara JM, Fitzpatrick J, et al. Phosphorylation of ULK1 (hATG1) by AMP-activated protein kinase connects energy sensing to Mitophagy. Science 2011; 331:456-461.

33. Emerling BM, Weinberg F, Snyder C, Burgess Z, Mutlu GM, Viollet B, Budinger GRS, Chandel NS. Hypoxic activation of AMPK is dependent on mitochondrial ROS but independent of an increase in AMP/ATP ratio. Free Radical Bio Med 2009; 46:1386-1391.

34. Choi J, Jo M, Lee E, Choi D. AKT is involved in granulosa cell autophagy regulation via mTOR signaling during rat follicular development and atresia. Reproduction 2014; 147:73-80.

35. Pursiheimo JP, Rantanen K, Heikkinen PT, Johansen T, Jaakkola PM. Hypoxia-activated autophagy accelerates degradation of SQSTM1/p62. Oncogene 2009; 28:334-344.

36. Narendra DP, Kane LA, Hauser DN, Fearnley IM, Youle RJ. p62/SQSTM1 is required for Parkin-induced mitochondrial clustering but not mitophagy; VDAC1 is dispensable for both. Autophagy 2010; 6:1090-1106.

37. Matsuda F, Inoue N, Manabe N, Ohkura S. Follicular growth and atresia in mammalian ovaries: regulation by survival and death of granulosa cells. The Journal of reproduction and development 2012; 58:44-50 


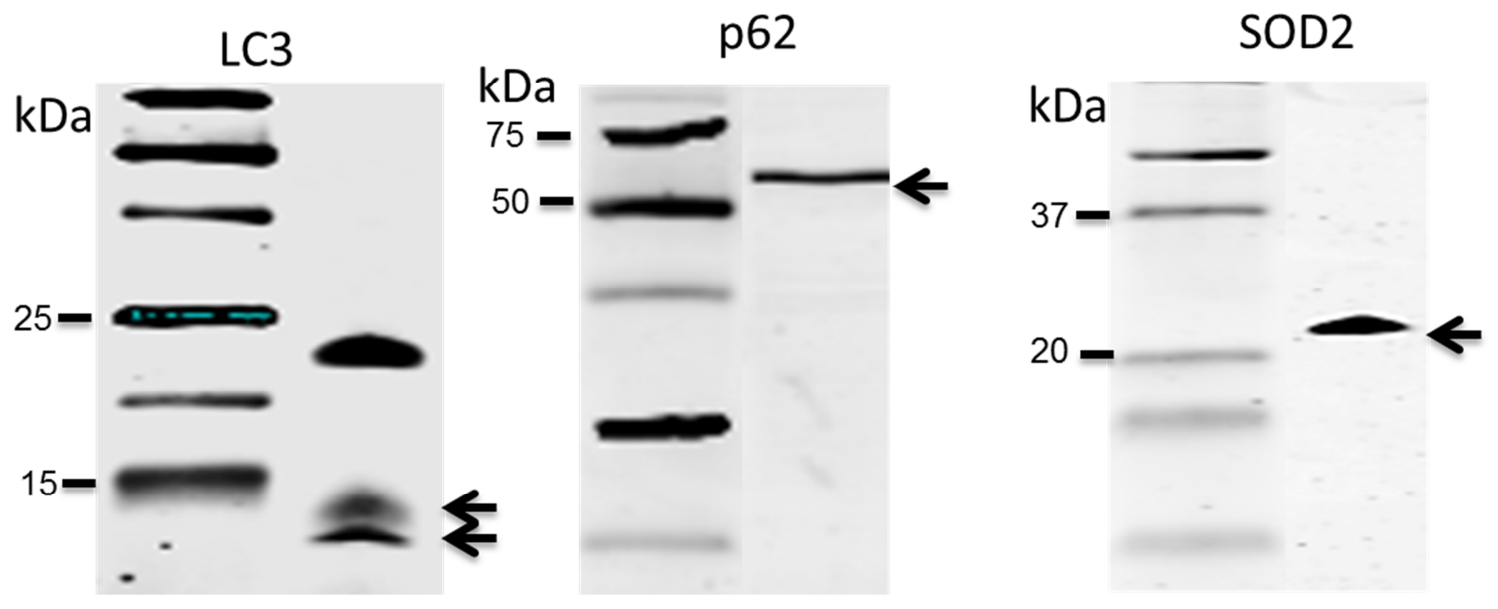

Supplemental Figure 1 - Western blot representing the presence of LC3, p62 and SOD2 in homogenates of rat ovaries after separation by SDS-polyacrylamide gel electrophoresis. The specific band at the expected size is indicated by an arrow. 



\section{Chapter 3}

Prolonged hypothyroidism severely reduces the ovarian primordial follicle reserve and the size of the growing follicle population in adult rats

L Meng $^{a}$, E Rijntjes $^{\mathrm{a}, \mathrm{b}}$, HJM Swarts $^{\mathrm{a}}, \mathrm{J} \mathrm{Keijer}^{\mathrm{a}}, \mathrm{KJ} \mathrm{Teerds}^{\mathrm{a}}$

${ }^{a}$ Human and Animal Physiology, Wageningen University, P.O. Box 338, $6700 \mathrm{AH}$, Wageningen, The Netherlands

${ }^{b}$ Institut für Experimentelle Endokrinologie, Charité Universitätsmedizin Berlin, Augustenburger Platz

1, 13353 Berlin, Germany

Submitted for publication 


\section{Abstract}

Objective: To investigate the consequences of prolonged hypothyroidism induced in adulthood for the size of the ovarian follicle pool.

Design: Female rats were given a control or an iodide deficient diet in combination with perchlorate supplementation to inhibit iodide uptake by the thyroid, resulting in mild chronic hypothyroidism. At the age of 26 weeks animals were sacrificed. Ovaries were histologically evaluated.

Settings: Centre for small animal experimentation, Wageningen University \& Research.

Animals: Adult female rats.

Interventions: Dietary intervention.

Main Outcome Measures: Ovarian follicle numbers (primordial, primary, pre-antral, antral and atretic follicles) as well as corpora lutea numbers were counted. Concentrations of relevant hormones (thyroid-stimulating hormone (TSH), tri-iodothyronine $\left(T_{3}\right)$, thyroxine $\left(T_{4}\right)$, folliclestimulating hormone (FSH), luteinizing hormone ( $\mathrm{LH}$ ) and anti-Müllerian hormone (AMH) in plasma were determined.

Results: Primordial, primary and preantral follicle numbers were significantly lower in the hypothyroid ovaries compared to the euthyroid controls $(p<0.05)$, while a downward trend in antral follicle numbers and corpora lutea was observed. The percentage of atretic follicles was not different between the groups. Plasma AMH showed a significant correlation with the growing follicle population represented by the total ovarian number of primary, preantral and antral follicles.

Conclusions: Prolonged mild hypothyroidism negatively affects ovarian follicular reserve as well as the size of the growing follicle population, which may impact fertility. AMH can serve, also under mild hypothyroid conditions, as a surrogate marker to assess the growing ovarian follicle population, offering a non-invasive way to evaluate the correlation between female reproductive health and thyroid status. 


\subsection{Introduction}

Thyroid hormone (TH) synthesis and release is controlled by hypothalamic thyrotropin releasing hormone (TRH) and pituitary thyroid-stimulating hormone (TSH) via a classical feedback loop mechanism ([1]. A disturbed thyroid status and concomitant alterations in $\mathrm{TH}$ production are known to affect key functions in growth, development and metabolism, such as basal metabolic rate, energy production, and carbohydrate and lipid metabolism [2,3]. Besides, there is substantial evidence that a prolonged reduction in plasma TH concentration leads to a broad spectrum of reproductive problems, including disturbed folliculogenesis, impaired ovulation and fertilization rate, miscarriage and late pregnancy complications [4]. In severe cases hypothyroidism may even lead to complete ovarian failure [5-7].

The majority of cases of hypothyroidism find their origin either in thyroid autoimmune disease, or insufficient iodine intake [8-10]. Thyroid autoimmune disease is characterized by the presence of anti-thyroglobulin and/or anti-thyroid peroxidase antibodies and affects $5-20 \%$ of women of childbearing age. Although thyroid autoimmune disease is considered to be one of the main causes of hypothyroidism, thyroid autoantibodies can be present without any clinical signs of thyroid dysfunction or subfertility [11]. The term subclinical hypothyroidism is used to describe the condition of elevated serum TSH concentrations in the presence of normal free thyroxine $\left(T_{4}\right)$ concentration [10]. Most studies investigating the relation between subclinical hypothyroidism and female fertility are retrospective and uncontrolled with the consequence that the underlying pathogenic mechanisms associating subclinical hypothyroidism and female fertility remain largely speculative [7]. This is of relevance, since the incidence of subclinical hypothyroidism in females of reproductive age is thought to range from $4 \%$ to $8.5 \%$ [12]. If thyroid antibodies are present, this condition may progress to overt (clinical) hypothyroidism $[7,13]$.

A condition that further increases the risk of women to develop hypothyroidism is pregnancy and the period after delivery; the incidence of hypothyroidism in pregnancy being $0.3-0.5 \%$ [14]. Postpartum thyroid dysfunction has a pooled prevalence of $8 \%$, while the chance to develop subclinical hypothyroidism after parturition is $2-3 \%$ [14-16]. The most common cause of this type of thyroid dysfunction is autoimmune lymphocytic thyroiditis. This disease usually consists of two phases, a hyperthyroid phase that in general becomes apparent after delivery, followed by a hypothyroid phase [15]. Until a few years ago it was thought that thyroid hormone levels in women that suffered from postpartum thyroid dysfunction would normalize within 6 to 12 months after delivery. Stuckey and colleagues, however, showed that $63 \%$ of women that experienced postpartum thyroid dysfunction 6 months postpartum, still suffered from (sub)clinical hypothyroidism 12 years later, indicative of long-term thyroid dysfunction $[15,17]$.

The incidence of hypothyroidism further depends on dietary iodine intake. There are indications that not only in underdeveloped countries, but also in $34 \%$ of the developed countries, such as USA, UK, Italy, France and Ireland, iodine intake, especially in pregnant women, is insufficient $[9,16]$. In the UK, two thirds of pregnant women are iodine deficient and therefore at risk to develop hypothyroidism. In general iodine deficiency is mild, but this can nevertheless have impact on pregnancy outcome and mental development of the child [16]. 
It may be apparent from the above that independent of the origin, (sub)clinical hypothyroidism is a less rare condition in women at reproductive age than anticipated. Although it has been generally acknowledged that TH disorders are associated with disturbed ovarian folliculogenesis, it is not known what the precise effects are of mild chronic hypothyroidism on follicular development and the size of the ovarian follicle pool, a question not easily addressed in humans. The number of animal studies investigating the effect of hypothyroidism on follicular development in adulthood is limited and the observations contradictory. Ortega et al. [18] have reported for instance that hypothyroidism in adult female rats induces a significant suppression in basal LH release, resulting in ovarian atrophy. Hapon et al. [19] have shown that virgin hypothyroid rats show prolonged periods of vaginal dioestrus, while Mattheij et al. [20] reported that in hypothyroid rats the oestrous cycle becomes irregular, but if females present vaginal proestrous, the subsequent LH surge is much higher than in the euthyroid controls. Other investigators have reported only small changes in LH and FSH release and the presence of corpora lutea and mature follicles under hypothyroid conditions [21], although pregnancy incidence and litter size are reduced when compared to euthyroid controls [22]. A detailed analysis of the size of the ovarian follicle pool under chronic hypothyroid conditions has not been performed, as far as we are aware.

In recent years, we have developed an animal model of diet-induced hypothyroidism by depleting the endogenous iodine stores of rats to study the effects of chronic hypothyroidism on ovarian follicular development [23]. In the present study we aim to use this animal model to investigate follicular development, and the effects on the size of the ovarian follicle pool under hypothyroid conditions in adult rats. This will give us insight in the effects of adult chronic hypothyroidism on ovarian follicular development and thus reproductive potential in rodents. The results of the present study may contribute to the understanding of the consequences of subclinical and mild hypothyroidism on the ovarian follicle population in women of reproductive age.

\subsection{Material and Methods}

\section{Chemicals}

All chemicals were purchased from Sigma (Zwijndrecht, the Netherlands) unless indicated otherwise.

\section{Animals and treatment}

Twenty 10-week-old female Wistar rats (HsdCpbWU) were obtained from Harlan (Horst, the Netherlands). The rats were housed individually and kept under controlled conditions (room temperature $20.5-21.5^{\circ} \mathrm{C}$; humidity $55-65 \%$; light regimen $60-80$ lux, lights on from 03:00 to 17:00 local daylight saving time). The animals had free access to food and tap water and were provided with cage enrichment in the form of a $10 \mathrm{~cm}$ sisal rope. Two weeks after arrival the female rats of the experimental group $(n=9)$ were put on an iodide-poor diet based on AIN 1993 requirements (Research Diet Services, Wijk bij Duurstede, the Netherlands) [24,25] supplemented with $0.75 \%$ sodium perchlorate in the drinking water to deplete endogenous iodie stores [26]. The control group $(n=11)$ was at the same time put on normal drinking water without sodium perchlorate and was given a euthyroid control diet, consisting of the iodide-poor diet, supplemented with $7 \mu \mathrm{g}$ iodide per $100 \mathrm{~g}$ dry weight of the diet to fulfill the normal iodide requirements of rats. The experimental hypothyroid diet was continued for 16 weeks, after which the animals were sacrificed. Rats were anesthetized 
using carbon dioxide and oxygen (flow: 1:2). Blood was obtained by heart puncture and collected in heparin-coated tubes. Rats were killed by decapitation and ovaries were dissected, fixed in Bouin's fluid for $24-48 \mathrm{~h}$ and stored in ethanol $70 \%$ until further processing. Plasma was stored at $-20{ }^{\circ} \mathrm{C}$ until further analysis. All animals were killed at the proestrous stage of the estrous cycle between 11.00 and $14.00 \mathrm{~h}$. The stage of the oestrous cycle was determined by daily analysis of vaginal smears, starting approximately two weeks before sacrifice.

The animal experiment was approved by the Animal Welfare Committee of Wageningen University (DEC 2004134a).

\section{Histological evaluation of ovarian tissues}

The ovaries of 4 to 5 animals were embedded in paraffin and serially sectioned at a thickness of 5 $\mu \mathrm{m}$. Every fifth section of each ovary was mounted on glass slides, stained with periodic acid Schiff's reagent (PAS) and Mayer's haematoxylin (Klinipath, Duiven, the Netherlands), and examined by light microscopy. From these sections the numbers of healthy primordial, primary, preantral and antral follicles were counted as described previously $[23,27,28]$. Briefly, follicles were scored as primordial if they contained an intact oocyte with a clear nucleus and nucleoli surrounded by a single layer of squamous pregranulosa cells. Follicles were scored as primary when they contained an intact, enlarged oocyte with a clear nucleus and nucleolus surrounded by a single layer of granulosa cells of which $50-100 \%$ had a cuboidal appearance. The granulosa layer of preantral follicles consisted of more than one layer of cuboidal cells, an oocyte with a clear nucleus and nucleolus and a developing theca layer. Antral follicles consisted of several layers of granulosa cells, an oocyte with a clear nucleus and nucleolus, an antrum of which the diameter was at least the size of the diameter of the oocyte, and a theca layer. In order to estimate the total number of follicles within one ovary, the number of primordial, primary, preantral and antral follicles counted in the mounted sections was multiplied by five to account for the fact that every fifth section was used in the follicle counting $[23,28]$.

Atretic preantral follicles were characterized by the presence of a degenerating oocyte, disorganized granulosa cell layer with the presence of a limited number of apoptotic nuclei, while the surrounding theca cells showed signs of hypertrophy. Antral follicles were considered to be atretic when more than $5 \%$ of the granulosa cells showed signs of apoptosis, while the theca layer of these follicles showed signs of hypertrophy. As atresia proceeded, the granulosa cells were lost completely and the oocyte degenerated, leaving remnants of the zona pellucida and hypertrophied theca cells. In order to prevent double counting of atretic follicles, we analysed in three sections of each ovary (at a quarter, half and three-quarters of the ovary) all preantral and antral healthy and atretic follicles, independently of the presence of an oocyte, as described previously with minor modifications $[28,29]$. Since the counted numbers reflect only part of the total follicle population in an ovary, the mean number of atretic follicles was expressed as percentage of the number of non-atretic plus atretic follicles. Primordial and primary follicles were excluded from this counting procedure $[23,29]$. In order to determine the number of corpora lutea (CLs) per ovary, overview pictures were taken of every $20^{\text {th }}$ ovarian section using a Zeiss Axioscoop II microscope equipped with an MRc5 camera and Axiovision 4.8.0.0 software (Zeiss $\mathrm{GmbH}$, Jena, Germany). By following the CLs throughout the ovary it was possible to determine the total number of CLs per ovary. 


\section{Radio immunoassays}

Total thyroxine $\left(\mathrm{T}_{4}\right)$ (DSL-3200; DSL, Webster, TX, USA) and total triiodothyronine $\left(\mathrm{T}_{3}\right)$ (DSL-3100) concentrations were assayed according to the manufactures protocol. Luteinizing hormone (LH), follicle stimulating hormone (FSH) and TSH concentrations were determined by validated in-house double-antibody RIAs for rat serum analysis [20,30,31] using materials supplied by the National Institute of Diabetes, Digestive and Kidney Diseases (NIDDK; Bethesda, MD, USA). For all in-house RIAs SACcel (donkey anti-rabbit) was used as the secondary antibody. The levels of the different hormones were expressed in terms of NIDDK standards. The detection limits for the assays were: 5 $\mathrm{ng} / \mathrm{ml}$ for total $\mathrm{T}_{4}, 0.25 \mathrm{ng} / \mathrm{ml}$ for total $\mathrm{T}_{3}, 0.03 \mathrm{ng} / \mathrm{ml}$ for $\mathrm{LH}, 0.1 \mathrm{ng} / \mathrm{ml}$ for TSH and $0.4 \mathrm{ng} / \mathrm{ml}$ for FSH. The intra- and inter-assay variation was determined using several pools of rat serum and was less than $11 \%$ for all purchased RIAs and less than $9.5 \%$ for all in-house RIAs.

\section{Plasma Anti-Müllerian Hormone ELISA}

Plasma anti-Müllerian hormone (AMH) concentrations were analysed using the AMH Gen II ELISA assay according to the manufacturer's instructions (Beckman Coulter, Sinsheim, Germany). The detection limit of the assay was $0.16 \mathrm{ng} / \mathrm{ml}$; the intra-assay coefficient of variation was $5.3 \%$.

\section{Statistical analysis}

Data were expressed as mean \pm standard error of the mean (SEM). GraphPad Prism version 5.03 (Graphpad Software, San Diego, USA) was used for statistical analysis. Data were checked for normality and when normality was confirmed the Student's t test was used for data analysis. In normality could not be assumed, data were $\log 10$ transformed. P-values $<0.05$ were considered significantly different.

\subsection{Results}

\section{Thyroid status}

To assess the thyroid status of the rats, plasma TSH, total $T_{4}$ and total $T_{3}$ concentrations were determined. Within 2 weeks after the start of dietary intervention plasma TSH concentrations had increased by approximately 15 -fold in the hypothyroid rats. By 16 weeks, TSH concentrations were even further increased to approximately 24 -fold the concentrations in the age-matched controls (Figure 1A). Concomitantly, $\mathrm{T}_{4}$ concentrations in the hypothyroid animals had become barely detectable (Figure 1B), while plasma $\mathrm{T}_{3}$ levels were reduced by approximately $30 \%$. (Figure $1 \mathrm{C}$ ). 


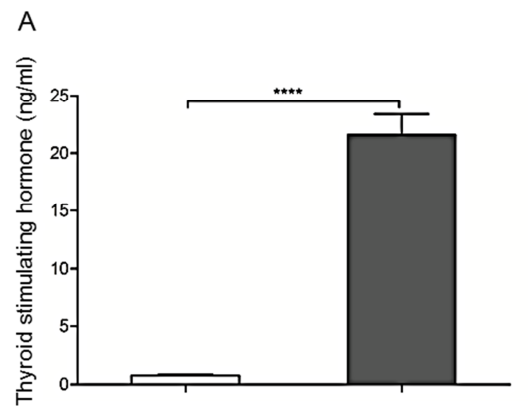

B

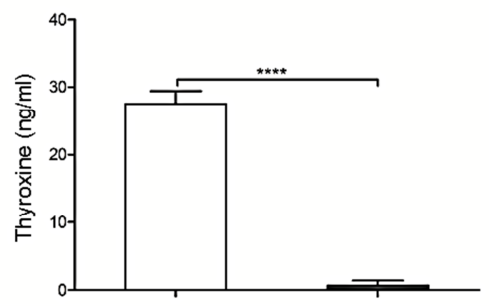

C

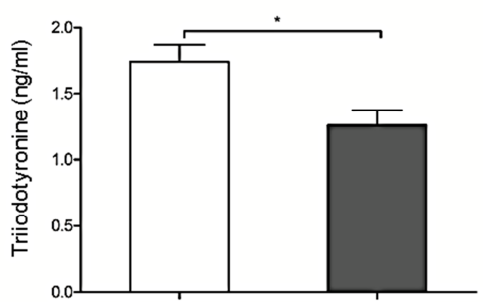

Figure 1 Plasma concentrations of thyroid-stimulating hormone (TSH) (A), thyroxine $\left(T_{4}\right)(B)$ and tri-iodothyronine $\left(T_{3}\right)$ were measured in euthyroid control rats (open bars, $n=11$ ) and hypothyroid rats (filled bars, $n=9$ ). Values represents mean \pm SEM. $* * * * p<0.0001 ; * p<0.05$.

\section{Plasma FSH, LH and AMH concentrations}

No difference was detected in plasma FSH concentrations between the hypothyroid female rats and the age-matched control rats (Figure 2A). Plasma LH concentrations, however, were significantly decreased in the hypothyroid animals compared to the age-matched euthyroid controls (Figure 2B). Plasma AMH concentrations were significantly lower in the hypothyroid rats compared to the controls (Figure $2 \mathrm{C}$ ).

A

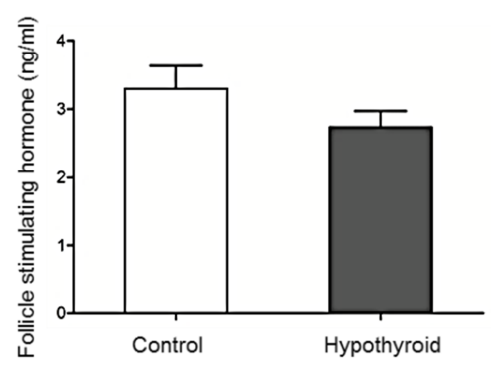

B

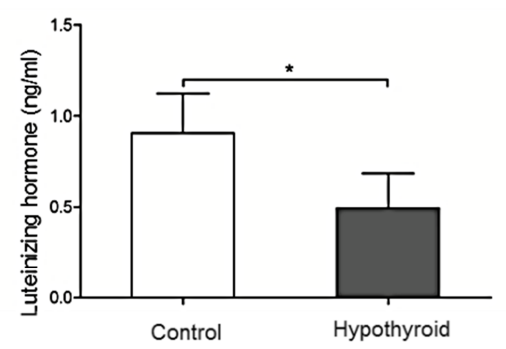

C

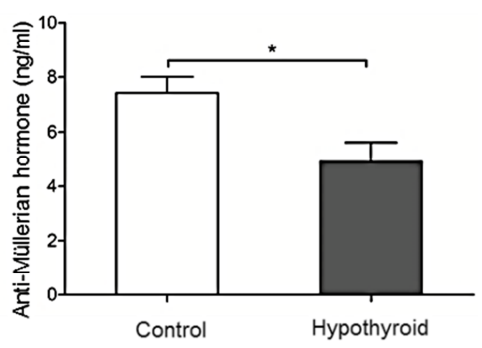

Figure 2 Plasma follicle-stimulating hormone (FSH) (A), luteinizing hormone (LH) (B) and anti-Müllerian hormone (AMH) concentrations $(C)$ in euthyroid control rats (open bars, $n=11$ ) and hypothyroid rats (filled bars, $n=9$ ). Values represents mean \pm SEM. ${ }^{*} p<0.05$.

\section{Follicular development}

In order to obtain further insight in the effects of prolonged mild hypothyroidism on ovarian follicle reserve in adult rats, the total number of follicles per ovary was determined. After 16 weeks of hypothyroidism the primordial follicle numbers were approximately $60 \%$ lower in the hypothyroid females compared with the age-matched euthyroid controls (Figure $3 \mathrm{~A}$ ). The number of primary (Figure 3B) and preantral (Figure 3C) follicles had decreased by about $40 \%$ in the hypothyroid rats compared with the controls, while a downward trend was observed in antral follicle numbers, though this did not reach the level of significance (Figure 3D).

To determine whether prolonged mild hypothyroidism affected follicular atresia in adult rats, the percentage of atretic follicles was determined. The results showed that there was no significant 
difference in the percentage of atretic follicles between hypothyroid rats and age-matched controls (Figure 3E).

In line with these observations the total number of CLs per ovary in the hypothyroid females showed a downward trend compared to the euthyroid controls, though this did not reach the level of significance (Figure 3F).

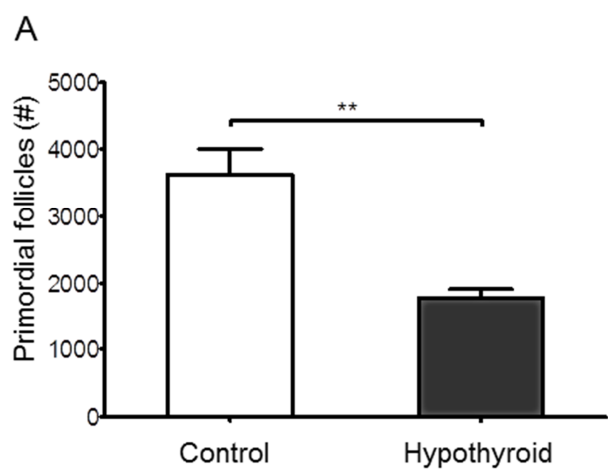

C

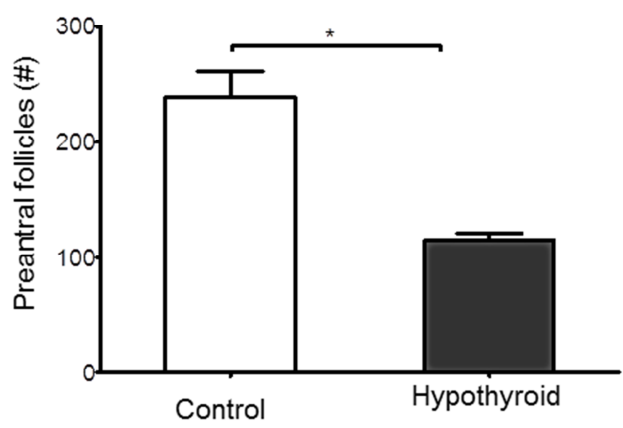

E

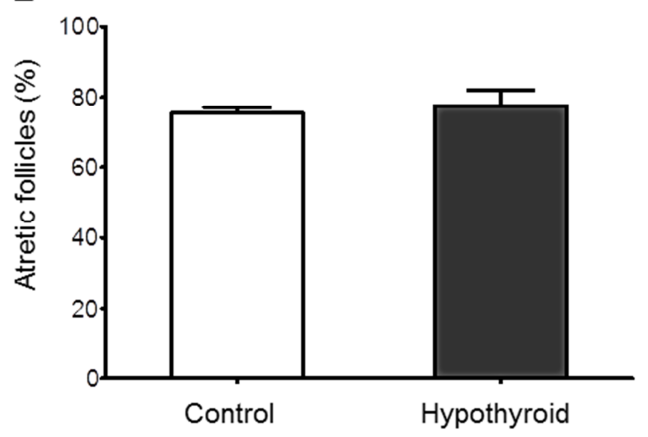

B

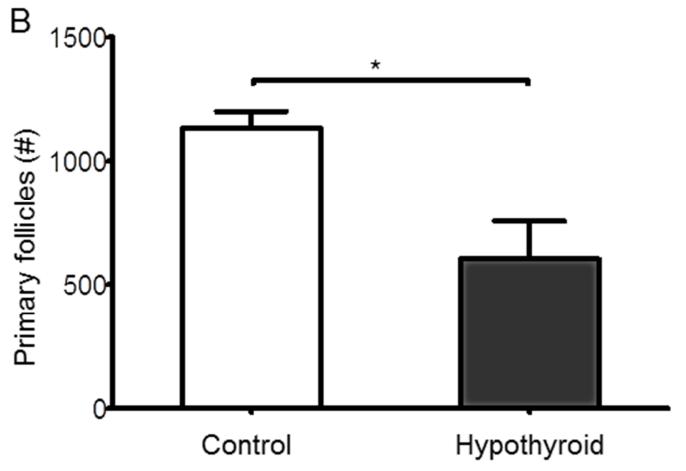

D

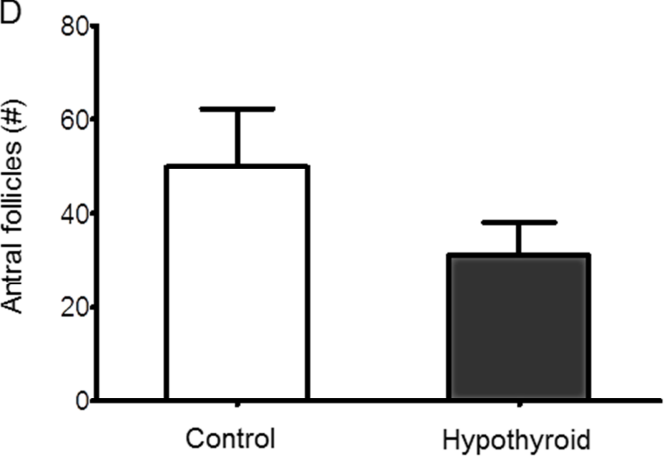

$\mathrm{F}$

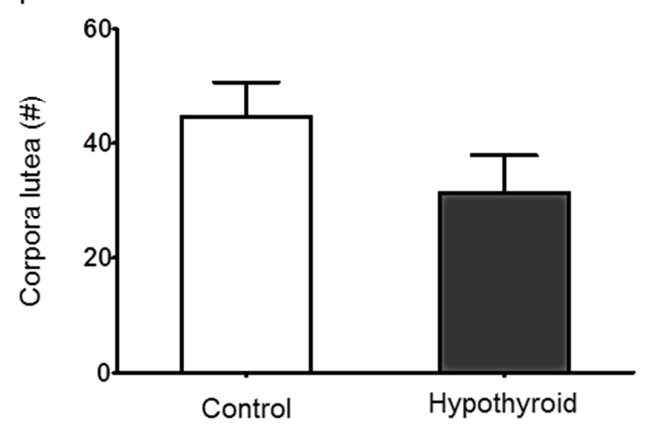

Figure 3 Effects of mild hypothyroidism on ovarian follicle numbers in euthyroid control rats (open bars) and hypothyroid rats (filled bars). Total number of ovarian primordial (A), primary (B), preantral (C), antral follicles (D), percentage of atretic follicles $(E)$ and total ovarian number of corpora lutea (CLS) (F). Values represent mean $\pm S E M ; n=4 .{ }^{*} p<0.05 ;{ }^{* *} p<0.01$.

There is some dispute about the use of plasma AMH concentrations as marker of ovarian follicular reserve [32-34]. According to Findlay and colleagues [33] AMH should be related to the growing follicle population (the ovulatory potential), excluding the primordial follicle pool. We therefore performed a correlation analysis between plasma $\mathrm{AMH}$ concentrations and the growing follicle population (consisting of primary, preantal and antral follicles) and observed a significant correlation 
between $\mathrm{AMH}$ and the growing follicle population (Figure 4). No correlation was observed between plasma AMH concentrations and primordial follicle numbers (data not shown).

A

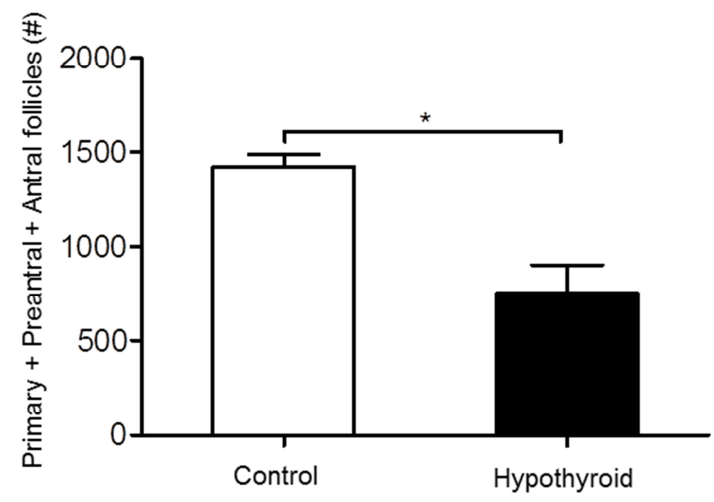

B

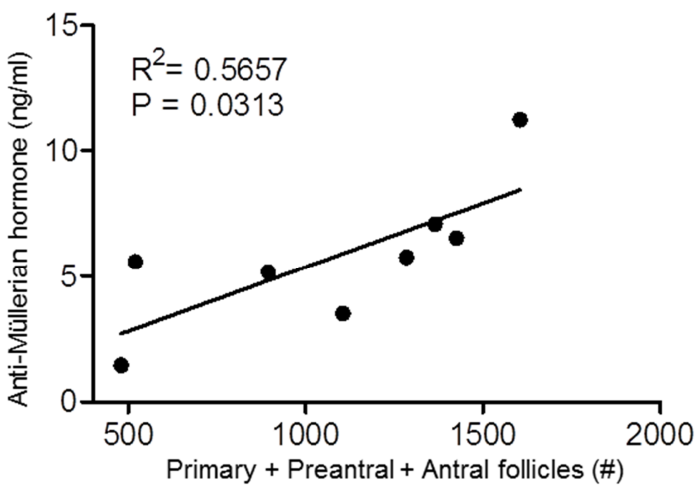

Figure 4 Effects of mild hypothyroidism on the size of the growing ovarian follicle population (consisting of primary plus preantral and antral follicle numbers) in euthyroid control (open bar) and hypothyroid rats (filled bar) ( $A$ ), and the correlation between the growing ovarian follicle population and plasma AMH concentration in hypothyroid rats (B). Values represent mean \pm SEM; $n=4$

\subsection{Discussion}

The present study is, to our knowledge, the first that provides a detailed analysis of the follicular reserve in adult female rats that are exposed to hypothyroid conditions for a prolonged period of time. Primordial, primary and preantral follicle numbers are significantly lower in the hypothyroid ovaries compared to the euthyroid controls, while a downward trend in antral follicle numbers and corpora lutea is observed. Quite surprisingly the percentage of atretic follicles was not different between the two groups, suggesting that the reduced preantral and antral follicle numbers do not seem to be due to increased degeneration of these follicle types in the hypothyroid group.

The reduction in the number of primordial follicles in the hypothyroid rats suggests that either recruitment of primordial follicles into the pool of growing follicles is enhanced or alternatively the low circulating thyroid hormone concentrations induce increased primordial follicle degeneration. Assuming that the initial recruitment of primordial follicles is indeed enhanced, this should lead to an increase in the primary follicle pool size. Our data do not support this assumption; on the contrary, primary follicle numbers are decreased significantly as are preantral follicle numbers. This implicates that recruited primordial and/or primary follicles may have degenerated before reaching the preantral stage. The manifestation of attrition in primordial and primary follicles is thought to be of short duration $[35,36]$ and therefore difficult to identify by plain histology. We may have simply missed these atretic follicles during our analysis. Furthermore, we have collected ovarian tissue at only one time-point, namely 16 weeks after the start of the dietary intervention. We do not know whether degeneration of these follicles takes place gradually over time, or whether follicles degenerate massively during the initial period of the dietary intervention when TH concentrations are decreasing, followed by a new equilibrium between recruitment and degeneration when $\mathrm{TH}$ concentrations have stabilized. Based on the observation that the number of preantral follicles is 
reduced by approximately the same percentage as the primary follicle number, and antral follicle numbers and $\mathrm{CL}$ numbers not being different from euthyroid control values, we favour the first explanation, i.e. gradual depletion.

Plasma LH concentrations are significantly decreased in chronic adult hypothyroid rats compared with the euthyroid controls. This observation is in agreement with previous reports by Hatsuta, et al. [37] and Tohei, et al. [38]. The number of studies reporting on gonadotropin serum concentrations in hypothyroid women is limited and data are contradictory. Tomasi and colleagues observed that in women of reproductive age chronic hypothyroidism leads to increased baseline $\mathrm{LH}$ and FSH concentrations [39], while in a more recent study Acharya et al. [40] showed that chronic hypothyroidism in premenopausal women led to reduced LH concentrations, while FSH concentrations were within the normal range. The latter observation is in line with what we observed in our hypothyroid female rats. The reduction in LH concentrations under hypothyroid conditions may be explained by an elevation in prolactin concentration, a phenomenon observed both in rats and humans $[7,37,41]$. Due to the disturbed thyroid function, thyrotropin-releasing hormone (TRH) release by the hypothalamus is increased, stimulating pituitary prolactin synthesis and release [42]. Elevated prolactin concentrations exert a negative influence on the pituitary response to gonadotropin releasing hormone $(\mathrm{GnRH})$ [37] and thus reduce LH secretion. Despite these reduced basal LH concentrations and menstrual/oestrous cycle irregularities, ovulation is not necessarily completely blocked under mild to moderate hypothyroid conditions $[7,20,38]$. On the contrary, the preovulatory LH peak may even be augmented, facilitating ovulation [20].

Studies investigating the incidence of fertility problems in hypothyroid women are scarce, in general retrospective and uncontrolled. Despite the fact that abnormalities in thyroid function have been associated with subfertility $[7,43]$, in most developed countries, national guidance does not recommend routine measurement of thyroid function in women with fertility problems $[43,44]$. Our data, however, implicate that prolonged mild hypothyroidism negatively affects reproductive poptential. A decrease in size of the ovarian follicle pool including non-growing and growing follicles as observed in the present study, may be correlated with a decline in female fertility, stressing the importance of knowledge concerning the reproductive potential in women with fertility and thyroid problems. However, histological analysis by counting of follicles is too invasive to apply to humans. We therefore used plasma AMH concentrations as biomarker of follicular reserve and correlated this with our follicle counts. We observe a strong correlation between the number of growing follicles (primary, preantral and antral follicles) and plasma AMH (Figure 4B). Other studies, in rats and humans have reported $\mathrm{AMH}$ as a surrogate marker for ovarian follicular reserve $[32,34,45,46]$. Findley et al. [33] recently questioned however, the use of biomarkers such as serum $A M H$ as indicator of ovarion follicular reserve. According to these authors these biomarkers do not provide direct measurement of the size of the "resting" pool of primordial follicles, but only reflect the presence of growing follicles (in fact presumably mostly antral follicles). Our data are in line with Findlay et al. [33] as plasma AHM concentrations under hypothyroid conditions correlate with the growing pool of follicles, also named ovulatory portential by these authors, and do not correlate with the number of primordial follicles, the primordial ovarian reserve [33].

Taken together, although one needs to be careful in extrapolating observations from animal studies to humans, the observed decrease in ovarian follicle numbers due to prolonged exposure to reduced 
TH concentrations warrants an extensive well controlled prospective evaluation of the correlation between female reproductive health and thyroid status in women with an unfulfilled child wish.

\section{Acknowledgements}

The authors would like to thank Diane Schoonhoven MSc for her help in the histological analysis of the tissues. This project was partially funded by the Deutsche Forschungsgemeinschaft under project RI 2457/1-1 to Eddy Rijntjes. Li Meng was funded by the China Scholarship Council (CSC) under grant number 2011685003. 


\subsection{References}

1. Chiamolera MI, Wondisford FE. Thyrotropin-releasing hormone and the thyroid hormone feedback mechanism. Endocrinology 2009; 150: 1091-96.

2. McAninch EA, Bianco AC. Thyroid hormone signaling in energy homeostasis and energy metabolism. Ann N Y Acad Sci 2014; 1311:77-87.

3. Sinha RA, Singh BK, Yen PM. Thyroid hormone regulation of hepatic lipid and carbohydrate metabolism. Trends Endocrinol Metab 2014;25:538-45.

4. Vissenberg R, Manders VD, Mastenbroek S, Fliers E, Afink GB, Ris-Stalpers C, Goddijn M, Bisschop PH. Pathophysiological aspects of thyroid hormone disorders/thyroid peroxidase autoantibodies and reproduction. Hum Reprod Update 2015;21:378-87.

5. Abalovich M, Mitelberg L, Allami C, Gutierrez S, Alcaraz G, Otero P, Levalle O. Subclinical hypothyroidism and thyroid autoimmunity in women with infertility. Gynecol Endocrinol 2007;23: 279-83.

6. Joshi JV, Bhandarkar SD, Chadha M, Balaiah D, Shah R. Menstrual irregularities and lactation failure may precede thyroid dysfunction or goitre. J. Postgrad. Med 1993;39:137-41.

7. Krassas GE, Poppe K, Glinoer D. Thyroid Function and Human Reproductive Health. Endocr Rev 2010;31:702-55.

8. Chai J, Yeung WY, Lee CY, Li HW, Ho PC, Ng HY. Live birth rates following in vitro fertilization in women with thyroid autoimmunity and/or subclinical hypothyroidism. Clin Endocrinol 2014;80:122-27.

9. Pearce EN, Andersson M, Zimmermann MB. Global iodine nutrition: Where do we stand in 2013? Thyroid 2013;23:52328.

10. Vanderpump MP. The epidemiology of thyroid disease. Br Med Bull 2011;99:39-51.

11. Poppe K, Velkeniers B, Glinoer D. The role of thyroid autoimmunity in fertility and pregnancy. Nat Clin Pract Endocrinol Metab 2008;4:393-405.

12. Canaris GJ, Manowitz NR, Mayor G, Ridgway EC. The Colorado thyroid disease prevalence study. Arch Intern Med 2000;160:526-34.

13. Garg A, Vanderpump MP. Subclinical thyroid disease. Br Med Bull 2013;107:101-16.

14. Lazarus J. Thyroid regulation and dysfunction in the pregnant patient. In: De Groot JL, Beck-Peccoz P, Chrousos G, Dungan K, Grossman A, Hershman J, Koch C, McLachlan R, New M, Rebar R, Singer F, Vinik A, Weickert MO, eds. Endotext, South Dartmouth (MA): MDText.com, Inc.; 2000-2015.

15. Stuckey BG, Kent GN, Allen JR, Ward LC, Brown SJ, Walsh JP. Low urinary iodine postpartum is associated with hypothyroid postpartum thyroid dysfunction and predicts long-term hypothyroidism. Clin Endocrinol 2011;74:631-35.

16. Lazarus JH. lodine status in Europe in 2014. Eur Thyroid J 2014;3:3-6.

17. Stuckey BG, Kent GN, Ward LC, Brown SJ, Walsh JP. Postpartum thyroid dysfunction and the long-term risk of hypothyroidism: results from a 12-year follow-up study of women with and without postpartum thyroid dysfunction. Clin Endocrinol 2010;73:389-95.

18. Ortega E, Rodriguez E, Ruiz E, Osorio C. Activity of the hypothalamo-pituitary ovarian axis in hypothyroid rats with or without triiodothyronine replacement. Life Sci 1990;46:391-95.

19. Hapon MB, Simoncini M, Via G, Jahn GA. Effect of hypothyroidism on hormone profiles in virgin, pregnant and lactating rats, and on lactation. Reproduction 2003;126:371-82.

20. Mattheij JA, Swarts JJ, Lokerse P, van Kampen JT, Van der Heide D. Effect of hypothyroidism on the pituitary-gonadal axis in the adult female rat. J Endocrinol 1995;146:87-94.

21. Armada-Dias L, Carvalho JJ, Breitenbach MMD, Franci CR, Moura EG. Is the infertility in hypothyroidism mainly due to ovarian or pituitary functional changes? Braz J Med Biol Res 2001;34:1209-15.

22. Parrott MW, Johnston ME, Durbin PW. The Effects of Thyroid and parathyroid deficiency on reproduction in the at. Endocrinology 1960;67:467-83.

23. Meng L, Rijntjes E, Swarts H, Bunschoten A, van der Stelt I, Keijer J, Teerds KJ. Dietary-induced chronic hypothyroidism negatively affects rat follicular development and ovulation rate and is associated with oxidative stress. Biol Reprod 2016;115.136515. 
24. Reeves PG, Nielsen FH, Fahey GC, Jr. AIN-93 purified diets for laboratory rodents: final report of the American Institute of Nutrition ad hoc writing committee on the reformulation of the AIN-76A rodent diet. J Nutr 1993;123:1939-51.

25. Schroder-van der Elst JP, van der Heide D, Morreale de Escobar G, Obregon MJ. lodothyronine deiodinase activities in fetal rat tissues at several levels of iodine deficiency: a role for the skin in 3,5,3'-triiodothyronine economy? Endocrinology 1998;139:2229-34.

26. Rijntjes E, Swarts HJM, Anand-Ivell R, Teerds KJ. Prenatal induced chronic dietary hypothyroidism delays but does not block adult-type Leydig cell development. Am J Physiol Endoc Metab 2009;296:E305-14.

27. Flaws JA, Abbud R, Mann RJ, Nilson JH, Hirshfield AN. Chronically elevated luteinizing hormone depletes primordial follicles in the mouse ovary. Biol. Reprod 1997;57:1233-37.29.

28. Slot KA, Kastelijn J, Bachelot A, Kelly PA, Binart N, Teerds KJ. Reduced recruitment and survival of primordial and growing follicles in GH receptor-deficient mice. Reproduction 2006;131:525-32.

29. Dijkstra G, de Rooij DG, de Jong FH, van den Hurk R. Effect of hypothyroidism on ovarian follicular development, granulosa cell proliferation and peripheral hormone levels in the prepubertal rat. Eur J Endocrinol 1996;134:649-54.

30. Palm IF, van der Beek EM, Swarts HJ, van der Vliet J, Wiegant VM, Buijs RM, Kalsbeek A. Control of the estradiolinduced prolactin surge by the suprachiasmatic nucleus. Endocrinology 2001;142:2296-02.

31. Palm IF, van der Beek EM, Wiegant VM, Buijs RM, Kalsbeek A, Palm IF, van der Beek EM, Swarts HJ, van der Vliet J, Wiegant $\mathrm{VM}$ et al. The stimulatory effect of vasopressin on the luteinizing hormone surge in ovariectomized, estradioltreated rats is time-dependent. Brain Res 2001;901:109-16.

32. Gruijters MJG, Visser JA,Durlinger ALL, Themmen APN. Anti-Müllerian hormone and its role in ovarian function. Mol Cell Endocrinol 2003;211:85-90.

33. Findlay JK, Hutt KJ, Hickey M, Anderson RA. What is the "ovarian reserve"? Fertil Steril 2015;103:628-30.

34. Saglam F, Onal ED, Ersoy R, Koca C, Ergin M, Erel O, Cakir B. Anti-Müllerian hormone as a marker of premature ovarian aging in autoimmune thyroid disease. Gynecol Endocrinol 2015;31:165-68.

35. Hirshfield AN. Relationship between the supply of primordial follicles and the onset of follicular growth in rats. Biol Reprod 1994;50:421-28.

36. Johnson J, Canning J, Kaneko T, Pru JK, Tilly JL. Germline stem cells and follicular renewal in the postnatal mammalian ovary (vol 428, pg 145, 2004). Nature 2004;430:1062-62.

37. Hatsuta M, Abe K, Tamura K, Ryuno T, Watanabe G, Taya K, Kogo H. Effects of hypothyroidism on the estrous cycle and reproductive hormones in mature female rat. Eur J Pharmacol 2004;486:343-48.

38. Tohei A, Imai A, Watanabe G, Taya K. Influence of thiouracil-induced hypothyroidism on adrenal and gonadal functions in adult female rats. J Vet Med Sci 1998;60:439-46.

39. Tomasi PA, Fanciulli G, Zini M, Demontis MA, Dettori A, Delitala G. Pulsatile gonadotrophin secretion in hypothyroid women of reproductive age. Eur J Endocrinol 1997;136:406-09.

40. Acharya N, Acharya S, Shukla S, Inamdar SA, Khatri M, Mahajan SN. Gonadotropin levels in hypothyroid women of reproductive age group. J Obstet Gynaecol India 2011;61:550-53.

41. Goel P, Kahkasha, Narang S, Gupta BK, Goel K. Evaluation of serum prolactin level in patients of subclinical and overt hypothyroidism. J Clin Diagn Res 2015;9:15-17.

42. Surks MI, Ortiz E, Daniels GH, Sawin CT, Col NF, Cobin RH, Franklyn JA, Hershman JM, Burman KD, Denke MA et al. Subclinical thyroid disease: scientific review and guidelines for diagnosis and management. JAMA 2004;291:228-38.

43. Jefferys A, Vanderpump M, Yasmin E. Thyroid dysfunction and reproductive health. Obstet Gynaecol 2015;17:39-45.

44. Practice Committee of the American Society for Reproductive Medicine. Subclinical hypothyroidism in the infertile female population: a guideline. Fertil Steril 2015;104:545-53.

45. Kevenaar ME, Meerasahib MF, Kramer P, de Lang-Born BMN, de Jong FH, Groome NP, Themmen APN, Visser JA. Serum anti-mullerian hormone levels reflect the size of the primordial follicle pool in mice. Endocrinology 2006;147:3228-34.

46. La Marca A, Ferraretti AP, Palermo R, Ubaldi FM. The use of ovarian reserve markers in IVF clinical practice: a national consensus. Gynecol Endocrinol 2016;32:1-5. 



\section{Chapter 4}

Dietary-induced chronic hypothyroidism negatively affects rat follicular development and ovulation rate and is associated with oxidative stress

Li Meng ${ }^{a}$, Eddy Rijntjes ${ }^{a, b}$, Hans Swarts ${ }^{a}$, Annelies Bunschoten ${ }^{a}$, Inge van der Stelt ${ }^{a}$, Jaap Keijer ${ }^{a}$, Katja Teerds $^{a}$

aHuman and Animal Physiology, Wageningen University \& Research, P.O. Box 338, $6700 \mathrm{AH}$, Wageningen, The Netherlands

${ }^{b}$ Institut für Experimentelle Endokrinologie, Charité Universitäts-Medizin Berlin, Berlin, Germany

Biology of Reproduction 2016; 94:1-11 


\section{Abstract}

The long-term effects of chronic hypothyroidism on ovarian follicular development in adulthood is not well known. Using a rat model of chronic diet induced hypothyroidism initiated in the foetal period, we investigated the effects of prolonged reduced plasma thyroid hormone concentrations on the ovarian follicular reserve and ovulation rate in prepubertal (12-day-old) and adult (64-day-old and 120-day-old) rats. Besides, antioxidant gene expression, mitochondrial density and the occurrence of oxidative stress were analyzed. Our results show that continuous hypothyroidism results in lower preantral and antral follicle numbers in adulthood, accompanied by a higher percentage of atretic follicles, when compared to euthyroid age-matched controls. Not surprisingly, ovulation rate was lower in the hypothyroid rats. At the age of 120 days the mRNA and protein content of superoxide dismutase 1 (SOD1) are significantly increased while catalase (CAT) mRNA and protein content is significantly decreased, suggesting a disturbed antioxidant defense capacity of ovarian cells in the hypothyroid animals. This is supported by a significant reduction in the expression of peroxiredoxin $3(\operatorname{Prd} \mathrm{x} 3)$, thioredoxin reductase 1 (Txnrd1), and uncoupling protein 2 (Ucp2) and a downward trend in glutathione peroxidase $3(G p \times 3)$ and glutathione S-transferase mu 2 (Gstm2) expression. These changes in gene expression are likely responsible for the increased immunostaining of the oxidative stress marker 4-hydroxynonenal (4-HNE). Together these results suggest that chronic hypothyroidism initiated in the foetal/neonatal period results in a decreased ovulation rate associated with a disturbance of the antioxidant defense system in the ovary. 


\subsection{Introduction}

Thyroid hormone (TH) is known to be a key factor in the regulation of many biological processes including growth, differentiation, metabolism, embryo development and female reproduction [1, 2]. Altered TH concentrations are associated with disturbed folliculogenesis, lower fertilization rate and reduced embryo quality [3], and in severe cases even lead to complete ovarian failure [4-6].

Proper ovarian follicular development is dependent on the subtle balance between pituitary gonadotropic hormones and locally as well as peripherally produced factors, such as transforming growth factor beta [7, 8], Insulin-like growth factor 1 [9], leptin [10] and adiponectin [11]. The active TH 3,3',5-triiodothyronine $\left(T_{3}\right)$ acts as such a peripheral factor by amplifying the action of the gonadotropic hormone follicle-stimulating hormone (FSH) on follicle growth [12]. FSH and $\mathrm{T}_{3}$ exert their effect on follicular development via stimulation of granulosa cell proliferation and inhibition of apoptosis through activation of the PI3K/AKT pathway [13].

Despite the relatively high incidence of hyperthyroidism in women, with a general prevalence of about $1 \%$, only a few studies have addressed the effects of excessive TH concentrations on neonatal development of the female reproductive tract [14]. For instance, Soliman and Reineke have shown that mild thyroidal stimulation in young female mice results in advancement of the age of vaginal opening and the onset of estrous cycles when compared to euthyroid controls. The ovaries of these hyperthyroid mice contain multiple growing follicles and corpora lutea [15].

The effects of TH deficiency on ovarian follicular development are commonly studied in animal models using propyl-2-thiouracyl (PTU) as goitrogen. However, various adverse effects are associated with prolonged PTU treatment, including agranulocytosis and hepatotoxicity [16]. Administration of PTU during pregnancy usually results in premature abortion. Consequently treatment is generally initiated around the time of delivery and stopped before the offspring reaches puberty $[17,18]$. These studies show that neonatal hypothyroidism in rats results in a delay or even complete inhibition in vaginal opening and sexual maturation with smaller ovaries, less antral follicles and more atretic follicles [17]. The application of a dietary induced (combination of sodium perchlorate and an iodide-poor diet) hypothyroidism rat model [19], allows us now to study the long-term effects of chronic hypothyroidism initiated in the foetal/neonatal period on ovarian follicular development.

Reactive oxygen species (ROS) are formed continuously in cells as a result of both biochemical reactions and external factors. It is increasingly realized that ROS at physiological amounts have an important signalling function [20]. Indeed, the regulated generation of ROS is necessary for the primary oocyte to resume the first meiotic division, showing ROS to be an important mediator of the ovulatory sequence [21]. Down regulation of ROS is necessary for progression through the second meiotic division [22], showing the need for a balance between ROS production and cellular ROS defense. A disturbance in the balance between the production of ROS, with mitochondria as an important source, and the antioxidant defense capacity of cells can lead to oxidative stress and concomitant pathology [23]. As in other tissues, cellular antioxidant defense in the ovary is comprised of an array of cytoplasmic and mitochondrial enzymes, including superoxide dismutases (SODs), catalase (CAT), glutaredoxins (GLRXs), peroxiredoxins (PRDXs), thioredoxins (TXNs) and glutathione S-transferases Mu (GSTMs) [24-28]. Several studies have shown that reduced TH 
concentrations can influence antioxidant defense. The observed effects are, however, highly variable. For example, chronic hypothyroidism in adult rats causes a decrease in renal lipid peroxidation, SOD2 and CAT mRNA and protein concentrations, while GPX1 is significantly increased [29]. SODs activity in the brain is decreased due to persistent hypothyroidism, while under the same conditions in the testis SODs and CAT activity are increased and GPXs activity decreased [30].

How chronic hypothyroidism affects the expression of genes related to ovarian redox balance is at present not known. Using our rat model of chronic hypothyroidism [19], we here investigate the effects of prolonged exposure to reduced serum TH concentration on ovarian follicular reserve and ovulation rate and relate these observations to mitochondrial and antioxidant gene expression and occurrence of oxidative stress in prepubertal and adult rats.

\subsection{Material and Methods}

\section{Chemicals and antibodies}

All chemicals were purchased from Sigma (Zwijndrecht, the Netherlands) unless indicated otherwise. Antibodies against 4-hydroxynonenal (4-HNE, lot no. GR126142-8, cat. no. ab48506), CAT (lot no GR21101-7, cat. no. ab1877), SOD1 (lot no GR196707-7, cat. no. ab16831), SOD2 (lot no GR67500-4, cat. no. ab13533), cytochrome c oxidase subunit IV (COX IV, lot no GR85489-1, cat. no. ab16056), $\beta$ actin (ACTB, cat. no. ab6276), were purchased from Abcam (Cambridge, UK).

\section{Animals and treatment}

Wistar WU (HsdCpbWU) rats were obtained from Harlan (Horst, the Netherlands) at the age of 8 weeks (females) or 10 weeks (males) and kept under controlled conditions (room temperature 20.5$21.5^{\circ} \mathrm{C}$; humidity 55-65\%; light regimen $60-80$ lux, lights on from 03:00 to 17:00 local daylight saving time). The female rats were housed individually after arrival and provided with cage enrichment in the form of a $10 \mathrm{~cm}$ sisal rope. Two weeks after arrival the female rats of the experimental group were put on an iodide-poor diet based on AIN 1993 requirements (Research Diet Services, Wijk bij Duurstede, the Netherlands) [31,32], supplemented with $0.75 \%$ sodium perchlorate in the drinking water to deplete endogenous iodide stores [19]. The control group received the same iodide-poor diet supplemented with $7 \mu \mathrm{g}$ iodide per $100 \mathrm{~g}$ dry weight of the diet to fulfill the normal iodide requirements of rats, and were provided with normal drinking water. At the age of 12 weeks, the female rats were mated. Pups were weaned on postnatal day 28 . The female offspring was grouphoused ( 3 to 4 animals per cage) up to the age of 73 days postpartum (pp), after which the remaining animals were housed pair wise.

The experimental hypothyroid diet was continued until sacrifice of the female offspring. Groups of 720 females were sacrificed at the age of $12,16,21,28,35,42,50,64,100$ and 120 days, respectively. From the age of 42 days onwards all female rats were sacrificed between 11.00 and $14.00 \mathrm{~h}$ at the proestrous stage of the estrous cycle. The proestrous stage of the cycle was determined by daily analysis of vaginal smears for a period of at least 10 days before sacrifice (except for the 42-day pp group where we started to take vaginal smears the day after vaginal opening). Analysis of the vaginal smears further showed that the length of the estrous cycle length in these female rats was 5 days; there was no difference in estrous cycle length between the hypothyroid rats and euthyroid controls. 
Rats were anesthetized using carbon dioxide and oxygen (flow: 1:2). Blood was collected by heart puncture and transferred to heparin-coated tubes. Rats were killed by decapitation, organs were dissected, snap-frozen and stored at $-80{ }^{\circ} \mathrm{C}$, or fixed in either Bouin's fluid or $4 \%$ phosphate buffered paraformaldehyde and stored in ethanol $70 \%$ or phosphate buffer. Plasma was stored at $-20{ }^{\circ} \mathrm{C}$ until further analysis.

All animal experiments were approved by the Animal Welfare Committee of Wageningen University and conducted in accordance with the Society for the Study of Reproduction guidelines.

\section{Histological evaluation of ovarian tissues}

The right ovaries of 4 to 5 animals aged 12, 64 or 120 days were fixed in Bouin's fluid for $24 \mathrm{~h}$ and embedded in paraffin. The ovaries were serial sectioned at a thickness of $5 \mu \mathrm{m}$ per section. Every fifth section of each ovary was mounted on glass slides, stained with periodic acid Schiff's reagent (PAS) and Mayer's haematoxylin (Klinipath, Duiven, the Netherlands), and examined by light microscopy. From these sections the numbers of healthy primordial, primary, preantral and antral follicles were counted as described previously $[33,34]$. In order to estimate the total number of follicles within one ovary, the number of primordial, primary, preantral and antral follicles counted in the mounted sections was multiplied by five to account for the fact that every fifth section was used in the follicle counting procedure [33].

Atretic preantral follicles were recognized by the presence of a degenerating oocyte, disorganized granulosa cell layer with the presence of some apoptotic nuclei, while the surrounding theca cells showed signs of hypertrophy. Antral follicles were considered to be atretic when more than $5 \%$ of the granulosa cells showed signs of apoptosis. The theca layer of these atretic antral follicles showed signs of hypertrophy. As atresia proceeded, the granulosa cells were lost completely and the oocyte degenerated, leaving remnants of the zona pellucida and hypertrophied theca cells. In order to prevent double counting of atretic follicles, we counted in three sections of each ovary (at a quarter, half and three-quarters of the ovary) all preantral and antral healthy and atretic follicles, independently of the presence of an oocyte, as described previously [17, 33]. Since the counted numbers reflect only part of the total follicle population in an ovary, the mean number of atretic follicles was expressed as percentage of the number of non-atretic plus atretic follicles. Primordial and primary follicles were excluded from this counting procedure.

In order to determine the number of corpora lutea $(\mathrm{CL})$ per ovary, pictures were taken of every 10th section of each ovary under a light microscope at a $5 x$ magnification (Zeiss Axioscope II, equipped with a MRc5 digital camera, Zeiss $\mathrm{GmbH}$, Jena, Germany). The pictures were stacked using Adobe Photoshop CS6; CL's were followed through the whole ovary and counted.

\section{Immunohistochemistry}

For immunohistochemical purposes, ovaries were fixed in $4 \%$ phosphate buffered paraformaldehyde at $4{ }^{\circ} \mathrm{C}$ for 24-48 h. After fixation, the ovaries were washed in phosphate buffer and embedded in paraffin. Five $\mu \mathrm{m}$ thick paraffin sections were cut and mounted on Superfrost plus slides (Menzel, Braunschweig, Germany). To determine the presence of 4-HNE a immunohistochemistry was performed according to Hoevenaars et al. [35] with modifications. Staining of sections of at least 3 different animals was carried out simultaneously in a single session at room temperature unless 
stated otherwise. Briefly, sections were deparaffinized, rehydrated after which epitope antigen retrieval with sodium citrate buffer $\left(\mathrm{pH} 6,10 \mathrm{~min}\right.$ ) in a microwave oven was performed at $96{ }^{\circ} \mathrm{C}$. Slides were cooled down to room temperature and subsequently rinsed with $0.01 \mathrm{M}$ phosphate buffered saline $\mathrm{pH} 7.4$ (PBS). Sections were pre-incubated with $10 \%(\mathrm{wt} / \mathrm{v})$ normal goat serum in PBS for $30 \mathrm{~min}$ and incubated overnight with the primary 4-HNE antibody (diluted 1:800in PBS to which 0.05\% BSAc (Aurion, Wageningen, The Netherlands) was added). The secondary goat-anti-mouse biotin labelled antibodies (Vector Laboratories, Burlingame, CA, USA) was diluted 1:400 (v/v), in PBSBSAc. The avidin-biotin complex (ABC) was diluted 1:1500 (v/v) Vector Laboratories) in PBS-BSAc. Bound antibody was visualized using the 3-3' diaminobenzidine kit (Immpact DAB, Vector Laboratories) diluted 1:400 (v/v). Sections were counterstained with Mayer's haematoxylin. Control sections were incubated with isotype IgG (Vector Laboratories) instead of the primary antibody according to the manufacturers' instructions. No background staining was observed in the controls.

\section{Total body fat measurement}

The body fat content of the offspring was determined by crude total body fat analysis. Briefly, the carcasses of the rats were weighed, put in a beaker to which $150 \mathrm{ml}$ water was added and autoclaved at $130{ }^{\circ} \mathrm{C}$ for 10 hours. The samples were cooled down to room temperature, weighed, homogenized twice and subsequently freeze-dried for $72 \mathrm{~h}$. Fat analysis was performed using the ether-extraction procedure as described previously [36].

\section{Western blotting}

Western blotting was performed as described by Kus et al [37] with minor modifications. Briefly, ovaries were homogenized in lyses buffer with protease inhibitors (complete Mini-EDTA free, cat no 04693159001, Roche, Mannheim, Germany) and phosphatase inhibitor mix I (cat no 39050, Serva, Heidelberg, Germany). Subsequently, the sample was sonicated using the Sonifier Cell Disruptor (Model SLPe, Branson, Eemnes, The Netherlands) and centrifuged for $10 \mathrm{~min}$ at $14000 \mathrm{rpm}$ at $4{ }^{\circ} \mathrm{C}$. Protein concentrations were determined using the RC DC Protein Assay Kit II (Bio-Rad, Veenendaal, The Netherlands). SDS-PAGE gels were run using the Mini-Protean Tetra cell system (Bio-Rad). Proteins from the SDS-PAGE gels were transferred onto a $0.20 \mu \mathrm{m}$ PVDF membrane (Millipore, Amsterdam, The Netherlands). The blot was incubated overnight at $4{ }^{\circ} \mathrm{C}$ with the primary antibodies (CAT, diluted 1:10000; SOD1, 1:2500; SOD2, 1:5000; COX IV, 1:5000; ACTB, 1:5000), rinsed with TBSTween $(0.1 \%)$ followed by incubation for $1 \mathrm{~h}$ with IRDye680-conjugated Donkey anti-Mouse (LI-COR Biosciences, Leusden, The Netherlands) or IRDye800-conjugated Donkey anti-Rabbit (LI-COR Biosciences) antibodies diluted 1:5000. Images of the membranes were obtained using the Odyssey infrared imaging system (LI-COR Biosciences). Quantification of the blots was performed using the Image Studio (LI-COR Biosciences) software.

\section{Radio immunoassays}

Total thyroxine $\left(T_{4}\right)$ (DSL-3200; DSL, Webster, TX, USA), total $T_{3}$ (DSL-3100), free $T_{3}$ (DSL-41100) and leptin (RL-83K, LINCO Research, St. Charles, MO, USA) levels were assayed according to the protocols of the respective manufacturers. Luteinizing hormone (LH), FSH and thyroid stimulating hormone (TSH) levels were determined by validated in-house double-antibody RIAs for rat serum analysis [3840], using materials supplied by the National Institute of Diabetes, Digestive and Kidney Diseases (NIDDK; Bethesda, MD, USA). For all in-house RIAs SACcel (donkey anti-rabbit; Wellcome Diagnostics, Dartford, UK) was used as secondary antibody. Hormone levels were expressed in terms of NIDDK 
standards. The detection limits of the assays were: $5 \mathrm{ng} / \mathrm{ml}$ for total $\mathrm{T}_{4}, 0.25 \mathrm{ng} / \mathrm{ml}$ for total $\mathrm{T}_{3}, 0.6$ $\mathrm{pg} / \mathrm{ml}$ for free $\mathrm{T}_{3}, 0.5 \mathrm{ng} / \mathrm{ml}$ for leptin, $0.03 \mathrm{ng} / \mathrm{ml}$ for $\mathrm{LH}, 0.1 \mathrm{ng} / \mathrm{ml}$ for TSH and $0.4 \mathrm{ng} / \mathrm{ml}$ for FSH. The intra- and interassay variation was determined using several pools of rat serum and was less than $11 \%$ for all purchased RIAs and less than $9.5 \%$ for all in-house RIAs.

\section{RNA isolation and quantitative real time reverse transcription polymerase chain reaction (qRT-PCR)} For RNA isolation, ovarian tissues were homogenized in liquid nitrogen and total RNA was isolated, using RNeasy columns according to the protocol of the manufacturer (Qiagen, Venlo, The Netherlands). RNA concentration and purity were measured using the Nanodrop spectrophotometer (IsoGen Life Science, Maarsen, The Netherlands); all RNA samples were of high purity. RNA quality was additionally checked on the Experion automated electrophoresis system (Bio-Rad, Veenendaal, The Netherlands).

For qRT-PCR analysis $1 \mu \mathrm{g}$ RNA of all individual samples was used for cDNA synthesis using the iScript cDNA synthesis kit (Bio-Rad). qRT-PCR reactions were performed with iQ SYBR Green Supermix (BioRad) using the MylQ single-colour real-time PCR detection system (Bio-Rad). Individual samples were measured in duplicate. A standard curve using serial dilutions of pooled sample (cDNA from all samples), a negative control without cDNA template, and a negative control without reverse transcriptase (RT) were included in every assay. Only standard curves with efficiency between 90 and $110 \%$ and a correlation coefficient above 0.99 were accepted. Data were normalized against reference genes ribosomal protein S18 (Rps18) and glyceraldehyde 3-phosphate dehydrogenase (Gapdh), which were chosen based on stable gene expression levels (geNorm, Ghent University Hospital, Ghent, Belgium). Primers were designed using the NCBI Primer-Blast (NCBI Web site). Sequences of the primers used and PCR annealing temperatures for each gene are summarized in Table 1.

\section{Statistical analysis}

Data are expressed as mean \pm standard error of the mean (SEM). GraphPad Prism version 5.03 (Graphpad Software, San Diego, CA, USA) was used for statistical analysis. Data were tested for normality using the Shapiro-Wilk test. If normality could be assumed, groups were compared using the Student's $t$ test for equality of means (corrected for equal variances); if normality could not be assumed the Mann-Whitney $U$ test was used. P-values $<0.05$ were considered significantly different. 
Table 1 Sequences of the primers used for qRT-PCR. Genes denoted with an asterisk were used as reference genes for normalization.

\begin{tabular}{|c|c|c|c|}
\hline Gene symbol & Forward primer (5'-->3') & Reverse primer (5'-->3') & $\begin{array}{l}\text { Anealing temp } \\
\left({ }^{\circ} \mathrm{C}\right)\end{array}$ \\
\hline Cat & TTTTCACCGACGAGATGGCA & CTGACTCTCCAGCGACTGTG & 60 \\
\hline Gapdh* & TACCAGGGCTGCCTTCTCTTG & GGATCTCGCTCCTGGAAGATG & 60 \\
\hline Glrx1 & CATAGGCGGATGCAGTGATCT & TGTCAGTATGGGCCTGCCA & 60 \\
\hline Gpx1 & CCGGGACTACACCGAAATGA & TGCCATTCTCCTGATGTCCG & 60 \\
\hline Gpx3 & CCATTCGGCCTGGTCATTCT & GGAGGGCAGGAGTTCTTCAG & 60 \\
\hline Gstm1 & GTTTGCAGGGGACAAGGTCA & TACTCCATTGGGCCAACTTCG & 60 \\
\hline Gstm2 & TACTCCGAATTCCTGGGCAAG & CTTCAGGCCCTCAAACCGAG & 57 \\
\hline Ppargc1 $\alpha$ & GAGAGAGGCAGAAGCAGAAAGC & TCCATCATCCCGCAGATTTACG & 60 \\
\hline $\operatorname{Prdx3}$ & GTGGTTTGGGCCACATGAAC & AGAGACCTCTGAGCGCAATG & 60 \\
\hline Rps18* & TTCAGCACATCCTGCGAGTA & TTGGTGAGGTCAATGTCTGC & 60 \\
\hline Sod1 & AAGAGAGGCATGTTGGAGACC & CGGCCAATGATGGAATGCTC & 60 \\
\hline Sod2 & GGTGGAGAACCCAAAGGAGAG & TGATTAGAGCAGGCGGCAAT & 58 \\
\hline Sod3 & GAGAGCTTGTCAGGTGTGGAA & AGTGCGTGTCGCCTATCTTC & 60 \\
\hline Txn2 & TGCCATTGAGTACGAGGTGT & CAAATGGGTTTCCAGCAGGC & 60 \\
\hline Txnrd1 & AGCTAAGGAGGCAGCCAAAT & TCCAGCCATAGTTGCGTGAG & 60 \\
\hline Txnrd2 & TTTGACCAGCAAATGGCGTC & ACCTGCAGTTGGTTAGTCGG & 60 \\
\hline Ucp2 & TCCAGCCATAGTTGCGTGAG & TCTTGACCACATCAACGGGG & 60 \\
\hline
\end{tabular}

Abbreviations: Cat, catalase; Gapdh, glyceraldehyde-3-phosphate dehydrogenase; Glrx1, glutaredoxin 1; Gpx1, glutathione peroxidase 1; Gpx3, glutathione peroxidase 3; Gstm1, glutathione S-transferase mu 1; Gstm2, glutathione S-transferase mu 2; Ppargc1 $\alpha$, Peroxisome proliferator-activated receptor gamma coactivator 1-alpha; Prdx3, peroxiredoxin 3; Rps18, ribosomal protein S18; Sod1, superoxide dismutase 1; Sod2, superoxide dismutase 2; Sod3, superoxide dismutase 3; Txn2, thioredoxin 2; Txnrd1, thioredoxin reductase 1; Txnrd2, thioredoxin reductase 2; Ucp2, uncoupling protein 2.

\subsection{Results}

\section{$T S H, T_{3}$ and $T_{4}$ hormone concentrations}

To assess the thyroid status of the hypothyroid rats, plasma TSH, total $T_{4}$ and $T_{3}$, and free $T_{3}$ concentrations were determined. Plasma TSH concentration was significantly increased in the hypothyroid group from day 12 to day $120 \mathrm{pp}$ compared with the age-matched controls (Figure 1A). Concomitantly, plasma $\mathrm{T}_{4}$ concentration was significantly lower in the hypothyroid rats (Figure 1B), 
while total plasma $T_{3}$ concentration was reduced by 30 to $50 \%$ in these animals from day $16 \mathrm{pp}$ onward (Figure 1C). Plasma free $\mathrm{T}_{3}$ concentration was reduced by $30-90 \%$ in the hypothyroid rats, depending on the age of the animals (Figure 1D).
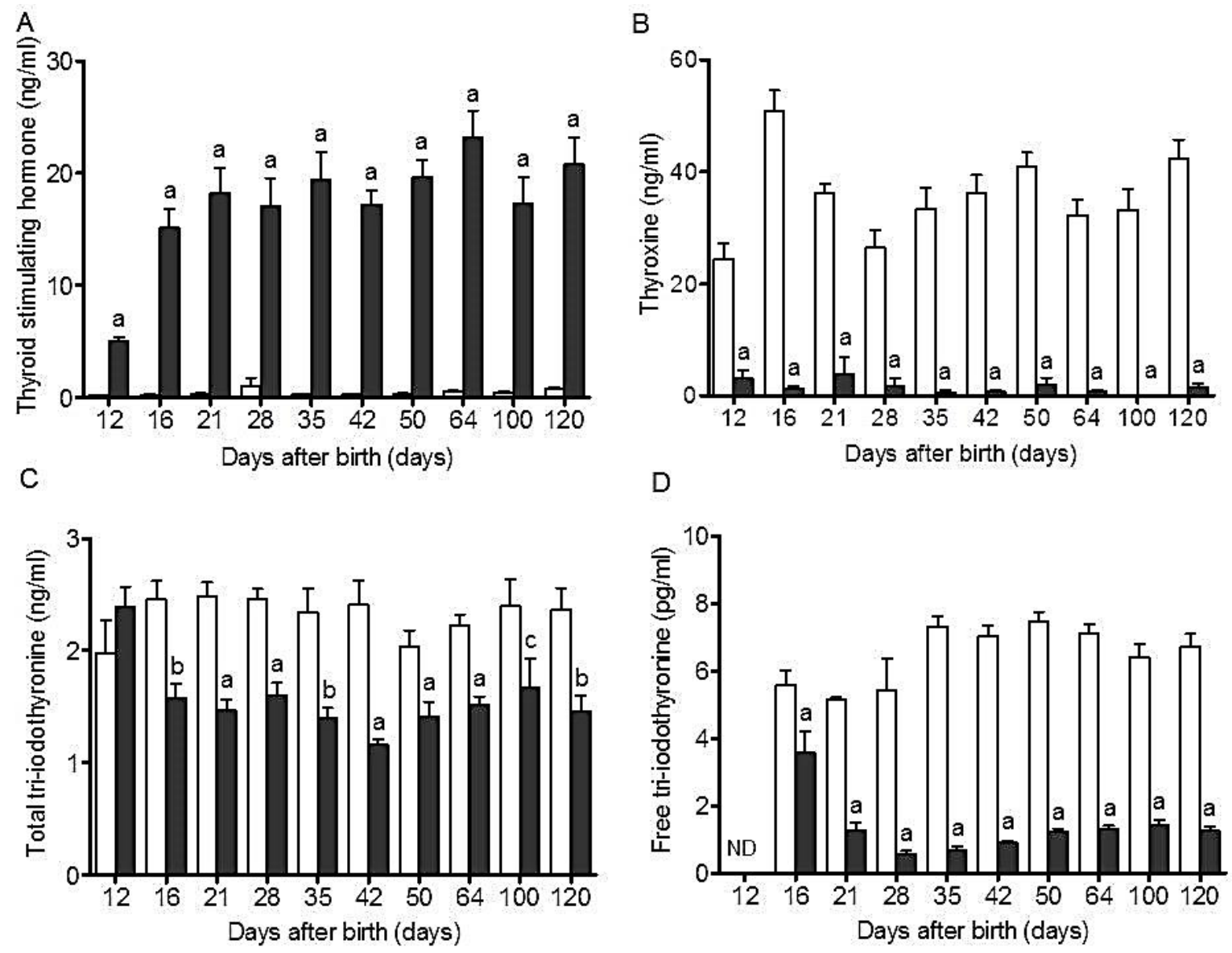

Figure 1. Plasma concentrations of thyroid-stimulating hormone (TSH) (A), thyroxine $\left(T_{4}\right)(B)$, total tri-iodothyronine $\left(T_{3}\right)(C)$ and free $\mathrm{T}_{3}$ (D) were measured in 12- to 120-day-old euthyroid control (open bars) and chronic hypothyroid rats (filled bars). Values represent means \pm SEM; $a-p<0.001 ; b-p<0.01 ; c-p<0.05$ ( $n=7-10$ for 12 - to 64 -days $p p, n=15-20$ for $100-$ to 120-days pp. ND, not determined).

\section{Body and organ weights}

The offspring were fed the control diet or the hypothyroid diet after weaning for up to 120 days pp. Body weight of hypothyroid animals was significantly reduced from day 12 to day 120 after birth, compared with the age-matched control rats (Figure $2 \mathrm{~A}$ ). Wet ovarian weights were significantly decreased in the hypothyroid animals from day $21 \mathrm{pp}$ onward (Figure 2B).

Dietary induced hypothyroidism did not seem to affect the liver in the way PTU administration does, as no difference in liver weigh/body weight ratios were observed between ethyroid control animals and hypothyroid animals at the age of 120 days pp. Histological analysis of the liver tissues also did not show any abnormalities in the livers of the hypothyroid animals compared to the euthyroid controls (data not shown). 
A

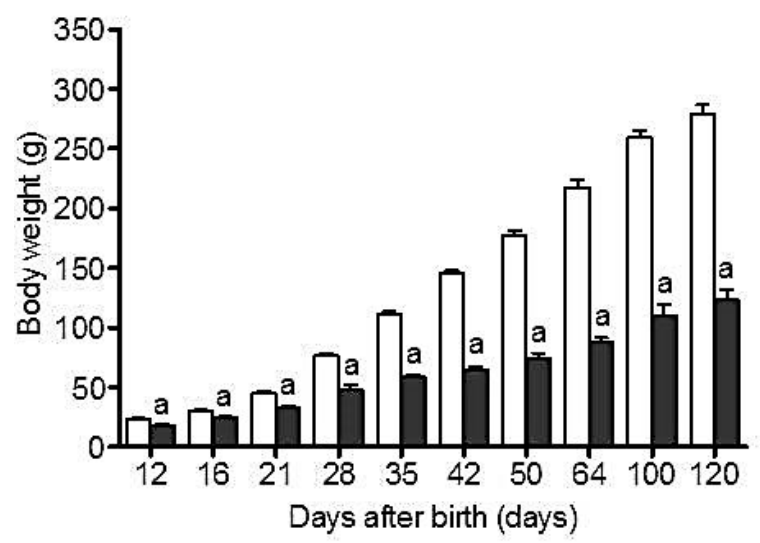

B

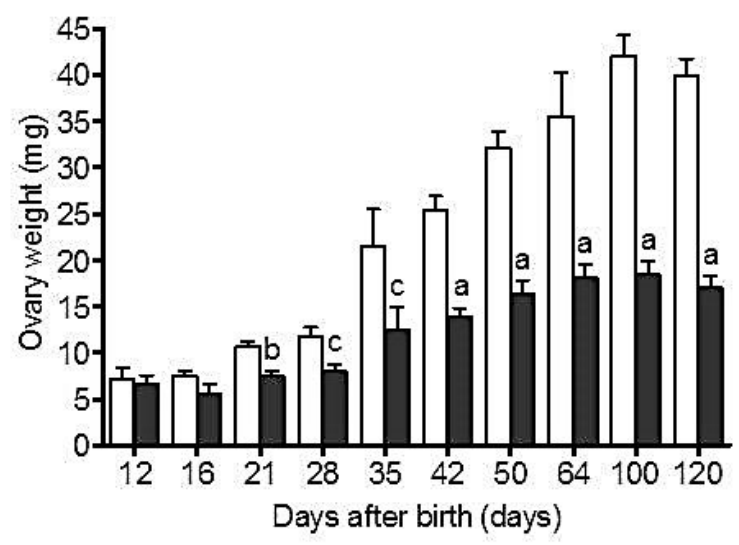

Figure 2. Body weight ( $\mathrm{A}$ ) and ovarian weight (B) of euthyroid control (open bars) and chronic hypothyroid rats (filled bars) aged 12 to 120 days. Values represent means \pm SEM; $a-p<0.001 ; b-p<0.01 ; c-p<0.05$ ( $n=7-10$ for ages 12 - to 64-days $p p$, $\mathrm{n}=15$-20 for ages 100- to 120-days pp).

\section{Puberty onset}

To assess the effect of hypothyroidism on the onset of puberty, the age of vaginal opening as a marker of puberty onset was checked. The age of vaginal opening ranged from 31 to 40 days (33.32 \pm $0.71, n=14)$ and from 33 to 39 days $(34.23 \pm 0.40, n=13)$ in control and hypothyroid female rats respectively.

As leptin plays an important role in the onset of puberty in females and plasma leptin concentrations are directly related to body fat mass [41], total body fat content and plasma leptin concentration were determined. Despite the significantly lower body weights of the hypothyroid animals, the percentage of body fat mass was significantly higher in these animals at the ages of 21, 28 and 42 days (Figure $3 \mathrm{~A}$ ). At the other ages analysed, a trend was visible when compared to the age-matched controls (Figure $3 \mathrm{~A}$ ). Total body fat mass per animal was not different between the hypothyroid females and controls up the onset of puberty, despite the lower body weight of the hypothyroid rats (Figure 2A, 3B). In line with this observation, plasma leptin concentrations were significantly higher in the hypothyroid animals at the age of 21 and 28 days, the day of weaning, while a trend was observed at most other ages (Figure 3C).
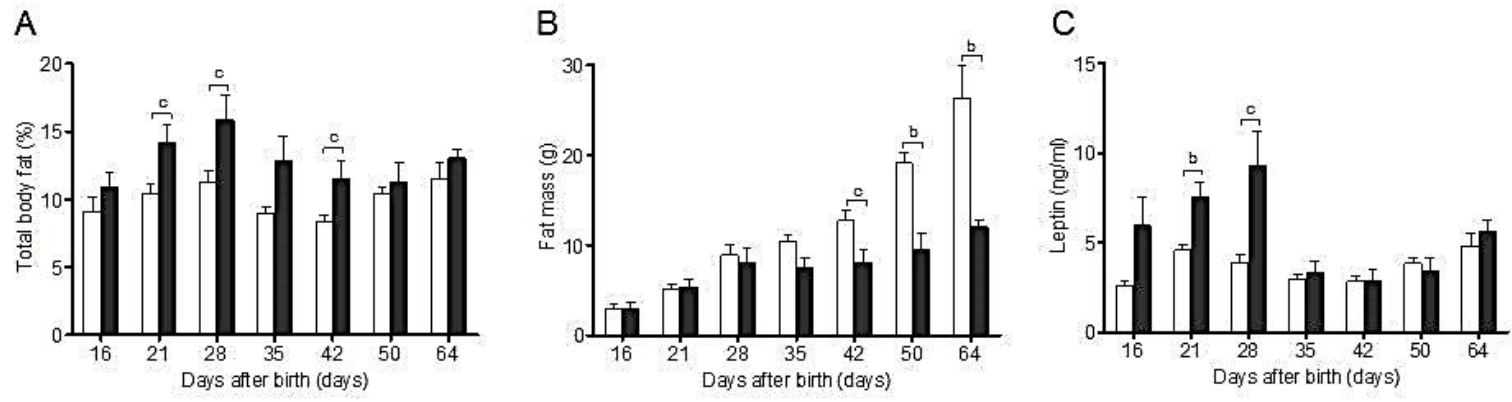

Figure 3. Body fat mass expressed as percentage of body weight (A), absolute body fat mass per animal (B), and plasma leptin concentration $(C)$ in euthyroid control (open bars) and hypothyroid rats (filled bars) from 16- to 64-days pp. Values represent means \pm SEM; $b-p<0.01 ; c-p<0.05(n=7-8)$. 


\section{Plasma FSH and LH concentrations}

No difference could be detected in plasma FSH (Figure 4A) and LH (Figure 4B) concentrations between the hypothyroid rats and the age-matched control animals, except at the age of 64 days when LH concentration in the hypothyroid group were significantly higher, while FSH concentration showed a trend for increase. This implicates that in contrast to the other animals, most of the rats in this age group were presumably killed around the time of the proestrous LH surge.

A

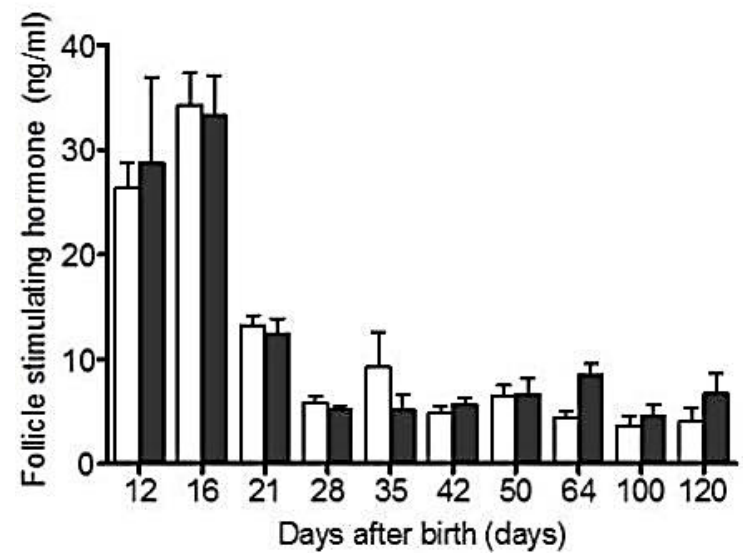

B

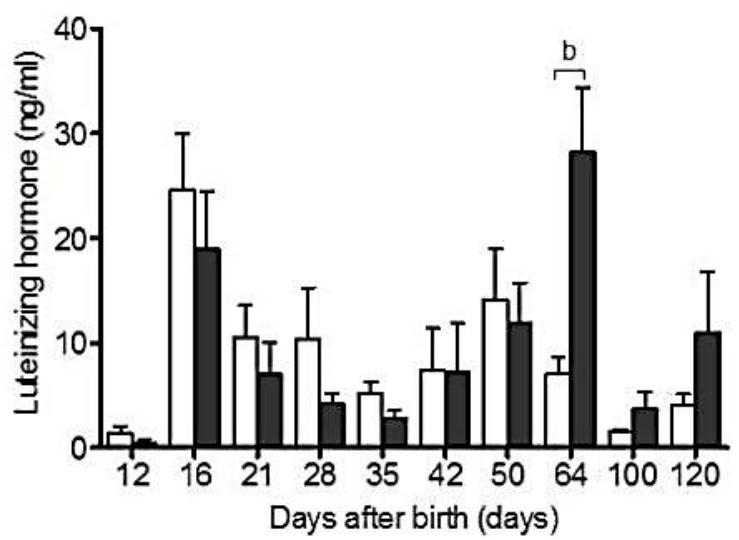

Figure 4. Plasma concentrations of follicle stimulating hormone (FSH) (A) and luteinizing hormone (LH) (B) in euthyroid control (open bars) and chronic hypothyroid rats (filled bars) aged 12- to 120-days. Values represents means \pm SEM; $b$ $p<0.01$ ( $n=7-10$ for ages 12 - to 64 -days $p p, n=15-20$ for ages 100 - to 120 -days $p p$ ).

\section{Follicular development}

To obtain more insight in the role of TH in ovarian follicle development, the total number of follicles per ovary was determined in 12-day-old (prepubertal), 64-day-old and 120-day-old (adult) hypothyroid rats and compared to age-matched controls.

In 12-day-old hypothyroid rats the number of primordial follicles was not different from the agematched control animals (supplemental Figure 1), suggesting that the presence of a hypothyroid condition during pregnancy did not affect the formation of the resting pool of primordial follicles in its offspring. Neither did chronic hypothyroidism affect the recruitment of primordial follicles into the growing pool as at the age of 120 days there continued to be no difference in the number of primordial follicles between hypothyroid and control animals (supplemental Figure 1).

No difference was detected in ovarian preantral and antral follicle numbers between hypothyroid and control rats at the age of 12 days (Figure 5A, 5D). In contrast, after puberty at the ages of 64 and 120 days, the number of preantral and antral follicles was significantly lower in the hypothyroid ovaries when compared to the respective euthyroid control groups (Figure 5B, 5C, 5E, 5F). Concomitantly, the percentage of atretic follicles was significantly higher in the hypothyroid ovaries compared to the age-matched controls (Figure 5G, 5H). In line with these observations, it seems likely that the number of ovulating follicles was reduced in the hypothyroid post-pubertal animals as depicted by a significant reduction in the number of corpora lutea per ovary (Figure $5 \mathrm{I}, 5 \mathrm{~J}$ ). This assumption is further supported by the fact that we did not find indications that estrous cycle length 
was influenced by the hypothyroid condition. The reduced number of (pre)antral follicles and CLs in the hypothyroid females is likely responsible for the reduced ovarian weight observed in Figure 2.

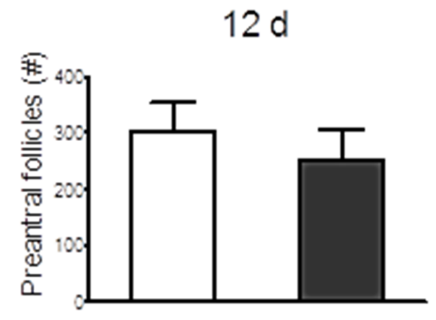

$12 d$

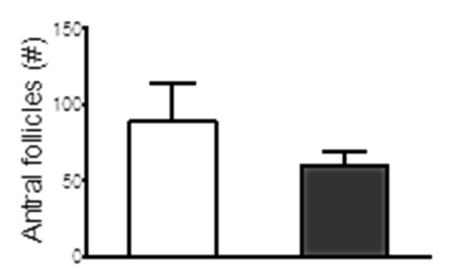

N.D

N.D
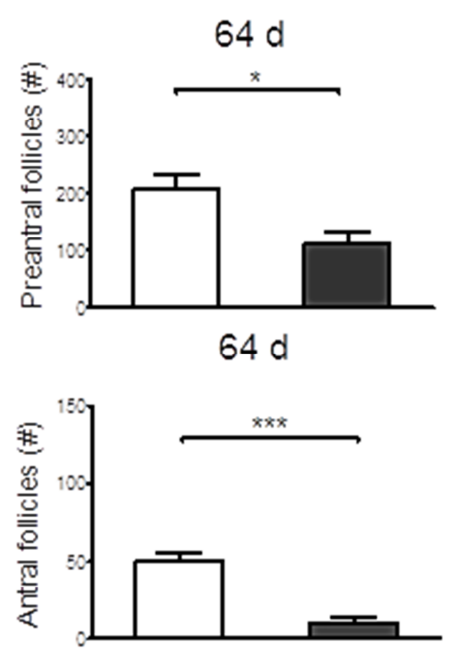

$64 d$

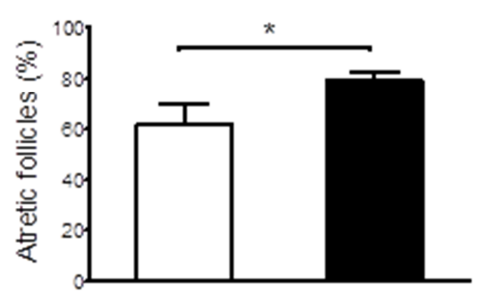

$64 d$

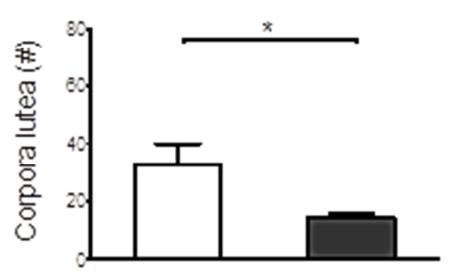

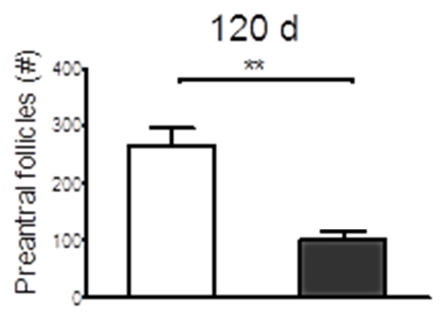

$120 \mathrm{~d}$

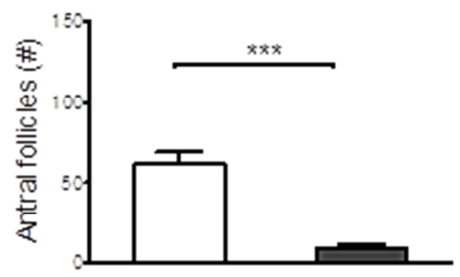

$120 \mathrm{~d}$

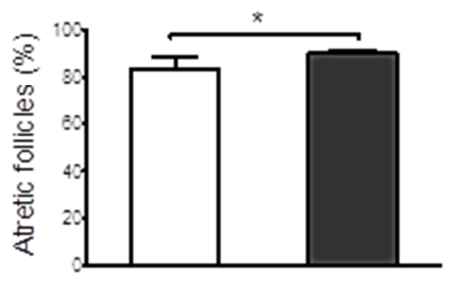

$120 d$

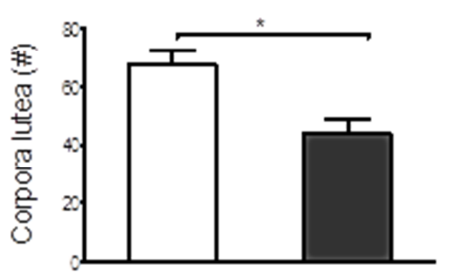

Figure 5. Effects of chronic hypothyroidism initiated in the foetal/neonatal period on postnatal ovarian follicular development. Total numbers of preantral (A-C) and antral (D-F) follicles per ovary in 12- (A, D), 64- (B, E) and 120-day-old (C, F) euthyroid control (open bars) and hypothyroid (filled bars) rats; (G, H) Percentages of atretic follicles in 64- and 120-dayold euthyroid control (open bars) and hypothyroid (filled bars) rats; I, J) Total number of copora lutea per ovary in euthyroid (open bars) and hypothyroid (filled bars) rats. Values represent means $\pm S E M ;{ }^{*}, p<0.05 ;{ }^{* *}, p<0.01 ; * * *, p<0.001 . n=4-5$.

\section{Hypothyroid-related alterations in antioxidant gene expression and protein content}

Quantitative real-time RT-PCR was used to measure ovarian mRNA content of antioxidant genes Cat, Glrx1, Gpx1, Gpx3, Gstm1, Gstm2, Prdx3, Sod1, Sod2, Sod3, Txn2, Txnrd1, Txnrd2 and uncoupling protein 2 (Ucp2) in the ovaries of 120-day-old hypothyroid and euthyroid rats. These antioxidant genes were selected based on reported ovarian antioxidant gene expression [27]. Peroxisome proliferator-activated receptor gamma coactivator 1 alpha (Ppargc1 $\alpha$ ), an important regulator of mitochondrial biogenesis, was taken along as a marker for mitochondrial biogenesis. The mRNA content of the cytosolic antioxidant enzyme Sod1 was significantly higher in the hypothyroid group (Figure 6A, Supplemental Figure 3). In contrast, the mRNA content of the cytosolic antioxidant genes 
Cat, Txnrd1, and the mitochondrial antioxidant enzyme $\operatorname{Prdx} 3$ was significantly lower in the hypothyroid group, as was the content of the mitochondrial protein Ucp2 (Figure 6A, Supplemental Figure 3). mRNA content of the cytosolic antioxidant enzymes Gpx3 and Gstm2 showed a downward trend in the hypothyroid group compared to the control group.

In line with the gene expression of Sod1 and Cat, the protein amount of SOD1 was significantly higher while CAT amount was significantly lower in the ovaries of hypothyroid rats. (Figure 6B-6E). No difference was detected in MRNA and protein amount of mitochondrial SOD2 between hypothyroid and control rats (Figure 6A, Supplemental Figure 2A, B). Mitochondrial biogenesis was not influenced by the hypothyroid condition as Ppargc1 $\alpha$ mRNA expression was unaffected and the protein amount of COX IV, a marker of mitochondrial density [42], was comparable between hypothyroid and control rats (Supplemental Figure 2A, C).

In order to investigate whether alterations in ovarian antioxidant gene and protein expression under chronic hypothyroid conditions were related to oxidative stress, the presence of 4-hydroxynonenal (4-HNE), an $\alpha, \beta$-unsaturated hydroxyalkenal produced by lipid peroxidation in cells during oxidative stress [43] was investigated. Immunohistochemical staining for 4-HNE in ovaries of 120-day-old euthyroid control animals was weak to absent (Figure 6F, H). In contrast, moderate to strong staining was observed in the hypothyroid ovaries in theca cells of atretic follicles, stroma cells and corpora lutea, indicative of the presence of oxidative stress (Figure 6G, I).

\subsection{Discussion}

The results of the present study show that continuous hypothyroidism, initiated in utero, results in lower preantral and antral follicle numbers in adulthood and a concomitant higher percentage of atretic follicles when compared to euthyroid age-matched control animals. Beside increased follicular atresia, the reduced follicle numbers may also be explained by a slower growth of the follicles. Consequently, the number of ovulating follicles per estrous cycle is lower in the hypothyroid females. At the age of 120 days pp the ovarian mRNA and protein content of SOD1, a cytosolic producer of reactive $\mathrm{H}_{2} \mathrm{O}_{2}$, is elevated under hypothyroid conditions, while the expression of the antioxidant genes Cat, Txnrd1 and Prdx3, all involved in the conversion of $\mathrm{H}_{2} \mathrm{O}_{2}$ to water (ROS inactivation), is lowered when compared to the expression in euthyroid controls. Concomitantly, lipid peroxidation, a marker of oxidative stress, seems to be enhanced in the hypothyroid ovaries. These results together suggest that chronic hypothyroidism is associated with a disturbance in redox balance in the ovary leading to oxidative damage and an increased level of follicular atresia. This may negatively impact ovulation rate and female fertility, although time resolved analysis is required to conclusively establish cause and consequence.

Surprisingly, the continuous hypothyroid rats entered puberty at the same age as the euthyroid control animals, despite their reduced body weight. This may be explained by the normal to elevated body fat mass and plasma leptin concentrations of the hypothyroid rats. Leptin acts as a permissive factor for puberty onset in rodents and humans $[41,44,45]$. Mice deficient in leptin (ob/ob mice) do 

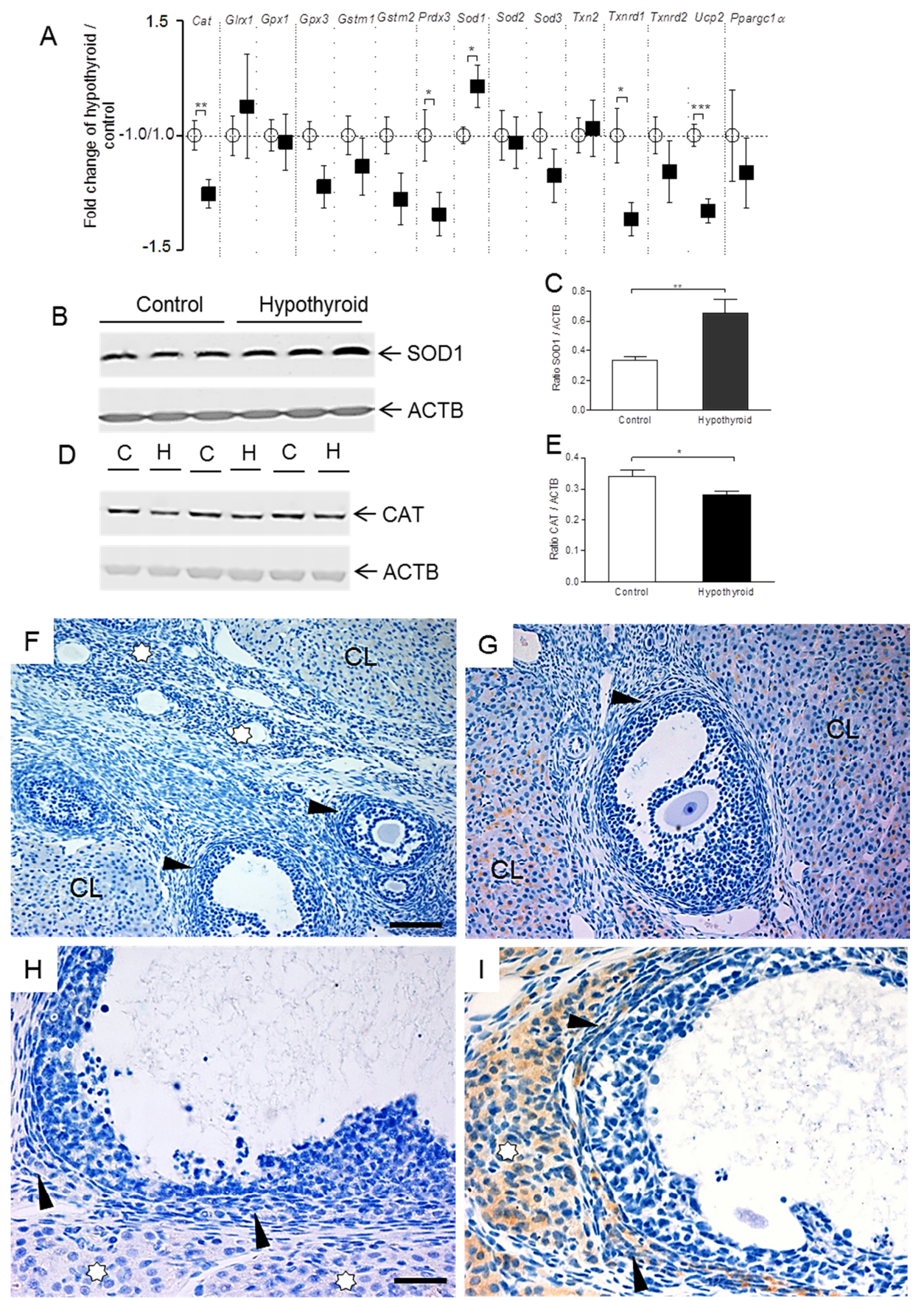

Figure 6. A). Relative gene expression in ovarian tissue of 120-day-old euthyroid control (open circles, $n=11-12$ ) and hypothyroid (filled squares, $n=11$ ) rats as measured by qRT-PCR. Gene expression is calculated as fold change of hypothyroid rats over euthyroid control rats. Gene expression in euthyroid controls was set to 1 for up regulated genes and -1 for down regulated genes. Antioxidant genes: Cat, catalase; Glrx1, glutaredoxin 1; Gpx1, glutathione peroxidase 1; Gpx3, glutathione peroxidase 3 ( $p=0.08$ ); Gstm1, glutathione S-transferase mu 1; Gstm2, glutathione S-transferase mu 2 ( $p=0.07$ ); $\operatorname{Prdx3}$, peroxiredoxin 3; Sod1, superoxide dismutase 1; Sod2, superoxide dismutase 2; Sod3, superoxide dismutase 3; Txn2, thioredoxin 2; Txnrd1, thioredoxin reductase 1; Txnrd2, thioredoxin reductase 2; Ucp2, uncoupling protein 2. Mitochondrial biogenesis and activity gene: Ppargc1 $\alpha$, Peroxisome proliferator-activated receptor gamma coactivator 1-alpha. B-E) Western blot data for SOD1 (B, C) and CAT (D, E) (C, control group $(n=6) ; H$, hypothyroid group $(n=6))$. Protein abundance is indicated as ratio over Actb; F-I) Representative pictures of 4-HNE immune staining (brown) a marker for oxidative stress in the ovary of euthyroid control $(F, H)$ and hypothyroid $(G, I)$ rats. Staining is faint to absent in the ovary of euthyroid control animals, while moderate to strong staining is present in remnants of atretic follicles (white asterisks), theca cells (arrowheads) and corpus luteum (CL), indicative of oxidative stress. Scale bars represent $50 \mu \mathrm{m}(\mathrm{F}, \mathrm{G})$ and $25 \mu \mathrm{m}(\mathrm{H}, \mathrm{I})$. $*, p<0.05 ; * *, p<0.01 ; * *, p<0.001$ 
not enter puberty unless supplied with leptin [46-47]. The normal start of puberty in the hypothyroid rats in the present study is in contrast to a previous report by Dijkstra et al [17] who showed that chronic neonatal hypothyroid female rats failed to enter puberty. In line with Dijkstra et al, Tamura and colleagues suggested that the absence of first preovulatory LH surge in hypothyroid rats accounted for the failure of entering puberty [48]. An explanation for these contradictory observations might be found in the different ways of inducing hypothyroidism. Dijkstra et al. [17] used PTU, which reduces TH synthesis by influencing thyroperoxidase, an enzyme critical in the synthesis of TH. Furthermore, PTU influences deiodinase type 1, the enzyme responsible for deiodination of both the phenolic and tyrosyl ring of TH metabolites [49]. Sodium perchlorate, however, influences the uptake of iodide by the thyrocytes through interaction with the sodium iodide symporter [50]. For the study by Tamura et al. [48] rats were thyroidectomised, resulting in a more severe hypothyroid condition compared to the present dietary intervention.

The chronic hypothyroid condition has no influence on the establishment of the primordial follicle pool in the foetal/neonatal period, but does influence the growth of recruited follicles. At the ages of 64 and 120 days pp, despite normal plasma FSH concentrations the number of preantral and antral follicles is significantly reduced in the hypothyroid rat ovaries when compared to the respective euthyroid control group. At the same time, the percentage of atretic follicles is significantly higher. These data suggest that $T_{3}$ may facilitate the effects of FSH on follicular development. Support for this hypothesis comes from in vitro studies which show that $\mathrm{T}_{3}$ alone does not affect follicle growth, but when applied in combination with FSH can amplify the effects of FSH on preantral follicle growth through up-regulation of FSH receptors [12]. $\mathrm{T}_{3}$ has further been shown to potentiate granulosa cell survival by inhibiting apoptosis and promoting cell proliferation when added together with FSH [13].

The reduction in the number of antral follicles and CLs is more striking than the increase in the percentage of atretic follicles. This apparent discrepancy can be explained by the fact that at 64 and $120 \mathrm{dpp}$ total ovarian follicle numbers were calculated based on counting every fifth ovarian section, while follicular atresia is expressed as percentage based on the counting of 3 sections at a quarter, half and three quarters of the ovary, to exclude double counting of the same atretic structure. Especially the late stages of atresia are difficult to follow in successive ovarian sections. Total ovarian follicle and $\mathrm{CL}$ numbers can therefore not be related directly to the percentage of atretic follicles.

Several studies have reported that THs beside playing an essential role in energy metabolism, can affect reactive oxygen metabolism by influencing antioxidant enzyme expression [51]. In the present study, SOD1 mRNA and protein concentrations are significantly higher in the hypothyroid rats, indicative of increased amounts of $\mathrm{H}_{2} \mathrm{O}_{2}$ formed in the cytoplasm. In contrast CAT mRNA and protein concentrations are significantly lower in the hypothyroid group. CAT can convert $\mathrm{H}_{2} \mathrm{O}_{2}$ into water in the cytoplasm of cells and in this manner plays an important role in the prevention of follicular apoptosis [23, 52]. In line with this, Das and Chainy [53] observed that TH deficiency induces the formation of increasing amounts of $\mathrm{H}_{2} \mathrm{O}_{2}$ in hepatocytes due to SOD over-activity and a concomitant decrease in CAT activity. Further support for the assumed increase in $\mathrm{H}_{2} \mathrm{O}_{2}$ comes from the observation that Txnrd1 mRNA content is significantly lower in the hypothyroid group, while Gpx3 mRNA content shows a clear downward trend). GPX3, like CAT, is involved in the neutralization of $\mathrm{H}_{2} \mathrm{O}_{2}$, reducing the effects of free radicals on cell function [54], while TXNRD1 maintains cytoplasmic TXN1 in a reduced state [55]. Finally, PRDX3 is a major regulator of mitochondrial $\mathrm{H}_{2} \mathrm{O}_{2}$ concentration 
and apoptosis [28]. Significant reduction in the mRNA content of this mitochondrion-specific $\mathrm{H}_{2} \mathrm{O}_{2}$ scavenging enzyme in the hypothyroid ovaries offers further support to the assumed increase in $\mathrm{H}_{2} \mathrm{O}_{2}$ production. To exclude the possibility that decreased expression of $\mathrm{Prdx} 3$ in hypothyroid ovaries was caused by a change in mitochondrial numbers, Ppargc1 $\alpha$ and COXIV, markers for mitochondrial biogenesis and density, respectively, were studied. The absence of a significant difference in mRNA expression of Ppargc1 $\alpha$ and protein content of COX IV indicates that mitochondrial numbers in the ovarian cells are not affected by hypothyroidism.

As indicated above, the changes in the expression of the antioxidant enzymes and proteins all point to an increased $\mathrm{H}_{2} \mathrm{O}_{2}$ production and a decreased degradation, suggestive of increased oxidative damage in ovarian cells. In vitro studies have shown that oxidative stress caused by exogenous $\mathrm{H}_{2} \mathrm{O}_{2}$ could induce apoptosis in granulosa cells [57]. Although we could not assess the cellular $\mathrm{H}_{2} \mathrm{O}_{2}$ content in vivo directly, the suggestion of increased oxidative stress is supported by immunohistochemical staining for 4-HNE. 4-HNE is a marker of oxidative stress, being a product of lipid hydrogen peroxide decomposition [43]. 4-HNE can affect membrane fluidity and activity of membrane-bound enzymes and cellular signaling pathways [43]. 4-HNE has also been shown to modify mitochondrial proteins, resulting in mitochondrial dysfunction [56]. Moderate to strong 4-HNE staining is observed in the ovaries of chronic hypothyroid rats group compared to the euthyroid control group, suggesting that chronic hypothyroidism leads to increased lipid peroxidation in the rat ovary. This assumption is supported by the observation that the mRNA content of Gstm2, which plays a role in the protection against lipid peroxidation, tended to decrease. These results are further consistent with studies in spleen and brain where hypothyroidism also induced increased lipid peroxidation [58, 59].

Under normal euthyroid conditions there are no indications that follicular atresia leads to increased lipid peroxidation, as studies in the bovine have shown that there is no difference in lipid peroxidation between healthy antral follicles and atretic antral follicles, and thus that lipid peroxidation does not play a role in follicular atresia under normal control conditions [60]. In support of these observations a more recent study in rats has shown that under normal euthyroid conditions the rate of lipid peroxidation in the ovary is low [61]. Thus, although lipid peroxidation does occur in the euthyroid ovary, levels are low and do not increase in case of follicular atresia. This low level of lipid preroxidation under normal euthyroid conditions, is therefore presumably responsible for the faint to absent 4-HNE staining in the euthyroid control ovaries in the present study.

While the main function of UCP2 is traditionally attributed to energy dissipation and body weight regulation, UCP2, as a non-enzymatic antioxidant, has subsequently been shown to have an important role in the regulation of ROS production $[62,63]$. Disruption of UCP2 expression can lead to increased ROS production. The reduced mRNA expression of Ucp2 in the hypothyroid ovaries, further strengthens therefore the hypothesis that the reduced follicle numbers and increased percentage of atresia are associated with increased oxidative damage.

In conclusion, the results show that continuous hypothyroidism initiated in the foetal/neonatal period results in lower growing follicle numbers in adulthood and a concomitant higher percentage of atretic follicles when compared to euthyroid age-matched control rats. Furthermore, continuous hypothyroidism disturbs anti-oxidant gene expression, which is associated with oxidative damage at the age of 120 days pp, offering a possible explanation for effects observed in the ovary of chronic hypothyroid rats. 


\section{Acknowledgements}

The authors would like to thank graduate students Jewa Reichart, Marieke van Meijl, Isolde van der Vaart and Annemarie Nieboer for their contribution to this research project. The practical support by dr. Vincent de Boer and Rudie Koopmanschap is greatly appreciated. 


\subsection{References}

1. Pearce EN. Thyroid dysfunction in perimenopausal and postmenopausal women. Menopause Int 2007; 13:8-13.

2. Vanderpas J. Nutritional epidemiology and thyroid hormone metabolism. Annu Rev Nutr 2006; 26:293-322.

3. Vissenberg R, Manders VD, Mastenbroek S, Fliers E, Afink GB, Ris-Stalpers C, Goddijn M, Bisschop PH. Pathophysiological aspects of thyroid hormone disorders/thyroid peroxidase autoantibodies and reproduction. Hum Reprod Update 2015; 21:378-387.

4. Abalovich M, Mitelberg L, Allami C, Gutierrez S, Alcaraz G, Otero P, Levalle O. Subclinical hypothyroidism and thyroid autoimmunity in women with infertility. Gynecol Endocrinol 2007; 23:279-283.

5. Joshi JV, Bhandarkar SD, Chadha M, Balaiah D, Shah R. Menstrual irregularities and lactation failure may precede thyroid dysfunction or goitre. J Postgrad Med 1993; 39:137-141.

6. Krassas GE, Pontikides N, Kaltsas T, Papadopoulou P, Paunkovic J, Paunkovic N, Duntas LH. Disturbances of menstruation in hypothyroidism. Clin Endocrinol (Oxf) 1999; 50:655-659.

7. Dorrington J, Chuma AV, Bendell JJ. Transforming growth factor beta and follicle-stimulating hormone promote rat granulosa cell proliferation. Endocrinology 1988; 123:353-359.

8. Teerds KJ, Dorrington JH. Immunohistochemical localization of transforming growth factor-beta-1 and factorbeta-2 during follicular development in the adult-rat ovary. Mol Cell Endocrinol 1992; 84:R7-R13.

9. Danilovich N, Wernsing D, Coschigano KT, Kopchick JJ, Bartke A. Deficits in female reproductive function in GH-RKO mice; role of IGF-I. Endocrinology 1999; 140:2637-2640.

10. Almog B, Gold R, Tajima K, Dantes A, Salim K, Rubinstein M, Barkan D, Homburg R, Lessing JB, Nevo N, Gertler A, Amsterdam $A$. Leptin attenuates follicular apoptosis and accelerates the onset of puberty in immature rats. Mol Cell Endocrinol 2001; 183:179-191.

11. Lagaly DV, Aad PY, Grado-Ahuir JA, Hulsey LB, Spicer LJ. Role of adiponectin in regulating ovarian theca and granulosa cell function. Mol Cell Endocrinol 2008; 284:38-45.

12. Kobayashi N, Orisaka M, Cao M, Kotsuji F, Leader A, Sakuragi N, Tsang BK. Growth differentiation factor-9 mediates follicle-stimulating hormone-thyroid hormone interaction in the regulation of rat preantral follicular development. Endocrinology 2009; 150:5566-5574.

13. Zhang C, Guo L, Zhu B, Feng Y, Yu S, An N, Wang X. Effects of 3, 5, 3'-triiodothyronine (t3) and follicle stimulating hormone on apoptosis and proliferation of rat ovarian granulosa cells. Chin J Physiol 2013; 56:298-305.

14. Krassas GE, Poppe K, Glinoer D. Thyroid Function and Human Reproductive Health. Endoc Rev 2010; 31:702-755.

15. Soliman FA, Reineke EP. Influence of Variations in Environmental Temperature and Thyroid Status on Sexual Function in Young Female Mice. Am J Physiol 1952; 168:400-405.

16. Rivkees SA, Mattison DR._Propylthiouracil (PTU) hepatoxicity in children and recommendations for discontinuation of use. Int J Pediatr Endocrinol 2009; doi: 10.1155/2009/132041. Epub 2009 Apr 21.

17. Dijkstra G, de Rooij DG, de Jong FH, van den Hurk R. Effect of hypothyroidism on ovarian follicular development, granulosa cell proliferation and peripheral hormone levels in the prepubertal rat. Eur J Endocrinol 1996; 134:649654.

18. Fedail JS, Zheng K, Wei Q, Kong L, Shi F. Roles of thyroid hormones in follicular development in the ovary of neonatal and immature rats. Endocrine 2014; 46:594-604.

19. Rijntjes E, Swarts HJM, Anand-Ivell R, Teerds KJ. Prenatal induced chronic dietary hypothyroidism delays but does not block adult-type Leydig cell development. Am J Physiol Endocol Metab 2009; 296:E305-E314.

20. Zuo L, Zhou T, Pannell BK, Ziegler AC, Best TM. Biological and physiological role of reactive oxygen species--the good, the bad and the ugly. Acta Physiol (Oxf) 2015; 214:329-348.

21. Takami M, Preston SL, Toyloy VA, Behrman HR. Antioxidants reversibly inhibit the spontaneous resumption of meiosis. Am J Physiol 1999; 276:E684-688.

22. Behrman HR, Kodaman PH, Preston SL, Gao S. Oxidative stress and the ovary. J Soc Gynecol Investig 2001; 8:S4042. 
23. Ruder EH, Hartman TJ, Blumberg J, Goldman MB. Oxidative stress and antioxidants: exposure and impact on female fertility. Hum Reprod Update 2008; 14:345-357.

24. Sato EF, Kobuchi H, Edashige K, Takahashi M, Yoshioka T, Utsumi K, Inoue M. Dynamic aspects of ovarian superoxide dismutase isozymes during the ovulatory process in the rat. FEBS Lett 1992; 303:121-125.

25. Hsieh CH, Tsai SP, Yeh HI, Sheu TC, Tam MF. Mass spectrometric analysis of rat ovary and testis cytosolic glutathione S-transferases (GSTs): identification of a novel class-alpha GST, rGSTA6*, in rat testis. Biochem J 1997; 323 ( Pt 2):503-510.

26. Osborne LJ, Tonissen KF, Tang VHM, Clarke FM. Expression and localisation of thioredoxin in mouse reproductive tissues during the oestrous cycle. Mol Reprod Dev 2001; 58:359-367.

27. Lim J, Luderer U. Oxidative damage increases and antioxidant gene expression decreases with aging in the mouse ovary. Biol Reprod 2011; 84:775-782.

28. Chang TS, Cho CS, Park S, Yu S, Kang SW, Rhee SG. Peroxiredoxin III, a mitochondrion-specific peroxidase, regulates apoptotic signaling by mitochondria. J Biol Chem 2004; 279:41975-41984.

29. Jena S, Chainy GB, Dandapat J. Hypothyroidism modulates renal antioxidant gene expression during postnatal development and maturation in rat. Gen Comp Endocrinol 2012; 178:8-18.

30. Sahoo DK, Roy A, Bhanja S, Chainy GB. Hypothyroidism impairs antioxidant defence system and testicular physiology during development and maturation. Gen Comp Endocrinol 2008; 156:63-70.

31. Reeves PG, Nielsen FH, Fahey GC, Jr. AIN-93 purified diets for laboratory rodents: final report of the American Institute of Nutrition ad hoc writing committee on the reformulation of the AIN-76A rodent diet. J Nutr 1993; 123:1939-1951.

32. Schroder-van der Elst JP, van der Heide D, Morreale de Escobar G, Obregon MJ. lodothyronine deiodinase activities in fetal rat tissues at several levels of iodine deficiency: a role for the skin in 3,5,3'-triiodothyronine economy? Endocrinology 1998; 139:2229-2234.

33. Slot KA, Kastelijn J, Bachelot A, Kelly PA, Binart N, Teerds KJ. Reduced recruitment and survival of primordial and growing follicles in $\mathrm{GH}$ receptor-deficient mice. Reproduction 2006; 131:525-532.

34. Flaws JA, Abbud R, Mann RJ, Nilson JH, Hirshfield AN. Chronically elevated luteinizing hormone depletes primordial follicles in the mouse ovary. Biol Reprod 1997; 57:1233-1237.

35. Hoevenaars FP, Keijer J, Herreman L, Palm I, Hegeman MA, Swarts HJ, van Schothorst EM. Adipose tissue metabolism and inflammation are differently affected by weight loss in obese mice due to either a high-fat diet restriction or change to a low-fat diet. Genes Nutr 2014; 9:391.

36. Zeinoaldini S, Swarts JJ, Van de Heijning BJ. A signaling role for leptin in puberty onset in female rats? J Pediatr Endocrinol Metab 2006; 19:1239-1247.

37. Kus V, Prazak T, Brauner P, Hensler M, Kuda O, Flachs P, Janovska P, Medrikova D, Rossmeisl M, Jilkova Z, Stefl B, Pastalkova $\mathrm{E}$, et al. Induction of muscle thermogenesis by high-fat diet in mice: association with obesity-resistance. Am J Physiol Endocrinol Metab 2008; 295:E356-367.

38. Mattheij JA, Swarts JJ, Lokerse P, van Kampen JT, Van der Heide D. Effect of hypothyroidism on the pituitarygonadal axis in the adult female rat. J Endocrinol 1995; 146:87-94.

39. Palm IF, van der Beek EM, Wiegant VM, Buijs RM, Kalsbeek A, Palm IF, van der Beek EM, Swarts HJ, van der Vliet J, Wiegant VM, Buijs RM, Kalsbeek A. The stimulatory effect of vasopressin on the luteinizing hormone surge in ovariectomized, estradiol-treated rats is time-dependent. Brain Res 2001; 901:109-116.

40. Palm IF, van der Beek EM, Swarts HJ, van der Vliet J, Wiegant VM, Buijs RM, Kalsbeek A. Control of the estradiolinduced prolactin surge by the suprachiasmatic nucleus. Endocrinology 2001; 142:2296-2302.

41. Elias CF. Leptin action in pubertal development: recent advances and unanswered questions. Trends Endocrin Met 2012; 23:9-15.

42. Nisoli E, Clementi E, Paolucci C, Cozzi V, Tonello C, Sciorati C, Bracale R, Valerio A, Francolini M, Moncada S, Carruba MO. Mitochondrial biogenesis in mammals: the role of endogenous nitric oxide. Science 2003; 299:896899.

43. Ullery JC, Marnett LJ. Protein modification by oxidized phospholipids and hydrolytically released lipid electrophiles: Investigating cellular responses. Biochim Biophys Acta 2012; 1818:2424-2435. 
44. Cheung CC, Thornton JE, Kuijper JL, Weigle DS, Clifton DK, Steiner RA. Leptin is a metabolic gate for the onset of puberty in the female rat. Endocrinology 1997; 138:855-858.

45. Farooqi IS, Matarese G, Lord GM, Keogh JM, Lawrence E, Agwu C, Sanna V, Jebb SA, Perna F, Fontana S, Lechler RI, DePaoli AM, et al. Beneficial effects of leptin on obesity, $T$ cell hyporesponsiveness, and neuroendocrine/metabolic dysfunction of human congenital leptin deficiency. J Clin Invest 2002; 110:1093-1103.

46. Mounzih K, Lu RH, Chehab FF. Leptin treatment rescues the sterility of genetically obese ob/ob males. Endocrinology 1997; 138:1190-1193.

47. Faroogi IS. Leptin and the onset of puberty: Insights from rodent and human genetics. Semin Reprod Med 2002; 20:139-144.

48. Tamura K, Hatsuta M, Watanabe G, Taya K, Kogo H. Blockage of gonadotropin-induced first ovulation caused by thyroidectomy and its possible mechanisms in rats. Am J Physiol Endocrinol Metab 1998; 275:E380-385.

49. Rijntjes E, Scholz PM, Mugesh G, Köhrle J. Se- and S- based thiouracil and methimazole analogues exert different inhibitory mechanisms on type 1 and type 2 deiododinases. Eur Thyroid J 2013; 2:252-258

50. Steinmans C, Pearl M, Kharrazi M, Blount BC, Miller MD, Pearce EN, Valentin-Blasinil, DeLorenze G, Hoofnagel AN, Liaw J. Thyroid hormones and moderate exposure to perchlorate during pregnancy in women in Southern California. Environ Health Perspect 2015; PMID:26485730

51. Villanueva I, Alva-Sanchez C, Pacheco-Rosado J. The role of thyroid hormones as inductors of oxidative stress and neurodegeneration. Oxid Med Cell Longev 2013 doi.org/10.1155/2013/218145.

52. Behl R, Pandey RS. FSH induced stimulation of catalase activity in goat granulosa cells in vitro. Anim Reprod Sci 2002; 70:215-221.

53. Das K, Chainy GB. Modulation of rat liver mitochondrial antioxidant defence system by thyroid hormone. Biochim Biophys Acta 2001; 1537:1-13.

54. Devine PJ, Perreault SD, Luderer U. Roles of reactive oxygen species and antioxidants in ovarian toxicity. Biol Reprod 2012; 86:27, 1-10.

55. Prigge JR, Eriksson S, Iverson SV, Meade TA, Capecchi MR, Arner ESJ, Schmidt EE. Hepatocyte DNA replication in growing liver requires either glutathione or a single allele of txnrd1. Free Radical Bio Med 2012; 52:803-810.

56. Roede JR, Jones DP. Reactive Species and Mitochondrial Dysfunction: Mechanistic Significance of 4Hydroxynonenal. Environ Mol Mutagen 2010; 51:380-390.

57. Nakahara T, Iwase A, Nakamura T, Kondo M, Bayasula, Kobayashi H, Takikawa S, Manabe S, Goto M, Kotani T, Kikkawa F. Sphingosine-1-phosphate inhibits $\mathrm{H} 2 \mathrm{O} 2$-induced granulosa cell apoptosis via the PI3K/Akt signaling pathway. Fertil Steril 2012; 98:1001-1008 e1001.

58. Ortiz-ButrOn R, Blas-Valdivia V, Franco-Colin M, Pineda-Reynoso M, Cano-Europa E. An increase of oxidative stress markers and the alteration of the antioxidant enzymatic system are associated with spleen damage caused by methimazole-induced hypothyroidism. Drug Chem Toxicol 2011; 34:180-188.

59. Cano-Europa E, Perez-Severiano F, Vergara P, Ortiz-Butron R, Rios C, Segovia J, Pacheco-Rosado J. Hypothyroidism induces selective oxidative stress in amygdala and hippocampus of rat. Metab Brain Dis 2008; 23:275-287.

60. Hennet ML, Hope YY, Combelles $\mathrm{CMH}$. Follicular fluid hydrogen peroxide and lipid hyperperoxide in bovine antral follicles of various size, atresia and dominance status. J Assist Reprod Genet 2013; 30:333-340.

61. Banerjee S, Banerjee S, Saraswat G, Bandyopadhyay SA, Kabir SN. Female reproductive aging is master-planned at the level of ovary. PLoS One 2014; 9(5):e96210.

62. Krauss $\mathrm{S}$, Zhang $\mathrm{CY}$, Lowell BB. A significant portion of mitochondrial proton leak in intact thymocytes depends on expression of UCP2. Proc Natl Acad Sci U S A 2002; 99:118-122.

63. Arsenijevic D, Onuma H, Pecqueur C, Raimbault S, Manning BS, Miroux B, Couplan E, Alves-Guerra MC, Goubern $M$, Surwit R, Bouillaud F, Richard D, et al. Disruption of the uncoupling protein-2 gene in mice reveals a role in immunity and reactive oxygen species production. Nat Genet 2000; 26:435-439. 
A

$12 \mathrm{~d}$

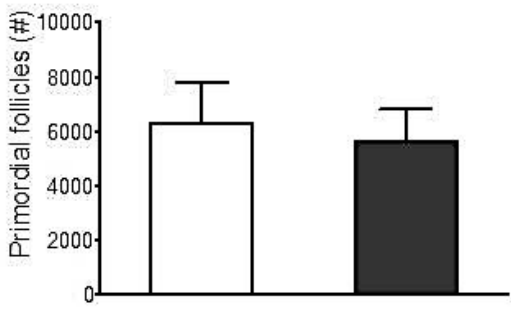

B

$12 \mathrm{~d}$

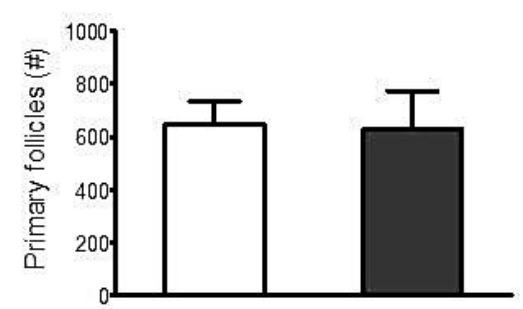

C

$120 \mathrm{~d}$

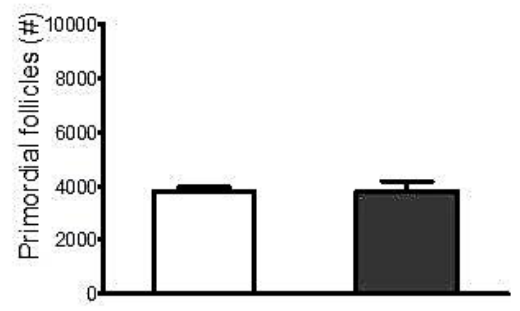

D

$120 \mathrm{~d}$

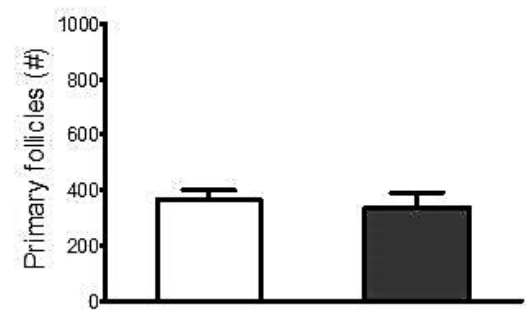

Supplemental Figure 1. Total numbers of primordial and primary follicles per ovary in 12- (A, B) and 120-day-old (C, D) euthyroid control (open bars) and hypothyroid (filled bars) rats. No significant differences were observed between the treatment groups. Therefore, primordial and primary follicle numbers in the 64-day-old testes were not determined.

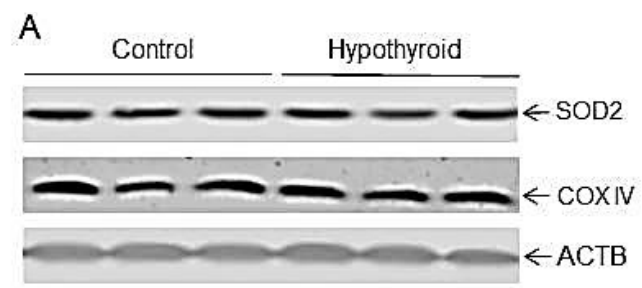

B

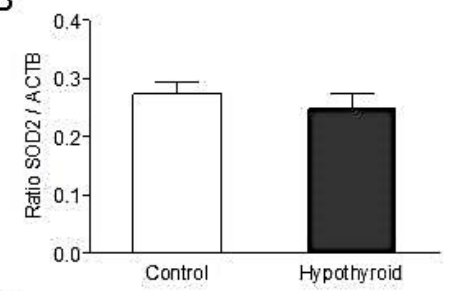

C

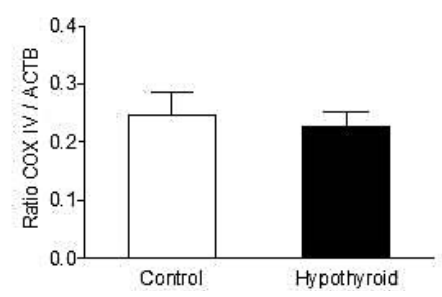

Supplemental Figure 2, Western blot data for $\operatorname{SOD2}(\mathrm{A}, \mathrm{B})$ and cytochrome c oxidase subunit IV (COX IV) (A, C); A, representative pictures of SOD2 and COX IV blots; B, C quantification of blots for SOD2 and COX IV, respectively $(n=6)$. Protein abundance is shown as ratio over ACTB. 

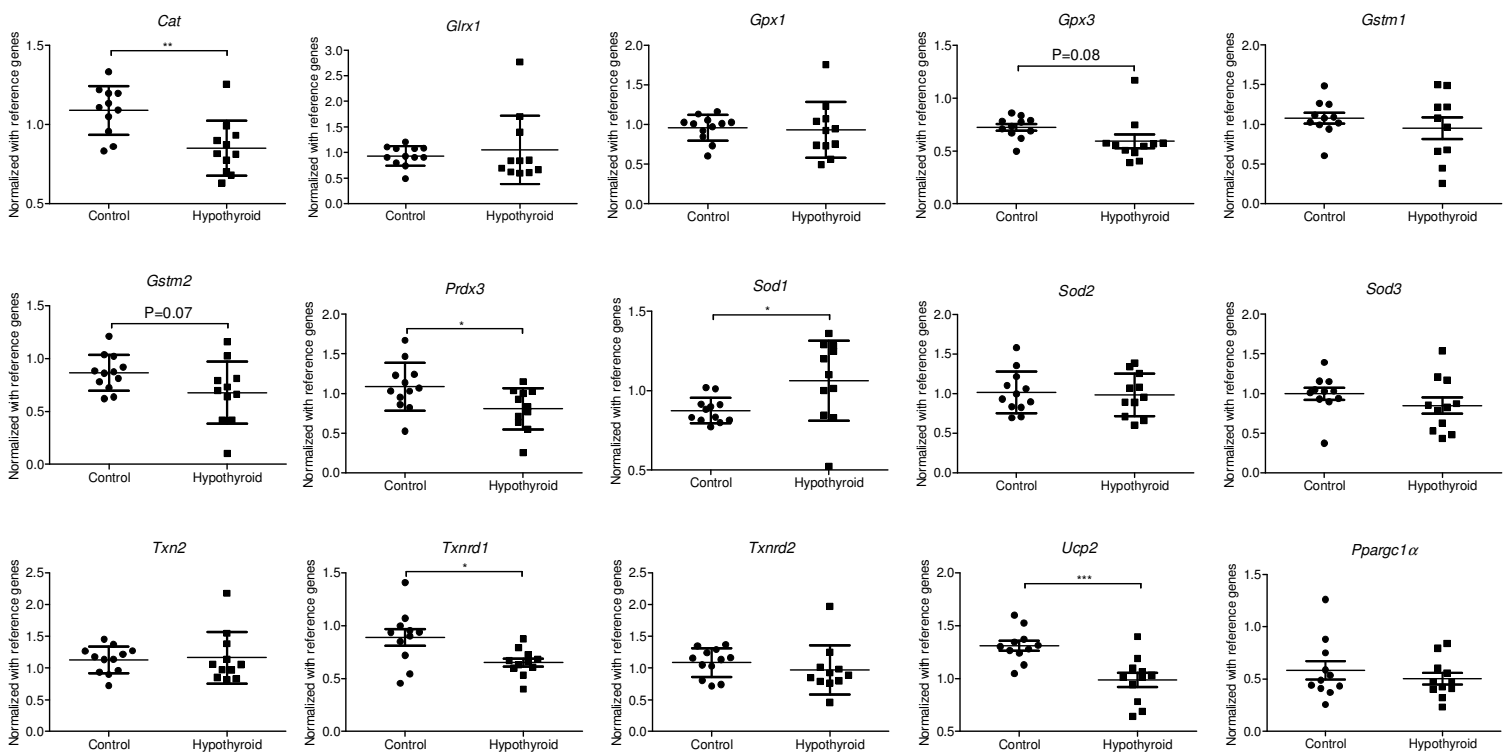

Supplemental Figure 3. Gene expression (dot plots) in ovarian tissue of 120-day-old euthyroid control and hypothyroid rats as measured by qRT-PCR. Gene expression was normalized to Rps18 and Gapdh as reference genes. Antioxidant genes: Cat, catalase; Glrx1, glutaredoxin 1; Gpx1, glutathione peroxidase 1; Gpx3, glutathione peroxidase 3 ( $p=0.08$ ); Gstm1,

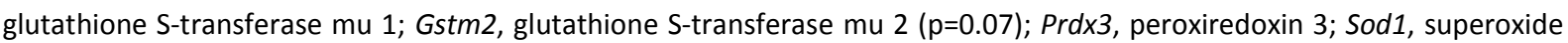
dismutase 1; Sod2, superoxide dismutase 2; Sod3, superoxide dismutase 3; Txn2, thioredoxin 2; Txnrd1, thioredoxin reductase 1; Txnrd2, thioredoxin reductase 2; Ucp2, uncoupling protein 2. Mitochondrial biogenesis and activity gene: Ppargc1 $\alpha$, Peroxisome proliferator-activated receptor gamma coactivator 1 -alpha. ${ }^{*}, p<0.05 ;{ }^{* *}, p<0.01 ;{ }^{* * *}, p<0.001$. 


\title{
Chapter 5
}

\section{Skeletal muscle pseudo-starvation driven energy expenditure negatively affects ovarian follicular development in mice}

\author{
Li Meng ${ }^{\text {a\# }}$, Verena Coleman ${ }^{\text {b\# }}$, Jaap Keijer ${ }^{a}$, Mario Ost ${ }^{b}$, Anja Voigt $^{b}$, Annelies Bunschoten ${ }^{\mathrm{a}}$, Katja \\ Teerds $^{\mathrm{b}}$, Susanne Klaus ${ }^{\mathrm{b}}$

\footnotetext{
${ }^{a}$ Human and Animal Physiology, Wageningen University \& Research, Wageningen, The Netherlands

${ }^{\mathrm{b}}$ German Institute of Human Nutrition, Potsdam-Rehbruecke, Germany

${ }^{\#}$ These authors contributed equally to this work.
}

In advanced stage of preparation 


\begin{abstract}
Female reproduction is tightly linked to body energy status. Both caloric restriction and excess exercise, conditions of reduced adiposity and fuel availability, have a negative impact on female fertility. To specifically examine whether and how a nutrient flux away from the ovaries towards skeletal muscle, without reducing adiposity, affects ovarian follicular development, we employed mice ectopically expressing UCP1 in skeletal muscle (UCP1-TG); a model of skeletal muscle pseudostarvation. UCP1-TG female mice had increased energy expenditure, reduced body size, maintained adiposity, and showed increased circulating fibroblast growth factor 21 (FGF21) and reduced insulinlike growth factor 1 (IGF1) levels, similar to their male counterparts. UCP1-TG mice have $30 \%$ lower healthy follicle numbers compared to WT mice. Primary and preantral follicles were $40 \%$ decreased in number, while the number of atretic follicles was significantly increased and corpora lutea (CL) were absent in $40 \%$ of the UCP1-TG mice. The elevated circulating FGF21 concentrations were not responsible for the ovarian phenotype, since UCP1-TG and UCP1-TG/FG21 $1^{--}$mice showed the same ovarian follicular phenotype. Comparison of WT with UCP1-TG mice reveals a significant correlation of circulating IGF1 levels with antral follicle and CL numbers, and differentially activated AKT in healthy antral follicles and activated IRS2 in atretic follicles implicates, that IGF1 is, at least partly, responsible for the ovarian phenotype of these mice. In conclusion, our data show that an energy drain towards skeletal muscle negatively impacts ovarian growing follicular reserve and ovulation rate, a process which is, at least in part, mediated by IGF1, and not by FGF21.
\end{abstract}




\subsection{Introduction}

Female reproduction, including folliculogenesis, ovulation, fertilization, embryo development, parturition, and lactation, is one of the most energy-costly biological processes that a female mammal can undertake (1). In fact, reproductive energy demand has been proposed to be a driving force in evolution (2). Although reproductive function is essential for the survival of a species, it is dispensable at the individual level, since reproduction can only be completed successfully when sufficient energy resources guarantee the metabolic demands imposed by pregnancy and, especially, lactation $(3,4)$. Therefore, a close relation exists between female reproduction and whole body energy status. Accordingly, caloric restriction without malnutrition in rodents starting at weaning, or even later in life, results in delayed puberty, reduced fertility and smaller litter sizes (5-7). Adult onset $\mathrm{CR}$ is shown to result in reduced fertility, which is associated with an increased number of primordial follicles and a reduced number of atretic follicles, suggesting a halt in follicle development. Indeed, after return to ad libitum food intake the CR mice are more fertile at old age (8). CR of female mice is an intervention that reduces energy intake. It results in deceased adiposity, increased metabolic efficiency and decreased availability of oxidizable fuel (9). It has been suggested, based on studies with biochemical inhibitors, that particularly the reduced fuel availability drives the reduced fertility (10). This agrees with the rapid restoration of fertility upon return to at libitum feeding $(8,11)$, which occurs before restoration of adiposity (11).

Limitation in fuel availability, resulting in energy insufficiency, can also result from increased energy expenditure. Exercise is an intervention that increases energy expenditure. While physical activity generally improves reproductive functioning in humans (12), excess physical activity in lean individuals, such as marathon runners or ballet dancers, has been reported to negatively impact female reproductive functioning $(13,14)$. As with $C R$, excessive exercise has many effects beyond its effect on energy availability (3). In an attempt to disentangle fuel availability from other physiological effects, we examined female reproductive functioning in mice with uncoupling protein 1 (UCP1) specifically overexpressed in muscle (UCP1-TG), a mouse model of skeletal muscle pseudo-starvation that displays a mild energy insufficiency with increased muscle energy and substrate demand (15).

UCP1 is located in the inner mitochondrial membrane and is normally expressed in brown adipose tissue, while specific conditions can induce its expression in white adipose tissue (16). UCP1 can be activated by adrenergic stimuli and cold. UCP1 activation results in dissipation of the proton gradient across the mitochondrial inner membrane, uncoupling the respiratory chain from ATP synthesis (17). Ectopic expression of UCP1 in skeletal muscle $(15,18,19)$ increases energy expenditure and imposes a condition of mild energy insufficiency. The muscle-specific UCP1 transgenic mice (UCP1-TG) show reduced growth, improved metabolic health and a diminished incidence of age-related diseases (1923). The UCP1-TG mouse model allows us to study the effect of skeletal muscle driven pseudostarvation on female reproductive performance, especially ovarian follicular development.

The reduced growth in UCP1-TG mice is likely due to growth hormone resistance $(18,24)$. These mice display decreased insulin-like growth factor 1 (IGF1) levels, despite increased growth hormone levels. IGF1 is a peptide hormone that functions as the major mediator of growth hormone stimulated growth. IGF1 also has an important role in the regulation of substrate metabolism, a function that is largely independent of growth hormone (25). IGF1 is primarily produced in the liver and is in the circulation tightly bound to IGF1 binding proteins to exert its endocrine functions. It is also produced 
locally in many mesenchymal tissues, where it is involved in growth hormone independent autocrine/paracrine functions. IGF1 primarily acts by binding to and activating the IGF1 receptor 1 (IGF1R) (26). This receptor is widely distributed, which enables blood-transported IGF1 to coordinate balanced growth among multiple tissues and organs. IGF1 is shown to also play an important role in ovarian function $(27,28)$. In the ovary, IGF1R is specifically expressed in granulosa cells of healthy growing follicles (29-32). Mice lacking IGF1 are infertile, with their follicular development is arrested at the small antral stage, resulting in anovulation $(33,34)$. In vitro studies have shown that IGF1 can amplify the action of the gonadotropic hormone follicle-stimulating hormone (FSH) on granulosa cells growth to ensure follicular survival (34-36). In addition, IGF1 promotes cell growth and suppresses apoptosis of granulosa cells by activating the phosphatidylinositol 3-kinase (PI3K)-AKT pathway (35, 37,38 ). Indeed, IGF1R inactivation reduces follicle growth, possibly by decreasing the activity of Phosphorylated AKT (35). IGF1 signalling in the ovaries is mediated by insulin receptor substrate 2 (IRS2), since its deletion results in female infertility (39).

UCP1-TG mice also display alterations in several other plasma hormones, including strongly increased levels of fibroblast growth factor 21 (FGF21) (24). While the liver is accepted as the usual primary contributor to circulating FGF21 levels (40), the elevated plasma FGF21 levels in UCP1-TG mice were shown to arise from muscle (24). These elevated FGF21 levels are responsible for white adipose tissue remodelling (41), which is characterized by a brown adipose tissue-like morphology and increased expression of UCP1. FGF21 is a peptide hormone, rather than a growth factor, that functions as a major metabolic regulator of glucose and lipid metabolism $(42,43)$. FGF21 binds to and activates fibroblast growth factor receptors in the presence of its co-receptor beta-klotho $(42,44$, 45). Studies on the effects of FGF21 on female reproduction are limited and the results are somewhat contradictory. FGF21 overexpression is shown to cause infertility in female mice on a chow diet $(46,47)$. FGF21 overexpressing mice (FGF21-TG) display delayed vaginal opening, reduced mating and anovulatory hypogonadism (46). Upon inactivation of beta-klotho in the suprachiasmatic nucleus, the inhibitory effect of FGF21 was lost, suggesting that the effects of FGF21 are centrally mediated in a neuroendocrine fashion (46). However, while chow fed FGF21-TG mice were infertile, high fat diet feeding restored fertility without altering circulating FGF21 concentrations (47). In addition, dietary interventions inducing high FGF21 levels, a ketogenic diet and fasting, increased serum FGF21 levels, but did not induce infertility (47). It was concluded that infertility of FGF21-TG mice results from their increased caloric requirements, but this was not formally tested (e.g. by inactivating FGF21), nor was the ovarian follicular reserve under high FGF21 levels examined.

Here, we investigate the effects of energy drain, caused by UCP1 overexpression in skeletal muscle, on ovarian follicular reserve and ovulation rate. While in particular male UCP1-TG mice have been investigated extensively metabolically (18-23), also female mice display increased energy expenditure and energy intake (18), making this a suitable model to examine effects of peripheral energy drain on ovarian follicular development, which as yet has not been investigated in UCP1-TG mice. We also addressed the roles of FGF21 and IGF1, two peptide hormones that are related to fertility and are strongly affected in UCP1-TG mice (24). 


\subsection{Material and Methods}

\section{Chemicals and antibodies}

All chemicals were purchased from Sigma (Zwijndrecht, the Netherlands) unless indicated otherwise. Antibodies against Phospho-AKT (Ser473) (lot no.19, cat. no. 4060), and cleaved Caspase 3 (cCASP3, lot no 37, cat. no. 96615) were purchased from Cell Signaling Technology (Leiden, The Netherlands). Antibodies against AKT (lot no. GR59504-43, cat. no. ab8805), Phospho-IRS2 (S731) (lot no.GR211245-1, cat. no. ab3690) and IRS2 (lot no. GR219213-2, cat. no.ab134101) were purchased from Abcam (Cambridge, UK).

\section{Animals}

Experiments were performed in female mice that were group-housed at $23{ }^{\circ} \mathrm{C}$ and exposed to a 12:12 h dark-light cycle for 12 weeks. The random-caged mice had ad libitum access to a chow diet (Ssniff A153F0300, Soest, Germany) and water. Hemizygous UCP1-TG mice (18) and Fgf21-knockout $\left(\right.$ FGF21 $1^{-1}$ ) mice (48) were generated as described previously. UCP1-TG mice were crossed with FGF21 ${ }^{-1}$ mice to produce four genotypes of mice: wild-type (WT), FGF21 ${ }^{-1}$, UCP1-TG, and UCP1$\mathrm{TG} / \mathrm{FGF} 21^{-}$mice (41). At 12 weeks of age the animals were euthanized with isoflurane. In a separate experiment at 12 weeks of age, 10 UCP1-TG mice and 10 WT mice were mated with WT male mice, respectively and the size of the resulting first litter was scored. The animal experiments were approved by the ethics committee of the Ministry of Agriculture and Environment (State Brandenburg, Germany, permission number GZ V3-2347-16-2013).

\section{Phenotypical assessments}

Body length was measured as the length between nose and anus. Body composition was measured by quantitative magnetic resonance (QMR, EchoMRI 2012 Body Composition Analyzer, Houston, USA). Indirect calorimetry was performed in a Phenomaster system (TSE Systems GmbH, Bad Homburg, Germany) to calculate energy expenditure and respiratory exchange ratio (RER), with parallel measurement of spontaneous physical activity using infrared detection (TSE Systems GmbH, Germany), at the age of 11 weeks. Body temperature was measured at 11 weeks of age using at BAT12 Microprobe thermometer (Physitemp, Clifton, NY, USA). Random blood samples from the tail vein were taken at the age of $4,5,6,8,10$ and 11 weeks to determine glucose levels using a Contour glucose sensor (Bayer, Leverkusen, Germany). For the oral glucose tolerance test (OGTT), $2 \mathrm{mg}$ glucose per $\mathrm{g}$ body weight was applied $2 \mathrm{~h}$ after food withdrawal to 10 week old mice. Blood glucose levels were measured before, 15, 30, 60, 120 and $240 \mathrm{~min}$ after glucose application using a Contour glucose sensor (Bayer, Germany). Insulin levels were measured before, 15 and 30 min after application by an ultra-sensitive ELISA assay (DRG Instruments $\mathrm{GmbH}$, Marburg, Germany).

\section{Plasma FGF21, IGF1, AMH and leptin measurements}

FGF21 values (plasma diluted 1:3 for WT, FGF21 ${ }^{-1}$, UCP1-TG/FGF21 ${ }^{-1}$ and 1:6 for UCP1-TG; Mouse/Rat FGF 21 Quantikine ELISA Kit; R\&D Systems, Abingdon, UK), IGF1 values (plasma diluted 1:500; Mouse/Rat IGF 1 Quantikine ELISA Kit; R\&D Systems), anti-Müllerian hormone (AMH) values (plasma diluted 1:4; AMH Gen II ELISA, Beckman Coulter, Sinsheim, Germany) and leptin levels (plasma diluted 1:5; Bio-Plex Pro mouse diabetes assay, BioRad, Veenendaal, The Netherlands) were determined according to the protocol of the respective suppliers as reported before $(41,49,50)$. 


\section{Histological evaluation of ovarian tissues}

The right ovaries of 6 to 8 animals were fixed in diluted Bouin's fluid $(0.9 \%$ picric acid, $4 \%$ formaldehyde, $5 \%$ glacial acetic acid) for $24 \mathrm{~h}$ at $4^{\circ} \mathrm{C}$ followed by embedding in paraffin. The ovaries were serially sectioned at a thickness of $5 \mu \mathrm{m}$. Every fifth section of each ovary was mounted on glass slides, stained with periodic acid Schiff's reagent (PAS) and Mayer's haematoxylin (Klinipath, Duiven, the Netherlands), and examined by light microscopy. From these sections the numbers of healthy primordial, primary, preantral and antral follicles were counted as described previously $(51,52)$. Briefly, follicles were scored as primordial if they contained an intact oocyte with a clear nucleus and nucleoli surrounded by a single layer of squamous pregranulosa cells. Follicles were scored as primary when they contained an intact, enlarged oocyte with a clear nucleus and nucleolus surrounded by a single layer of granulosa cells of which $50-100 \%$ had a cuboidal appearance. The granulosa layer of preantral follicles consisted of more than one layer of cuboidal cells, an oocyte with a clear nucleus and nucleolus and a developing theca layer. Antral follicles consisted of several layers of granulosa cells, an oocyte with a clear nucleus and nucleolus, an antrum of which the diameter was at least the size of the diameter of the oocyte, and a theca layer. In order to estimate the total number of follicles within one ovary, the number of primordial, primary, preantral and antral follicles counted in the mounted sections was multiplied by five to account for the fact that every fifth section was used in the follicle counting (51).

Atretic preantral follicles were recognized by the presence of a degenerating oocyte, disorganized granulosa cell layer, while the surrounding theca cells showed signs of hypertrophy. Antral follicles were considered to be atretic when more than $5 \%$ of the granulosa cells showed signs of apoptosis. The theca layer of these atretic antral follicles showed signs of hypertrophy. As atresia proceeded, the granulosa cells were lost completely and the oocyte degenerated, leaving remnants of the zona pellucida and hypertrophied theca cells. In order to prevent the counting of the same atretic follicle more than once, an estimate of the percentage of atretic follicles was made as described previously (53).

To determine the number of corpora lutea (CLs) per ovary, complete overview pictures were taken of every tenth ovarian section using a Zeiss Axioscoop II microscope equipped with an MRc5 camera and Axiovision 4.8.0.0 software (Zeiss $\mathrm{GmbH}$, Jena, Germany). By following the CLs throughout the ovary it was possible to determine the total number of CLs per ovary.

\section{Immunohistochemistry}

Five $\mu \mathrm{m}$ thick paraffin sections were cut and mounted on Superfrost plus slides (Menzel, Braunschweig, Germany). To determine the presence of Phospho-AKT (Ser473), AKT, Phospho-IRS2 (S731), IRS2, and CCASP3, immunohistochemistry was performed as previously reported (54) with minor modifications. Staining of all slides of at least 4 different animals per group was carried out simultaneously in a single session at room temperature. Briefly, sections were deparaffinized, rehydrated after which epitope antigen retrieval with sodium citrate buffer ( $\mathrm{pH} \mathrm{6,} 10 \mathrm{~min}$ ) in a microwave oven was performed at $96{ }^{\circ} \mathrm{C}$. Slides were cooled down to room temperature and subsequently rinsed with $0.01 \mathrm{M}$ phosphate buffered saline $\mathrm{pH} 7.4$ (PBS). Sections were preincubated with $10 \%\left(\mathrm{wt} / \mathrm{v}\right.$ ) normal goat serum in PBS for $30 \mathrm{~min}$ and incubated overnight at $4{ }^{\circ} \mathrm{C}$ with the respective primary antibodies (Phospho-AKT, diluted1:200; AKT, diluted 1:500; Phospho-IRS2, diluted 1:100; IRS2, diluted 1:200; and cCASP3, diluted 1:1000 in PBS to which 0.05\% BSAc (Aurion, 
Wageningen, The Netherlands) was added). The secondary goat-anti-rabbit biotin labelled antibodies (Vector Laboratories, Burlingame, CA, USA) were diluted 1:400 (v/v), in PBS-BSAc. The avidin-biotin complex (ABC) was diluted 1:1500 (v/v) (Vector Laboratories) in PBS-BSAc. Bound antibody was visualized using a 3-3' diaminobenzidine kit (Immpact DAB, Vector Laboratories) diluted 1:400 (v/v). Sections were counterstained briefly with Mayer's haematoxylin. Control sections were incubated with isotype IgG (Vector Laboratories) instead of the primary antibody according to the manufactures instructions. No background staining was observed in the controls.

\section{Statistical analysis}

Data are expressed as mean \pm standard error of the mean (SEM). GraphPad Prism version 5.03 (Graphpad Software, San Diego, CA, USA) was used for statistical analysis, with Student's t test being used to compare the two groups if normally distributed. Two-way ANOVA (repeated measures, matched values) followed by Bonferroni post hoc test was used for body weight, body composition, body temperature and OGTT in time analysis. The relation between IGF1 and body length as well as ovarian follicular numbers were analysed using linear regression. $P$ values $<0.05$ were considered significantly. 


\subsection{Results}

\section{Physiological phenotype of UCP1-TG mice}

Body weight of female UCP1-TG mice was significantly lower than WT littermate controls from week 4 onwards. At sacrifice, at the age of 12 weeks, the UCP1-TG mice weighted $15.3 \pm 0.4 \mathrm{~g}$, which was significantly lower than the WT mice with a body weight of $21.0 \pm 0.5 \mathrm{~g}$ (Figure 1A). UCP1-TG mice showed a decreased body length (Figure 1B) and quadriceps weight (Figure 1C) compared with WT mice. The UCP1-TG mice showed a lower lean mass (Figure 1D) and an identical fat mass (Figure 1F), resulting in a reduced lean mass percentage (Figure $1 \mathrm{E}$ ) and an increased fat mass percentage (Figure 1G) from week 7 onwards in UCP1-TG compared to WT littermates.
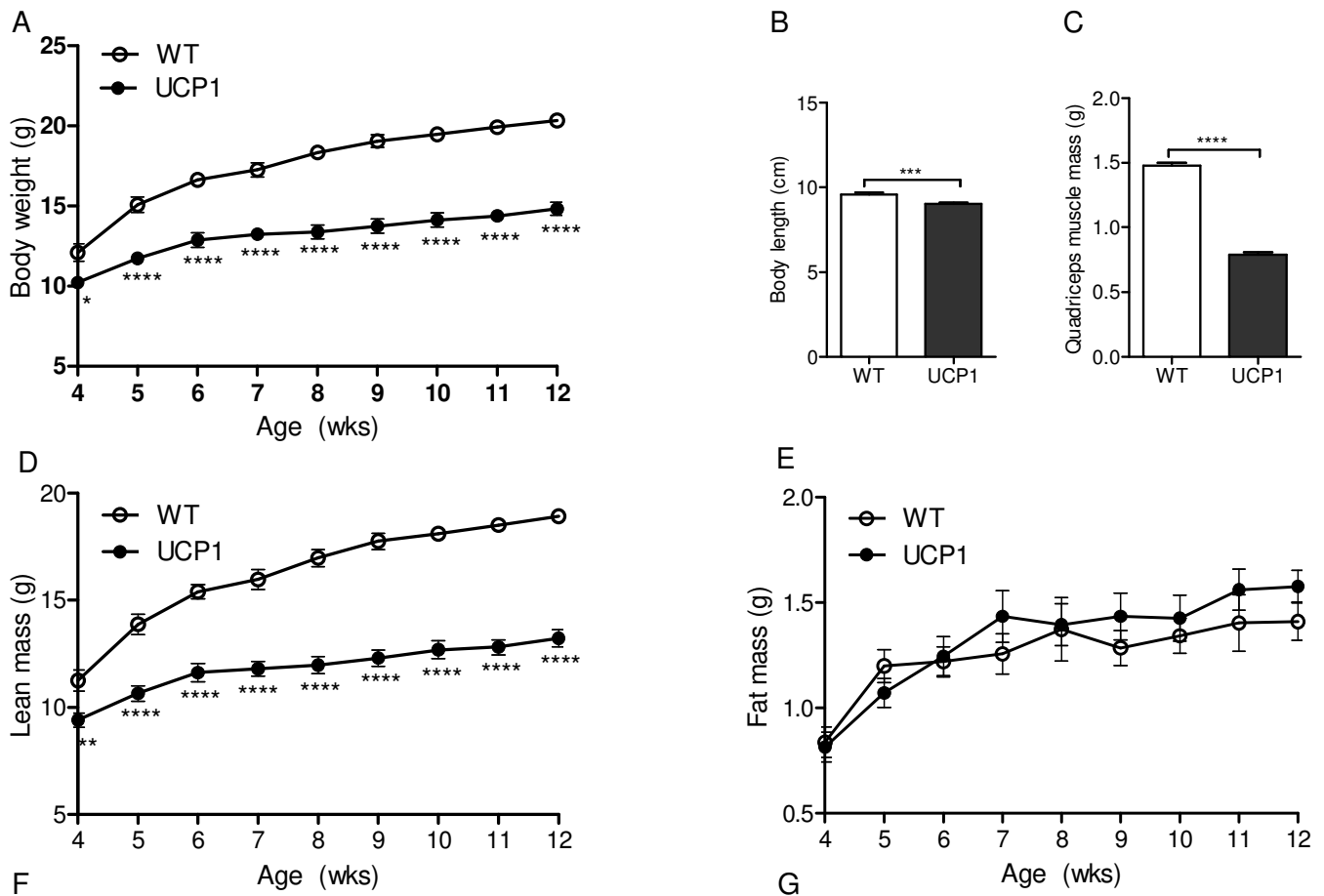

$\mathrm{F}$
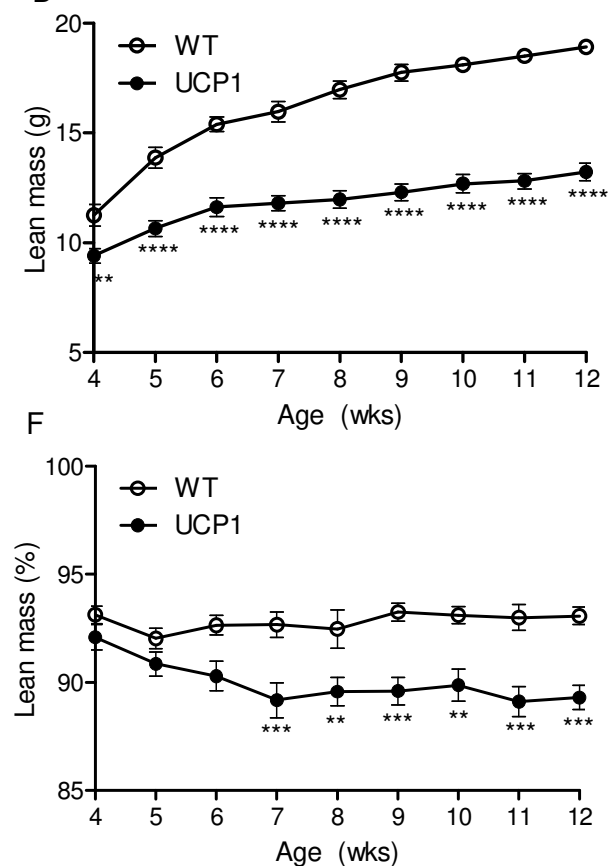
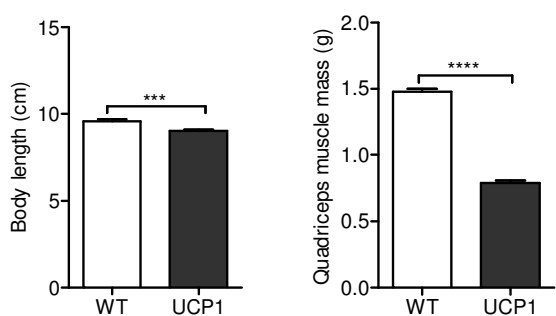

C

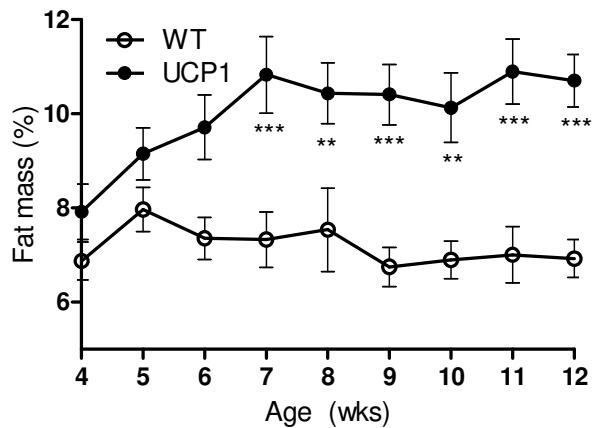

Figure 1. Physiological phenotype of female mice overexpressing UCP1 in muscle (UCP1-TG; UCP1) and wild-type (WT) littermate controls, both fed chow diets for 12 weeks. Body weight development (A), body length at week 12 (B), quadriceps weight at week 12 (C), lean mass development (D), fat mass development (E), percentage of lean mass (F) and percentage of fat mass (G) were determined. Open circles and white bars represent WT; Closed circles and black bars represent UCP1-TG. \% = percentage. Statistical analyses were done based on 8 mice per group, except for body length and quadriceps weight $(n=10) .{ }^{*} p<0.05,{ }^{* *} p<0.01, * * * p<0.001, * * * * p<0.0001$ 


\section{Energy metabolism}

Energy intake, energy expenditure, physical activity and RER were measured during indirect calorimetry in week 11. Energy intake and energy expenditure were significantly increased, accompanied by a decreased physical activity in the UCP1-TG mice compared with WT mice (Table 1). These results suggest that the increased energy expenditure is not due to increased physical activity, but results from UCP1 overexpression in the skeletal muscle. The combined increase in energy expenditure and energy intake furthermore indicated an increased substrate flux, as previously shown for male mice (18). $24 \mathrm{~h}$ mean RER was not different between UCP1-Tg and WT mice (Table 1). RER is a marker of substrate oxidation, values near 0.7 account for lipid oxidation, values near 1.0 represents carbohydrate oxidation and values higher than 1.0 indicate lipid synthesis from carbohydrates (55). Mean RER during the night was significantly increased in UCP1-TG mice compared to WT (Table 1), with UCP1-TG showing a mean RER slightly above 1.0. This may indicate a preference for carbohydrate utilization and lipid synthesis from carbohydrates in female UCP1-TG mice, consistent with data previously observed in male UCP1-TG mice (18). There were no differences in rectally determined body temperature between UCP1-TG and WT (Table 1).

Table 1, Parameters of energy metabolism in transgenic UCP1-TG mice and WT litter mates.

\begin{tabular}{llll}
\hline & WT & UCP1-TG & $P$ Value* \\
\hline Total energy intake, ${\mathrm{kJ} . \mathrm{day}^{-1} \cdot \mathrm{g}^{-1}}^{-1}$ & $2.64 \pm 0.18$ & $3.29 \pm 0.17$ & 0.02 \\
Energy expenditure, $\mathrm{kJ} \cdot \mathrm{day}^{-1} \cdot \mathrm{g}^{-1}$ & $1.83 \pm 0.04$ & $2.01 \pm 0.05$ & 0.007 \\
Activity, counts $/ 24 \mathrm{~h}$ & $6855.08 \pm 644.10$ & $5243.07 \pm 383.90$ & 0.045 \\
Total RER $/ 24 \mathrm{~h}$ & $0.91 \pm 0.01$ & $0.92 \pm 0.01$ & $\mathrm{~ns}$ \\
Night RER $/ 12 \mathrm{~h}$ & $0.98 \pm 0.01$ & $1.02 \pm 0.01$ & 0.02 \\
Body temperature, ${ }^{\circ} \mathrm{C}$ & $36.89 \pm 0.24$ & $37.10 \pm 0.14$ & $\mathrm{~ns}$ \\
\hline
\end{tabular}

Analysis was done in week 11. Energy intake and energy expenditure in kJ per body weight (g) per day; Statistical analyses were done on 10 mice per group, except for body temperature $(n=8) .{ }^{*}$, Student t-test. RER, respiratory exchange ratio.

\section{Circulating parameters and oral glucose tolerance test (OGTT)}

Glucose homeostasis as a marker of health status was assessed by analysis of random daytime blood glucose levels between week 4 and week 11 and by performing an OGTT in week 10. UCP1-TG mice showed blood glucose levels in the normal range, comparable to WT mice (Figure 2A). No difference could be observed in the blood glucose response to the OGTT between UCP1-TG and WT mice (Figure 2B). However, the insulin response to the OGTT was considerably lower in UCP1-TG mice compared to WT littermates, indicating improved insulin sensitivity (Figure 2C, 2D) as shown previously for male mice $(21,22)$. In full agreement with OGTT data, fasting insulin did not differ between these two groups at sacrifice (data not shown). The UCP1-TG mice showed significantly higher plasma FGF21 levels and significantly lower plasma IGF1 levels than WT mice (Figure 2E, 2F), as previously described for male UCP1-TG mice (24). Leptin levels did not differ between WT and UCP1-TG groups (1.03 $\pm 0.23 \mathrm{ng} / \mathrm{mL}$ and $0.69 \pm 0.07 \mathrm{ng} / \mathrm{mL}$, respectively). 
A
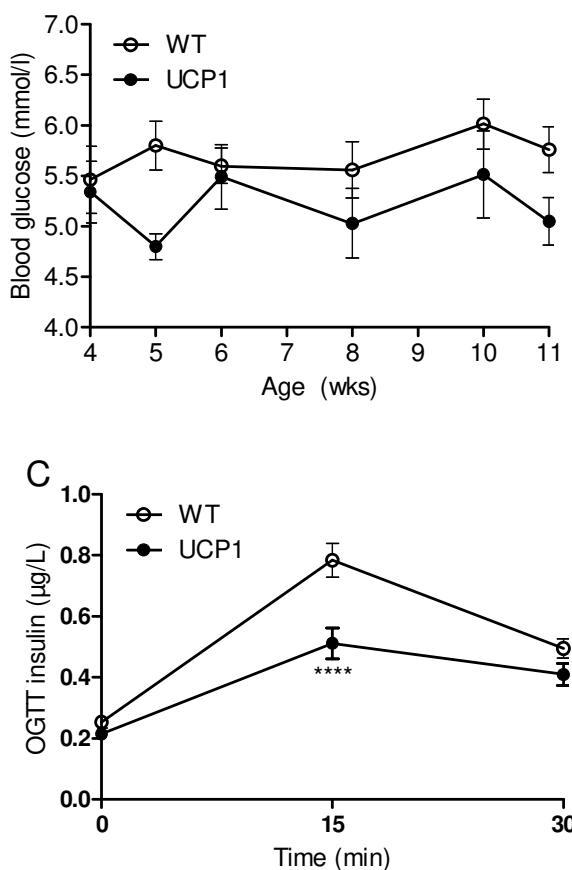

$\mathrm{E}$

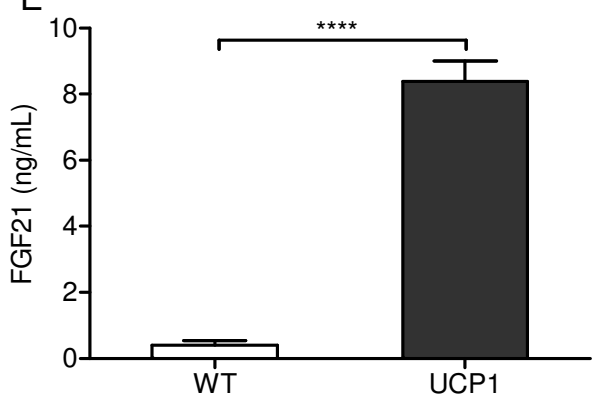

$\mathrm{B}$
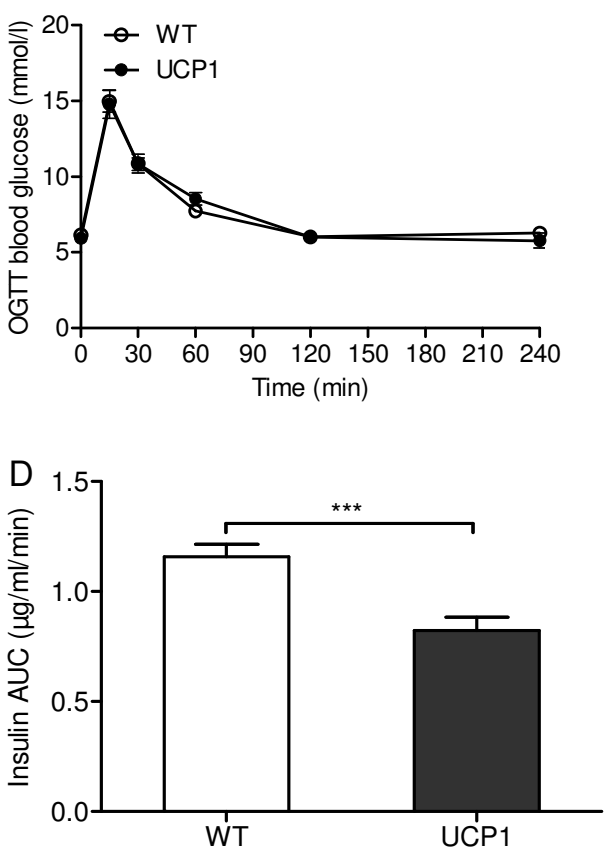

$\mathrm{F}$

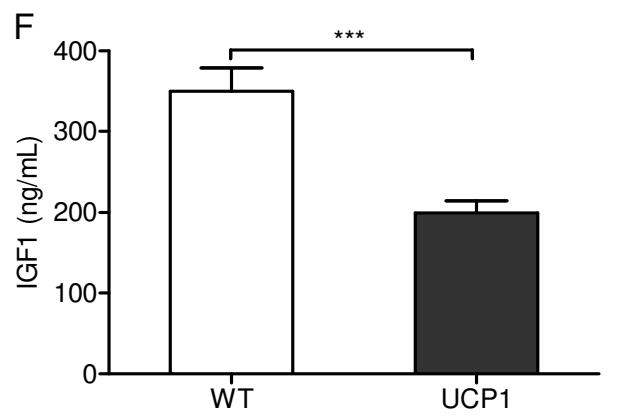

Figure 2. Metabolic health related circulation parameters of UCP1-TG (UCP1) and WT mice. Blood glucose levels from week 4 until week 11 (A), glucose response to an oral glucose tolerance test (OGTT) in week 10 (B), insulin response to the OGTT in week 10 (C), incremental area under the curve of the insulin response to the OGTT (D), plasma fibroblast growth factor 21 (FGF21) (ng/ml) levels (E) and plasma insulin-like growth factor 1 (IGF1) (ng/ml) levels (F). Open circles and white bars represent WT; Closed circles and black bars represent UCP1-TG. Statistical analyses were done on 10 mice per group. *** $\mathrm{p}<0.001, * * * * \mathrm{p}<0.0001$

\section{Histological ovarian follicular development of UCP1-TG mice}

The effect of muscle driven pseudo-starvation, resulting in limitation of substrate availability by an energy drain towards skeletal muscle tissue, on ovarian follicle development was analysed by determination of the follicle composition per ovary in UCP1-TG mice and compared to WT littermates. The presence of CLs ovaries, implicating that ovulation had taken place, is considered as an indicator of reproductive health. In the WT ovaries numerous CLs were present (figure $3 \mathrm{~A}$ ) while in several of the UCP1-TG mice CLs were absent (figure 3B). The total number of healthy follicles was $30 \%$ lower in UCP1-TG mice compared to WT mice (Figure $3 \mathrm{C}$ ), while a downward trend was observed in primordial follicle number (Figure 3D). The number of primary follicles (Figure 3E) and preantral follicles (Figure 3F) were decreased by $40 \%$ in UCP1-TG mice compared with WT mice. Also 
the number of antral follicles was decreased in the UCP1-TG mice compared with WT controls (Figure 3G). A significant increase in the percentage of atretic follicles was seen in UCP1-TG mice compared to WT (Figure $3 \mathrm{H}$ ). In line with this observation, the total number of CLs per ovary in the UCP1-TG group was significantly decreased compared with the WT controls (Figure 3I). Absence of CLs was observed in around $40 \%$ (3/8) of the ovaries of the UCP1-TG females. Finally, cCASP3 immunostaining was performed to assess apoptosis. A significantly higher percentage of antral follicles with cCASP3 positive granulosa cells was observed in UCP1-TG compared to WT mice (Figure 3J). No difference in cCASP3 positive granulosa cells in the preantral follicles was observed between these two groups (data not shown), validating the relevance of the observed difference in the antral follicle numbers. Plasma AMH concentrations, a marker for the growing follicle pool (primary, preantral and antral follicles ) (56), were determined and showed a significant decrease in the UCP1-TG group (Figure 3K), fully in agreement with the histological analysis. To test for differences in fertility, litter size was determined. No difference in litter size was observed between these groups (4.90 \pm 0.84 (WT) vs 4.90 \pm 0.64 (UCP1-TG)).

\section{Histological ovarian follicle development of FGF21\%mice}

To investigate whether impaired ovarian follicular development in the UCP1-TG mice was caused by increased FGF21 levels, we used FGF21 $1^{-/}$and UCP1-TG/FGF21 $1^{--}$mouse models. No circulating FGF21 could be detected in FGF21 ${ }^{--}$and UCP1-TG/FGF21 ${ }^{-1}$ mice, while plasma FGF21 levels were highly increased in UCP1-TG compared to WT mice, validating these mouse models for FGF21 (supplemental Figure 1A). FGF21/- mice showed plasma IGF1 levels comparable to WT mice, while UCP1-TG/FGF21 ${ }^{-1-}$ mice showed significantly lower IGF1 levels, comparable to those of UCP1-TG mice (supplemental Figure 1B).

Next the follicle composition of each group was determined. The primary question was whether FGF21 had a role in the altered follicular development of the UCP1-TG mice. Therefore, ovaries of UCP1-TG/FGF21 ${ }^{-/}$mice and UCP1-TG mice were compared. No differences in total follicle number, the percentage of atretic follicles or CL numbers were detected between UCP1-TG/FGF21 $1^{-/}$mice and UCP1-TG mice (Figure 4A, 4B, 4C). In addition, also no differences were seen in the primordial, primary, preantral and antral follicle numbers between UCP1-TG/FGF $21^{--}$mice and UCP1-TG mice (Supplemental Figure 2). At the same time the total follicle numbers in UCP1-TG/FGF21 ${ }^{-}$group were significantly lower compared with $\mathrm{FGF} 21^{-/}$group (Figure $4 \mathrm{~A}$ ). Concomitantly, a significant higher percentage of atretic follicles was observed in UCP1-TG/FGF21 $1^{-}$group compared with FGF $21^{-\%}$ group (Figure 5B). The total number of CLs per ovary in the UCP1-TG/FGF21 $1^{-1}$ group was significantly lower compared with $\mathrm{FGF} 21^{-1}$ group (Figure $4 \mathrm{C}$ ). Finally, no significant differences in in total follicle numbers, atretic follicle numbers or CLs could be observed between WT and FGF21 $1^{-1-}$ mice (Figure 4A-C). Together, these results indicate that the impaired follicular development observed in UCP1-TG mice was not due to the increase in circulating FGF21 levels. 

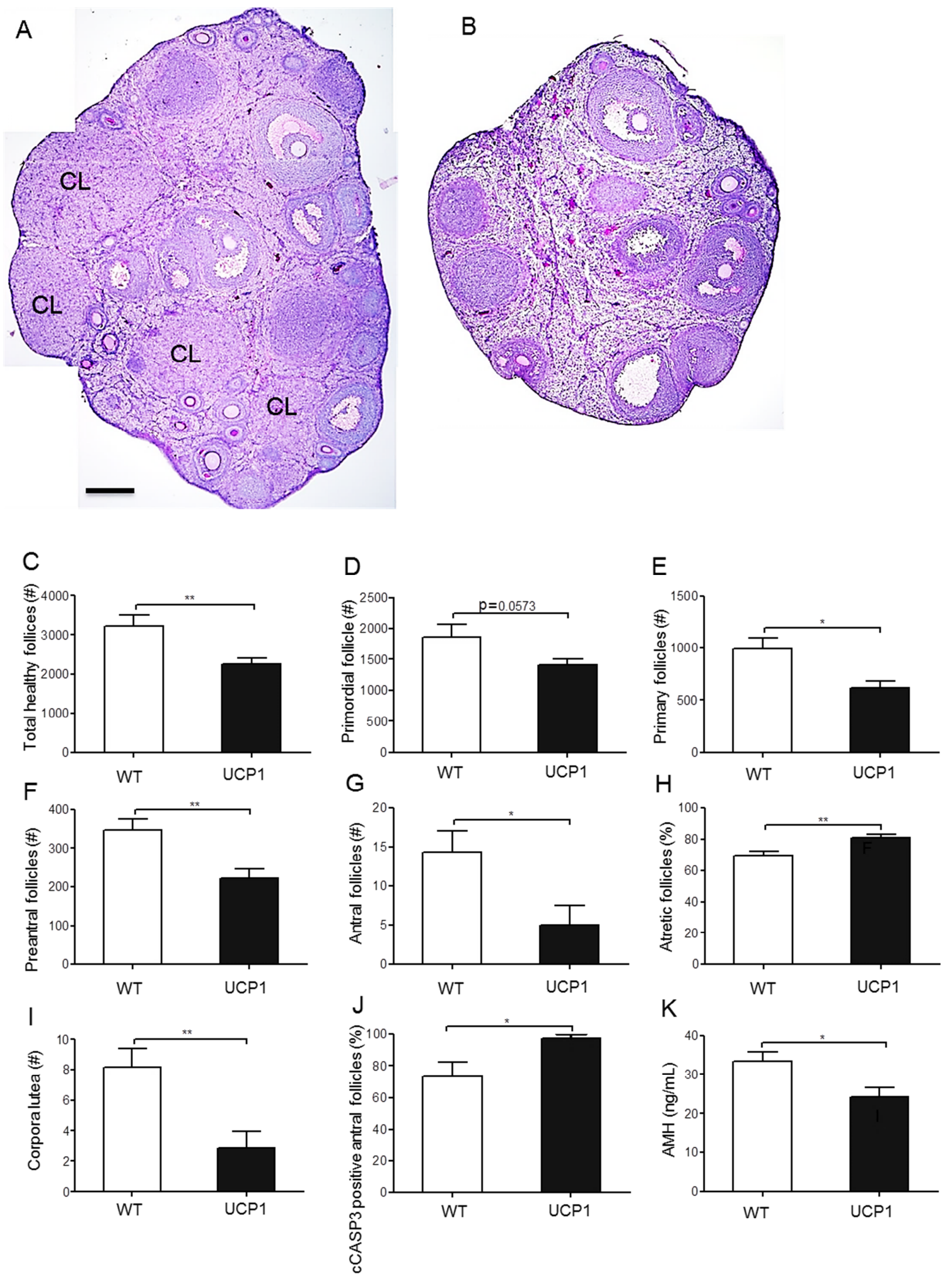

Figure 3. Ovarian follicular development of UCP1-TG (UCP1) and WT mice. Representative images of the gross ovarian morphology of WT (A) and UCP1-TG (B) mice. CL, corpus lutea. Scale bar represent $50 \mu \mathrm{m}$. Numbers of total healthy follicles (C), primordial follicles $(D)$, primary follicles $(E)$, preantral follicles $(F)$, antral follicles $(G)$, atretic follicles $(H)$ and corpora lutea (I). Percentage of apoptosis marker cleaved caspase 3 (CCASP3) positive antral follicles of WT and UCP1-TG mice (J). Plasma anti-Müllerian hormone (AMH) levels $(\mathrm{ng} / \mathrm{mL})(\mathrm{K})$. \# = number, \% = percentage. White bars represent WT; Black bars represent UCP1-TG. Values represent means \pm SEM; Statistical analyses were done on 8 mice per group, except for cCASP3 $(n=4) .{ }^{*}, p<0.05 ;{ }^{* *}, p<0.01$. 
A

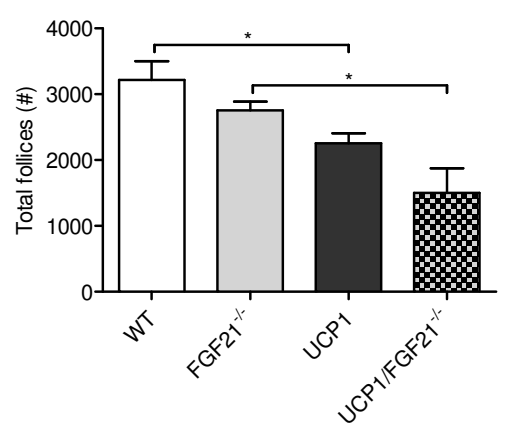

B

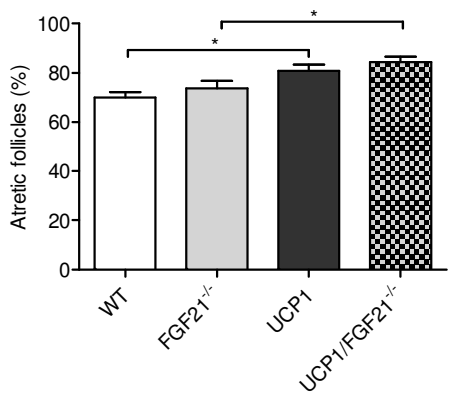

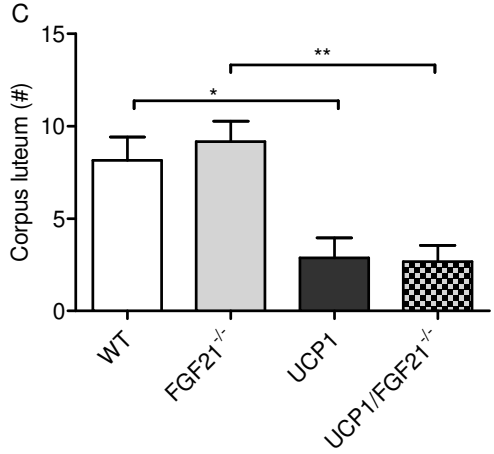

Figure 4. FGF21 and ovarian follicular development. Numbers of healthy follicles (A), percentage of atretic follicles (B), and numbers of corpora lutea (C) in WT (white), FGF21 knock out (FGF21 ${ }^{--}$; grey), UCP1-TG (UCP1; black) and FGF21 $1^{-/} /$UCP1-TG $\left(\mathrm{FGF} 21^{-/} / \mathrm{UCP} 1\right)$ mice (mixed). Statistical analyses were done on $6-8$ mice per group. ${ }^{*}, \mathrm{p}<0.05 ;{ }^{* *}, \mathrm{p}<0.01$.

\section{Correlation of IGF1 levels with physiological phenotypes and ovarian follicle numbers}

To assess the possible role of IGF1, we performed linear regression analyses. Plasma IGF1 levels were significantly correlated with body length (Figure $5 \mathrm{~A}$ ) and were also significantly correlated with antral follicle numbers (Figure 5B), and with CL numbers (Figure 5C), indicating that IGF1 may play a role in the impaired ovarian follicular development in UCP1-TG mice.

A

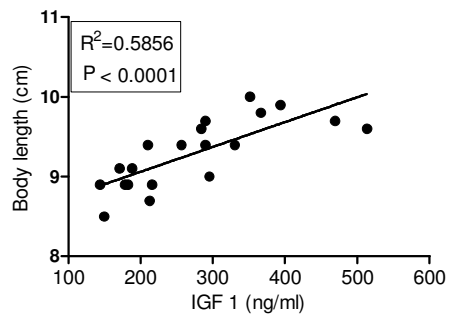

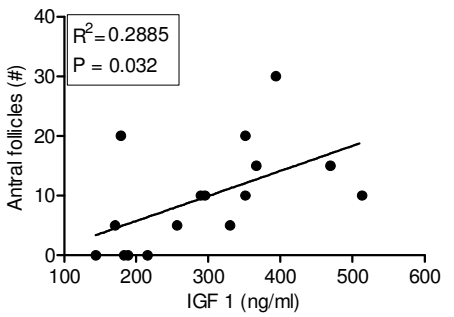

C

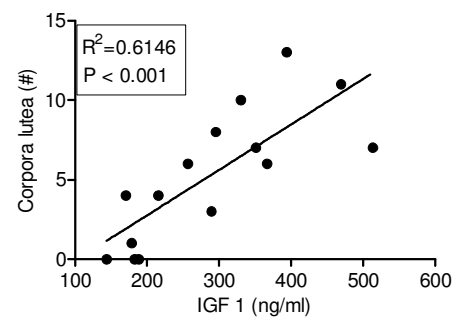

Figure 5. Correlation of IGF1 levels with body length and parameters of ovarian follicular development in WT and UCP1-TG (UCP1) mice. Correlation of IGF1 levels (ng/ml) with body length (A), number of antral follicles (B) and number of corpora lutea (C). Statistical analyses were done on 8 - 10 mice per group.

\section{Effects of UCP1 overexpression on the Phospho-AKT and Phospho-IRS2 expression of ovarian} follicles

To substantiate the role of IGF1 in ovarian follicular development of UCP1-TG mice, we performed immunohistochemistry on the activation state of AKT and IRS2, key intermediates in IGF1 signalling. The staining was analysed in preantral follicles, healthy antral follicles and atretic antral follicles and compared between WT and UCP1-TG mice.

In healthy preantral follicles of approximately the same developmental stage of WT (Supplemental Figure 3 C) as well as UCP1-TG (Supplemental Figure 3D) mice, moderate to strong Phospho-AKT 
staining was observed in the granulosa cells. Staining was faint to absent in oocytes and in theca cells of healthy preantral follicles of the two groups. Granulosa cells, theca cells and oocytes of healthy preantral follicles of both mouse models showed moderate staining for total AKT (Supplemental Figure 3A, 3B). Similarly, healthy preantral follicles of WT (Supplemental Figure 3G) as well as UCP1TG (Supplemental Figure $3 \mathrm{H}$ ) mice showed strong Phospho-IRS2 and moderated total IRS2 staining (Supplemental Figure 3E, 3F) in granulosa cells, theca cells and oocytes. These data indicate that IGF1 does not seem to play a role in healthy preantral follicle development in the UCP1-TG mice.

In healthy antral follicles of WT mice, strong Phospho-AKT staining was observed in granulosa cells (Figure 6C), while faint to absent staining was observed in the granulosa cells of UCP1-TG mice (Figure 6D). Like in preantral follicles, Phospho-AKT staining was faint to absent in both oocytes and theca cells. No differences were observed for total AKT staining in granulosa cells, theca cells and oocytes of healthy follicles, which was moderate in both groups (Figure 6A, 6B). Healthy antral follicles of both WT and UCP1-TG mice showed strong Phospho-IRS2 staining of granulosa cells, theca cells and oocytes (Figure 6G, 6H). No differences were observed in total IRS2 staining, which was moderate in granulosa cells, theca cells and oocytes of mice of both groups (Figure 6E, 6F). Activation of insulin/IGF1 signalling (Phospho-AKT levels, with concomitant IRS2 activation) in healthy follicles corresponded to IGF1 levels in the two mouse models.

In atretic antral follicles of WT (Figure 7C) as well as UCP1-TG (Figure 7D) mice, faint to absent Phospho-AKT staining was observed in the granulosa cells, while staining for total AKT was moderate and not different between WT (Figure 7A) and UCP1-TG (Figure 7B) mice. The differential staining of activated AKT between healthy and atretic antral follicles for WT, but not UCP1-TG, reflects the differences in antral follicle atresia between these two mouse models. Strong Phospho-IRS2 staining was observed in granulosa cells, theca cells and oocytes in atretic antral follicles of WT mice (Figure 7G), while faint to absent staining was present in atretic antral follicles of UCP1-TG mice (Figure 7H). No differences were seen for total IRS2 staining which was moderate to strong in granulosa cells, theca cells and oocytes in atretic antral follicles in both groups (Figure 7E, 7F). IRS2 activation in atretic follicles thus corresponds to IGF1 levels in the two mouse models.

These results strongly suggest that IGF1 signalling plays a role in the antral follicle atresia of UCP1-TG mice. 

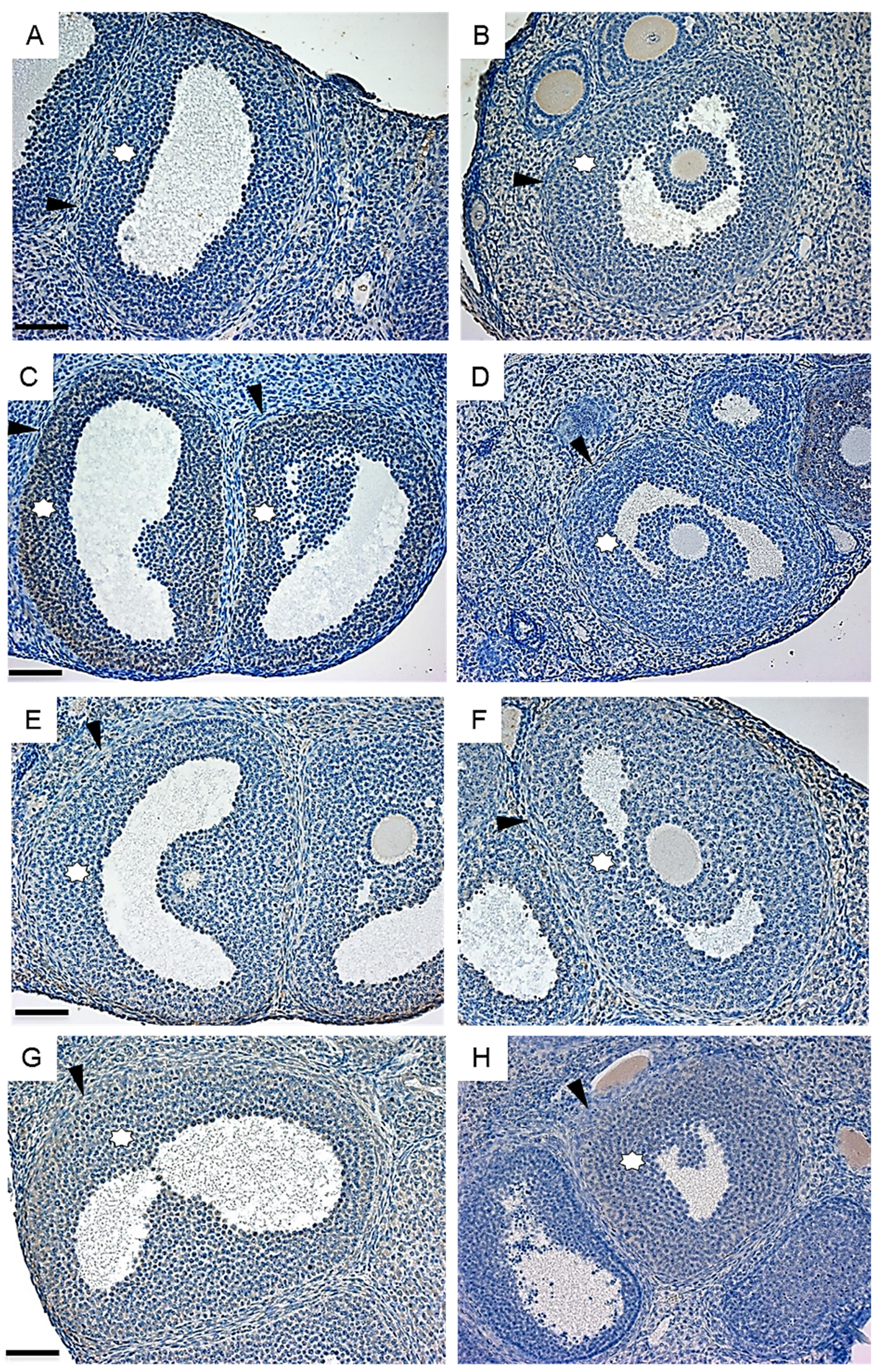

Figure 6. Immunostaining for activated AKT and IRS2 as markers of IGF1 signalling in healthy antral follicles. Representative AKT (A, B), Phospho-AKT (C, D) and IRS2 (E, F), Phospho-IRS2 (G, H) staining (brown) of ovarian follicles of WT (A, C, E, G) and UCP1-TG (B, D, F, H) mice. Granulosa cells are indicated by asterisks, theca cells by arrowheads. Scale bars represent 50 $\mu \mathrm{m}$. 

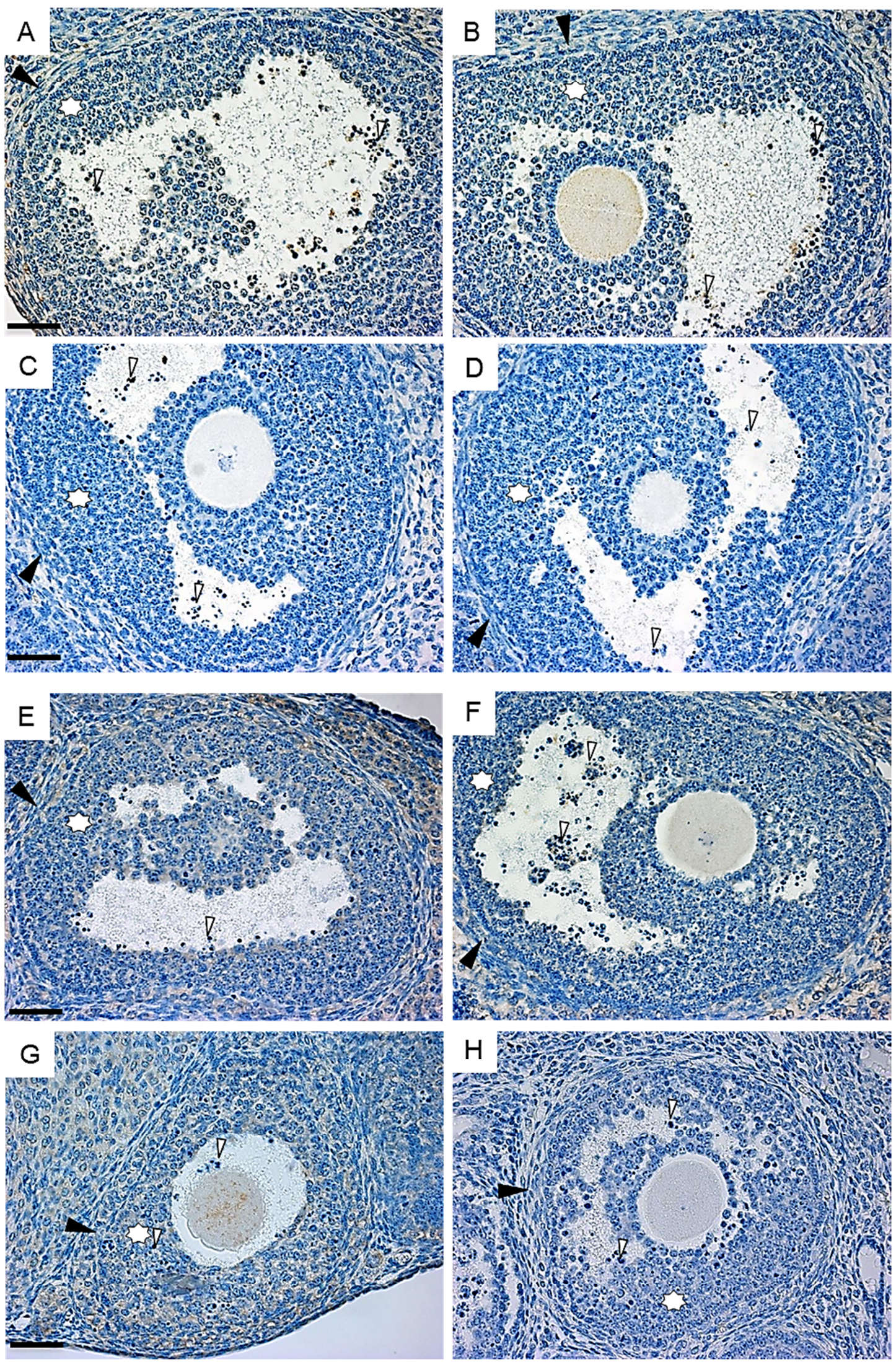

Figure 7. Immunostaining for activated AKT and IRS2 as markers of IGF1 signalling in atretic antral follicles. Representative AKT (A, B), Phospho-AKT (C,D) and IRS2 (E, F), Phospho-IRS2 (G, H) (brown) of ovarian follicles of WT (A, C, E, G) and UCP1TG $(B, D, F, H)$ mice. Granulosa cells are indicated by asterisks, theca cells by arrowheads. Representative apoptotic bodies are indicated by white arrow heads. Scale bars represent $50 \mu \mathrm{m}$. 


\subsection{Discussion}

Female UCP1-TG mice show increased energy expenditure, validating the mice as a model of skeletal muscle pseudo-starvation. These mice also display a reduced body size, maintain adiposity and leptin levels, and show increased circulating FGF21 and reduced IGF1 levels, all similar to their male counterparts $(18,21,22,24)$. Energy drain towards skeletal muscle tissue in these mice impaired ovarian follicular development, since UCP1-TG mice show a significant reduction in primary, preantral and antral follicle numbers as well as $\mathrm{CL}$ numbers, while the number of atretic follicles is significantly increased. Although FGF21 has been linked to female reproduction (46), we excluded the elevated circulating FGF21 levels as cause of impaired ovarian follicular development, by employing WT, FGF21 ${ }^{-1}$, UCP1-TG and UCP1-TG/FGF21 ${ }^{-1}$ mouse models. On the other hand, circulating IGF1 levels were significantly correlated with antral follicle numbers as well as $\mathrm{CL}$ numbers. IGF1 signalling in the ovary is mediated by IRS2 (39). The decreased AKT phosphorylation in healthy antral follicles and the decreased IRS2 phosphorylation in atretic antral follicles of the UCP1-TG mice confirms that IGF1 is, at least in part, responsible for the female ovarian phenotype of the UCP1-TG mice. Our data newly show that energy drain towards skeletal muscle negatively impacts ovarian follicular reserve and ovulation rate in female mice, which is, at least in part, mediated by IGF1, but not by FGF21.

We did not find an effect of FGF21 on ovarian follicular development, since inactivation of FGF21 in UCP1-TG mice, that have elevated circulating FGF21, did not restore the ovarian phenotype. In particular, there was no difference in total healthy follicle numbers, percentage of atretic follicles and CLs between UCP1-TG and UCP1-TG/FGF21 ${ }^{--}$mice (Figure 4). Our results seem in contrast with data obtained with mice that overexpress FGF21 in liver (FGF21-TG) that are infertile (46). While UCP1-TG as well as UCP1-TG/FGF21 $\%$ mice show reduced numbers of CL, with CLs being absent in around $40 \%(3 / 8)$ of the ovaries, $\mathrm{CL}$ were fully absent in FGF21-TG mice. One explanation for this contradictory observations related to ovulation rate and FGF21 levels may related to differences in circulating FGF21 concentrations. One study using FGF21-TG mice reported plasma FGF21 concentrations to be 100 fold higher $(1000 \mathrm{ng} / \mathrm{ml})$ compared to WT (57) and what we observed. Such a very high circulating FGF21 concentration may be able to completely inhibit the proestrus surge in luteinizing hormone, thus preventing ovulation and $\mathrm{CL}$ formation. However, in the FGF21-TG mice models plasma FGF21 concentrations are only approximately twice as high compared to our study, nevertheless these mice do not ovulate $(46,58)$, making the explanation that elevated FGF21 levels inhibit ovulation less likely. In line with this, peripheral infusion of FGF21, resulting in plasma concentrations of $8 \mathrm{ng} / \mathrm{ml}$, also terminated the estrous cycle (46), stressing that differences in circulating FGF21 concentrations a less likely explanation. FGF21 overexpression increases energy expenditure, inducing weight loss and infertility, which is restored by high fat diet feeding while maintaining FGF21 levels, suggesting that energy insufficiency, rather than FGF21, is responsible for the observed infertility (47). This is supported by the observation that diets that significantly increase serum FGF21 levels (to $10 \mathrm{ng} / \mathrm{ml}$, levels similar to our study) did not induce infertility (ketogeneic diet) or alter transient infertility (fasting) (47). These results, indicating that FGF21 is not a direct physiological regulator of fertility in female mice, are in full agreement with our findings that show in UCP1-TG mice that FGF21 does not play a role in the ovarian follicular development. Although the energy insufficiency is probably responsible for the infertility of FGF21-TG mice, the underlying mechanism is not clear. Moreover, $25 \%$ of the high fat diet fed FGF21-TG mice were still infertile (47) and mice with restored fertility produced maximally only $50 \%$ of the litter size of WT mice (47) 
indicating that the infertility in the FGF21-TG mice may alternatively be explained by IGF1, since FGF21-TG also have reduced IGF1 levels (59), similar to the UCP1-TG and UCP1-TG/FGF21-- mice, as reported here.

The reduced plasma IGF1 levels of UCP1-TG mice are strongly correlated to reduced numbers of antral follicles and CLs. This is in line with observations in growth hormone receptor as well as growth hormone binding protein knockout (GHR/GHBP-KO) mice, which are fertile, but have strongly reduced IGF1 levels as well as reduced preantral and antral follicle numbers, and an increased percentage of atretic follicles (49). Restoration of IGF1 levels in these mice rescued the healthy antral follicle numbers and decreased the percentage of atretic follicles per ovary (51). GHR/GHBP-KO mice, and related mouse models such as the Ames dwarf mouse, show reduced size and reduced fertility, but also increased longevity (e.g. (60)), which all have been attributed to decreased IGF1 levels (61). Also in the FGF21-TG males and females, the increased life span is attributed to decreased IGF1 levels (59). The UCP1-TG mice also display an increased life span, in particular females on adverse diets (23). CR is a non-genetic, dietary intervention leading to reduced fertility and increased life span (11, 62), again, IGF1 signalling being implicated in both effects. For example, CR could not further increase life span extension in the GHR/GHBP-KO mice (63). In bovine CR decreased circulating IGF1 right from the start leading to anoestrous. Upon refeeding, concentrations of plasma IGF1 increased linearly until resumption of ovulation (64). From these and other studies (e.g.(65) IGF1 has emerged as an important factor balancing female reproductive functioning and longevity, a notion that is enforced by our results.

As can be expected, female IGF1 knockout mice that survive into adulthood are infertile. This is due to arrest of follicular development at the small antral stage $(33,66)$. Around $40 \%(3 / 8)$ of the UCP1TG mice show only small antral follicles and absence of $\mathrm{CL}$, indicating a similar arrest in follicular development at the small antral stage in these mice. Significantly reduced growing follicle numbers and the concomitant increase of (pre)antral follicular atresia in UCP1-TG ovaries is supported by a significant reduction in circulating $\mathrm{AMH}$ concentrations. AMH is mainly produced in the granulosa cells of growing ovarian follicles and its production levels peak at the late preantral stage in rodents. It is therefore widely used as biomarker of ovarian reproductive potential (56). Our data show that energy drain towards skeletal muscle impairs ovarian follicle development in the UCP1-TG mice. The reduced number of (pre)antral follicles together with the increased percentage of atretic follicles, has presumably contributed to the lower number of CLs in the UCP1-TG mice. The reduction in the number of (pre)antral follicles and CLs is however more striking than the increase in the percentage of atretic follicles. This may be explained by differences in counting; counting healthy follicles in every $5^{\text {th }}$ section and determining the percentage of atretic follicles by counting only 3 sections, as discussed previously (54). Thus, the total ovarian follicle and CL numbers cannot be directly related to the percentage of atretic follicles.

Surprisingly, litter size was not different between UCP1-TG and WT mice. This may possibly be explained by an increase in the quality of oocytes in the UCP1-TG mice, as has been shown for adult onset CR (67). Indeed, cumulative evidence obtained in various organisms suggests that upregulation of antioxidant defence systems occurs simultaneously with down regulation of fertility (62). Increased defence systems could drive an increase in oocyte quality. On the other hand, our mice were investigated at a young age (12 weeks) and only the first litter was scored. In female mice 
overexpressing defective mitochondrial DNA (mt DNA) polymerase, which show premature onset of aging-related characteristics, fertility was not affected until 20 weeks of age, before which these mice had delivered one or two litters of normal size (68). To obtain further insight in the fertility of the UCP1-TG mice, future studies should examine fertility in older female mice over a longer time period.

Although IGF1 is essential for female reproduction (69), the role of IGF receptors is more controversial, since female mice that lack both IGF1R and IGF2R are fertile (70). One explanation is that part of the IGF1 effect is mediated by the insulin receptor or related receptors (71). Although IGF1 seems not essential for oocyte maturation (72), it is shown to be essential for granulosa cell proliferation and follicular growth (73). In vitro studies have shown that AKT is a downstream node of growth factor signalling and is necessary for IGF1 mediated steroidogenesis in granulosa cells (74). Our data show reduced AKT activation in granulosa cells of healthy antral follicles of UCP1-TG mice compared to WT mice (Figures $6 \mathrm{~B}, 6 \mathrm{D}$, vs $6 \mathrm{~A}, 6 \mathrm{C}$ ). These data link IGF1 levels, which are higher in the WT mice, to AKT activation in granulosa cells. AKT activation was decreased and not different in atretic follicles of both genotypes (Figure 7). These results indicate that Phospho-AKT is related to granulosa cell functioning. Other data show that IGF1 promotes cell growth and suppresses apoptosis of granulosa cells by activating the phosphatidylinositol 3-kinase (PI3K)-AKT pathway $(35,37,38)$. The lower IGF1 levels and the decreased Phospho - AKT in the UCP1-TG mice thus are in agreement with, and may explain, the decreased antral follicle numbers and increased atresia in the UCP1-TG mice. IRS2, which is a more upstream component of both the insulin receptor and IGF1R signalling cascades, was identified as an essential integrator of female reproduction and energy homeostasis (39). Consistent with a role for IGF1 signalling in granulosa cells, we identified Phospho-IRS2 staining in granulosa cells of healthy antral follicles (Figure 6G, 6H). The differential activation of IRS2 in atretic antral follicles (Figure 7G, 7H) between UCP1-TG and WT mice is likely related to different IGF1 levels in these mice, since there is no difference in the fasted circulating insulin levels between the two groups (week 10; Figure 2 and sacrifice; data not shown) and the UCP1-TG mice are more, rather than less, insulin sensitive (Figure 2). The higher IGF1 levels in WT mice seem to evoke an IRS2 activation response in the granulosa cells of atretic follicles, a possible rescue attempt, which lacks in the UCP1-TG mice. The IRS2 response confirms IRS2 as an important component in ovarian IGF1 signalling, although questions remain on its functional role during follicular atresia. IRS proteins can form higher molecular weight complexes with so-called IRS associated proteins that have a role in intracellular localization and stability of IRS proteins and, consequently, in their functionality (75). Since little is known on the role of these proteins in ovarian follicular development, it is of interest to include them as well as other IRS proteins (IRS1, IRS3 and IRS 4) and negative regulators such as phosphatase and tensin homolog (PTEN) and tribbles homolog 3 (TRIB3), in examination of IGF1 signalling in the context of granulosa cell functioning. Above all, our data show that decreased IGF1 levels are probably responsible for the decreased antral follicles and concomitantly increased the ovarian follicular atresia in the UCP1-TG mice.

Compared to the role of IGF1 on antral follicle development, the function of IGF1 in preantral follicle development is not yet clear. Follicles seem to develop relatively normally until the early antral stage in IGF1 null mice (33), although numerical counting was not performed. This indicates that IGF1 is not essential in preantral follicles development. This is in agreement with our data, which show in UCP1TG mice that in preantral follicles the IGF1 signalling intermediates, Phospho-IRS2 and Phospho-AKT, were not different from WT mice. This is further supported by data from GHR/GHBP-KO mice, where 
IGF1 administration did not restore the significant reduced number of preantral follicles that were observed (51). If not IGF1, what might be mediators for preantral follicle development that are affected in UCP1-TG mice? In addition to FGF21, other myokines are induced in the male UCP1-TG mice. One of these is growth and differentiation factor 15 (GFD15) (19). GDF15 has been reported as marker for ovarian cancer (e.g. (76)). It is therefore of interest to examine whether circulating GDF15 is also increased in UCP1-TG female mice and whether it contributes to granulosa cells and preantral follicle development.

Energy availability is closely associated with female reproductive functioning. Indeed, CR and excess exercise result in reduced female fertility $(5-7,13,14)$. However, reproductive competence is maintained as long as food intake is maintained, even under energetic demanding conditions such as high amounts of exercise and cold exposure ((10) and references therein). Feeding studies show a rapid restoration of fertility, before restoration of adiposity, upon at libitum feeding after CR (11), suggesting that the primary driver is availability of metabolic fuels, rather than adiposity. This hypothesis is supported by studies with biochemical inhibitors (10). This makes sense form an evolutionary perspective (77), where a temporary halt in fertility makes energy available for maintenance, preserving viability and fertility. In the UCP1-TG mouse model of skeletal muscle pseudo starvation, energy is drained towards the muscle $(15,19)$. In the female UCP1-TG mice, follicular reserve and ovulation rate is impaired, despite maintenance of adiposity and leptin levels. Our results, obtained using a genetic model of energy dissipation, thus confirm the hypothesis that availability of metabolic fuels, and not stored energy, drives fertility.

\section{Acknowledgements}

The authors would like to thank Danielle Smeitink for her technical contributions. LM was funded by the China Scholarship Council (CSC) under grant number 2011685003.

\section{Authors contributions}

VC, MO, AV, SK performed the animal study. LM, KT performed ovarian histology. LM, VC, MO, AV, $A B$ performed the various other analyses. Manuscript layout was drafted by JK, with LM and VC. All authors were involved in data analysis, interpretation and discussion and in writing. The manuscript was finalized by KT and SK. 


\subsection{References}

1. Wade, G. N., and Schneider, J. E. (1992) Metabolic fuels and reproduction in female mammals. Neurosci Biobehav $\operatorname{Rev} 16,235-272$

2. Speakman, J. R., and Krol, Z. (2010) The Heat Dissipation Limit Theory and Evolution of Life Histories in Endotherms-Time to Dispose of the Disposable Soma Theory? Integr Comp Biol 50, 793-807

3. Evans, J. J., and Anderson, G. M. (2012) Balancing ovulation and anovulation: integration of the reproductive and energy balance axes by neuropeptides. Hum Reprod Update 18, 313-332

4. Bartke, A., Sun, L. Y., and Longo, V. (2013) Somatotropic Signaling: Trade-Offs Between Growth, Reproductive Development, and Longevity. Physiol Rev 93, 571-598

5. Widdowson, E. M., and Cowen, J. (1972) The effect of protein deficiency and calorie deficiency on the reproduction of rats. Br J Nutr 27, 85-95

6. Holehan, A. M., and Merry, B. J. (1985) The control of puberty in the dietary restricted female rat. Mech Ageing Dev 32, 179-191

7. Visscher, M. B., King, J. T., and Lee, Y. C. (1952) Further studies on influence of age and diet upon reproductive senescence in strain A female mice. Am J Physiol 170, 72-76

8. Selesniemi, K., Lee, H. J., and Tilly, J. L. (2008) Moderate caloric restriction initiated in rodents during adulthood sustains function of the female reproductive axis into advanced chronological age. Aging Cell 7, 622-629

9. Speakman, J. R., and Mitchell, S. E. (2011) Caloric restriction. Mol Aspects Med 32, $159-221$

10. Wade, G. N., Schneider, J. E., and Li, H. Y. (1996) Control of fertility by metabolic cues. Am J Physiol 270, E1-19

11. Ball, Z. B., Barnes, R. H., and Visscher, M. B. (1947) The effects of dietary caloric restriction on maturity and senescence, with particular reference to fertility and longevity. Am J Physiol 150, 511-519

12. Rich-Edwards, J. W., Spiegelman, D., Garland, M., Hertzmark, E., Hunter, D. J., Colditz, G. A., Willett, W. C., Wand, H., and Manson, J. E. (2002) Physical activity, body mass index, and ovulatory disorder infertility. Epidemiology 13, 184-190

13. Gudmundsdottir, S. L., Flanders, W. D., and Augestad, L. B. (2009) Physical activity and fertility in women: the North-Trondelag Health Study. Hum Reprod 24, 3196-3204

14. Warren, M. P. (1980) The effects of exercise on pubertal progression and reproductive function in girls. J Clin Endocrinol Metab 51, 1150-1157

15. Couplan, E., Gelly, C., Goubern, M., Fleury, C., Quesson, B., Silberberg, M., Thiaudiere, E., Mateo, P., Lonchampt, M., Levens, N., de Montrion, C., Ortmann, S., Klaus, S., Gonzalez-Barroso, M. D. M., Cassard-Doulcier, A. M., Ricquier, D., Bigard, A. X., Diolez, P., and Bouillaud, F. (2002) High level of uncoupling protein 1 expression in muscle of transgenic mice selectively affects muscles at rest and decreases their Ilb fiber content. J Biol Chem $\mathbf{2 7 7}$, 43079-43088

16. Sanchez-Gurmaches, J., Hung, C. M., and Guertin, D. A. (2016) Emerging Complexities in Adipocyte Origins and Identity. Trends Cell Biol 26, 313-326

17. Klaus, S., Casteilla, L., Bouillaud, F., and Ricquier, D. (1991) The uncoupling protein UCP: a membraneous mitochondrial ion carrier exclusively expressed in brown adipose tissue. Int J Biochem 23, 791-801

18. Klaus, S., Rudolph, B., Dohrmann, C., and Wehr, R. (2005) Expression of uncoupling protein 1 in skeletal muscle decreases muscle energy efficiency and affects thermoregulation and substrate oxidation. Physiol Genomics 21, $193-200$

19. Ost, M., Keipert, S., van Schothorst, E. M., Donner, V., van der Stelt, I., Kipp, A. P., Petzke, K. J., Jove, M., Pamplona, R., Portero-Otin, M., Keijer, J., and Klaus, S. (2015) Muscle mitohormesis promotes cellular survival via serine/glycine pathway flux. FASEB J 29, 1314-1328

20. Gates, A. C., Bernal-Mizrachi, C., Chinault, S. L., Feng, C., Schneider, J. G., Coleman, T., Malone, J. P., Townsend, R. R., Chakravarthy, M. V., and Semenkovich, C. F. (2007) Respiratory uncoupling in skeletal muscle delays death and diminishes age-related disease. Cell Metab 6, 497-505 
21. Neschen, S., Katterle, Y., Richter, J., Augustin, R., Scherneck, S., Mirhashemi, F., Schurmann, A., Joost, H. G., and Klaus, S. (2008) Uncoupling protein 1 expression in murine skeletal muscle increases AMPK activation, glucose turnover, and insulin sensitivity in vivo. Physiol Genomics 33, 333-340

22. Katterle, Y., Keipert, S., Hof, J., and Klaus, S. (2008) Dissociation of obesity and insulin resistance in transgenic mice with skeletal muscle expression of uncoupling protein 1. Physiol Genomics 32, 352-359

23. Keipert, S., Voigt, A., and Klaus, S. (2011) Dietary effects on body composition, glucose metabolism, and longevity are modulated by skeletal muscle mitochondrial uncoupling in mice. Aging Cell 10, 122-136

24. Keipert, S., Ost, M., Johann, K., Imber, F., Jastroch, M., van Schothorst, E. M., Keijer, J., and Klaus, S. (2014) Skeletal muscle mitochondrial uncoupling drives endocrine cross-talk through the induction of FGF21 as a myokine. Am J Physiol Endocrinol Metab 306, E469-482

25. LeRoith, D., and Yakar, S. (2007) Mechanisms of Disease: metabolic effects of growth hormone and insulin-like growth factor 1. Nat Rev Endocrinol 3, 302-310

26. Werner, H., Weinstein, D., and Bentov, I. (2008) Similarities and differences between insulin and IGF-I: structures, receptors, and signalling pathways. Arch Physiol Biochem 114, 17-22

27. Ohlsson, C., Mohan, S., Sjogren, K., Tivesten, A., Isgaard, J., Isaksson, O., Jansson, J. O., and Svensson, J. (2009) The role of liver-derived insulin-like growth factor-I. Endocr Rev 30, 494-535

28. Slot, K. A., Voorendt, M., de Boer-Brouwer, M., van Vugt, H. H., and Teerds, K. J. (2006) Estrous cycle dependent changes in expression and distribution of Fas, Fas ligand, Bcl-2, Bax, and pro- and active caspase-3 in the rat ovary. J Endocrinol 188, 179-192

29. Zhou, J., Chin, E., and Bondy, C. (1991) Cellular pattern of insulin-like growth factor-I (IGF-I) and IGF-I receptor gene expression in the developing and mature ovarian follicle. Endocrinology 129, 3281-3288

30. Wandji, S. A., Wood, T. L., Crawford, J., Levison, S. W., and Hammond, J. M. (1998) Expression of mouse ovarian insulin growth factor system components during follicular development and atresia. Endocrinology 139, 52055214

31. Armstrong, D. G., Gutierrez, C. G., Baxter, G., Glazyrin, A. L., Mann, G. E., Woad, K. J., Hogg, C. O., and Webb, R. (2000) Expression of mRNA encoding IGF-I, IGF-II and type 1 IGF receptor in bovine ovarian follicles. J Endocrinol $165,101-113$

32. Hastie, P. M., and Haresign, W. (2006) Expression of mRNAs encoding insulin-like growth factor (IGF) ligands, IGF receptors and IGF binding proteins during follicular growth and atresia in the ovine ovary throughout the oestrous cycle. Anim Reprod Sci 92, 284-299

33. Baker, J., Hardy, M. P., Zhou, J., Bondy, C., Lupu, F., Bellve, A. R., and Efstratiadis, A. (1996) Effects of an Igf1 gene null mutation on mouse reproduction. Mol Endocrinol 10, 903-918

34. Zhou, J., Kumar, T. R., Matzuk, M. M., and Bondy, C. (1997) Insulin-like growth factor I regulates gonadotropin responsiveness in the murine ovary. Mol Endocrinol 11, 1924-1933

35. Zhou, P., Baumgarten, S. C., Wu, Y., Bennett, J., Winston, N., Hirshfeld-Cytron, J., and Stocco, C. (2013) IGF-I signaling is essential for FSH stimulation of AKT and steroidogenic genes in granulosa cells. Mol Endocrinol 27, 511-523

36. Glister, C., Tannetta, D. S., Groome, N. P., and Knight, P. G. (2001) Interactions between follicle-stimulating hormone and growth factors in modulating secretion of steroids and inhibin-related peptides by nonluteinized bovine granulosa cells. Biol Reprod 65, 1020-1028

37. Hu, C. L., Cowan, R. G., Harman, R. M., and Quirk, S. M. (2004) Cell cycle progression and activation of Akt kinase are required for insulin-like growth factor I-mediated suppression of apoptosis in granulosa cells. Mol Endocrinol 18, 326-338

38. Sun, G. W., Kobayashi, H., Suzuki, M., Kanayama, N., and Terao, T. (2003) Follicle-stimulating hormone and insulinlike growth factor I synergistically induce up-regulation of cartilage link protein (Crtl1) via activation of phosphatidylinositol-dependent Kinase/Akt in rat granulosa cells. Endocrinology 144, 793-801

39. Burks, D. J., Font de Mora, J., Schubert, M., Withers, D. J., Myers, M. G., Towery, H. H., Altamuro, S. L., Flint, C. L., and White, M. F. (2000) IRS-2 pathways integrate female reproduction and energy homeostasis. Nature 407, $377-$ 382 
40. Nishimura, T., Nakatake, Y., Konishi, M., and Itoh, N. (2000) Identification of a novel FGF, FGF-21, preferentially expressed in the liver. Biochim Biophys Acta 1492, 203-206

41. Ost, M., Coleman, V., Voigt, A., van Schothorst, E. M., Keipert, S., van der Stelt, I., Ringel, S., Graja, A., Ambrosi, T., Kipp, A. P., Jastroch, M., Schulz, T. J., Keijer, J., and Klaus, S. (2016) Muscle mitochondrial stress adaptation operates independently of endogenous FGF21 action. Mol Metab 5, 79-90

42. Itoh, N., Ohta, H., and Konishi, M. (2015) Endocrine FGFs: Evolution, Physiology, Pathophysiology, and Pharmacotherapy. Front Endocrinol (Lausanne) 6, 154

43. Fisher, F. M., and Maratos-Flier, E. (2016) Understanding the Physiology of FGF21. Annu Rev Physiol 78, 223-241

44. Gimeno, R. E., and Moller, D. E. (2014) FGF21-based pharmacotherapy--potential utility for metabolic disorders. Trends Endocrinol Metab 25, 303-311

45. Goetz, R., Beenken, A., Ibrahimi, O. A., Kalinina, J., Olsen, S. K., Eliseenkova, A. V., Xu, C., Neubert, T. A., Zhang, F., Linhardt, R. J., Yu, X., White, K. E., Inagaki, T., Kliewer, S. A., Yamamoto, M., Kurosu, H., Ogawa, Y., Kuro-o, M., Lanske, B., Razzaque, M. S., and Mohammadi, M. (2007) Molecular insights into the klotho-dependent, endocrine mode of action of fibroblast growth factor 19 subfamily members. Mol Cell Biol 27, 3417-3428

46. Owen, B. M., Bookout, A. L., Ding, X., Lin, V. Y., Atkin, S. D., Gautron, L., Kliewer, S. A., and Mangelsdorf, D. J. (2013) FGF21 contributes to neuroendocrine control of female reproduction. Nat Med 19, 1153-1156

47. Singhal, G., Douris, N., Fish, A. J., Zhang, X., Adams, A. C., Flier, J. S., Pissios, P., and Maratos-Flier, E. (2016) Fibroblast growth factor 21 has no direct role in regulating fertility in female mice. Mol Metab 5, 690-698

48. Hotta, Y., Nakamura, H., Konishi, M., Murata, Y., Takagi, H., Matsumura, S., Inoue, K., Fushiki, T., and Itoh, N. (2009) Fibroblast growth factor 21 regulates lipolysis in white adipose tissue but is not required for ketogenesis and triglyceride clearance in liver. Endocrinology 150, 4625-4633

49. Hasky, N., Uri-Belapolsky, S., Goldberg, K., Miller, I., Grossman, H., Stemmer, S. M., Ben-Aharon, I., and Shalgi, R. (2015) Gonadotrophin-releasing hormone agonists for fertility preservation: unraveling the enigma? Hum Reprod 30, $1089-1101$

50. Duivenvoorde, L. P., van Schothorst, E. M., Swarts, H. M., Kuda, O., Steenbergh, E., Termeulen, S., Kopecky, J., and Keijer, J. (2015) A Difference in Fatty Acid Composition of Isocaloric High-Fat Diets Alters Metabolic Flexibility in Male C57BL/6JOlaHsd Mice. PLoS One 10, e0128515

51. Slot, K. A., Kastelijn, J., Bachelot, A., Kelly, P. A., Binart, N., and Teerds, K. J. (2006) Reduced recruitment and survival of primordial and growing follicles in GH receptor-deficient mice. Reproduction 131, 525-532

52. Flaws, J. A., Abbud, R., Mann, R. J., Nilson, J. H., and Hirshfield, A. N. (1997) Chronically elevated luteinizing hormone depletes primordial follicles in the mouse ovary. Biol Reprod 57, 1233-1237

53. Dijkstra, G., de Rooij, D. G., de Jong, F. H., and van den Hurk, R. (1996) Effect of hypothyroidism on ovarian follicular development, granulosa cell proliferation and peripheral hormone levels in the prepubertal rat. Eur $\mathrm{J}$ Endocrinol 134, 649-654

54. Meng, L., Rijntjes, E., Swarts, H., Bunschoten, A., van der Stelt, I., Keijer, J., and Teerds, K. (2016) Dietary-Induced Chronic Hypothyroidism Negatively Affects Rat Follicular Development and Ovulation Rate and Is Associated with Oxidative Stress. Biol Reprod 94:1-11

55. Jequier, E., Acheson, K., and Schutz, Y. (1987) Assessment of energy expenditure and fuel utilization in man. Annu Rev Nutr 7, 187-208

56. Findlay, J. K., Hutt, K. J., Hickey, M., and Anderson, R. A. (2015) What is the "ovarian reserve"? Fertil Steril 103, $628-630$

57. Bookout, A. L., de Groot, M. H., Owen, B. M., Lee, S., Gautron, L., Lawrence, H. L., Ding, X., Elmquist, J. K., Takahashi, J. S., Mangelsdorf, D. J., and Kliewer, S. A. (2013) FGF21 regulates metabolism and circadian behavior by acting on the nervous system. Nat Med 19, 1147-1152

58. Inagaki, T., Lin, V. Y., Goetz, R., Mohammadi, M., Mangelsdorf, D. J., and Kliewer, S. A. (2008) Inhibition of growth hormone signaling by the fasting-induced hormone FGF21. Cell Metab 8, 77-83

59. Zhang, Y., Xie, Y., Berglund, E. D., Coate, K. C., He, T. T., Katafuchi, T., Xiao, G., Potthoff, M. J., Wei, W., Wan, Y., Yu, R. T., Evans, R. M., Kliewer, S. A., and Mangelsdorf, D. J. (2012) The starvation hormone, fibroblast growth factor21, extends lifespan in mice. Elife 1, e00065 
60. Bartke, A., Sun, L. Y., and Longo, V. (2013) Somatotropic signaling: trade-offs between growth, reproductive development, and longevity. Physiol Rev 93, 571-598

61. Chandrashekar, V., and Bartke, A. (2003) The role of insulin-like growth factor-I in neuroendocrine function and the consequent effects on sexual maturation: inferences from animal models. Reprod Biol 3, 7-28

62. Tilly, J. L., and Sinclair, D. A. (2013) Germline energetics, aging, and female infertility. Cell Metab 17, 838-850

63. Bonkowski, M. S., Rocha, J. S., Masternak, M. M., Al Regaiey, K. A., and Bartke, A. (2006) Targeted disruption of growth hormone receptor interferes with the beneficial actions of calorie restriction. Proc Natl Acad Sci U S A 103, 7901-7905

64. Bossis, I., Wettemann, R. P., Welty, S. D., Vizcarra, J., and Spicer, L. J. (2000) Nutritionally induced anovulation in beef Heifers: ovarian and endocrine function during realimentation and resumption of ovulation. Biol Reprod 62 , 1436-1444

65. Rocha, J. S., Bonkowski, M. S., Masternak, M. M., Franca, L. R., and Bartke, A. (2012) Effects of adult onset mild calorie restriction on weight of reproductive organs, plasma parameters and gene expression in male mice. Anim Reprod 9, 40-51

66. Zhou, J., Kumar, T. R., Matzuk, M. M., and Bondy, C. (1997) Insulin-like growth factor I regulates gonadotropin responsiveness in the murine ovary. Mol Endocrinol 11, 1924-1933

67. Selesniemi, K., Lee, H. J., Muhlhauser, A., and Tilly, J. L. (2011) Prevention of maternal aging-associated oocyte aneuploidy and meiotic spindle defects in mice by dietary and genetic strategies. Proc Natl Acad Sci U S A 108, $12319-12324$

68. Trifunovic, A., Wredenberg, A., Falkenberg, M., Spelbrink, J. N., Rovio, A. T., Bruder, C. E., Bohlooly, Y. M., Gidlof, S., Oldfors, A., Wibom, R., Tornell, J., Jacobs, H. T., and Larsson, N. G. (2004) Premature ageing in mice expressing defective mitochondrial DNA polymerase. Nature 429, 417-423

69. Stratikopoulos, E., Szabolcs, M., Dragatsis, I., Klinakis, A., and Efstratiadis, A. (2008) The hormonal action of IGF1 in postnatal mouse growth. Proc Natl Acad Sci U S A 105, 19378-19383

70. Ludwig, T., Eggenschwiler, J., Fisher, P., D'Ercole, A. J., Davenport, M. L., and Efstratiadis, A. (1996) Mouse mutants lacking the type 2 IGF receptor (IGF2R) are rescued from perinatal lethality in Igf2 and Igf1r null backgrounds. Dev Biol 177, 517-535

71. Efstratiadis, A. (1998) Genetics of mouse growth. Int J Dev Biol 42, 955-976

72. Pitetti, J. L., Torre, D., Conne, B., Papaioannou, M. D., Cederroth, C. R., Xuan, S., Kahn, R., Parada, L. F., Vassalli, J. D., Efstratiadis, A., and Nef, S. (2009) Insulin receptor and IGF1R are not required for oocyte growth, differentiation, and maturation in mice. Sex Dev 3, 264-272

73. Kadakia, R., Arraztoa, J. A., Bondy, C., and Zhou, J. (2001) Granulosa cell proliferation is impaired in the Igf1 null ovary. Growth Horm IGF Res 11, 220-224

74. Mani, A. M., Fenwick, M. A., Cheng, Z., Sharma, M. K., Singh, D., and Wathes, D. C. (2010) IGF1 induces upregulation of steroidogenic and apoptotic regulatory genes via activation of phosphatidylinositol-dependent kinase/AKT in bovine granulosa cells. Reproduction 139, 139-151

75. Hakuno, F., Fukushima, T., Yoneyama, Y., Kamei, H., Ozoe, A., Yoshihara, H., Yamanaka, D., Shibano, T., SoneYonezawa, M., Yu, B. C., Chida, K., and Takahashi, S. (2015) The Novel Functions of High-Molecular-Mass Complexes Containing Insulin Receptor Substrates in Mediation and Modulation of Insulin-Like Activities: Emerging Concept of Diverse Functions by IRS-Associated Proteins. Front Endocrinol 6, 73

76. Staff, A. C., Bock, A. J., Becker, C., Kempf, T., Wollert, K. C., and Davidson, B. (2010) Growth differentiation factor15 as a prognostic biomarker in ovarian cancer. Gynecol Oncol 118, 237-243

77. Shanley, D. P., and Kirkwood, T. B. (2000) Calorie restriction and aging: a life-history analysis. Evolution 54, 740750 

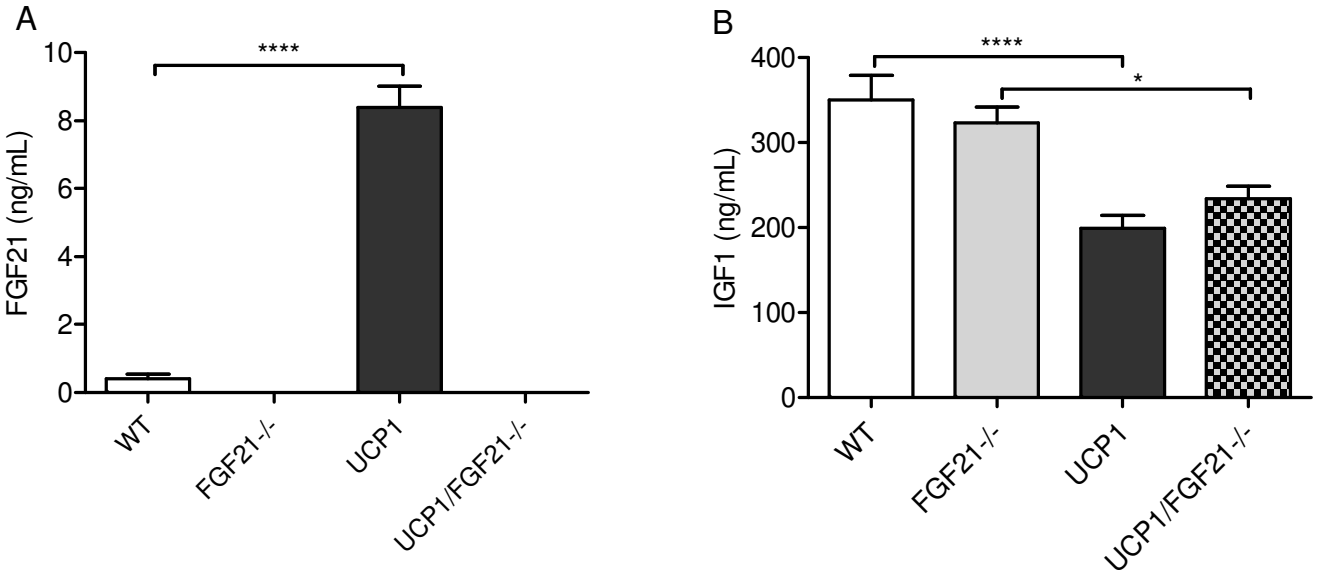

Supplemental Figure 1. Plasma FGF21 and IGF1 levels. Concentration of plasma FGF21 (A) and IGF1 (B) in WT (white), FGF21 $1^{--}$(grey) UCP1-TG (UCP1; black) and FGF21 ${ }^{-\%}$ / UCP1-TG (FGF21\%/UCP1; mixed) mice. Statistical analyses were based $\mathrm{n}=4-6$ for FGF21 and $\mathrm{n}=10$ for IGF1. ${ }^{*}, \mathrm{p}<0.05 ; * * * \mathrm{p}<0.0001$.

A

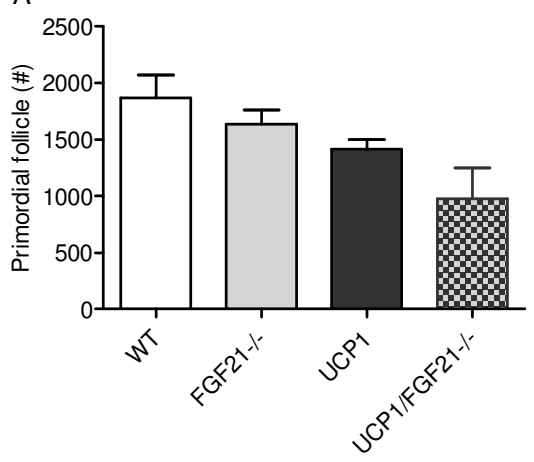

C

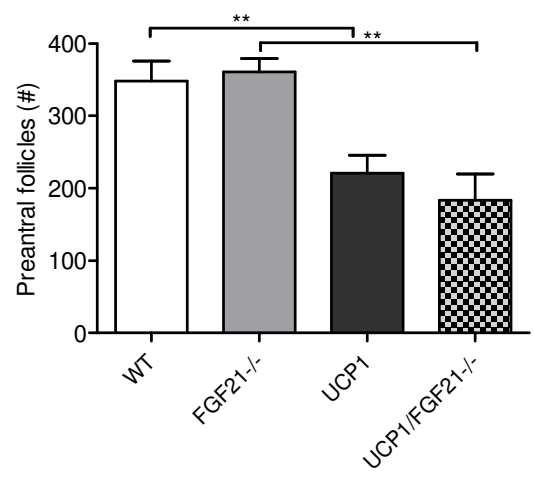

B

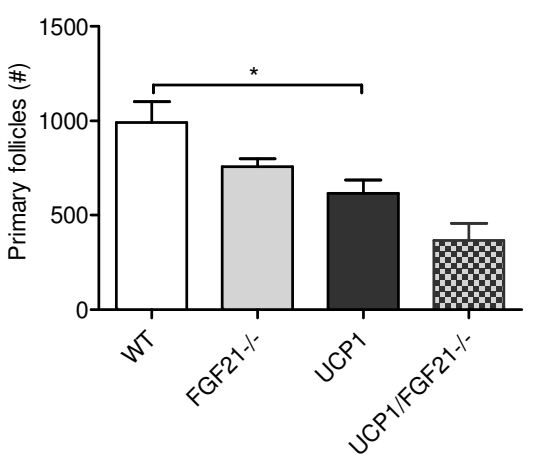

D

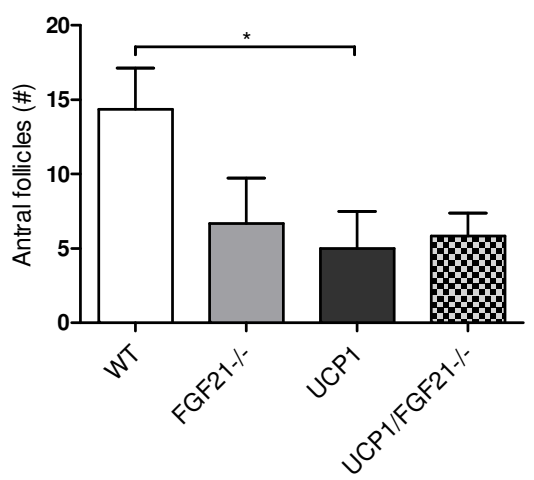

Supplemental Figure 2. FGF21 and follicle types. Number of primordial follicles (A), primary follicles (B), preantral follicles (C) and antral follicles (D) in WT (white), FGF21 knock out (FGF21-/-; grey), UCP1-TG (UCP1; black) and FGF21 /- / UCP1-TG mice (FGF21 $1^{-1} /$ UCP1; mixed). Statistical analyses were done on $6-8$ mice per group. ${ }^{*}, \mathrm{p}<0.05 ;{ }^{* *}, \mathrm{p}<0.01$. 

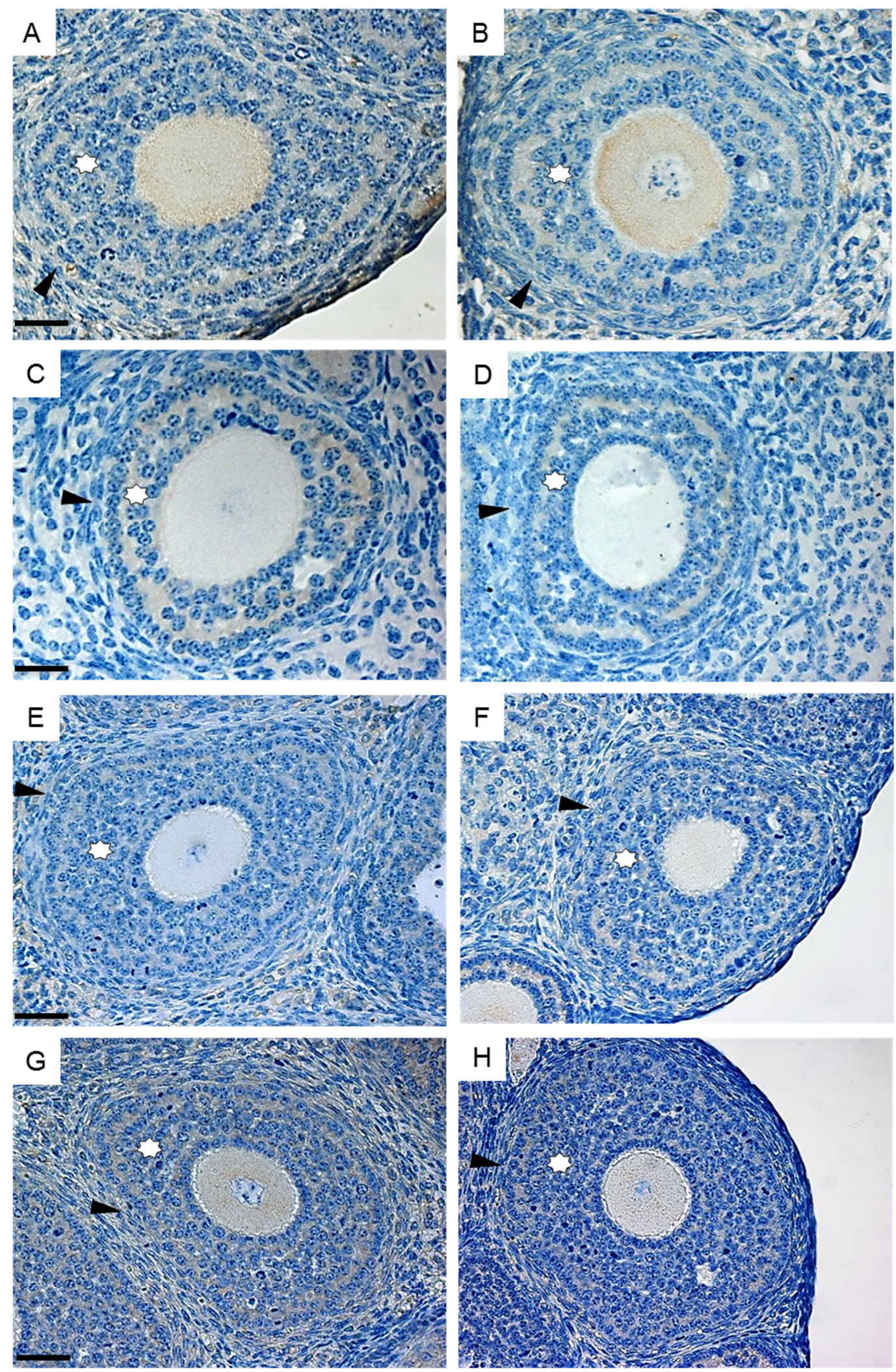

Supplemental Figure 3. Immunostaining for activated IRS2 and AKT as markers of IGF1 signalling in healthy preantral follicles. Representative AKT (A, B), Phospho-AKT (C,D) and IRS2 (E, F), Phospho-IRS2 (G, H) (brown) of ovarian follicles of WT (A, C, E, G) and UCP1-TG (B, D, F, H) mice; Granulosa cells are indicated by asterisks, theca cells by arrowheads. Scale bars represent $50 \mu \mathrm{m}$. 
Chapter 6

General Discussion 



\subsection{Major findings}

The overall goal of this thesis was to investigate the effects of an altered body nutrient flux, by altering energy status, on ovarian follicular development. Two animal models were used: a dietinduced thyroid hormone (TH) deficiency model and a genetic model of skeletal muscle semistarvation. The major findings in this thesis are:

- Antral follicular attrition is initiated by massive granulosa cell apoptosis, while preantral follicles atresia occurs mainly via enhanced granulosa cell autophagy (chapter 2 )

- Chronic hypothyroidism induced in adulthood results in a significant decrease in primordial, primary and preantral follicle numbers (chapter 3 ).

- Independent of changes in primordial follicle numbers, impairment of the population of healthy growing follicles is observed along with an increased percentage of follicular atresia in female rats in which a chronic hypothyroidism condition is induced from the foetal/postnatal period onwards. The reduction in growing follicle numbers is associated with oxidative stress (chapter 4).

- The difference in effects of reduced TH levels on the ovarian follicle pool as described in chapter 3 and 4 suggests that the age at onset of the hypothyroid condition determines which population of follicles is affected most.

- A lower availability of metabolic fuels induced by ectopic expression of UCP1 in skeletal muscle has a negative effect on the population of healthy growing follicles and concomitantly induces an increase in follicular atresia, which is not due to FGF21, but is associated with IGF1 levels and involves, at least in part, IGF1 signalling.

\subsection{Methods used in the thesis}

\section{Immunohistochemistry and ovarian functional analysis}

In this thesis, histology/immunohistochemistry in combination with light microscopy are the main techniques used. Immunohistochemistry $(\mathrm{IHC})$ is used to understand the cellular localization of proteins of interest $[1,2]$. This technique is especially useful in an organ like the ovary with its heterogeneous follicle population; Follicles in different developmental stages and health status as well as corpora lutea from different ovulations are found next to each other. IHC makes it possible to allocate proteins to specific cell types, i.e., theca, granulosa and luteal cells, and oocytes of follicles in different stages of development. This method is used in my thesis in chapters 2, 3 and 5.

Antigens can be detected by IHC directly by the use of a primary antibody coupled to a fluorophore or several biotin molecules which can complex with avidin or streptavidin. This is a rapid method of protein detection, but has a disadvantage that it is not very sensitive. The IHC technique used in my thesis is an indirect method in which the protein of interest is targeted by a primary antibody. The primary antibody can be detected by a secondary antibody tagged either with several biotin molecules or a fluorophore. The secondary antibody must be raised against the same IgG class of the animal species in which the primary antibody has been raised. This detection method is more sensitive than the direct approach because several secondary antibodies can bind to each primary antibody. Further amplification can be obtained if the secondary antibody is conjugated to several biotin molecules which, for instance, can complex with peroxidase labelled avidin. Avidin is a large 
glycoprotein with a high affinity for biotin. The avidin-biotin peroxidase complex can react with diaminobenzidine (DAB) to produce an insoluble product (brown). This method is termed the $A B C$ (for avidin-biotin-complex) peroxidase method, and is one of the most widely used IHC methods today $[2,3]$. Its sensitivity is approximately 100 -fold higher compared with fluorescent methods using a directly tagged secondary antibody [2]. In combination with haematoxylin as nuclear counterstain, morphology and specific proteins can be targeted simultaneously and in this way it is, for example, possible to discriminate between atretic follicles and healthy follicles based on morphological characteristics of the apoptotic cells as well as the use of specific apoptotic marker enzymes. However, IHC is not a quantitative method and therefore in some cases IHC observations are expanded with another technique, Laser Capture Microdissection (LCM) followed by RT-qPCR to analyse the mRNA levels of the genes of interest.

\section{LCM and ovarian functional analysis}

LCM followed by real time RT-PCR is an advanced technique to analyse gene expression of homogeneous cell populations from specific microscopic areas in heterogeneous tissue sections [4]. With LCM, it is possible to isolate macromolecules from collected cells for several types of analyses, including real time RT-PCR, microarray, RNA sequencing, and proteomics [5]. The big advantage of LCM is that it is possible to combine histologic examination with gene expression analysis. Therefore, this technique is a useful tool to investigate the functioning of specific cell populations, like granulosa cells, in the heterogeneous ovary tissue at a molecular level. This technique has been used in chapter 2 .

For LCM, however, there is often a trade-off between obtaining good quality RNA/DNA and proteins and maintaining a good morphology of the tissue [6-8]. The quality and quantity of RNA/DNA and proteins are highly dependent on the way of tissue collection and processing. Fresh or snap-frozen tissue samples are the proper material for molecular analysis because they provide the best source of intact macromolecules [9]. However, these samples do not provide precise morphological details and thus are not routinely used in studies where it is important to obtain detailed information about the tissue morphology as well. Chemically fixed and paraffin-embedded tissues are normally used in these studies [10]. From all the chemical fixatives, alcohol-based methacarn has been tested to be one of the best fixatives, based on its time-independent effects on mRNA preservation [10].

In the study described in chapter 2, methacarn fixed paraffin-embedded ovaries are used for LCM, in order to discriminate atretic follicles from healthy follicles (Figure 1). Granulosa cells were collected, RNA was isolated and mRNA of reference genes and genes of interest have been amplified by real time RT-PCR. For future studies, LCM followed by RNA sequencing can be used to obtain a wider overview of the molecular changes that occur. 

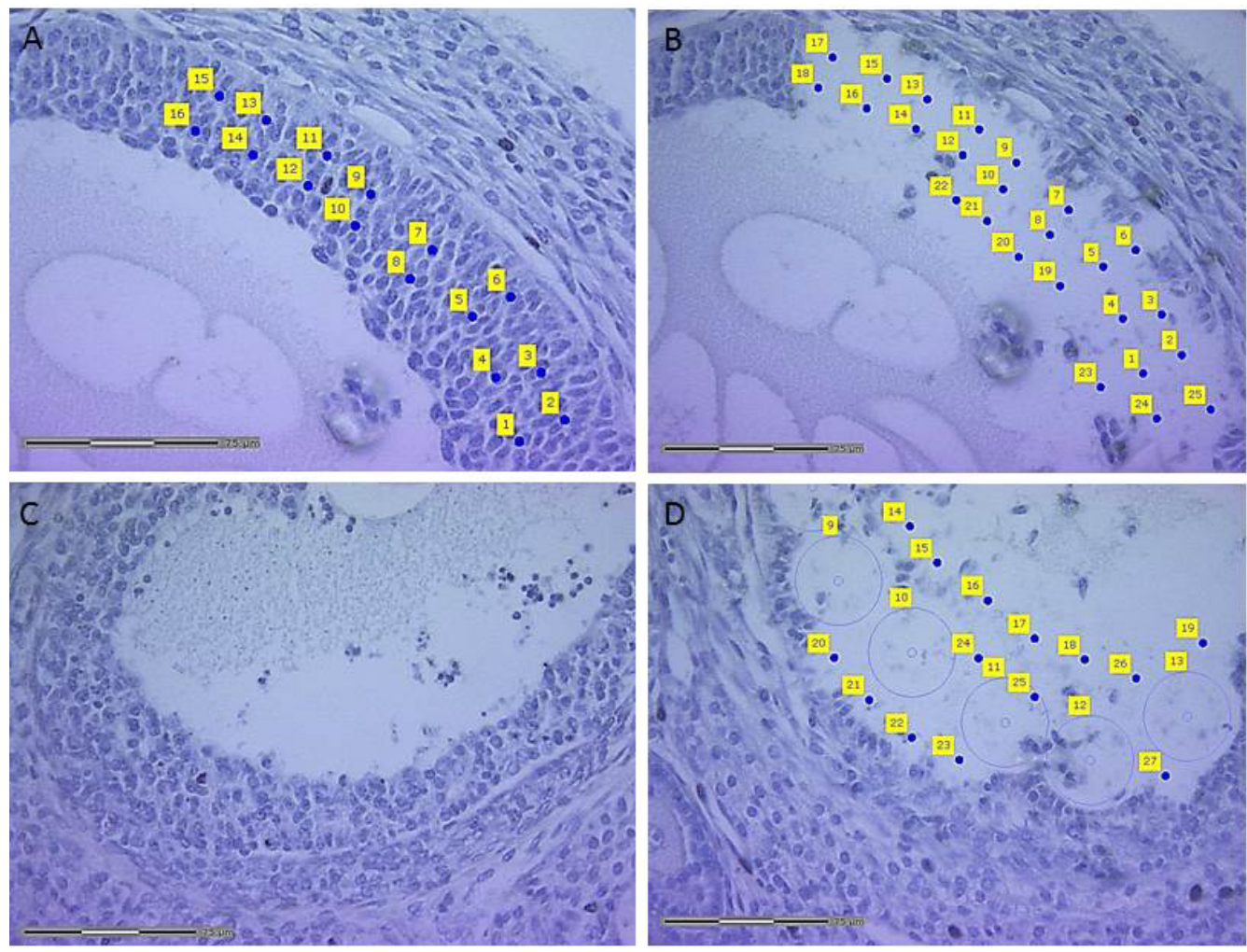

Figure 1, Representative pictures of LCM collection of granulosa cells for RNA isolation. Healthy antral follicle before (A) and after LCM (B), atretic antral follicle before (C) and after LCM (D). Rectangular yellow box, laser dot for granulosa cell layer.

\subsection{Autophagy-dependent cell death and ovarian follicle atresia}

Programmed cell death is a conserved and genetically regulated process that plays a crucial role in development and growth. Until now, three types of programmed cell death have been identified, apoptosis, autophagy-dependent cell death, and necroptosis, a programmed form of necrosis [11, 12]. Autophagy-dependent cell death is characterized by the presence of numerous autophagosomes involved in degradation of the bulk of cytoplasmic organelles in the cell, ultimately leading to cell death. As autophagy is also a well-known cell survival mechanism, there is controversy as to whether autophagy is a casual mechanism inducing cell death (cell death by autophagy) or simply occurs when cells are dying (cell death with autophagy) [13-15]. Under conditions of nutrient shortage, for example, autophagy is used to produce amino acids and energy to maintain cell viability through bulk degradation of cytoplasmic material. Therefore, the presence of autophagy in dying cells has also been described to be a stress adapting mechanism to maintain cell viability [16].

Despite of these observations, recent studies strongly support the notion that autophagy can promote cell death. Evidence in support of this assumption comes from several studies. First of all, in Drosophila melanogaster it has been shown that autophagy is the main process involved in cell death and not apoptosis or necrosis [17, 18]. In U937 monocytoid cells and 2929 fibrosarcoma cells, cell death is blocked by knockdown of either Beclin 1 or Atg7, two genes essential for the execution of autophagy [19]. In another study it is shown that mice embryonic fibroblast cells in which both Bax and Bak, two key pro-apoptotic genes, were inactivated, undergo non-apoptotic cell death. Death of 
these cells was associated with increased numbers of autophagosomes and autolysosomes, and could be inhibited by knockdown of the autophagy related genes Atg5 or Beclin1 [20]. In human ovarian surface epithelial cells, expression of the H-Ras ${ }^{\mathrm{V} 12}$ oncogene leads to caspase-independent cell death with characteristics of autophagy-dependent cell death, along with up-regulation of Beclin 1 [21]. Moreover, activation of autophagy-inducing peptide by in vitro induced starvation or in vivo during certain types of ischemia, can cause autophagy gene-dependent cell death, also named autosis. This type of cell death is blocked by either pharmacological or genetic inhibition of autophagy, but not by impairment of known regulators of either apoptosis or necrosis [22]. In neonatal mice, neuron-specific deletion of Atg7 protects against cerebral hypoxia-ischemia-induced hippocampal neuron death [23]. In adult rats, shRNA targeting Beclin 1 prevents neuronal death in the thalamus following focal cerebral infarction [24].

In recent years, the role of autophagy-dependent cell death in the ovary has increasingly received attention [25]. Each oestrous cycle, numerous ovarian follicles undergo atresia. Originally, follicular atresia was thought to occur entirely by apoptosis. The discovery of granulosa cell death by oxidised LDL-dependent lectin-type receptor-activated autophagy, however, suggests that autophagy may also play a role $[26,27]$. In line with these observations, the faint to absent p62 immunostaining in atretic preantral follicles as shown in chapter 2 suggests that autophagy-induced cell death is involved in preantral follicular atresia. However, although p62 plays an important role in autophagy, analysis of p62 alone is not sufficient as the marker for a role of autophagy in the regulation of cell death . In some cells, the overall levels of p62 are not altered in spite of induction of autophagy [12]. In other conditions a decrease in p62 has been related to a blockage of autophagy due to caspase induced cleavage of some autophagy-related proteins, including p62 [12]. In line with these observations, it has been shown that p62 is a substrate for caspase 6 and caspase 8, which may confound its use as a marker in autophagy-dependent cell death [28]. Thus, using p62 in combination with other markers of autophagy is recommended. Therefore, in chapter 2, I used LC3 in combination with p62 to demonstrate the presence of autophagy in preantral follicular atresia. I did not observe a difference in LC3 immunostaining between healthy and atretic follicles, which can be explained by the characteristic of the LC3 antibody used, detecting total LC3 protein including both LC3I and LC3II. The activated form of LC3, LC3II, is the marker correlated with autophagosome formation and thus autophagy. The total amount of LC3 does not necessarily need to change with increased autophagy [29]. As LC3II is concentrated on the autophagosome membrane, counting the number of LC3 puncta per cell using immunofluorescence staining is a common method that is used to quantify autophagosomes in GFP-LC3 transgenic animals or cells $[12,29]$. However, I was unable to detect LC3 protein by indirect immunofluorescence in ovarian follicles, presumably due to strong autofluorescence present in the formalin-fixed paraffin embedded ovarian sections. Another method to detect autophagosomes is by using electron microscopical analysis, which remains one of the most widely used techniques for autophagy detection [12, 29]. Despite of this, by combining p62 and LC3 immunostaining with western blotting and LCM / RT-qPCR, I obtained sufficient evidence to assume an important role for autophagy in preantral follicular atresia (chapter 2). Autophagy can also be examined by analysis of other proteins, such as autophagy initiation complexes, the ULK complex and the Beclin1-Vsp34 complex. The ULK complex is regulated by differential phosphorylation by AMP activated protein kinase (AMPK; stimulation) and Mammalian target of rapamycin complex 1 (mTORC1; inhibition) [30]. ULK1 can phosphorylate BECLIN1, thereby enhancing the activity of the BECLIN1-VPS34 complex [31]. Analysis of the phosphorylation states of ULK1 and BECLIN1 may be 
used to further investigate the role autophagy and autophagy regulation in follicular atresia [32]. However, at the time of the work described in chapter 2 there were no properly working antibodies available against (phosphorylated) BECLIN1 and ULK1 that could be used for immunohistochemical purposes in order to investigate this.

In line with my observation that autophagy plays a role in follicular atresia, in a mice model investigating the effects of cigarette smoke on follicular development, it was shown that cigarette smoke induced autophagy-dependent cell death in granulosa cells [33-35]. There are also indications for a higher incidence of autophagy-dependent granulosa cell death in obese women, which may contribute to the increased rate of infertility in these women [26]. In contrast, under foetal/postnatal hypothyroid conditions (chapter 4), the absence of any difference in LC3II and p62 protein levels between the euthyroid and hypothyroid animals (Figure 2) suggests that autophagy is not likely involved in the observed increased ovarian follicular atresia. These results are in line with the absence of a difference in the percentage of atretic preantral follicles between the hypothyroid and euthyroid groups, since preantral antral follicle atresia is mainly through autophagy as indicated in the study described in chapter 2. Additionally, it has to be taken into account that for Figure 2 the whole ovary with mixed types of cells has been used for the western blot analysis, which may have masked changes in autophagy-related protein levels [12]. The above data suggest that, like in other tissues, the specific context determines whether granulosa cell death is induced by autophagy or apoptosis [12, 36-39].

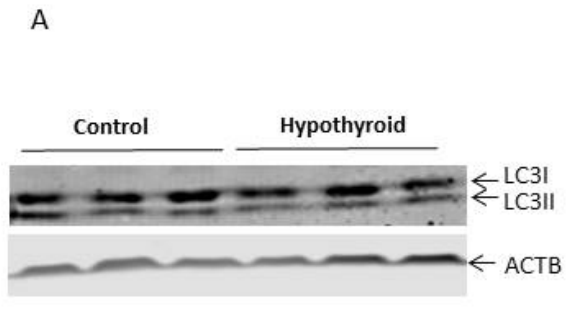

$\mathrm{C}$

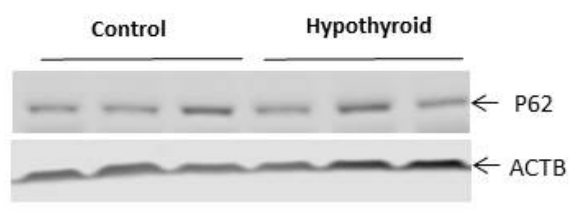

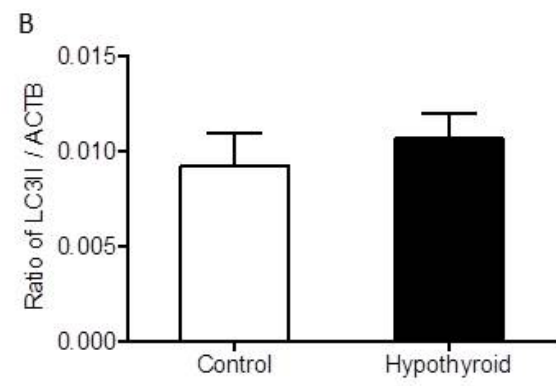

D

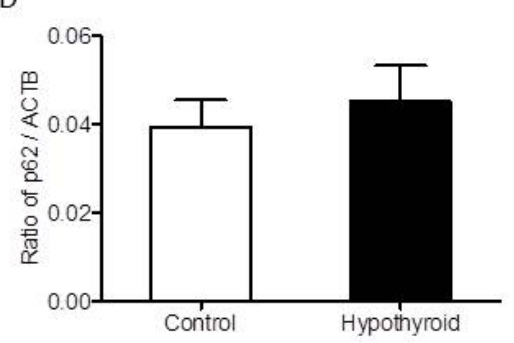

Figure 2 Western blot analysis autophagy of ovaries of control and hypothyroid Wistar rats at the age of 120 days (for details see chapter 4). The panels show LC3 (A, B) and p62 (C, D); A, Representative pictures of LC3 and p62 blots; B, D quantification of blots for LC3 and p62, respectively $(n=6)$. Protein abundance is shown as ratio over ACTB.

\subsection{Comparison between foetal/neonatal and adult hypothyroidism}

TH is taking part in the regulation of metabolic processes in the body and is essential for normal growth and development. Reduced $\mathrm{TH}$ levels are often associated with hypometabolism characterized by a reduced basic metabolic rate, increased cholesterol levels, reduced lipolysis, and 
reduced gluconeogenesis [40]. It has become more and more clear that reduced thyroid function (hypothyroidism) influences female reproduction including folliculogenesis, fertilization, and ongoing pregnancy [41]. Until recently there were hardly any studies performed that directly compare the effects of neonatally induced hypothyroidism with hypothyroidism induced in adulthood on follicular development and ovarian follicular reserve. Chapter 3 and chapter 4 in this thesis specifically address this topic. In the study described in chapter 3 , it is shown that the induction of hypothyroidism in adulthood leads to a dramatic decrease in primordial and primary follicle numbers after 16 weeks of dietary intervention with consequences for the preantral and antral follicle pool. In contrast, when the hypothyroid condition is already induced during foetal life and continued throughout postnatal life, no such change in primordial and primary follicle numbers is observed (chapter 4). Although these observations suggest that the age at onset of the hypothyroid condition determines the extent of the effect on ovarian follicle reserve, it remains challenging to find an explanation for these apparent contradictory findings. What we do know is that the switch from a euthyroid to a hypothyroid diet in adulthood leads to a 10 to 15 -fold increase in plasma TSH levels within two weeks' time. This acute transition from a euthyroid to a hypothyroid condition will cause a disturbance in whole body energy homeostasis, and thus may alter the ovarian microenvironment. Consequently, the process of initial recruitment and follicular growth may become affected. In support of this hypothesis, Mattheij et al. found that oestrous cycles becomes prolonged and irregular in ${ }^{131}$ I-radio-thyroidectomized adult female rats, within 2 weeks after TH supply was stopped [42]. Tohel et al. observed that ovarian weight and the number of ovulated oocytes becomes reduced within 16 days after the induction of hypothyroidism in adult female rats [43]. In the study described in chapter 4 , the offspring have been exposed to reduced TH levels from the foetal/neonatal period onwards and have never been exposed to normal TH levels. This may offer an explanation for the absence of reduced primordial and primary follicles in these animals in adulthood.

The question remains, however, through which pathway are the primordial and growing follicle numbers affected in the adult onset hypothyroidism. When considering this in the context of nutrient flux, one possibility is the mTORC1 kinase pathway. mTOR is a conserved serine/threonine kinase and a central component of the mTORC1 complex. mTORC1 acts as a crucial cellular energy sensor that couples intracellular energy status, availability of metabolic fuels and growth factors and hormone levels to the protein synthesis on the one hand and autophagy on the other [44, 45]. In addition to mTOR, mTORC1 contains two characteristic components, Raptor (regulatory-associated protein of mTOR) and PRAS40 (proline-rich AKT substrate 40kDa). Full mTORC1 activity is dependent on nutrient availability (via RAG GTPases), cellular energy status (AMPK activity, impacting via TSC1/TSC2 and RHEB) and growth factor signalling (via AKT, TSC1/TSC2 and RHEB). Tuberous sclerosis 1 (TSC1) and tuberous sclerosis 2 (TSC2) form a heterodimeric complex that negatively regulates mTORC1 by inactivating RHEB $[45,46]$. Elevated mTORC1 activity in mouse oocytes, due to deletion of the $T s c 1 / T s c 2$ genes leads to premature primordial follicle recruitment around puberty, causing a premature exhaustion of the primordial follicle pool [47, 48]. In contrast, suppression of increased mTORC1 activity by treatment with the specific mTORC1 inhibitor rapamycin prevents the excessive recruitment of primordial follicles thus maintaining the pool of dormant primordial follicles and preserving the length of female reproductive life [49]. 
Further evidence for the role of mTORC1 signalling in regulating the primordial follicle reserve comes from an experiment with diet induced obesity in rats. It was shown that obesity in rats leads to upregulation of mTORC1 signalling and concomitantly increased recruitment of primordial follicles and an increase in developing and mature follicles [50]. Caloric restriction has the opposite effects: inhibition of mTORC1 signalling and accumulation of primordial follicles [50-53]. A relation between mTORC1 signalling and TH has recently been demonstrated. Varela et al. have shown that elevated levels of TH induce up-regulation of mTORC1 signalling in the hypothalamus [54]. Based on these findings, it would be interesting to investigate the effect of adult and foetal/postnatal hypothyroidism on mTORC1 signalling in the ovary. Immunohistochemistry in combination with LCM may help to answer this question whether hypothyroidism affects ovarian follicle development via mTORC1. Alternatively, whole transcriptome RNA sequencing in combination with LCM could be performed to identify more candidate genes involved in this pathway, for example, by examining altered expression of downstream functional genes of mTORC1.

\subsection{Hypothyroidism, oxidative stress and follicular atresia}

In recent years, there has been increasing interest in the role of reactive oxygen species (ROS) and oxidative stress in female reproduction. ROS include superoxide anion, hydroxyl radicals, and hydrogen peroxide $\left(\mathrm{H}_{2} \mathrm{O}_{2}\right)$, among others. ROS have a key role in normal physiological signalling, but high levels of ROS are associated with disease and cell death. ROS are formed through escape of electrons from the inner mitochondrial membrane during oxidative phosphorylation and ATP generation. In steroidogenic tissues such as the ovary, steroidogenic cytochrome P450 enzymes are also sources of ROS $[55,56]$. An association between ROS and oxidative stress is described in chapter 4. There is evidence that ROS plays an important role in the initiation of apoptosis of granulosa cells in antral follicles induced by conditions such as gonadotropin withdrawal, exogenous toxicants and ionizing radiation [55]. Besides these factors, it has been reported that THs can affect reactive oxygen metabolism [57]. Next I will focus on the discussion of a possible relationship between hypothyroidism, oxidative stress and ovarian follicular atresia.

Since TH plays an important role in stimulating basal metabolic rate by increasing ATP production, it is generally believed that hyperthyroidism may be associated with oxidative stress by increasing ROS production, while hypothyroidism is thought to reduce ROS production by lowering basic metabolic rate [57]. These assumptions are in contrast to my observations described in chapter 4 , where I observed increased lipid peroxidation in the ovaries of hypothyroid rats. However, careful analysis of the published literature makes clear that the effects of hyper- and hypothyroidism on oxidative stress parameters are less straightforward than initially thought. Hyperthyroidism has been found to increase the levels of lipid peroxidation in metabolically active tissues such as heart muscle $[58,59]$ while in another metabolically active tissue, the liver, hyperthyroidism is shown to reduce the levels of protein oxidation [60] and lipid peroxidation [61]. In the same studies hypothyroidism has only a marginal or no effect on lipid peroxidation in the liver $[59,61]$, but induced a marked reduction in oxidative markers in heart and muscle tissue [62]. Furthermore, Das and Chainy [63] observed that hypothyroidism induces higher levels of $\mathrm{H}_{2} \mathrm{O}_{2}$ in hepatocyte mitochondria. In line with this last study, oxidative stress markers are reported to be significantly increased in the spleen, brain and heart under hypothyroid conditions [64-66]. On the whole, the inconsistencies among these studies may 
be attributed to the treatment employed (dosage, route of administration, duration, and strategy for altering thyroid gland function) in the animals studied and also to the type of tissues investigated [57]. Therefore, in reproductive organs with a high rate of cell proliferation, such as the ovary, oxidative stress due to hypothyroidism may not only be explained by changes in mitochondrial metabolic activity, but also by an imbalance between ROS production and the antioxidant defence system, which has been described in detail in chapter 4 . Besides, other sources of ROS production in the ovary, e.g. the activity of for instance the steroidogenic cytochrome P450 enzymes, should also be taken into account, since hepatic cytochrome P450 enzymes are affected by hypothyroidism [67].

Recently, it has been hypothesized that oxidative stress can lead to atresia of large antral follicles. In vitro experiments have shown that oxidative stress induces apoptosis in preovulatory follicles, which can be prevented by the addition of FSH. This anti-apoptotic effect of FSH is mediated at least in part by stimulation of follicular GSH production, suppressing ROS production [68]. Several studies report that exposure to chemotherapeutic drugs such as cyclophosphamide, dimethylbenzanthracene, and methoxychlor, increases ROS levels in follicles and induce signs of oxidative stress and concomitantly follicle atresia [55]. For example, mice treated with methoxychlor show increased antral follicular atresia along with increased ROS production, reduced activity of SOD1, GPX and CAT as well as protein and DNA damage as assessed by nitrotyrosine and 8-hydroxy-2'-deoxyguanosine immunostaining, respectively. Primordial and preantral follicles are not affected by this treatment [69]. This data provide further support to the hypothesis that oxidative stress is associated with ovarian follicular atresia. Similarly, in the study described in chapter 4, hypothyroidism is associated with increased follicular atresia, decreased CAT and Txnrd1 expression and increased SOD1 expression and strong immunostaining of the lipid peroxidation marker 4-HNE (Figure 3).

TH may either affect ovarian follicular development directly through its receptors in ovarian cells [70] or may exert its effects indirectly by its influence on whole body basic metabolic rate, leading to altered nutrient flux, and thus metabolic fuel availability [57]. From the study in chapter 4 it is not clear whether hypothyroidism influences ovarian oxidative stress via a direct and/or indirect way leading to granulosa cells apoptosis and follicular atresia or whether the changes in the expression of genes related to oxidative damage are a consequence of increased follicular atresia as such caused by hypothyroidism. However, the observations that follicular ROS increases prior to any morphological or physiological indicators of apoptosis in cultured preovulatory follicles following gonadotropin withdrawal, suggests a role for oxidative stress in the initiation of apoptosis [68]. Furthermore, $\mathrm{H}_{2} \mathrm{O}_{2}$ induced granulosa cell membrane lipid oxidation has been shown to induce apoptosis [71]. Based on these observations, I hypothesize that chronic hypothyroidism induces increased oxidative stress in the ovary leading to an increase in follicular atresia as indicated above. Further support for this hypothesis comes from the following studies. TH can directly affect cellular antioxidant genes expression [57]. Metabolic fuel availability has also been reported to be responsible for alteration of the antioxidant status of cells. For example, caloric restriction, with reduced metabolic fuel availability, can reduce oxidative stress by increasing antioxidant defence [72]. In contrast, obesity, with increased metabolic fuel availability, can increase oxidative stress via decreased antioxidant defences [73]. However, in order to prove this hypothesis, additional experiments need to be performed, such as treatment of hypothyroid rats with exogenous antioxidants to inhibit oxidative stress within the ovary. Oxidative stress inducing experimental conditions such as toxicant administration or irradiation, can be counteracted by treatment with $17 \beta-$ 
oestradiol $\left(E_{2}\right)$ [74], N-acetylcysteine [75] or melatonin [76] which have an antioxidant effect within the ovary when provided at pharmacologic levels.

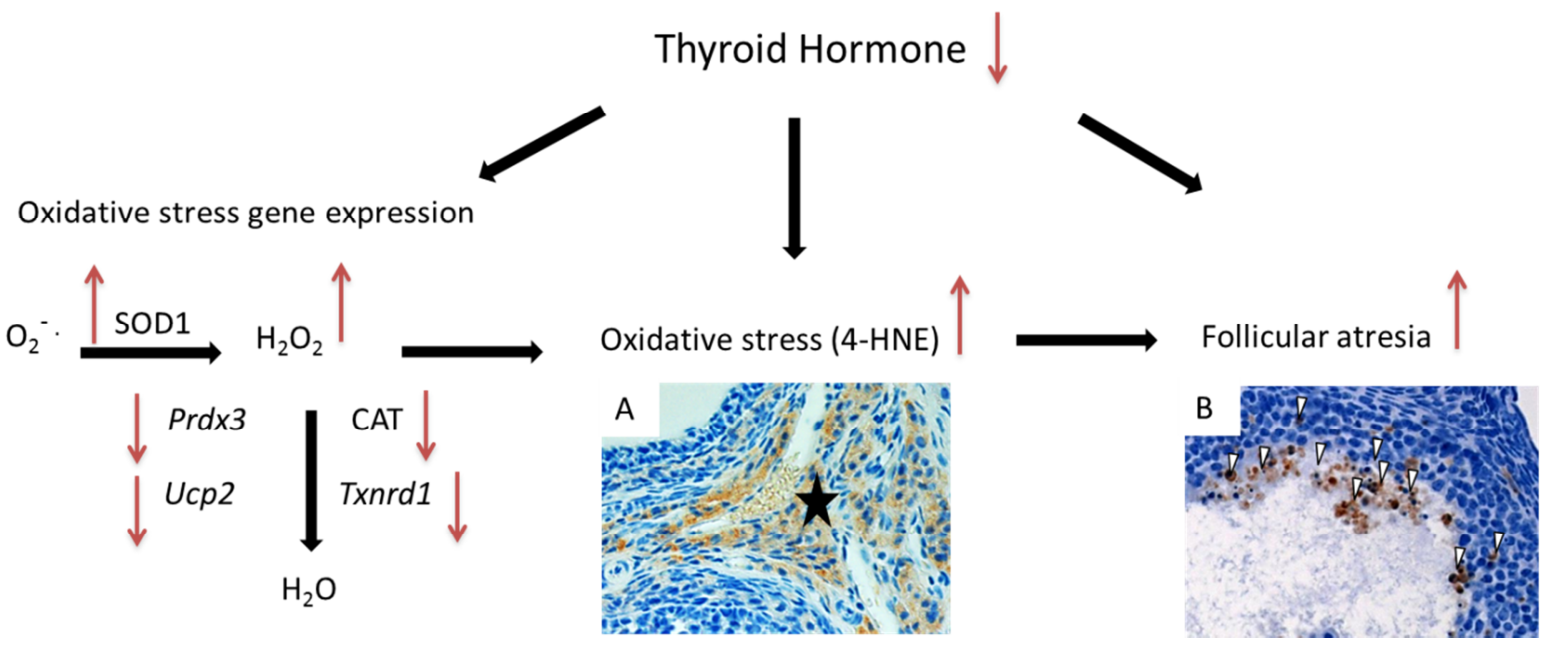

Figure 3. Schematic representation showing the mechanistic effects of dietary-induced chronic hypothyroidism on follicular development. Up regulation of SOD1 mRNA and protein expression suggests increased conversion of the superoxide anion radical $\left(\mathrm{O}_{2}\right)$ into $\mathrm{H}_{2} \mathrm{O}_{2}$. Concomitant down regulation of CAT mRNA and protein expression and Txnrd1, Prdx3 and Ucp2 mRNA expression suggests reduced conversion of $\mathrm{H}_{2} \mathrm{O}_{2}$ into $\mathrm{H}_{2} \mathrm{O}$ and hence reduced inactivation of $\mathrm{H}_{2} \mathrm{O}_{2}$. This likely causes the increased immunostaining (brown) of the oxidative stress marker 4-HNE (A). Oxidative stress can mediate follicular atresia, which was confirmed by cleaved CASP3 immunostaining in atretic follicles (B). Apoptotic cells positively stained for cleaved CASP3 are indicated (white arrowheads).

\subsection{Availability of metabolic fuels and ovarian follicle development}

The availability of sufficient energy is thought to be of the utmost importance for successful female reproductive performance (Figure 4) [77]. Several studies offer supports to this assumption. For instance, food deprivation in sheep leads to a suppressed pulsatile secretion of $\mathrm{LH}$, which can be rapidly restored by refeeding, prior to an increase in body fat content or plasma leptin concentration becomes apparent [78]. Similarly, in Syrian hamsters, fasting-induced anestrous is reversed by refeeding with no apparent immediate increase in plasma leptin concentrations $[79,80]$. Finally, fertility of most animals responds quickly to alteration in fuel availability, too rapidly to attribute the changes in reproduction to the slow process of lipid accumulation [81-83]. These data suggest that the proper functioning of the hypothalamic-pituitary-ovarian axis depends on a sufficient supply of metabolic fuels [77]. Further evidences supporting this assumption stem from studies of Schneider and Wade [84]. These authors compared the effects of food deprivation in obese and lean female hamsters and observed that $48 \mathrm{~h}$ of food shortage induced anestrous in lean, but not in obese hamsters. However, the protective effects of obesity were blocked by treating the obese hamsters with methyl palmoxirate, an inhibitor of fatty acid oxidation, leading to anestrus in food-deprived fat hamsters, although the body fat content of these animals did not differ from the food-deprived vehicle treated control animals with normal estrous cycle treated with vehicles. Furthermore, in Syrian hamsters, fasting-induced anestrous can be reversed by leptin treatment, but not when the availability of oxidizable metabolic fuels is blocked by the use of pharmacological inhibitors of glucose and fatty acid oxidation $[85,86]$. In line with this study, in rats, pulsatile LH secretion is inhibited by fasting or treatment with inhibitors of glucose or fatty acid oxidation $[87,88]$. Control of reproductive processes by the availability of oxidizable metabolic fuels has been documented in 
other model systems as well [89-93]. Based on these data, I conclude that the hypothalamicpituitary-ovarian axis is mainly responsive to the availability of oxidizable metabolic fuels.
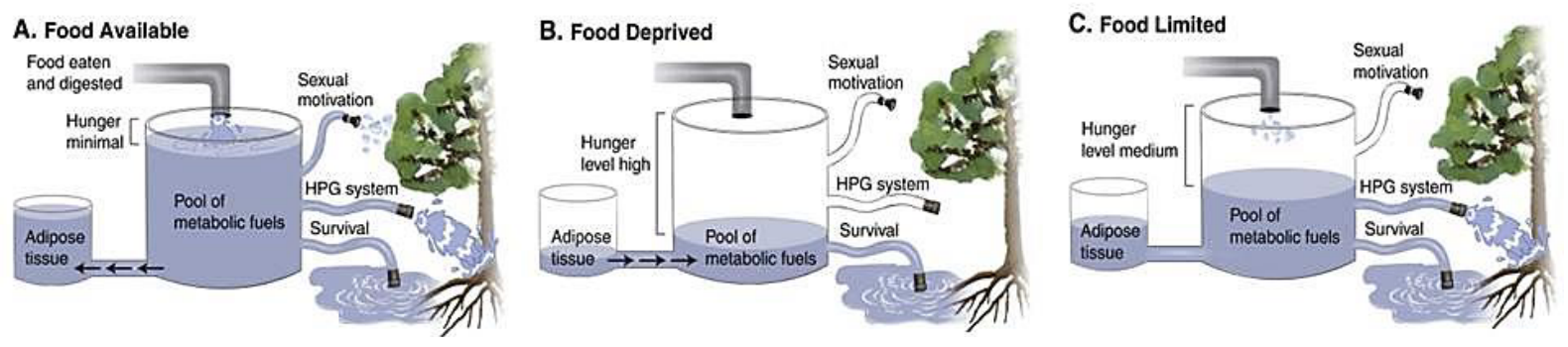

Figures 4. The pool of oxidizable metabolic fuels is depicted as the liquid in panels A, B, and C. These fuels can be chemically transformed and stored as glycogen in muscle or lipids in adipose tissue (the small tank on the left), and used for maintenance of the reproductive system, all behaviours, and cellular processes (the tree on the right). When energy demand is low and food is available, sufficient levels of oxidizable fuels are present for both survival and reproduction (A). When food is not available, animals hydrolyze and mobilize fuels from their fat stores, and when the availability of fuels is low, the hunger for food is urgent, and reproductive function can be inhibited to conserve fuels necessary for survival (symbolized by the roots) (B). Mild energetic challenges can inhibit sexual motivation and appetitive sex behaviour (symbolized by the leaves), increase hunger, and without inhibition of the hypothalamic-pituitary-gonadal (HPG) system (symbolized by the tree trunk) (C). Pictures are adapted from [77].

In the study described in chapter 5, the importance of availability of metabolic fuels on ovarian function is investigated in adult mice in which the UCP1 gene is ectopically expressed in the skeletal muscle tissue, resulting in an increase in energy expenditure and concomitantly an energy drain to the skeletal muscle tissue. The data from this study suggest that this condition leads to impaired ovarian follicular development. Circulating IGF1 concentration was decreased by $40 \%$ compared with the WT controls. IGF1 signalling plays an important role in body growth and metabolism. After binding to its receptor, the activated IGF1 receptor phosphorylates insulin receptor substrate complexes, subsequently leading to the activation of the Phosphatidylinositol 3-kinase (PI3K)-AKTmTORC1 pathway, which play an important role in protein synthesis and cell growth [94]. The function of the IGF1 signalling pathway on ovarian follicle development is still not fully understood. IGF1 signalling has been proven to have a role in amplifying the effect of FSH on granulosa cell function to ensure follicular survival [95-97]. In addition, IGF1 can promote cell growth and suppress apoptosis of granulosa cells, also by activating PI3K-AKT [96, 98, 99]. As discussed in chapter 5, reduced immunostaining of Phospho-AKT in healthy antral follicles and lower Phospho-IRS2 immunostaining in the atretic antral follicles of UCP1-TG mice indicates that reduced IGF1 signalling may be involved in the observed impaired follicular development. While differences in granulosa cell activated AKT between WT and UCP1-TG mice correspond to IGF1 levels and differences in follicular atresia, in agreement with the role of PI3K-AKT in suppression of granulosa cell apoptosis [96, 98, 99], the loss of IRS2 activation in antral atretic follicles in the UCP1-TG mice is more puzzling. Possibly the higher IGF1 levels in the WT mice, compared to the UCP1-TG mice, evoke a rescue response in the atretic antral follicles. A downstream lack of effect may be due to blockage of signalling, possibly by upregulation of inhibitory components such as PTEN [100] or Tribbles [101]. It has been reported that PTEN impacts the survival state of granulosa and/or luteal cells, since targeted disruption of Pten not only facilitates ovulation but also extends the life span of luteal cells in the adult mouse ovary [102]. In contrast, an increase in PTEN activity can suppress IGF1-induced AKT phosphorylation and cell proliferation during luteinization in human granulosa cells [103]. Inactivation of TRIB1, one of the 
three Tribble gene family members, causes infertility in female mice. Moreover, TRIB1, TRIB2 and TRIB3 are all expressed in cumulus cells, specialized granulosa cells anchoring the oocyte, and are related to oocyte maturation, indicating a functional role in ovarian follicular development [104]. Little is known on their role in regulating IGF1 signalling during follicular atresia.

Alternatively, there may be a role for other IRS proteins. It has been demonstrated recently that IRS1, IRS2 and IRS4 proteins are located in ovarian granulosa cells, but the functional roles of these proteins in ovarian follicle development have not been completely elucidated [105]. Activation of IRS1 in granulosa cells has been shown to play an important intermediate role in the FSH signalling pathway [106]. To understand the role of IGF1 signalling during atresia, it is necessary not only to examine downstream signalling components, negative regulators such as PTEN and Tribbles, and a wider range of IRS proteins, but also IRS associated proteins which have a role in intracellular localization and activity of the IRS proteins (see discussion chapter 5). Downstream of AKT, mTORC1 controls protein synthesis, metabolism, and autophagy. Moreover, mTORC1 also plays an important role in preantral and antral follicle development in addition to primordial follicle recruitment. Therefore, identification of the activity of MTORC1 in the UCP1-TG mice may be a valuable addition to the work presented in chapter 5. mTORC1 activity can be monitored by phosphorylation of key substrates, such as EIF4EBP1/4E-BP1/PHAS-I and RPS6KB/p70S6 kinase or the latter's downstream target, RPS6/S6, for which good commercial antibodies are available for protein analysis [12]. Furthermore, to directly confirm the role of IGF1 in the impaired follicle development in UCP1-TG mice, a conclusive experiment would be to infuse IGF1 in UCP1-TG mice, by using implantable Alzet pumps. In such an experiment, it is key to use relevant physiological concentrations of IGF1. Support for such an experiment can be found in IGF1 treatment that was shown to restore antral follicle development in GHR/GHBP-KO mice that display severely reduced IGF1 levels [107].

It has been reported that under energy insufficient conditions, such as calorie restriction and undernutrition, not only growing follicle development, but also primordial follicle development can be influenced. A 40\% reduction in caloric intake for 4 months initiated after sexual maturation of adult mice, resulted in accumulation of primordial follicle numbers; The numbers of primordial follicle was twice as high as in ad libitum (AL)-fed age-matched controls, while reproductive capacity was impaired [108]. However, these animals remained fertile much longer than continuously AL-fed controls, once they were allowed to resume AL feeding again. In contrast, Bernal et al have shown that $50 \%$ reduction in caloric intake, compared to AL-fed controls, of mothers during pregnancy and lactation significantly reduced the number of primordial follicles in the adulthood of offspring born to these undernourished mothers, even though the offspring were kept on a standard diet from weaning until sacrifice [109]. These results suggest that lower availability of metabolic fuels can modify the primordial follicle development, probably in a way that is related with the timing of energy insufficiency. This agrees with our observations in the study of chapter 5, where a trend towards a decrease $(\mathrm{P}=0.0573)$ of primordial follicle numbers was observed in UCP1-TG mice compared to WT mice, while the primary follicle numbers were significantly reduced compared to WT controls. Nevertheless, it has to be taken into account that we only investigated ovarian histology at the age of 12 weeks, therefore it remains to be determined whether this decrease of primordial follicle numbers in UCP1-TG mice is due to abnormal primordial follicle recruitment or disturbed establishment of the ovarian reserve during foetal life. 


\subsection{Conclusions}

Overall, the observations as outlined in this thesis have provided new insights in the mechanisms of follicular degeneration and on the role of conditions that alter metabolic fuel availability on ovarian follicular development. Although we need to be careful in translating observations from animal studies to the human situation, the observed impairment in ovarian follicle numbers due to disturbed energy balance and thus alteration of availability of metabolic fuels could contribute to better understanding of underlying mechanisms of metabolic homeostasis on female reproductive performance.

Finally, while my thesis provides new insights in the biology of reproduction, it also has practical implications. Human clinical studies on female reproduction are mostly retrospective and lack proper controls, which makes the experimental results more controversial and difficult to compare. Therefore, extensive fully-controlled human experiments using proper controls, with prospective non-invasive analyses, e.g. by measuring circulating AMH levels, are warranted to better evaluate ovarian follicle development and thus female reproductive health in women with aberrations of their metabolic state. Furthermore, the impaired ovarian follicular development due to decrease of availability of metabolic fuels, shown in my thesis, suggests that a well-monitored evaluation of female reproductive health with respect to dietary behaviour and physical activity is necessary in women suffering from reproductive difficulties. Similarly, I have obtained evidence that nutrient fluxes impact on ovarian follicular development. This is potentially important not only with regards to humans, but also for production animals. 


\subsection{References}

1. Ivell R, Teerds K, Hoffman GE. Proper application of antibodies for immunohistochemical detection: antibody crimes and how to prevent them. Endocrinology 2014; 155:676-687.

2. Hoffman GE, Le WW, Sita LV. The importance of titrating antibodies for immunocytochemical methods. Curr Protoc Neurosci 2008; Chapter 2:Unit 212.

3. Davidoff $M$, Schulze W. Combination of the peroxidase anti-peroxidase (PAP)- and avidin-biotin-peroxidase complex ( $A B C)$-techniques: an amplification alternative in immunocytochemical staining. Histochemistry 1990; $93: 531-536$.

4. Bonnet A, Bevilacqua C, Benne F, Bodin L, Cotinot C, Liaubet L, Sancristobal M, Sarry J, Terenina E, Martin P, Tosser-Klopp G, Mandon-Pepin B. Transcriptome profiling of sheep granulosa cells and oocytes during early follicular development obtained by laser capture microdissection. BMC Genomics 2011; $12: 417$.

5. Lovendorf MB, Mitsui H, Zibert JR, Ropke MA, Hafner M, Dyring-Andersen B, Bonefeld CM, Krueger JG, Skov L. Laser capture microdissection followed by next-generation sequencing identifies disease-related microRNAs in psoriatic skin that reflect systemic microRNA changes in psoriasis. Exp Dermatol 2015; 24:187-193.

6. Golubeva Y, Salcedo R, Mueller C, Liotta LA, Espina V. Laser capture microdissection for protein and NanoString RNA analysis. Methods Mol Biol 2013; 931:213-257.

7. Lovendorf MB, Mitsui H, Zibert JR, Ropke M, Hafner M, Dyring-Andersen B, Bonefeld C, Krueger JG, Skov L. Laser capture microdissection followed by next-generation sequencing identifies disease-related microRNAs in psoriatic skin that reflect systemic microRNA changes in psoriasis. J Invest Dermatol 2014; 134:S2-S2.

8. Sugino Y, O'Malley KJ, Wang Z, Tyagi P, Birder LA, Ogawa O, Yoshimura N. Laser-capture microdissection for analysis of cell type-specific gene expression of muscarinic receptor subtypes in the rat bladder with cyclophosphamide-induced cystitis. Int Urol Nephrol 2015; 47:637-642.

9. Mikulowska-Mennis A, Taylor TB, Vishnu P, Michie SA, Raja R, Horner N, Kunitake ST. High-quality RNA from cells isolated by laser capture microdissection. Biotechniques 2002; 33:176-179.

10. Dotti I, Bonin S, Basili G, Nardon E, Balani A, Siracusano S, Zanconati F, Palmisano S, De Manzini N, Stanta G. Effects of Formalin, Methacarn, and FineFIX Fixatives on RNA Preservation. Diagn Mol Pathol 2010; 19:112-122.

11. Schweichel JU, Merker HJ. The morphology of various types of cell death in prenatal tissues. Teratology 1973; 7:253-266.

12. Klionsky DJ, Abdelmohsen K, Abe A, Abedin MJ, Abeliovich H, Arozena AA, Adachi H, Adams CM, Adams PD, Adeli K, Adhihetty PJ, Adler SG, et al. Guidelines for the use and interpretation of assays for monitoring autophagy (3rd edition). Autophagy 2016; 12:1-222.

13. Baehrecke EH. Autophagy: dual roles in life and death? Nat Rev Mol Cell Biol 2005; 6:505-510.

14. Marino G, Niso-Santano M, Baehrecke EH, Kroemer G. Self-consumption: the interplay of autophagy and apoptosis. Nat Rev Mol Cell Biol 2014; 15:81-94.

15. Levine B, Yuan J. Autophagy in cell death: an innocent convict? J Clin Invest 2005; 115:2679-2688.

16. Lin L, Baehrecke EH. Autophagy, cell death, and cancer. Mol Cell Oncol 2015; 2:e985913.

17. Denton D, Shravage B, Simin R, Mills K, Berry DL, Baehrecke EH, Kumar S. Autophagy, Not Apoptosis, Is Essential for Midgut Cell Death in Drosophila. Curr Biol 2009; 19:1741-1746.

18. Chang TK, Shravage BV, Hayes SD, Powers CM, Simin RT, Harper JW, Baehrecke EH. Uba1 functions in Atg7-and Atg3-independent autophagy. Nat Cell Biol 2013; 15: 1067-1078.

19. Yu L, Alva A, Su H, Dutt P, Freundt E, Welsh S, Baehrecke EH, Lenardo MJ. Regulation of an ATG7-beclin 1 program of autophagic cell death by caspase-8. Science 2004; 304:1500-1502.

20. Shimizu S, Kanaseki T, Mizushima N, Mizuta T, Arakawa-Kobayashi S, Thompson CB, Tsujimoto Y. Role of Bcl-2 family proteins in a non-apoptotic programmed cell death dependent on autophagy genes. Nat Cell Biol 2004; 6:1221-1228.

21. Elgendy M, Sheridan C, Brumatti G, Martin SJ. Oncogenic Ras-induced expression of Noxa and Beclin-1 promotes autophagic cell death and limits clonogenic survival. Mol Cell 2011; 42:23-35. 
22. Liu Y, Shoji-Kawata S, Sumpter RM, Jr., Wei Y, Ginet V, Zhang L, Posner B, Tran KA, Green DR, Xavier RJ, Shaw SY, Clarke PG, et al. Autosis is a $\mathrm{Na}+, \mathrm{K}+-\mathrm{ATPase}$-regulated form of cell death triggered by autophagy-inducing peptides, starvation, and hypoxia-ischemia. Proc Natl Acad Sci U S A 2013; 110:20364-20371.

23. Koike M, Shibata M, Tadakoshi M, Gotoh K, Komatsu M, Waguri S, Kawahara N, Kuida K, Nagata S, Kominami E, Tanaka K, Uchiyama Y. Inhibition of autophagy prevents hippocampal pyramidal neuron death after hypoxicischemic injury. Am J Pathol 2008; 172:454-469.

24. Xing S, Zhang Y, Li J, Zhang J, Li Y, Dang C, Li C, Fan Y, Yu J, Pei Z, Zeng J. Beclin 1 knockdown inhibits autophagic activation and prevents the secondary neurodegenerative damage in the ipsilateral thalamus following focal cerebral infarction. Autophagy 2012; 8:63-76.

25. Weckman A, Di leva A, Rotondo F, Syro LV, Ortiz LD, Kovacs K, Cusimano MD. Autophagy in the endocrine glands. J Mol Endocrinol 2014; 52:R151-163.

26. Duerrschmidt N, Zabirnyk O, Nowicki M, Ricken A, Hmeidan FA, Blumenauer V, Borlak J, Spanel-Borowski K. Lectin-like oxidized low-density lipoprotein receptor-1-mediated autophagy in human granulosa cells as an alternative of programmed cell death. Endocrinology 2006; 147:3851-3860.

27. Serke H, Vilser C, Nowicki M, Hmeidan FA, Blumenauer V, Hummitzsch K, Losche A, Spanel-Borowski K. Granulosa cell subtypes respond by autophagy or cell death to oxLDL-dependent activation of the oxidized lipoprotein receptor 1 and toll-like 4 receptor. Autophagy 2009; 5:991-1003.

28. Norman JM, Cohen GM, Bampton ET. The in vitro cleavage of the hAtg proteins by cell death proteases. Autophagy 2010; 6:1042-1056.

29. Klionsky DJ, Abdalla FC, Abeliovich H, Abraham RT, Acevedo-Arozena A, Adeli K, Agholme L, Agnello M, Agostinis P, Aguirre-Ghiso JA, Ahn HJ, Ait-Mohamed O, et al. Guidelines for the use and interpretation of assays for monitoring autophagy. Autophagy 2012; 8:445-544.

30. Kim J, Kundu M, Viollet B, Guan KL. AMPK and mTOR regulate autophagy through direct phosphorylation of Ulk1. Nat Cell Biol 2011; 13:132-U171.

31. Russell RC, Tian Y, Yuan HX, Park HW, Chang YY, Kim J, Kim H, Neufeld TP, Dillin A, Guan KL. ULK1 induces autophagy by phosphorylating Beclin-1 and activating VPS34 lipid kinase. Nat Cell Biol 2013; 15:741-750.

32. Green DR, Levine B. To Be or Not to Be? How Selective Autophagy and Cell Death Govern Cell Fate. Cell 2014; 157:65-75.

33. Gannon AM, Stampfli MR, Foster WG. Cigarette smoke exposure leads to follicle loss via an alternative ovarian cell death pathway in a mouse model. Toxicol Sci 2012; 125:274-284.

34. Gannon AM, Stampfli MR, Foster WG. Cigarette Smoke Exposure Elicits Increased Autophagy and Dysregulation of Mitochondrial Dynamics in Murine Granulosa Cells. Biol Reprod 2013; 88:1-11.

35. Furlong HC, Stampfli MR, Gannon AM, Foster WG. Cigarette Smoke Exposure Triggers the Autophagic Cascade via Activation of the AMPK Pathway in Mice. Biol Reprod 2015; 93:1-10.

36. Oral O, Oz-Arslan D, Itah Z, Naghavi A, Deveci R, Karacali S, Gozuacik D. Cleavage of Atg3 protein by caspase-8 regulates autophagy during receptor-activated cell death. Apoptosis 2012; 17:810-820.

37. Fulda S. Autophagy and cell death. Autophagy 2012; 8:1250-1251.

38. Loos B, Engelbrecht AM, Lockshin RA, Klionsky DJ, Zakeri Z. The variability of autophagy and cell death susceptibility: Unanswered questions. Autophagy 2013; 9:1270-1285.

39. Kliosnky D. Guidelines for the Use and Interpretation of Assays for Monitoring Autophagy (3rd edition) (vol 12, pg 1, 2015). Autophagy 2016; 12:443-443.

40. Mullur R, Liu YY, Brent GA. Thyroid hormone regulation of metabolism. Physiol Rev 2014; 94:355-382.

41. Mintziori G, Kita M, Duntas L, Goulis DG. Consequences of hyperthyroidism in male and female fertility: pathophysiology and current management. J Endocrinol Invest 2016; 39: 849-853.

42. Mattheij JA, Swarts JJ, Lokerse P, van Kampen JT, Van der Heide D. Effect of hypothyroidism on the pituitarygonadal axis in the adult female rat. J Endocrinol 1995; 146:87-94. 
43. Tohei A, Imai A, Watanabe G, Taya K. Influence of thiouracil-induced hypothyroidism on adrenal and gonadal functions in adult female rats. J Vet Med Sci 1998; 60:439-446.

44. Haissaguerre M, Saucisse N, Cota D. Influence of mTOR in energy and metabolic homeostasis. Mol Cell Endocrinol 2014; 397:67-77.

45. Laplante M, Sabatini DM. mTOR signaling in growth control and disease. Cell 2012; 149:274-293.

46. Bar-Peled L, Sabatini DM. Regulation of mTORC1 by amino acids. Trends Cell Biol 2014; 24:400-406.

47. Adhikari D, Flohr G, Gorre N, Shen Y, Yang H, Lundin E, Lan Z, Gambello MJ, Liu K. Disruption of Tsc2 in oocytes leads to overactivation of the entire pool of primordial follicles. Mol Hum Reprod 2009; 15:765-770.

48. Adhikari D, Zheng W, Shen Y, Gorre N, Hamalainen T, Cooney AJ, Huhtaniemi I, Lan ZJ, Liu K. Tsc/mTORC1 signaling in oocytes governs the quiescence and activation of primordial follicles. Hum Mol Genet 2010; 19:397410.

49. Adhikari D, Risal S, Liu K, Shen Y. Pharmacological inhibition of mTORC1 prevents over-activation of the primordial follicle pool in response to elevated PI3K signaling. PLoS One 2013; 8:e53810.

50. Wang N, Luo LL, Xu JJ, Xu MY, Zhang XM, Zhou XL, Liu WJ, Fu YC. Obesity accelerates ovarian follicle development and follicle loss in rats. Metabolism 2014; 63:94-103.

51. Seli E, Babayev E, Collins SC, Nemeth G, Horvath TL. Minireview: Metabolism of female reproduction: regulatory mechanisms and clinical implications. Mol Endocrinol 2014; 28:790-804.

52. Li L, Fu YC, Xu JJ, Lin XH, Chen XC, Zhang XM, Luo LL. Caloric restriction promotes the reserve of follicle pool in adult female rats by inhibiting the activation of mammalian target of rapamycin signaling. Reprod Sci 2015; 22:6067.

53. Zhang H, Liu K. Cellular and molecular regulation of the activation of mammalian primordial follicles: somatic cells initiate follicle activation in adulthood. Hum Reprod Update 2015; 21:779-786.

54. Varela L, Martinez-Sanchez N, Gallego R, Vazquez MJ, Roa J, Gandara M, Schoenmakers E, Nogueiras R, Chatterjee K, Tena-Sempere M, Dieguez C, Lopez M. Hypothalamic mTOR pathway mediates thyroid hormone-induced hyperphagia in hyperthyroidism. J Pathol 2012; 227:209-222.

55. Devine PJ, Perreault SD, Luderer U. Roles of reactive oxygen species and antioxidants in ovarian toxicity. Biol Reprod 2012; 86:27.

56. Hanukoglu I. Antioxidant protective mechanisms against reactive oxygen species (ROS) generated by mitochondrial P450 systems in steroidogenic cells. Drug Metab Rev 2006; 38:171-196.

57. Villanueva I, Alva-Sanchez C, Pacheco-Rosado J. The Role of Thyroid Hormones as Inductors of Oxidative Stress and Neurodegeneration. Oxid Med Cell Longev 2013.

58. Araujo ASR, Diniz GP, Seibel FER, Branchini G, Ribeiro MFM, Brum IS, Khaper N, Barreto-Chaves MLM, Bello-Klein A. Reactive oxygen and nitrogen species balance in the determination of thyroid hormones-induced cardiac hypertrophy mediated by renin-angiotensin system. Mol Cell Endocrinol 2011; 333:78-84.

59. Asayama K, Dobashi K, Hayashibe H, Megata Y, Kato K. Lipid-Peroxidation and Free-Radical Scavengers in ThyroidDysfunction in the Rat - a Possible Mechanism of Injury to Heart and Skeletal-Muscle in Hyperthyroidism. Endocrinology 1987; 121:2112-2118.

60. Pamplona R, Portero-Otin M, Ruiz C, Bellmunt MJ, Requena JR, Thorpe SR, Baynes JW, Romero M, Lopez-Torres M, Barja G. Thyroid status modulates glycoxidative and lipoxidative modification of tissue proteins. Free Radic Biol Med 1999; 27:901-910.

61. Guerrero A, Pamplona R, Portero-Otin M, Barja G, Lopez-Torres M. Effect of thyroid status on lipid composition and peroxidation in the mouse liver. Free Radic Biol Med 1999; 26:73-80.

62. Asayama K, Dobashi K, Hayashibe H, Megata Y, Kato K. Lipid peroxidation and free radical scavengers in thyroid dysfunction in the rat: a possible mechanism of injury to heart and skeletal muscle in hyperthyroidism. Endocrinology 1987; 121:2112-2118.

63. Das K, Chainy GB. Modulation of rat liver mitochondrial antioxidant defence system by thyroid hormone. Biochimica et biophysica acta 2001; 1537:1-13. 
64. Ortiz-ButrOn R, Blas-Valdivia V, Franco-Colin M, Pineda-Reynoso M, Cano-Europa E. An increase of oxidative stress markers and the alteration of the antioxidant enzymatic system are associated with spleen damage caused by methimazole-induced hypothyroidism. Drug Chemical Toxicol 2011; 34:180-188.

65. Cano-Europa E, Perez-Severiano F, Vergara P, Ortiz-Butron R, Rios C, Segovia J, Pacheco-Rosado J. Hypothyroidism induces selective oxidative stress in amygdala and hippocampus of rat. Metab Brain Dis 2008; 23:275-287.

66. Carmona YV, Coria MJ, Oliveros LB, Gimenez MS. Hypothyroidism and oxidative stress: differential effect on the heart of virgin and pregnant rats. Horm Metab Res 2014; 46:14-20.

67. Ram PA, Waxman DJ. Hepatic P450 Expression in Hypothyroid Rats - Differential Responsiveness of Male-Specific P450 Form-2a (liia2), Form-2c (lic11), and RIm2 (lia2) to Thyroid-Hormone. Mol Endocrinol 1991; 5:13-20.

68. Tsai-Turton $\mathrm{M}$, Luderer $\mathrm{U}$. Opposing effects of glutathione depletion and follicle-stimulating hormone on reactive oxygen species and apoptosis in cultured preovulatory rat follicles. Endocrinology 2006; 147:1224-1236.

69. Gupta RK, Schuh RA, Fiskum G, Flaws JA. Methoxychlor causes mitochondrial dysfunction and oxidative damage in the mouse ovary. Toxicol Appl Pharmacol 2006; 216:436-445.

70. Fedail JS, Zheng K, Wei Q, Kong L, Shi F. Roles of thyroid hormones in follicular development in the ovary of neonatal and immature rats. Endocrine 2014; 46:594-604.

71. Nakahara T, Iwase A, Nakamura T, Kondo M, Bayasula, Kobayashi H, Takikawa S, Manabe S, Goto M, Kotani T, Kikkawa F. Sphingosine-1-phosphate inhibits H2O2-induced granulosa cell apoptosis via the PI3K/Akt signaling pathway. Fertil Steril 2012; 98:1001-1008 e1001.

72. Qiu X, Brown K, Hirschey MD, Verdin E, Chen D. Calorie restriction reduces oxidative stress by SIRT3-mediated SOD2 activation. Cell Metab 2010; 12:662-667.

73. Furukawa S, Fujita T, Shimabukuro M, Iwaki M, Yamada Y, Nakajima Y, Nakayama O, Makishima M, Matsuda M, Shimomura I. Increased oxidative stress in obesity and its impact on metabolic syndrome. J Clin Invest 2004; 114:1752-1761.

74. Nathan L, Chaudhuri G. Antioxidant and prooxidant actions of estrogens: potential physiological and clinical implications. Semin Reprod Endocrinol 1998; 16:309-314.

75. Xue LJ, Li JH, Li Y, Chu C, Xie GT, Qin J, Yang MF, Zhuang DG, Cui LX, Zhang HZ, Fu XL. N-acetylcysteine protects Chinese Hamster ovary cells from oxidative injury and apoptosis induced by microcystin-LR. Int J Clin Exp Med 2015; 8:4911-4921.

76. Kim JK, Lee CJ. Effect of exogenous melatonin on the ovarian follicles in gamma-irradiated mouse. Mutat Res 2000; 449:33-39.

77. Schneider JE, Wise JD, Benton NA, Brozek JM, Keen-Rhinehart E. When do we eat? Ingestive behavior, survival, and reproductive success. Horm Behav 2013; 64:702-728.

78. Szymanski LA, Schneider JE, Friedman MI, Ji H, Kurose Y, Blache D, Rao A, Dunshea FR, Clarke IJ. Changes in insulin, glucose and ketone bodies, but not leptin or body fat content precede restoration of luteinising hormone secretion in ewes. J Neuroendocrinol 2007; 19:449-460.

79. Schneider JE, Blum RM, Wade GN. Metabolic control of food intake and estrous cycles in syrian hamsters. I. Plasma insulin and leptin. Am J Physiol Regul Integr Comp Physiol 2000; 278:R476-485.

80. Wade GN, Lempicki RL, Panicker AK, Frisbee RM, Blaustein JD. Leptin facilitates and inhibits sexual behavior in female hamsters. Am J Physiol 1997; 272:R1354-1358.

81. Bronson FH. Food-restricted, prepubertal, female rats: rapid recovery of luteinizing hormone pulsing with excess food, and full recovery of pubertal development with gonadotropin-releasing hormone. Endocrinology 1986; 118:2483-2487.

82. Bronson FH. Energy balance and ovulation: small cages versus natural habitats. Reprod Fertil Dev 1998; 10:127137.

83. Armstrong JD, Britt JH. Nutritionally-induced anestrus in gilts: metabolic and endocrine changes associated with cessation and resumption of estrous cycles. J Anim Sci 1987; 65:508-523. 
84. Schneider JE, Wade GN. Decreased availability of metabolic fuels induces anestrus in golden hamsters. Am J Physiol 1990; 258:R750-755.

85. Papaspyrou-Rao S, Schneider SH, Petersen RN, Fried SK. Dexamethasone increases leptin expression in humans in vivo. J Clin Endocrinol Metab 1997; 82:1635-1637.

86. Schneider JE, Goldman MD, Tang S, Bean B, Ji H, Friedman MI. Leptin indirectly affects estrous cycles by increasing metabolic fuel oxidation. Horm Behav 1998; 33:217-228.

87. True C, Kirigiti MA, Kievit P, Grove KL, Smith MS. Leptin is not the critical signal for kisspeptin or luteinising hormone restoration during exit from negative energy balance. J Neuroendocrinol 2011; 23:1099-1112.

88. Nagatani S, Thompson RC, Foster DL. Prevention of glucoprivic stimulation of corticosterone secretion by leptin does not restore high frequency luteinizing hormone pulses in rats. J Neuroendocrinol 2001; 13:371-377.

89. Berriman SJ, Wade GN, Blaustein JD. Expression of Fos-like proteins in gonadotropin-releasing hormone neurons of Syrian hamsters: effects of estrous cycles and metabolic fuels. Endocrinology 1992; 131:2222-2228.

90. Bucholtz DC, Vidwans NM, Herbosa CG, Schillo KK, Foster DL. Metabolic interfaces between growth and reproduction. V. Pulsatile luteinizing hormone secretion is dependent on glucose availability. Endocrinology 1996; 137:601-607.

91. Murahashi K, Bucholtz DC, Nagatani S, Tsukahara S, Tsukamura H, Foster DL, Maeda KI. Suppression of luteinizing hormone pulses by restriction of glucose availability is mediated by sensors in the brain stem. Endocrinology 1996; 137:1171-1176.

92. Shahab M, Sajapitak S, Tsukamura H, Kinoshita M, Matsuyama S, Ohkura S, Yamada S, Uenoyama Y, I'Anson H, Maeda K. Acute lipoprivation suppresses pulsatile luteinizing hormone secretion without affecting food intake in female rats. J Reprod Dev 2006; 52:763-772.

93. Moriyama R, Reyes BA, Tsukamura H, Maeda K. Glucoprivation-induced Fos expression in the hypothalamus and medulla oblongata in female rats. J Reprod Dev 2003; 49:151-157.

94. Anisimov VN, Bartke A. The key role of growth hormone-insulin-IGF-1 signaling in aging and cancer. Crit Rev Oncol Hematol 2013; 87:201-223.

95. Zhou J, Kumar TR, Matzuk MM, Bondy C. Insulin-like growth factor I regulates gonadotropin responsiveness in the murine ovary. Mol Endocrinol 1997; 11:1924-1933.

96. Zhou P, Baumgarten SC, Wu Y, Bennett J, Winston N, Hirshfeld-Cytron J, Stocco C. IGF-I signaling is essential for FSH stimulation of AKT and steroidogenic genes in granulosa cells. Mol Endocrinol 2013; 27:511-523.

97. Glister C, Tannetta DS, Groome NP, Knight PG. Interactions between follicle-stimulating hormone and growth factors in modulating secretion of steroids and inhibin-related peptides by nonluteinized bovine granulosa cells. Biol Reprod 2001; 65:1020-1028.

98. Hu CL, Cowan RG, Harman RM, Quirk SM. Cell cycle progression and activation of Akt kinase are required for insulin-like growth factor I-mediated suppression of apoptosis in granulosa cells. Mol Endocrinol 2004; 18:326-338.

99. Sun GW, Kobayashi H, Suzuki M, Kanayama N, Terao T. Follicle-stimulating hormone and insulin-like growth factor I synergistically induce up-regulation of cartilage link protein ( $\mathrm{Crt} / 1)$ via activation of phosphatidylinositoldependent Kinase/Akt in rat granulosa cells. Endocrinology 2003; 144:793-801.

100. Leslie NR, Downes CP. PTEN function: how normal cells control it and tumour cells lose it. Biochem J 2004; 382:111.

101. Prudente S, Sesti G, Pandolfi A, Andreozzi F, Consoli A, Trischitta V. The mammalian tribbles homolog TRIB3, glucose homeostasis, and cardiovascular diseases. Endocr Rev 2012; 33:526-546.

102. Fan HY, Liu ZL, Cahill N, Richards JS. Targeted disruption of Pten in ovarian granulosa cells enhances ovulation and extends the life span of luteal cells. Mol Endocrinol 2008; 22:2128-2140.

103. Goto M, Iwase A, Harata T, Takigawa S, Suzuki K, Manabe S, Kikkawa F. IGF1-induced AKT phosphorylation and cell proliferation are suppressed with the increase in PTEN during luteinization in human granulosa cells. Reproduction 2009; 137:835-842. 
104. Brisard D, Chesnel F, Elis S, Desmarchais A, Sanchez-Lazo L, Chasles M, Maillard V, Uzbekova S. Tribbles expression in cumulus cells is related to oocyte maturation and fatty acid metabolism. J Ovarian Res 2014; 7:44.

105. Yen HW, Jakimiuk AJ, Munir I, Magoffin DA. Selective alterations in insulin receptor substrates-1,-2 and-4 in theca but not granulosa cells from polycystic ovaries. Mol Hum Reprod 2004; 10:473-479.

106. Hunzicker-Dunn ME, Lopez-Biladeau B, Law NC, Fiedler SE, Carr DW, Maizels ET. PKA and GAB2 play central roles in the FSH signaling pathway to PI3K and AKT in ovarian granulosa cells. Proc Natl Acad Sci U S A 2012; 109:E29792988.

107. Slot KA, Kastelijn J, Bachelot A, Kelly PA, Binart N, Teerds KJ. Reduced recruitment and survival of primordial and growing follicles in GH receptor-deficient mice. Reproduction 2006; 131:525-532.

108. Selesniemi K, Lee HJ, Tilly JL. Moderate caloric restriction initiated in rodents during adulthood sustains function of the female reproductive axis into advanced chronological age. Aging Cell 2008; 7:622-629.

109. Bernal AB, Vickers MH, Hampton MB, Poynton RA, Sloboda DM. Maternal Undernutrition Significantly Impacts Ovarian Follicle Number and Increases Ovarian Oxidative Stress in Adult Rat Offspring. PLoS One 2010; 5. 


\section{SUMMARY}

Female reproduction is tightly linked to body energy status and it has become increasingly clear that disturbed energy metabolism can negatively affect reproductive performance. Nevertheless, the way how a disturbed energy status affects ovarian follicular reserve as well as follicular recruitment and growth is little investigated and not fully elucidated. Therefore, the overall goal of this thesis was to investigate the effects of an altered metabolism, and particularly an altered energy status, on ovarian follicular development. To achieve this goal, the first aim was to establish the role of autophagy in follicular degeneration under normal physiological conditions, with focus on preantral and antral follicles; The second aim was to elucidate the effects of a diet-induced reduction in thyroid hormone concentrations, affecting whole body metabolism, on ovarian follicular development; The third aim was to investigate the effect of an increased nutrient flux towards skeletal muscle on ovarian follicular development and the possible underlying mechanism.

It is well known that granulosa cell death via apoptosis is the main cause of atresia of antral follicles, however, whether preantral follicular attrition makes use of the same cell death pathway is not clear. Therefore, in chapter $\mathbf{2}$ I have investigated different cell death pathways in the adult rat ovary to examine whether they represent the reported histological differences between preantral and antral atretic follicles. Based on the results of studies in other organs, I used microtubule-associated lightchain protein 3 (LC3) and QSQTM1/p62 as markers of autophagy and cleaved caspase 3 (CCASP3) as marker of apoptosis, using immunohistochemistry, western blotting, and laser capture microdissection followed by qRT-PCR. The results showed that in the granulosa cells of atretic preantral follicles, p62 immunostaining was less intense compared to healthy preantral follicles, while no difference in LC3 immunostaining intensity was observed. In contrast, in antral follicles, no difference in both immunostaining and mRNA levels of LC3 and p62 were found between healthy and atretic follicles, indicating that autophagy was not responsible for attrition of antral follicles. cCASP3 immunostaining was scarce in the granulosa cells of atretic preantral follicles, whereas many cCASP3 positive apoptotic cells were present in atretic antral follicles, indicating that apoptosis is a major cell death pathway activated in antral follicle degeneration. Immunostaining for superoxide dismutase 2 (SOD2) was reduced in preantral and antral atretic follicles. This observation was confirmed by a concomitant down regulation of Sod 2 mRNA levels. These findings suggest that preantral follicular atresia mainly makes use of autophagy as cell death pathway, while antral follicles degenerate mainly via apoptosis.

In chapter 3, the consequences of prolonged exposure to reduced thyroid hormone concentrations in adulthood on the size of the ovarian follicle pool are investigated. Besides having a direct effect on the functioning of many cells, changes in thyroid hormone levels also influence metabolism. In this study female rats at the age of 10 weeks were given a control diet or an iodide deficient diet in combination with perchlorate supplementation to inhibit iodide uptake by the thyroid, resulting in a relatively mild chronic hypothyroid condition. At the age of 26 weeks animals were sacrificed and ovaries histologically evaluated. Plasma concentrations of relevant hormones (thyroid-stimulating hormone (TSH), tri-iodothyronine $\left(T_{3}\right)$, thyroxine $\left(T_{4}\right)$, follicle-stimulating hormone $(F S H)$, luteinizing hormone (LH) and anti-Müllerian hormone (AMH) were determined. Primordial, primary and preantral follicle numbers were significantly lower in the hypothyroid ovaries compared to the 
euthyroid controls, while a downward trend in antral follicle numbers and corpora lutea was observed. The percentage of atretic follicles was not different between the two groups. Plasma AMH concentrations showed a significant correlation with the growing follicle population represented by the total number of primary, preantral and antral follicles per ovary. The data indicate that prolonged mild hypothyroidism negatively affects ovarian follicular reserve as well as the size of the growing follicle population, which may impact fertility. AMH can serve, also under mild hypothyroid conditions, as a surrogate marker to assess the size of the growing ovarian follicle population, offering a non-invasive way to evaluate the correlation between female reproductive health and thyroid status.

Subsequently, in chapter 4, the long-term effects of chronic hypothyroidism initiated already in the foetal/neonatal period on ovarian follicular development were investigated. In contrast to the experiments described in chapter $\mathbf{3}$, the rats in this experiment were exposed to reduced thyroid hormone levels from the moment of conception until necropsy. Effects on the ovarian follicular reserve and ovulation rate in prepubertal (12-day-old) and adult (64-day-old and 120-day-old) rats were studied. Besides, antioxidant gene expression, mitochondrial density and the occurrence of oxidative stress were analyzed. The results of this investigation showed that continuous fetal/postnatal hypothyroidism resulted in lower preantral and antral follicle numbers in adulthood, accompanied by a higher percentage of atretic follicles, when compared to euthyroid age-matched controls. Not surprisingly, ovulation rate was lower in the hypothyroid rats. At the age of 120 days, the mRNA and protein content of superoxide dismutase 1 (SOD1) was significantly increased, while catalase (CAT) mRNA and protein content was significantly decreased, suggesting a disturbed antioxidant defense capacity of ovarian cells in the hypothyroid animals. This was supported by a significant reduction in peroxiredoxin $3(\operatorname{Prd} d \times 3)$, thioredoxin reductase 1 (Txnrd1), and uncoupling protein 2 (Ucp2) mRNA content and a downward trend in glutathione peroxidase $3(G p \times 3)$ and glutathione S-transferase mu 2 (Gstm2) mRNA content. These changes in gene expression were likely responsible for the increased immunostaining of the oxidative stress marker 4-hydroxynonenal. Together these results suggest that chronic hypothyroidism initiated in the foetal/neonatal period resulted in a decreased ovulation rate associated with a disturbance of the antioxidant defense system in the ovary. In contrast to hypothyroidism induced in adulthood (chapter $\mathbf{3}$ ), no reduction in primordial or primary follicle numbers was observed, suggesting that the ovarian reserve was not affected.

Chapter 5 addressed the question what the consequences were of a change in nutrient flux on ovarian follicular development. In this chapter mice were employed that ectopically express uncoupling protein 1 (UCP1) in skeletal muscle (UCP1-TG). This did not affect adiposity, but led to a redistribution of energy sources away from the ovaries towards skeletal muscle tissue,; a model of skeletal muscle pseudo-starvation. The results showed that UCP1-TG female mice had increased energy expenditure, reduced body size, unchanged adiposity, increased plasma fibroblast growth factor 21 (FGF21) concentrations and reduced insulin-like growth factor 1 (IGF1) levels. UCP1-TG mice had a $30 \%$ lower number of healthy follicle compared to WT mice. Primary and preantral follicle numbers were decreased by $40 \%$, while the number of atretic follicles was significantly increased and corpora lutea (CL) were absent in $40 \%$ of the ovaries of UCP1-TG mice. The latter suggested that these mice did not ovulate and thus were infertile. The elevated circulating FGF21 concentrations were not responsible for the ovarian phenotype, since UCP1-TG and UCP1-TG/FG21 ${ }^{-1}$ mice show 
the same ovarian follicular phenotype. Significant correlation of circulating IGF1 levels with antral follicle, $\mathrm{CL}$ numbers and differentially activated AKT in healthy antral follicles and activated IRS2 in atretic follicles between WT and UCP1-TG mice shows, that IGF1 is, at least partly, responsible for the ovarian phenotype of these mice. Together, our data show that an energy drain towards skeletal muscle tissue negatively impacts growing pool of ovarian follicles and ovulation rate in female mice, which is, at least in part, mediated by IGF1, and not by FGF21.

In conclusion, the results of my thesis research shows that preantral atresia occurs mainly through autophagy. Dietary induced chronic hypothyroidism, an intervention that reduces basal metabolic rate, initiated either during foetal/neonatal or adulthood impairs ovarian follicle development. The age at onset of hypothyroidism modified the effects of this condition on ovarian follicular development. A change in nutrient flux away from the ovaries towards skeletal muscle tissue negatively affects ovarian follicle development. Overall, the results of my thesis have provided new insights in the mechanisms of follicular attrition and shows that conditions that alter metabolic fuel use impact on ovarian follicular development. 


\section{ACKNOWLEDGEMENT}

The day finally comes, no matter how far away you thought it would be. Of course, a place should be put to thank all the people who support me along this journey.

First, I would like to express my gratitude to Chinese Scholarship Council to financially support me to complete my PhD study in the Netherlands.

I would like to thank my promoter Jaap. Jaap, thanks for your enthusiasm, your structural feedback and suggestions. Of course I would like to thank my co-promoters, Katja, thank you for all your help, support and feedback. Without both of you, I could not have reached so far.

Obviously, I want to thank my colleagues at HAP. First, Annelies, Inge and Hans, Melissa, our technicians and thus the key persons of the lab. Annelies, without you it would be a lot less fun in HAP! Thanks for all the help and support for me. Hans, thank you very much for all the fun and the nice help for my experiments. I still remember on the new year day when we did experiment in the CKP. Inge and Melissa, thank you also for all the help and support. I always thought it was very fun to work together with you. Annika and Annet, thank you all the practical help. Evert and Vincent, thanks for the great input and suggestions. Lonneke, Wenbiao, Jeske, Marjanne, Lianne, Jose, Natasja and Jing, thank you all for all the fun and support for me. Wenbiao and Lianne, thank you for agreeing to be my paranymphs during PhD ceremony. Furthermore all the other (former) colleagues at HAP: Arie, Jessica, Sander, Bart, Shujin, and Taolin, Dorien, Inge P, Femke, Elisa and Loes, it was a lovely time at HAP, thanks for cooperation, help and fun.

I would also like to thank all the students who have worked on my projects: Annemarie, Danielle, Shuangcheng, and Vasilianna. Thank you all very much for your contributions to my project. Unfortunately, not everything is written in this thesis, but all your projects have led to new insights and thus are appreciated!

Feng Wang, my former boss in China, thank you very much for all support and tips for looking for a job. I also would like to thank all my friends which I have met during over four years. Qingyuan Li, Lifei Li, Yanyan Sun, Yu Hong, Min Liu, Xinxin Wang, Juncai Chen, Wenjuan Mu, Xuezhen Guo, Mandy Bo, Yuan He, Lei Mao, Qiuyu Wang, Haibo Lu, Wei Xu, Shuwen Xia, Tian Yu, and other names that I may not cover here. Thank you for all the fun and support.

My parents, mom and dad, thank you so much for support, encouragement and care you gave me all the time when we could not meet. My younger sister, Yanyan, thank you very much for all the care, especially when I met difficulties, you gave me a lot of mental support and nice advice. 


\section{CURRICULUM VITAE}

Li Meng (孟立) was born on May 6 ${ }^{\text {th }}, 1984$ in Shandong province, P.R.China. He completed his preuniversity education in No.1 high school of Caoxian in 2003 after which in the autumn of the same year, he started his Bsc in Animal Science at Shandong Agricultural University in Taian. Following the completion of his Bsc studies in 2007, he started his Msc study in Animal Breeding and Reproduction at Nanjing Agricultural University, where he worked on cloning of human lactoferrin transgenic goats and the methylation status of some Imprinted genes. He obtained his Msc diploma in 2010. From July 2010 till April 2012 Li Meng worked as a techniqican at the department of Animal Science of Nanjing Agricultural University. The acquisition of a scholarship from the Chinese Scholarship Council made it possible for him to move to Human and Animal Physiology of Wageningen University and Research where from May 2012 till August 2016 he performed his experiment in this thesis describled PhD project. From Janurary 2017 onward, he will be employed as assistant professor in the group of Animal Science at South China Agricultural University. 


\section{LIST OF PUBLICATIONS}

- Meng L, Rijntjes E, Swarts HJM, Keijer J, Teerds KJ et al. Dietary-induced chronic hypothyroidism negatively affects rat follicular development and ovulation rate: a role for disturbed redox balance. Biology of Reproduction 2016; 94:1-11.

- Meng L, Rijntjes E, Swarts HJM, Keijer J, Teerds KJ. Prolonged mild hypothyroidism severely reduces ovarian follicle reserve in adult rats. 2016, Submitted for publication.

- Meng L, Jan SZ, Hamer G, Swarts HJM, Keijer J, Teerds KJ. Preantral follicular atresia occurs mainly by autophagy, while antral follicles degenerate mainly by apoptosis. 2016, In advanced stage of preparation.

- Meng L, Coleman V, Keijer J, Ost M, Voigt A, Bunschoten A, Teerds KJ, Klaus S. Skeletal muscle pseudo-starvation driven energy expenditure negatively affects ovarian follicular development in mice. 2016, In advanced stage of preparation.

- Meng L, Jia RX, Sun YY, Wang ZY, Wan YJ, Zhang YL, Zhong BS, Wang F. Growth regulation, imprinting, and epigenetic transcription-related gene expression differs in lung of deceased transgenic cloned and normal goats. Theriogenology 2014; 81:459-466.

- Meng L, Wan YJ, Sun YY, Zhang YL, Wang ZY, Song Y, Wang F. Generation of Five Human Lactoferrin Transgenic Cloned Goats Using Fibroblast Cells and Their Methylation Status of Putative Differential Methylation Regions of IGF2R and H19 Imprinted Genes. PLoS One 2013; 8.

- Wan YJ, Zhang YL, Zhou ZR, Jia RX, Meng L, Song H, Wang ZY, Wang LZ, Zhang GM, You JH, Wang F. Efficiency of donor cell preparation and recipient oocyte source for production of transgenic cloned dairy goats harboring human lactoferrin. Theriogenology 2012; 78(3):58392.

- Zhang YL, Wan YJ, Wang ZY, Xu D, Pang XS, Meng L, Wang LH, Zhong BS, Wang F. Production of dairy goat embryos, by nuclear transfer, transgenic for human acid beta-glucosidase. Theriogenology 2010; 73:681-690. 


\section{TRAINING AND EDUCATION}

The Basic Package (3.0 ECTS)

WIAS Introduction Course

Course on philosophy of science and/or ethics

Scientific Exposure (9.0 ECTS)

International conferences

Conference associated with Mitochondrial Physiology Course (Copenhagen, 26-30. 08.

2013)

NuGo Week (Castellammare di Stabia, 08-11. 09. 2014)

Ovarian club V (Barcelona, 14-15. 11. 2015)

Seminars and workshops

Wias science days ( Wageningen, 2013-2015)

Molecular nutrition workshop (Tarragona, 26-27. 06. 2014)

Poster presentations

Mitochondrial Physiology Conference (Copenhagen, 26-30. 08. 2013 )

NuGo Week (Castellammare di Stabia, 08-11. 09. 2014)

Ovarian club V (Barcelona, 14-15. 11. 2015)

Oral presentations

Molecular nutrition workshop (Tarragona, 26-27. 06. 2014)

2nd Wageningen PhD Symposium (Wageningen, 06-05-2015)

In-Depth Studies (8.0 ECTS)

Disciplinary and interdisciplinary courses

Mitochondrial physiology course (Copenhagen, 26-30. 08. 2013 )

Epigenesis and Epigenetics (Wageningen, 21-23. 05. 2014)

Advanced Microscopy (Ghent, 15-19. 06. 2015)

Advanced statistics courses

Advanced statistics courses: design of experiments (Wageningen, 09-11. 10. 2013)

Basic statistics ( Wageningen, 26 -27 May and 4th-6th June, 2014 )

Statutory Courses (3.0 ECTS)

Use of Laboratory Animals (mandatory when working with animals) (Wageningen, 2014)

Professional Skills Support Courses (6.0 ECTS)

Practical English Plus (Wageningen, 09.2012-02.2013)

Effective behaviour in your professional surroundings (Wageningen, 2013)

Techniques for writing and presenting scientific papers (Wageningen, 15-18. 10. 2013)

Project and Time management (Wageningen, 2013)

High-Impact Writing Course (Wageningen, 06-09. 07.2015)

Research Skills Training (2.0 ECTS)

Laser Capturing microscope training (08.2014-05.2015, Academic Medical Center) 
Didactic Skills Training (7.0 ECTS)

Supervising practicals and excursions

Healthy Aging Practical course (2x) (2014-2015)

Endocrinology practical course (2014)

Supervising theses

Supervision of Annemarie Nieberg for MSc major

Supervision of Daniëlle Smeitink for MSc minor

Supervision of Shuangcheng Wu for MSc major 


\section{Colophon}

The research described in this thesis was financially supported by China Scholarshop Council, China and Human and Animal Physiology Group of Wageningen University, the Netherlands.

Financial support from the Human and Animal Physiology Group of Wageningen University and TSE Systems $\mathrm{GmbH}$ and Stichting Gilles Hondius Foundation for printing this thesis is gratefully acknowledged.

Layout and printing: Li Meng; Digiforce-Proefschriftmaken.nl Cover design: Li Meng \&Digiforce

PhD thesis, Li Meng, 2016 